\title{
الدور التربوي لعضو هيئة التدريس في تصين طلابه ضد التلوث الثقافي وسبل تطويره هن وجهة نظره
}

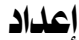

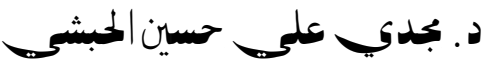 \\ قسم أصول التربية \\ كلية التربية بالإسماعيلية - جامعة قناة السويس
}

مجلة بحوث التربية النوعية ـ جامعة المنصورة

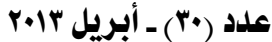




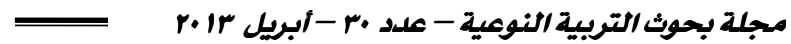

\section{الدور التربوي لهضو هيئة التدريس في تهصين طلابه}

\section{ضد التلوث الثقافي وسبل تطويره هن وجهة نظره}

إعداد

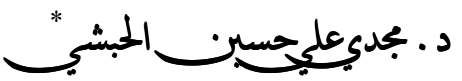

يهدف البحث إلى الوقوف على التلوث الثقايِّ التي يستهدف الشبـاب المصري بصفة عامـة،

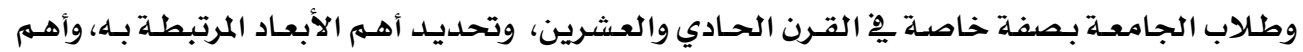

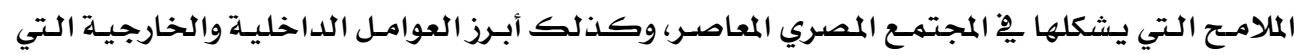

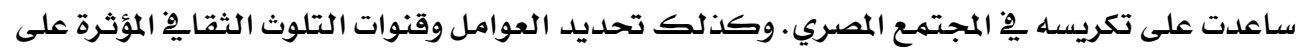

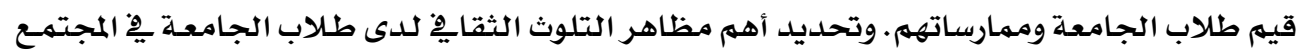
المصري.

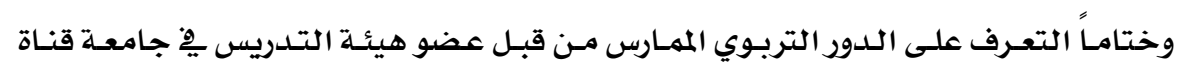

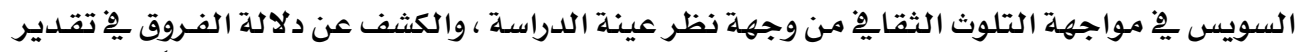

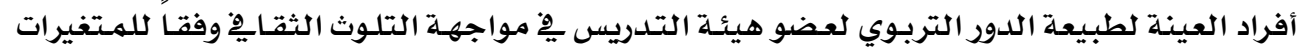

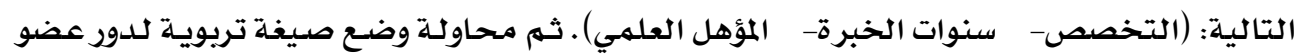

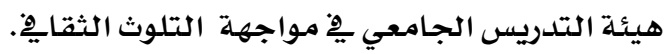

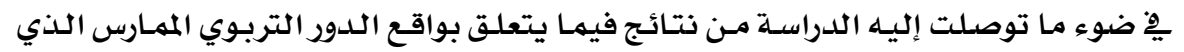

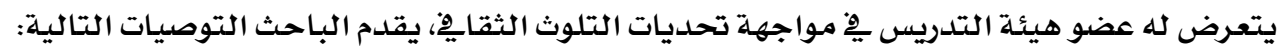

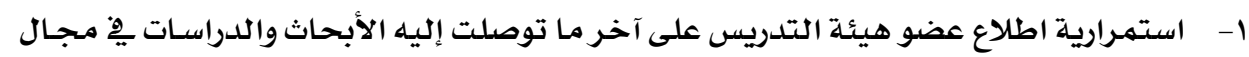

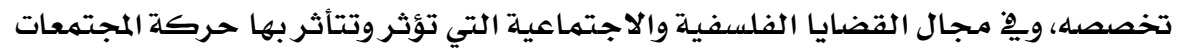

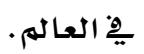

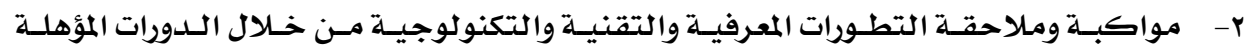

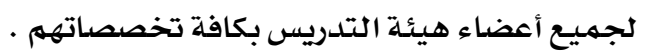

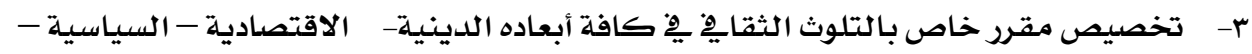

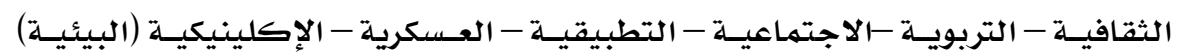

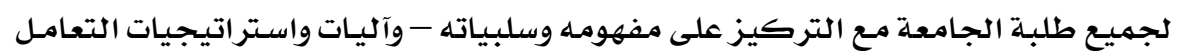

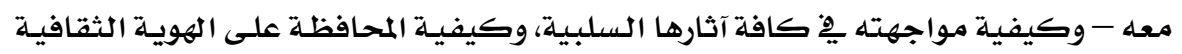

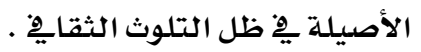

* قسم أصول التربية كلية التربية بالإسماعيلية- جامعة قناة السويس 
ع- تركيز عضو هيئة التدريس على بناء شخصية الطالب الجـامعي بتكامليـة أكبر ِِِ جميع

$$
\text { جوانب شخصيته . }
$$

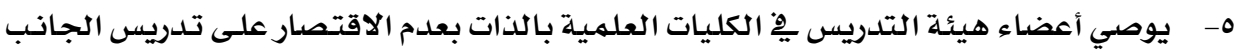

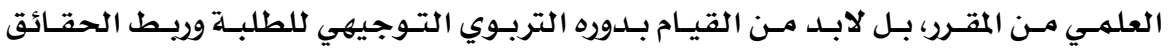

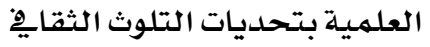


The educational role of the faculty member to immunize students against the cultural pollution and ways to develop.

\section{Dr. Magdi Ali Hussien Elhabashi}

\section{Abstract:}

The study aims to identify the pollution cultural which targeted Egyptian youth in general and university students in particular, in the twenty- first century, and to identify the most important dimensions associated with it, and the most important features that formed in Egyptian society today, and also highlighted the internal and external factors that have helped to perpetuate in Egyptian society, to identify the factors and channels of the cultural pollution affecting values of university students and their practices, and identify the most important aspects of the cultural pollution of university students in the Egyptian society.

Finally identify educational role practiced by a faculty member at the University of the Suez Canal in the face of the cultural pollution from point of view the study sample. Detection of significant differences in the estimation of the sample to the nature of the educational role of the faculty member in the face of the cultural pollution according to the following changes: (specialization -years of Experience - Qualification). And then try to put the formula of the educational role to university faculty member in the face of cultural pollution.

In light of the findings of the study results with regard to by educational role of the practitioner who exposed him a faculty member in the face of the challenges of cultural pollution, the researcher makes the following recommendations:

1- continuity of reading of the faculty member on the latest research and studies in the field of specialization, and in the area of philosophical and social issues that affect and are affected by the movement of societies in the world. 


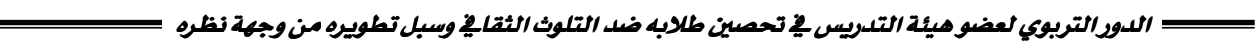

2- keep up with the knowledge and technical developments and technological during the qualifying sessions for all faculty members in all specialties.

3- allocate special course to the cultural pollution in all its dimensions religious - economic - political - cultural - educational - social Applied - military - Clinical (environmental) for all college students with a focus on concept and Negatives - and the mechanisms and strategies to deal with it and how to confront its negative impacts, and how to maintain the authentic cultural identity in light of cultural pollution.

4- concentration faculty member at the building a university student more in all aspects of his personality.

5- recommends faculty members in science colleges in particular not only to teach the scientific aspect of the course, but it must be done in turn educational guideline for students and linking the scientific facts with the cultural pollution challenges. 


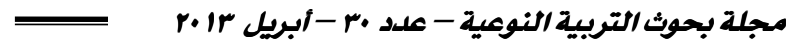

\section{الدور التربوي لهضو هيئة التدريس في تهصين طلابه}

\section{ضد التلوث الثقافي وسبل تطويره هن وجهة نظره}

إعداد

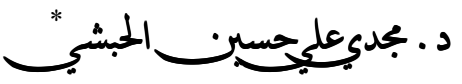

\section{أولاً: الإطار العام للدراسة}

مقدمة الدراسة:

يعد الاستثمار فِ الموارد البشرية من الأهداف الرئيسية للتعليهم مـن أجل اكتشاف قدراتها

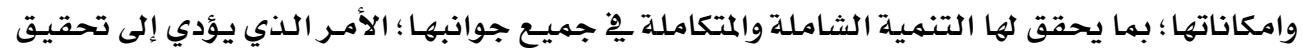
تنمية مجتمعية يْ مختلف الجوانب السياسية والاقتصادية والاجتماعية والثقافية. (1)

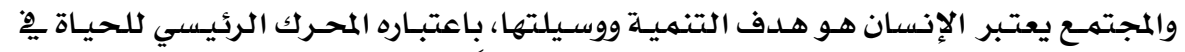

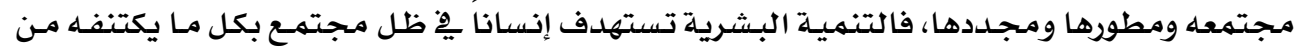

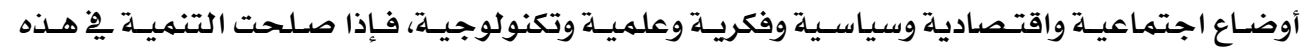

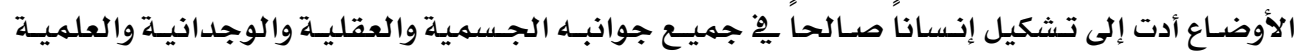

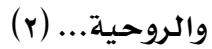

وإذا كان ثمة تسليم بضرورة الاهتمام بالإنسان ورعايته باعتباره غاية التربية ووسيلتها، فإن إن إنهان

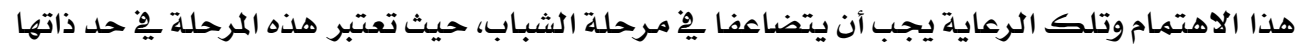

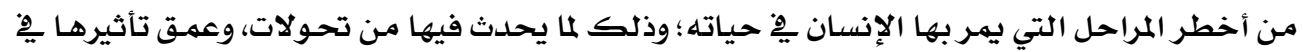

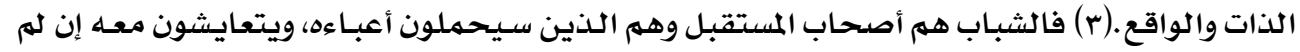

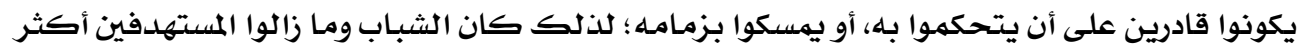

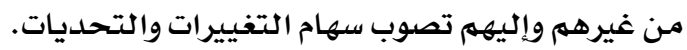

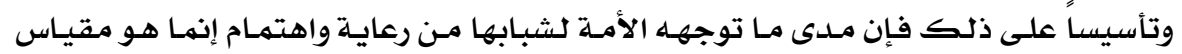

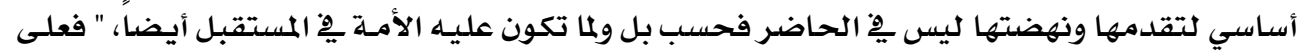

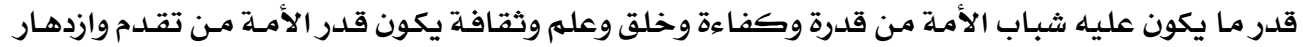

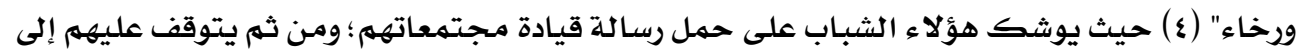

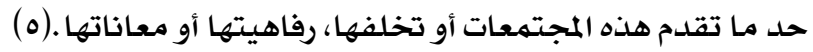
وإذا كان العالم اليوم يهتم بشئون الشباب وقضاياهم وحمـايتهم ضده الأخطار التي تحسدق

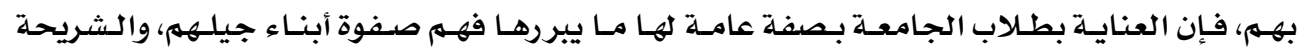

* قسم أصول التربية كلية التربية بالإسماعيلية- جامعة قناة السويس 


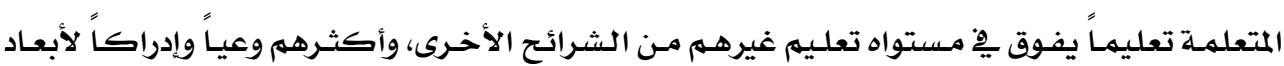

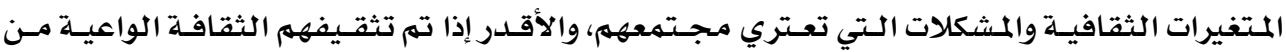

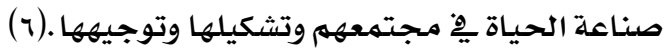

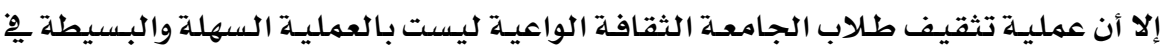

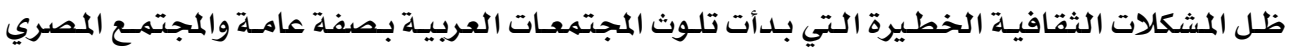

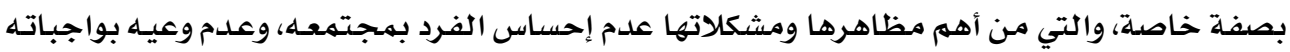

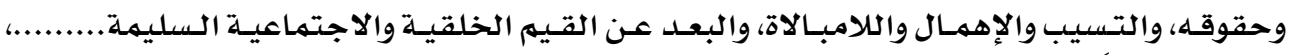

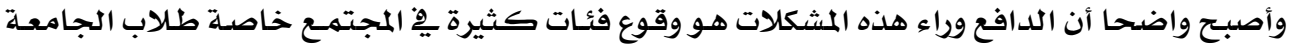

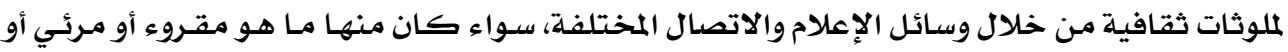

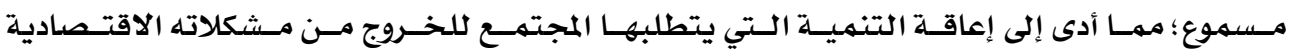
والاجتماعية.

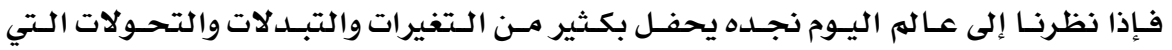

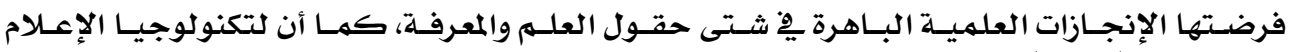

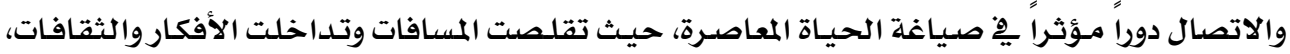
وأصبح العالم قرية كونية صغيرة. (v) والاتهرأ فكما أن البيئة الطبيعية تتلوث بمخالطة الشوائب الغريبة والضارة لعناصرها من ماء وهواء الضهاء

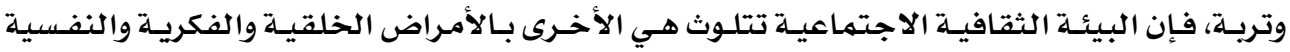
والاجتماعية.

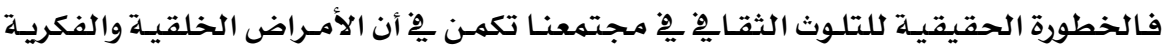

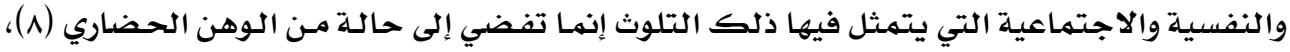

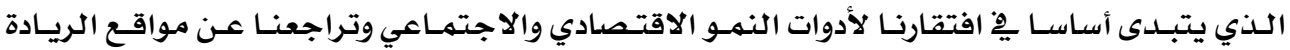

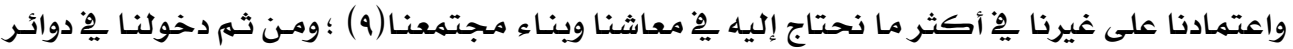

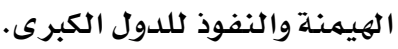

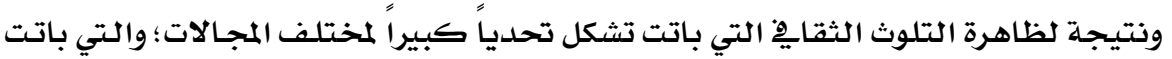

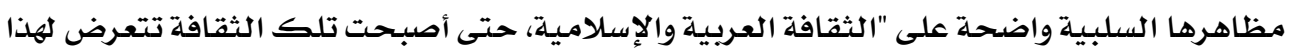

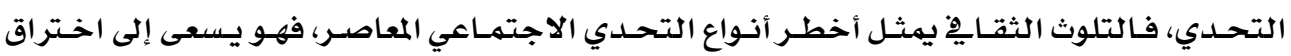

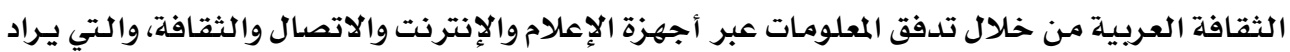

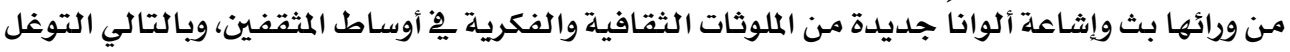

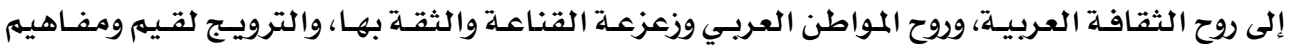
الثقافة الأمريكية.

وبذلك تجلت تحديات التلوث الثقايِِ ِِِ أعتى مظاهره السلبية من خلال "احتكار الولايـات

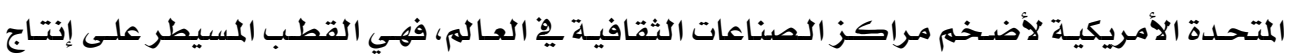


الصورة والمعلومـات، حيث تتمركز بها مجمعـات الصناعات الثقافيـة الضخمـة، والتي يسيطر عليها

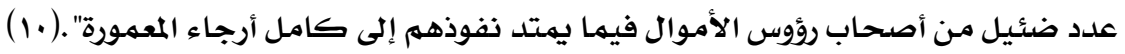

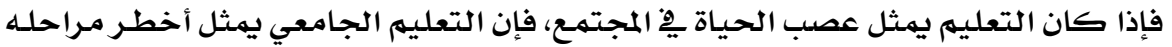

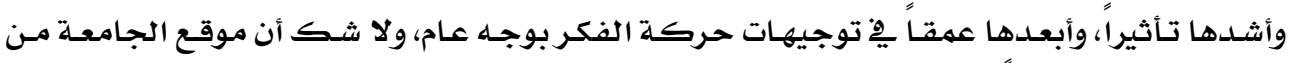

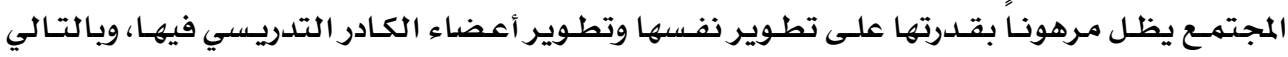

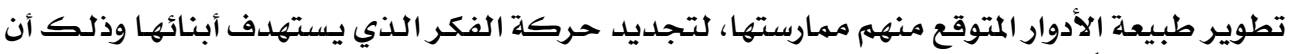
التطوير ضمانا للاستمرارية والبقاء.

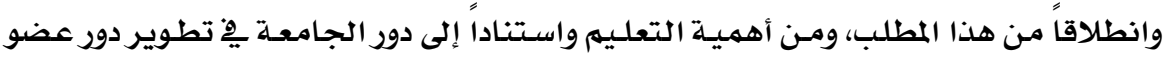

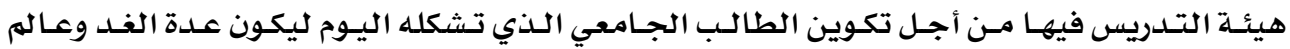

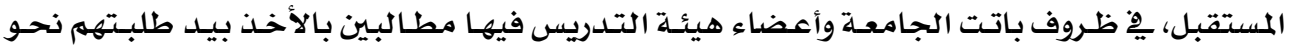

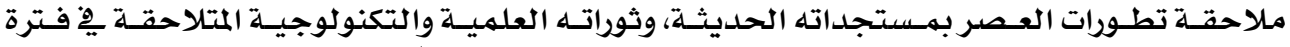

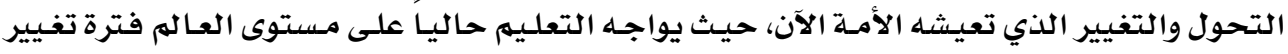

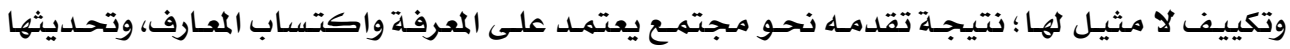

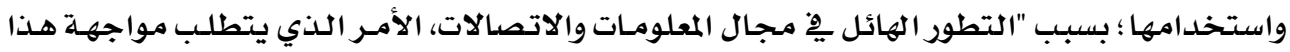

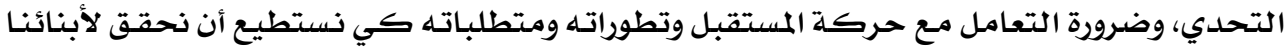

(11). المزيد من التقدي، وضروة التعامل

وإذا كان هذا العصر قد أفرز هذه التحديات بهصاعبها ومتاعبها التي ستضاف إلى المشاكل

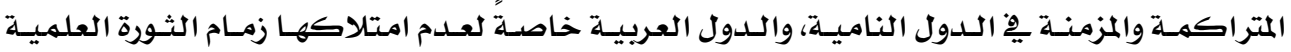

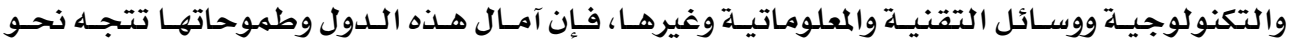

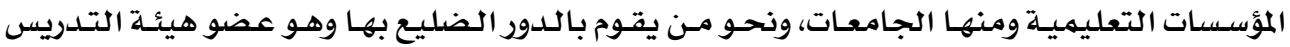

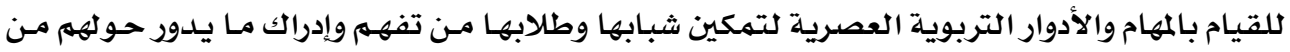

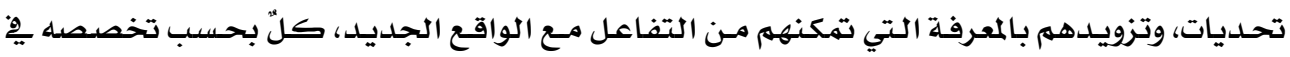

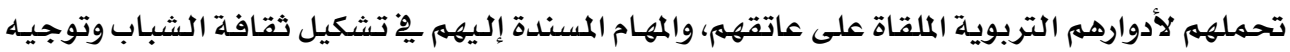

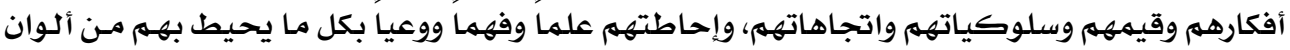

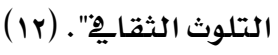

وانطلاقاً من هذه النظرة فقد قام الباحث ِِّ هذه الدراسـة بهحاولـة التعرف على واقع الدور

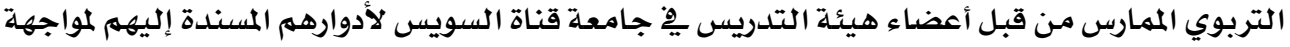

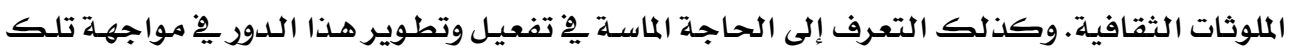

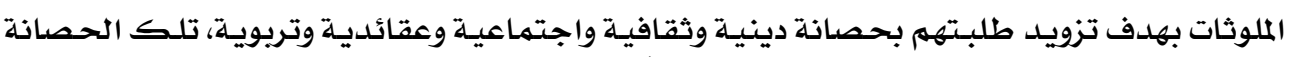

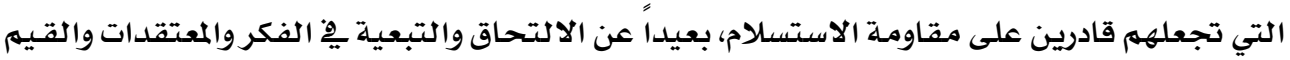

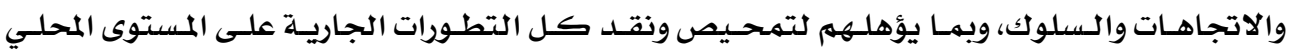

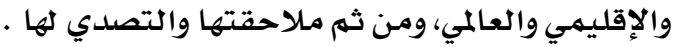




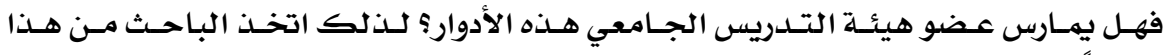

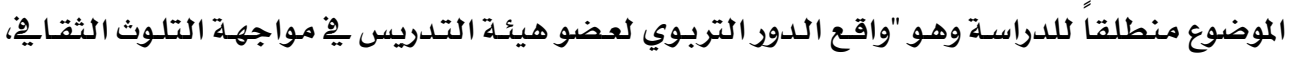

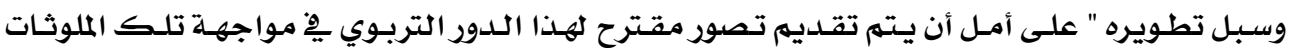

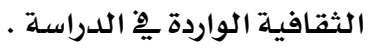

مشكلة الدراسة:

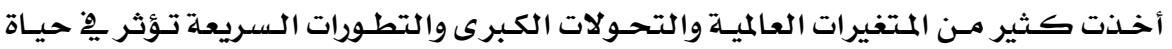

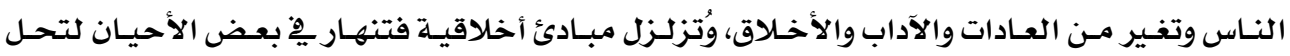

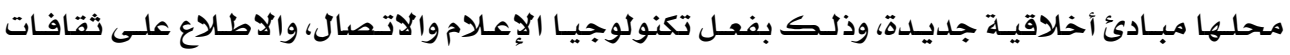

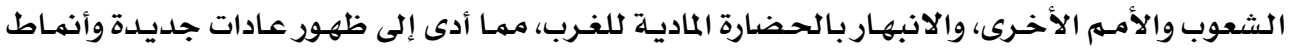

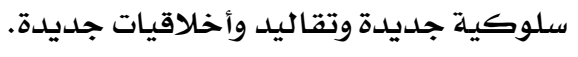

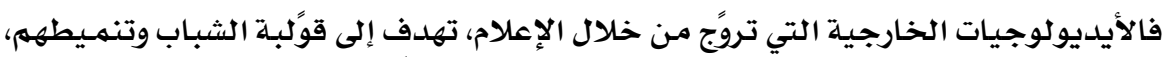

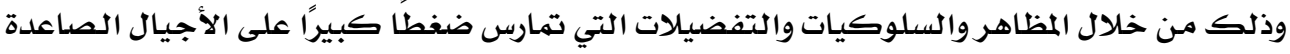

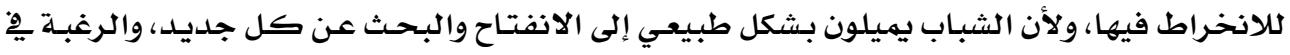

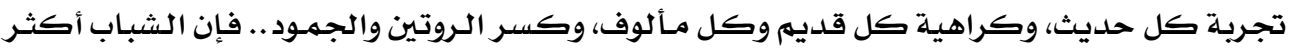

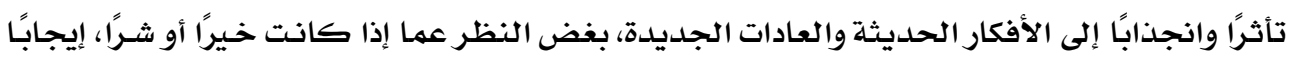

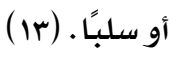

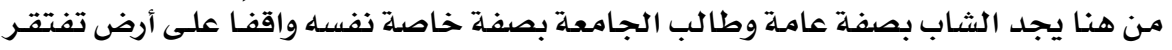

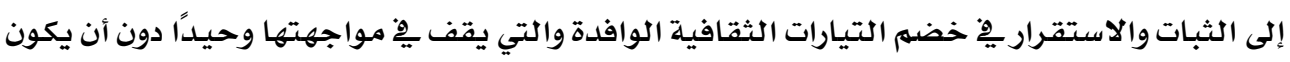

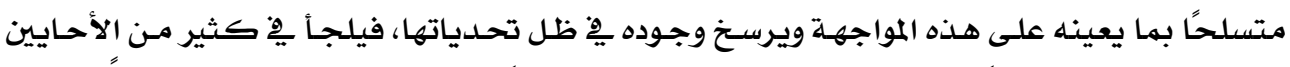

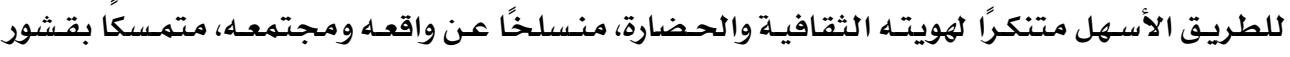

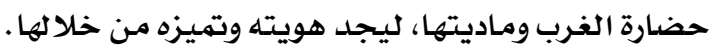

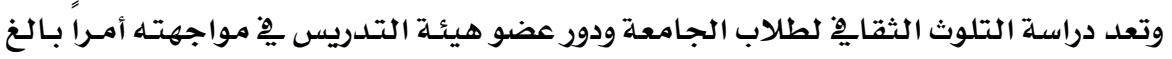

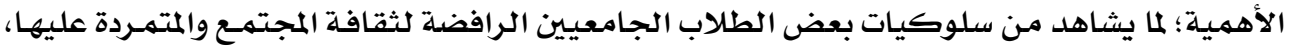

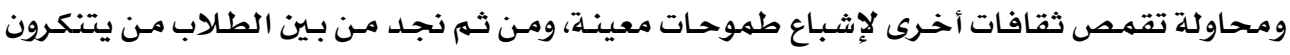

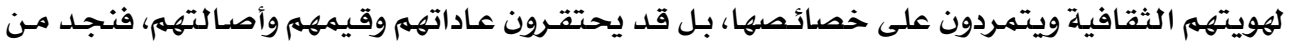

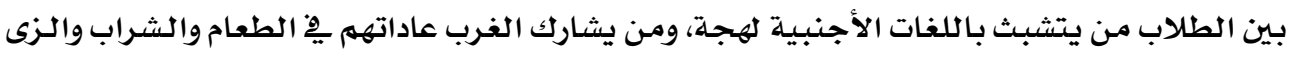

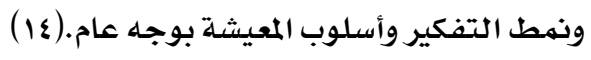
كما تعد العلاقة بين الطالب والأستاذ الجامعي لها دور يِ بناء ذات الفرد وتحقيق إنسانيته،

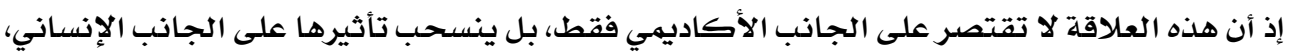

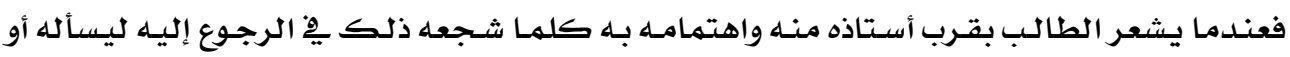

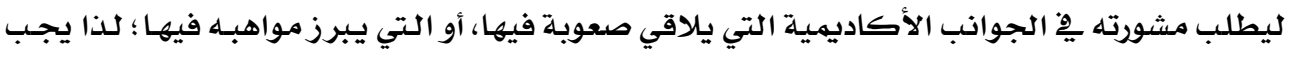

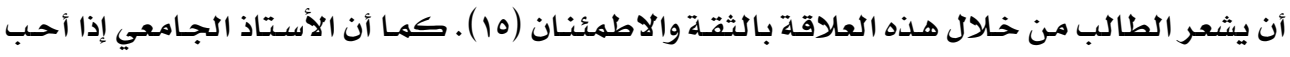


طلبته واحتر مهـهم ووعاملهم على أساس أنهم أبناؤه وأخوته وحرص على تعليمهم وإرشادهم ومسـاعدتهم

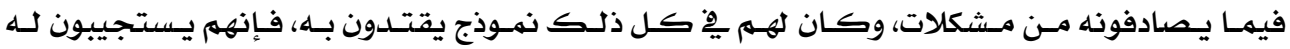

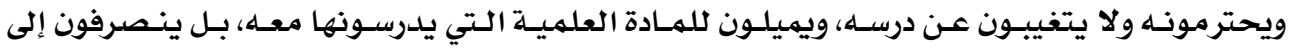

دراستها بجدية تحقق لهم تحصيلا علميا ونتائج أفضل .

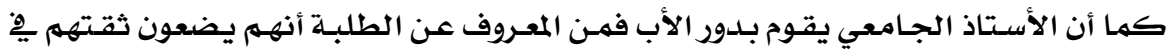

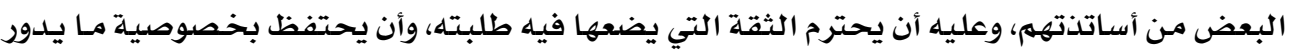

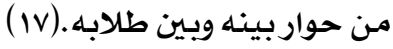

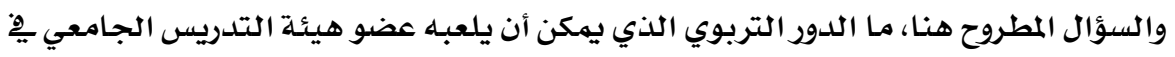

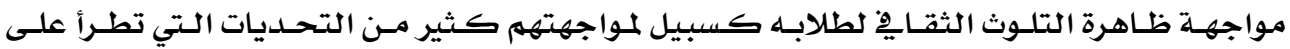

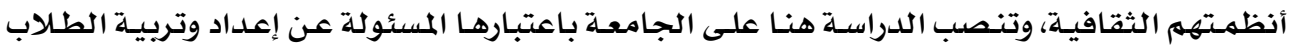

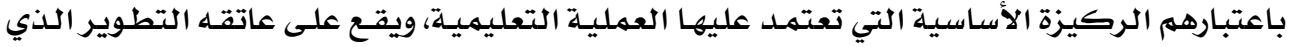

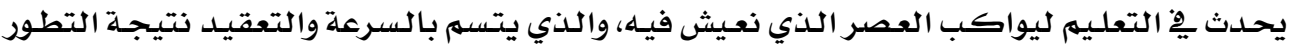

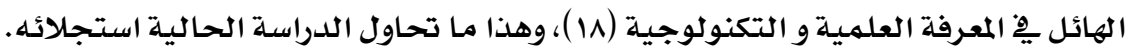

من هنا تتمثل مشكلة الدراسة يٍ السؤال الرئيس التالي :

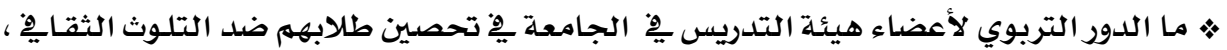

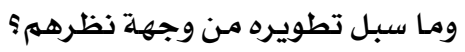

\section{ويتفرع من هذا السؤال الرئيس الأسئلة الفرعية التالية :}

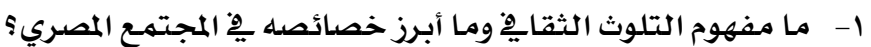

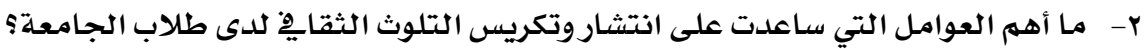

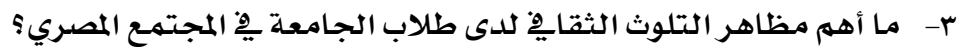

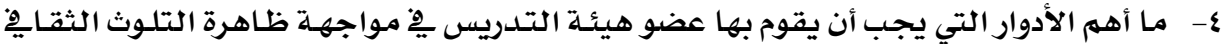
لدى طلابه؟

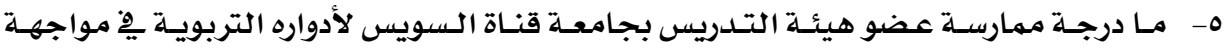
التلوث الثقايِّْ

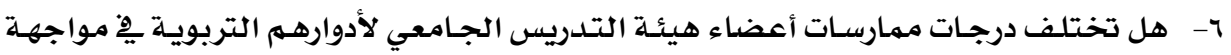

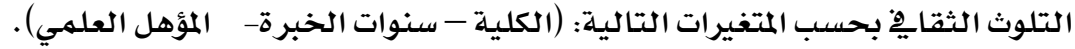

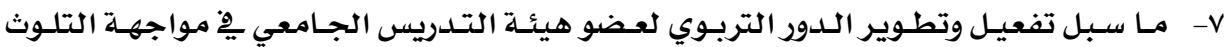




$$
\text { وِِّْ ضوء ما تقدم يمكن للبحث أن يشير إلي الأهداف الآتية:- }
$$

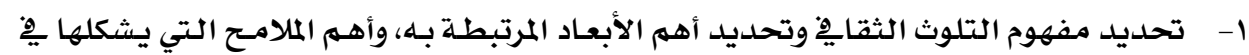

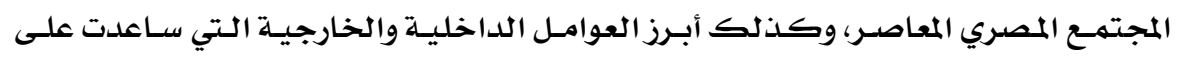

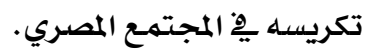

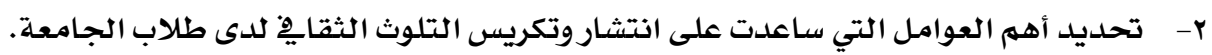

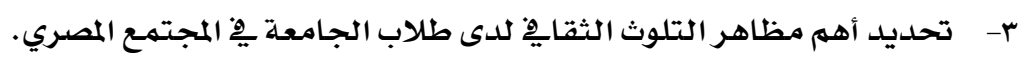

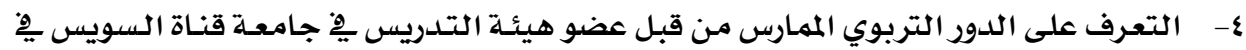

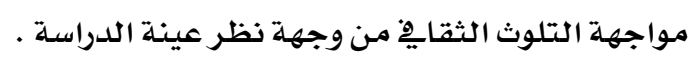

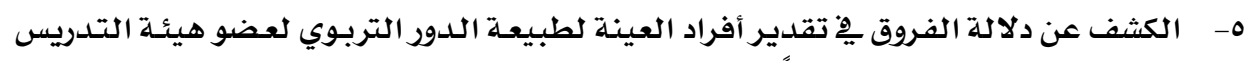

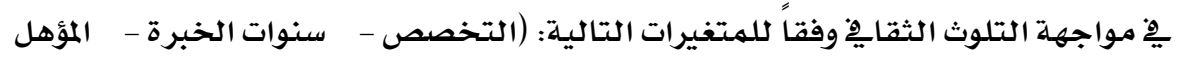

$$
\text { العلمي). }
$$

ז- محاولة وضع صيغة تريوية لدور عضو هيئة التدريس الجامعي يِّ مواجهة التلوث الثقايِّ.

$$
\text { تتضح أهمية الدراسة فيما يلي: }
$$

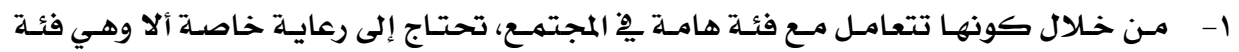

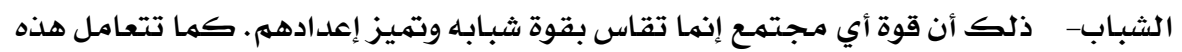

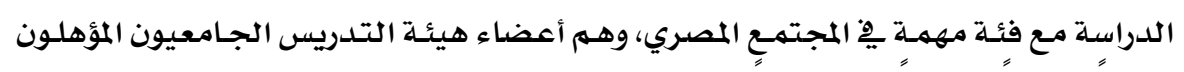

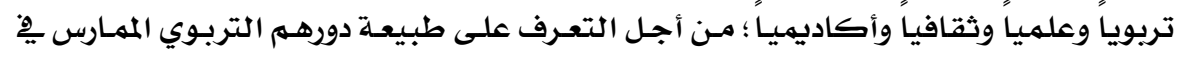

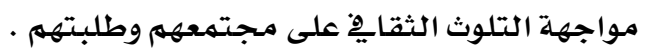

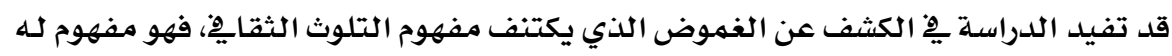
علاقة مباشرة بالشخصية القومية وا لهوية الثقافية.

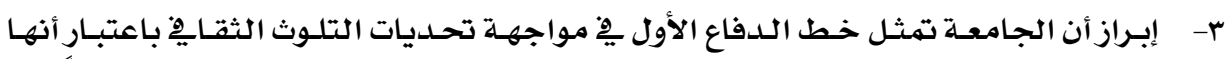

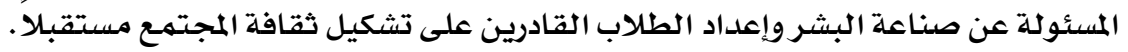

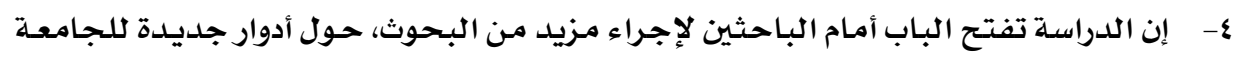

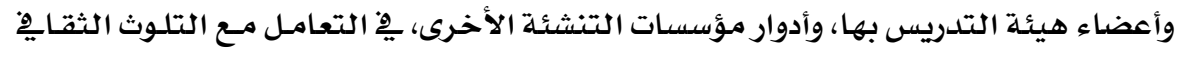
للطلاب.

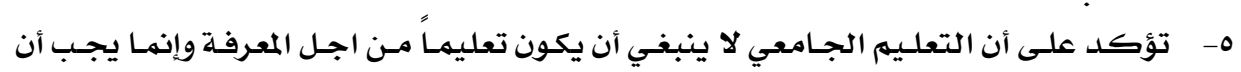

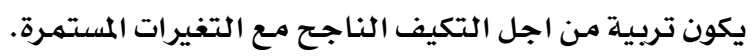

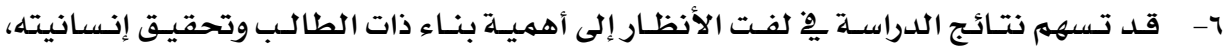

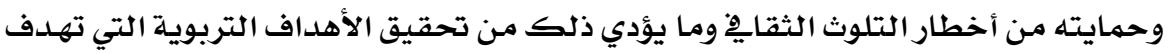


1- أن التلـوث الثقـايِّ فعل بشر يستند إلى إرادات بشرية ومؤسسـات عالميـة تهـدف إلى السيطرة

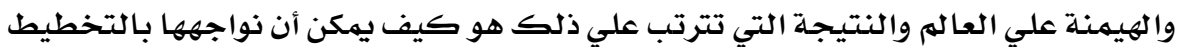
والتدبير.

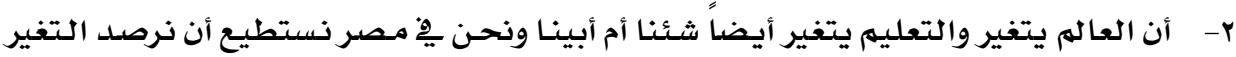
من خلال الجامعات وأعضاء هيئة التدريس فيها.

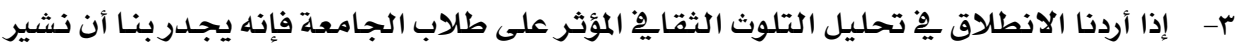
إلى حقيقتين تتعلق بطلاب الجامعة وهما : • أنهم حقيقة بيولوجية وسيكولوجين تئية واجتماعية.

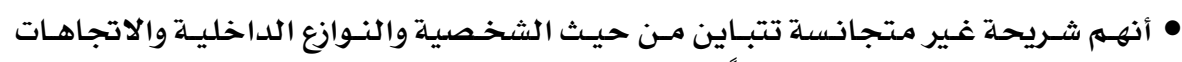

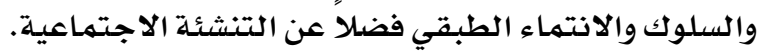

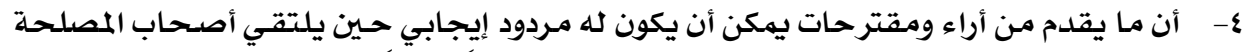

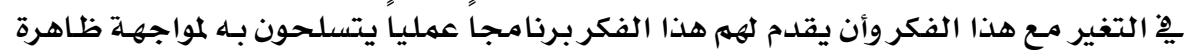

\section{التلوث الثقايِّ.}

مصطلحات الدراسة: تضمنت الدراسـة عدة مفـاهيه، وهي الدور التربـوي، التلـوث الثقـاِف، وعضو هيئـة التـريس، وتلتزم الدراسـة بالتعريفات التالية:

$$
\text { • الدور التربوي: }
$$

المقصود بالدور التربـوي ِِّ هـذه الدراسـة هـو :"مجهـوع الأنشطة التي يقـوم بهـا عضو هيئسة

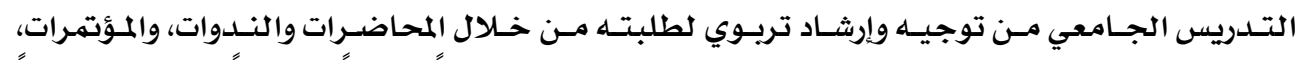

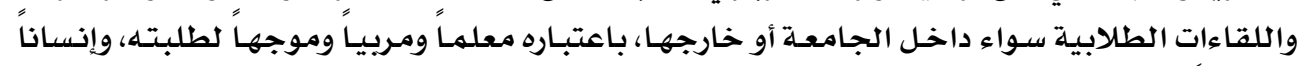

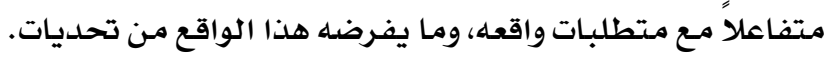

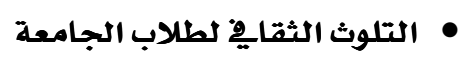

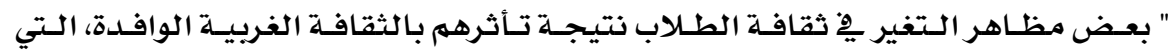

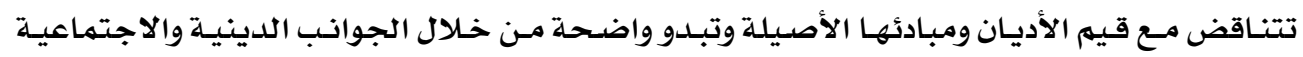
والتربويية والعلميـة.

$$
\text { • عضو هيئة التدريس:- }
$$

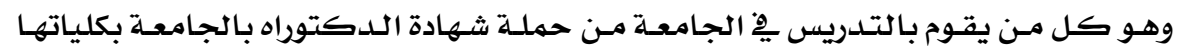


مـن خـلال اطِّلاع البـاحـث علـى الأدب التربــوي والدراســات السـابقة الـتي عالجـت الظــواهر

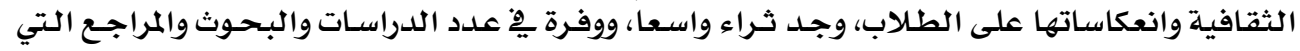

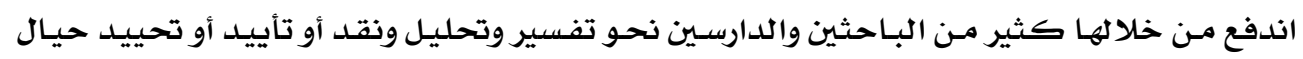

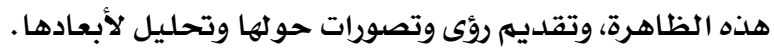
وقد رتب الباحث الدراسـات السابقة حسب تاريخ النشر فبـدأ بالأحسدث مـن الدراسـات العربيـة

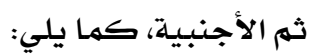
أولاً: الدراسات العربية:

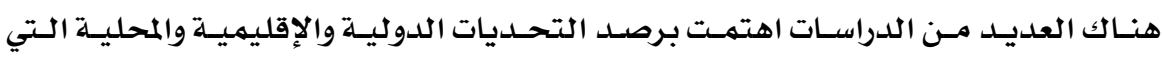

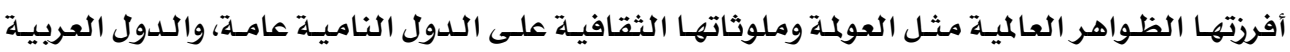

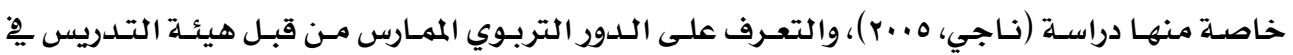

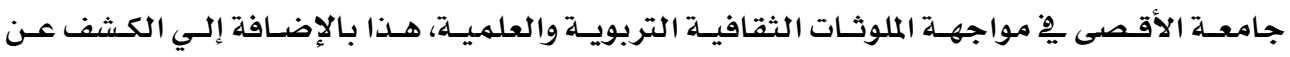

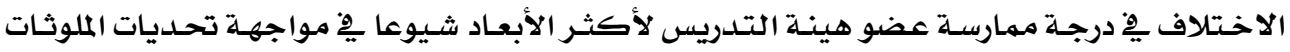

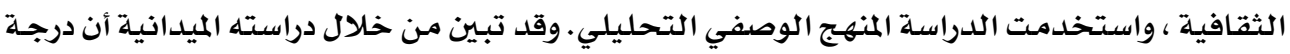

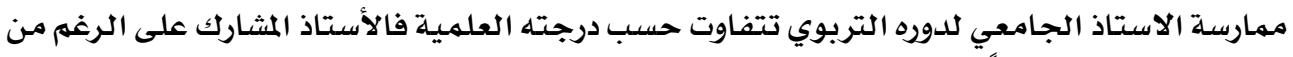

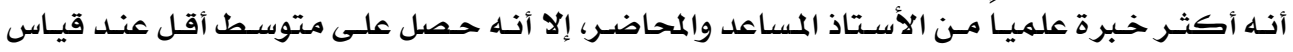

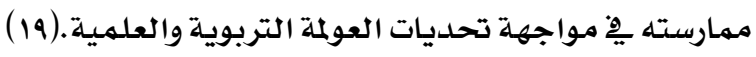

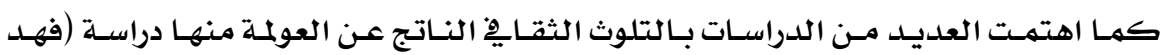

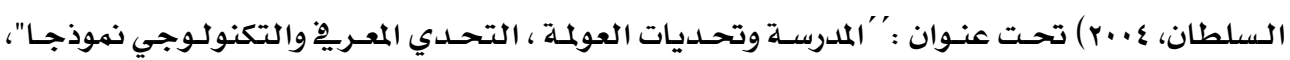

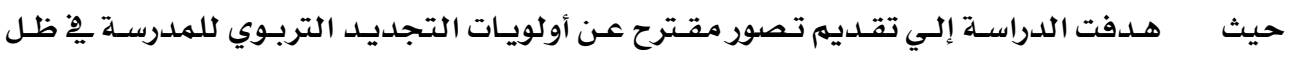

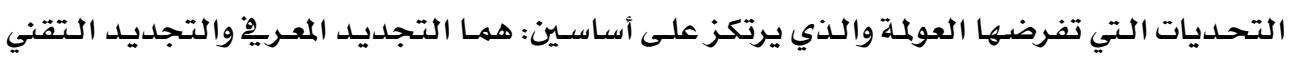

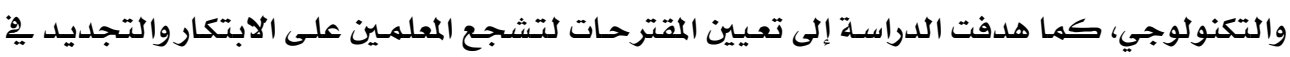

عمليات التعلهم والتعليه. (r. (r)

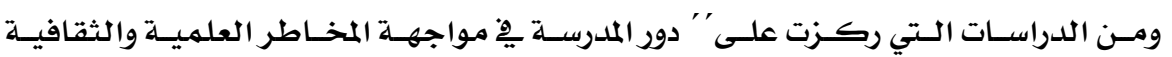

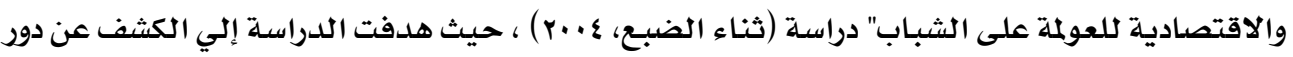

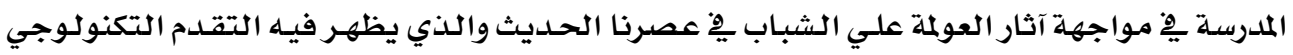

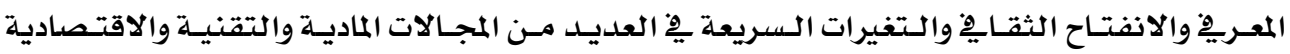

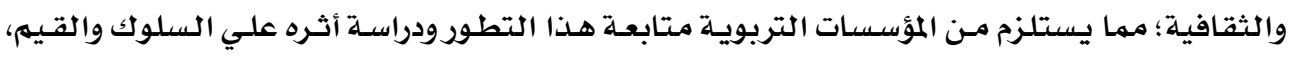

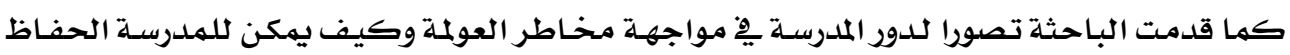

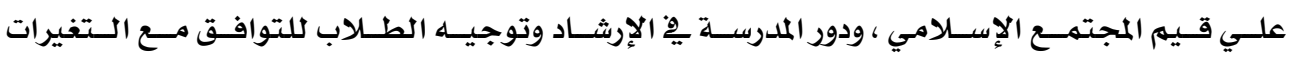

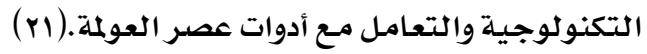




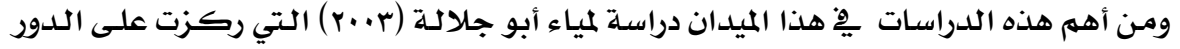

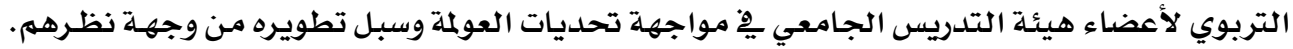

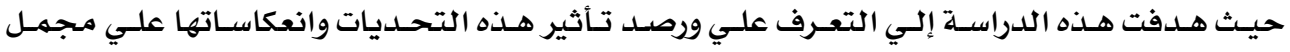

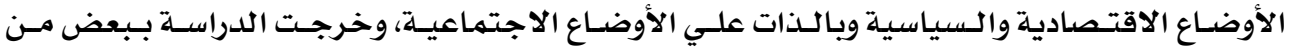

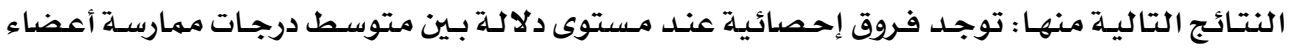

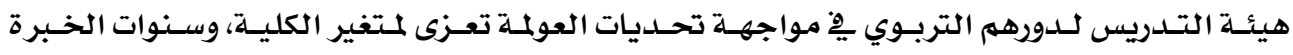

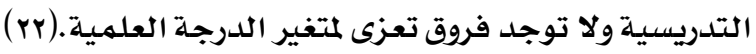

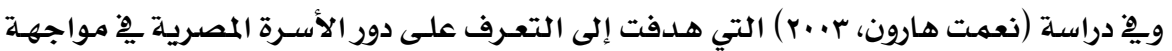

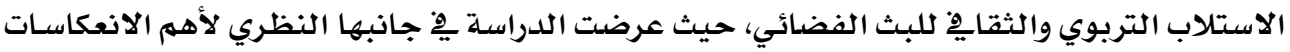

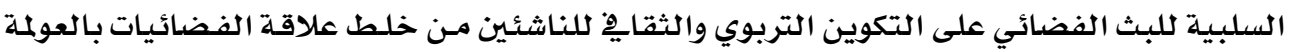

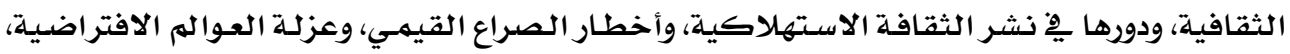

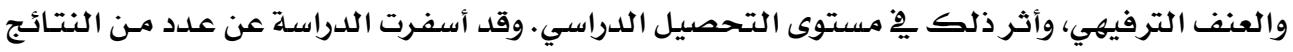

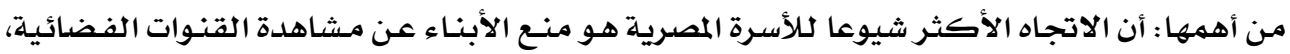

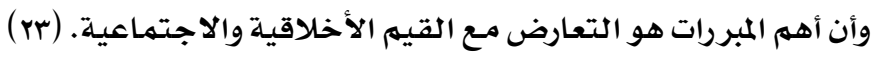

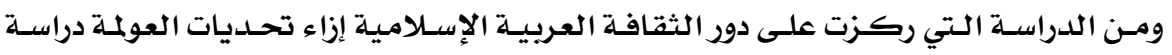

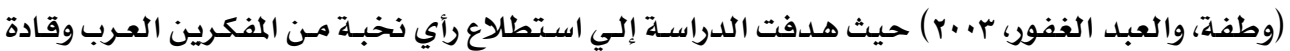

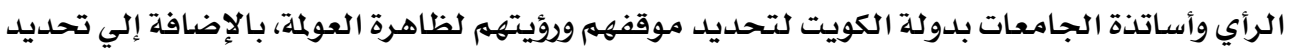

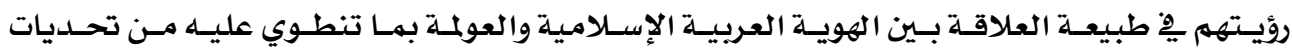

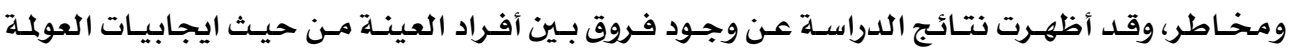

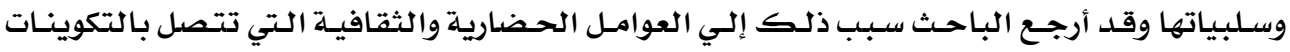

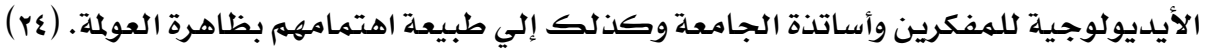

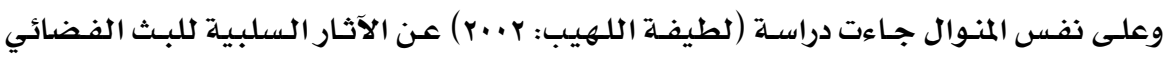

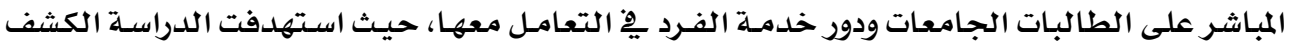

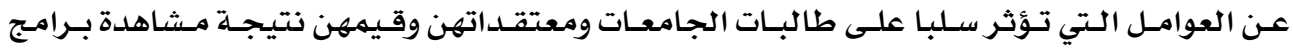

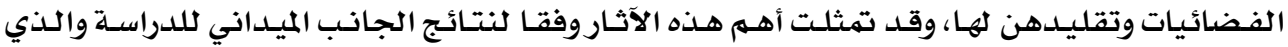

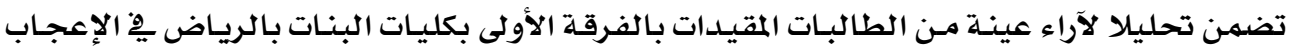

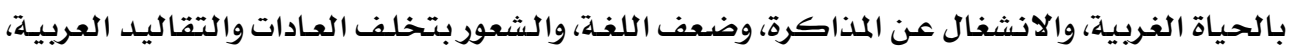

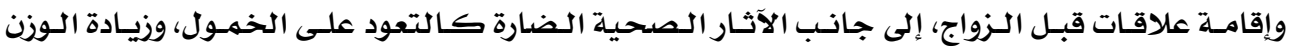

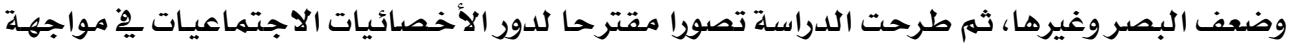

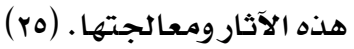

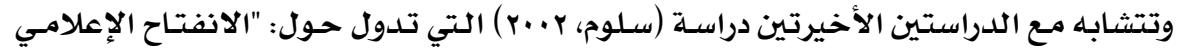

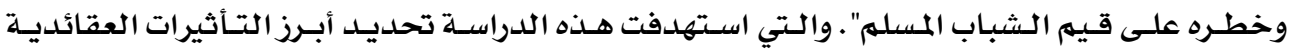




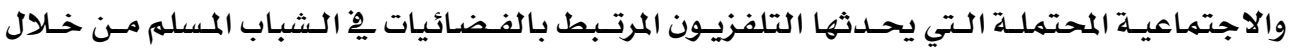

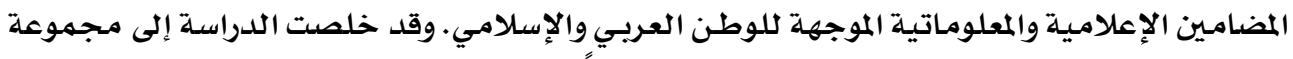

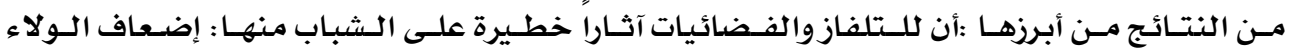

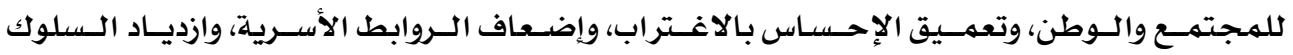

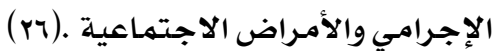

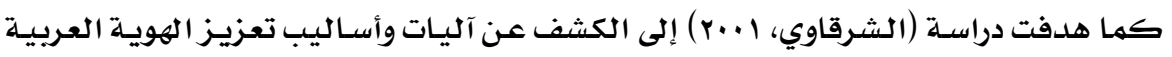

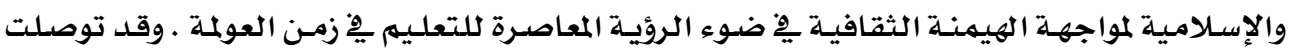

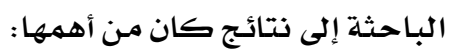

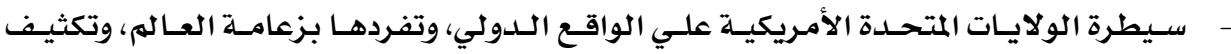

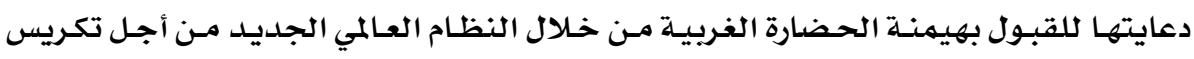
هيمنتها على العالهم.

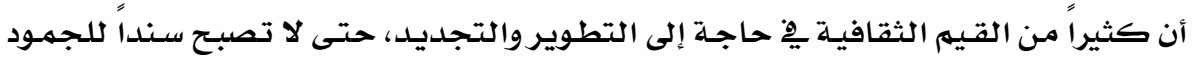

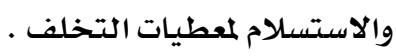

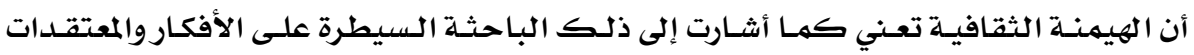

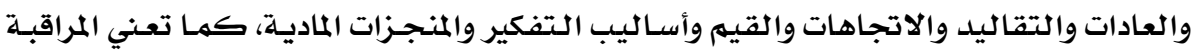

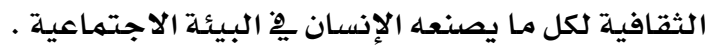
وِِّ ضوء تلك النتائج قدمت الباحثة مقترحات كان من أهمها : أن تتحمل إدارة التعليهم مسئولية الحفاظ على الهوية الثقافية وتعزيزها من خلال ما يلي :

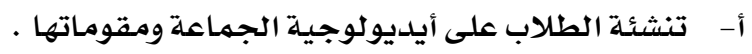

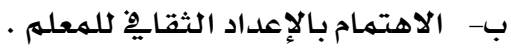

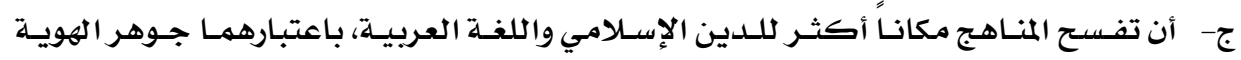
الثقافية .

(rV). د- دراسة تأثير المخرجات الثقافية على البيئة المحيطة الميطة

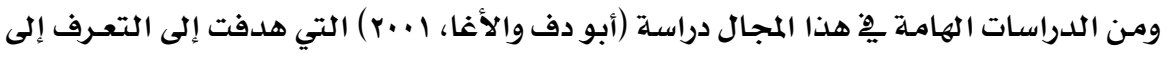

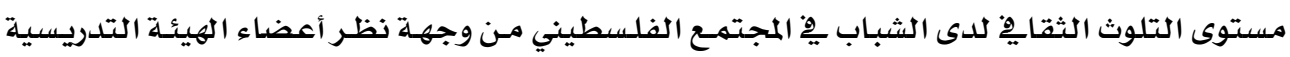

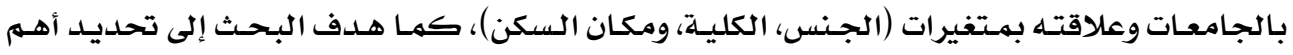

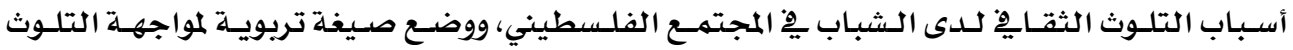

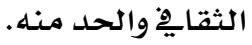

\section{وتوصل البحث إلى النتائج التالية:}

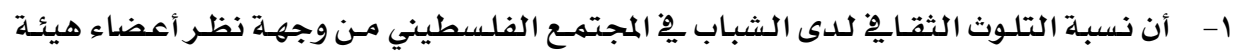

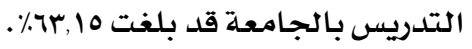




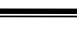
مجلة بحوث التربية النوعية - علد •r - أبريل r مr

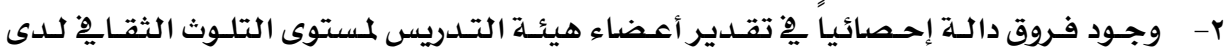
الشباب الفلسطيني يغزى لمتغير الجنس لصالح دوالئ الإناث.

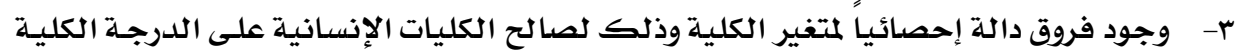

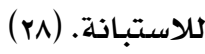

ومـن الدراسـات التي ركزت على الملوثات الثقافيـة وانعكاسـاتها على الهويـة الثقافيـة دراسـة

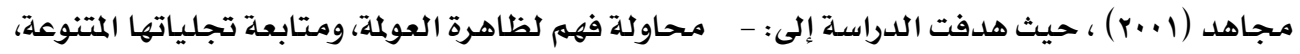

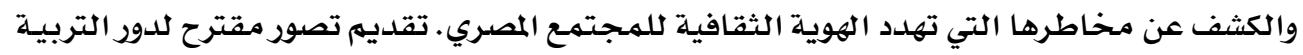

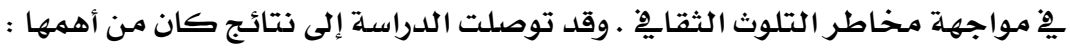

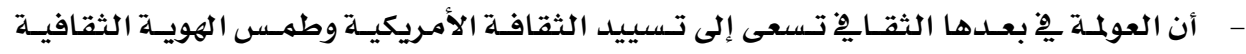

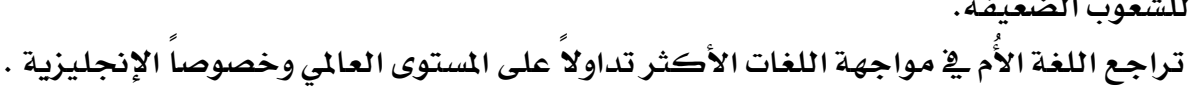

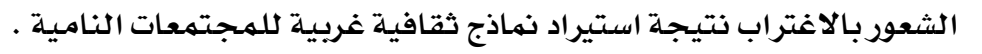

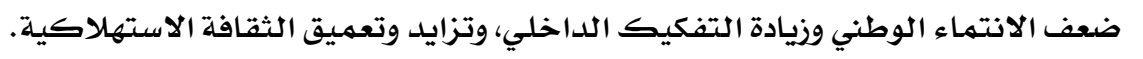

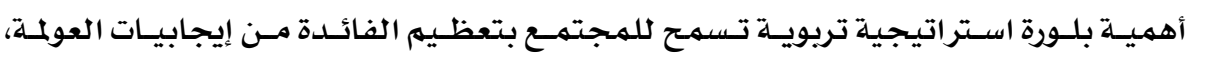

وتحجيه سلبياتها .

وتقدم الباحث بعدة تصورات يستطيع الباحث أن يستفيد منها:

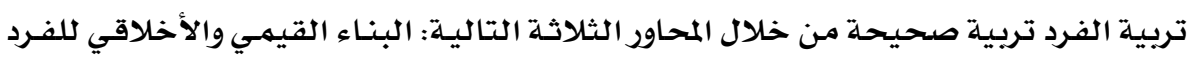

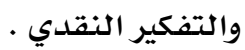

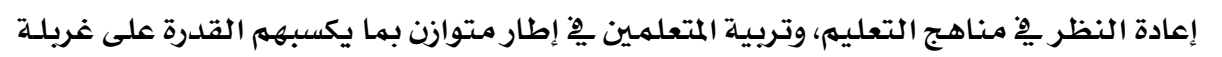

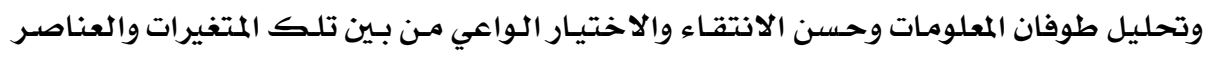

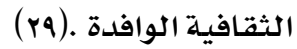

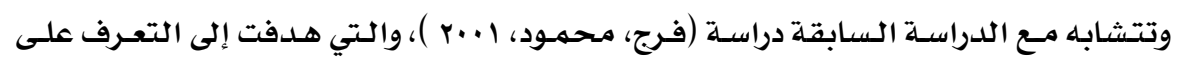

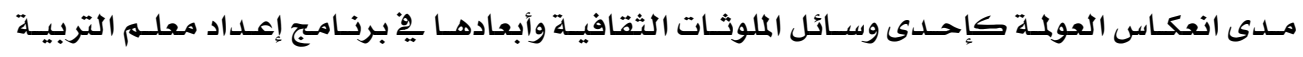

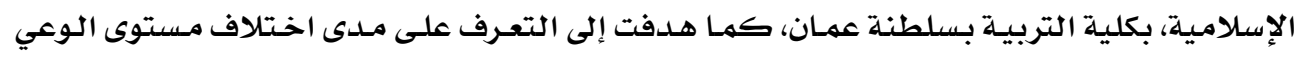

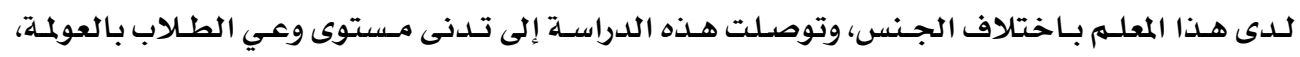

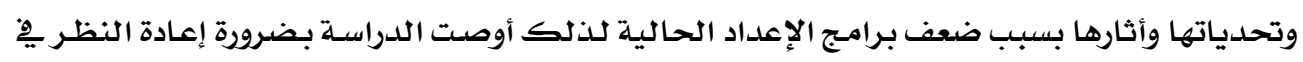

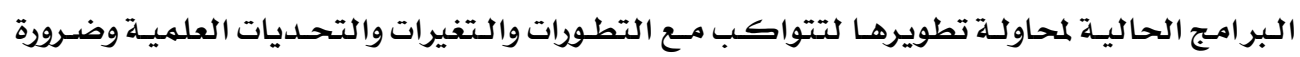

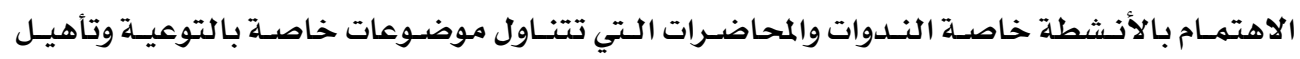

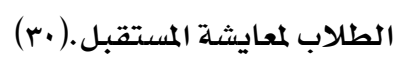

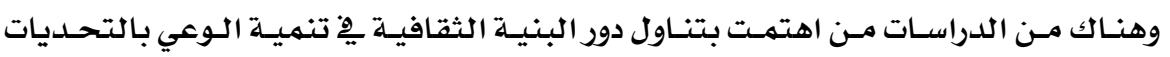

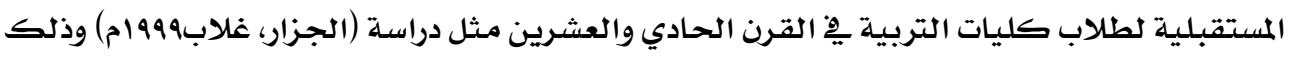

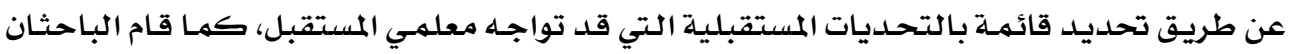




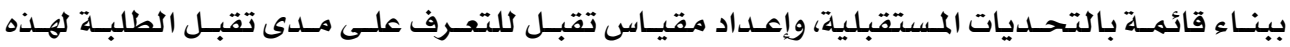

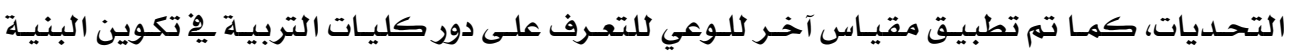

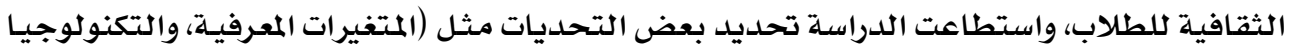

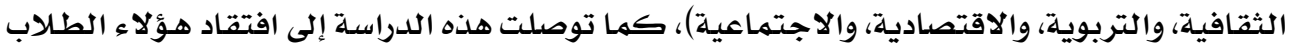

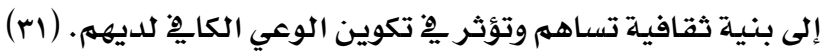

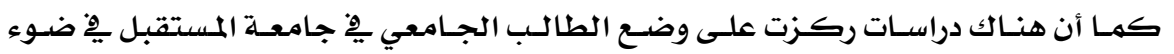

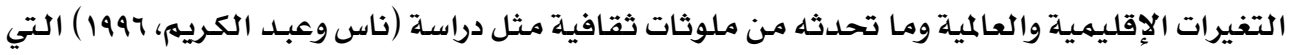

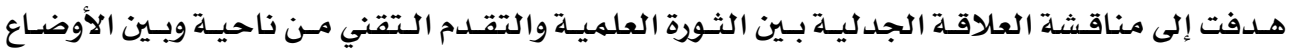

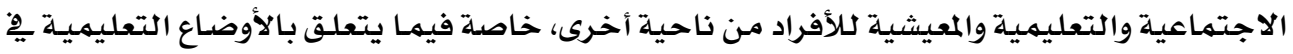

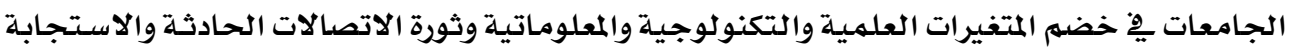

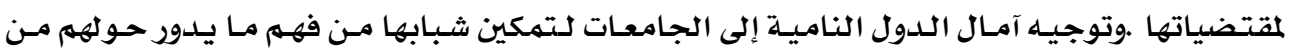

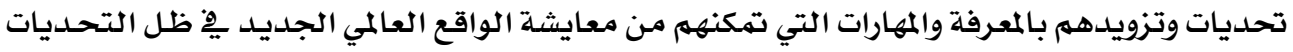

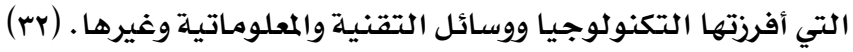

الدراسات الأجنبية: الدرية

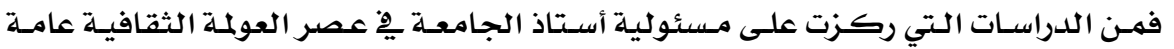

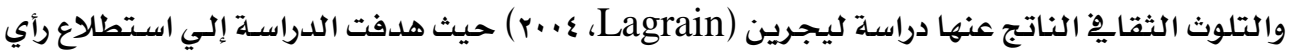

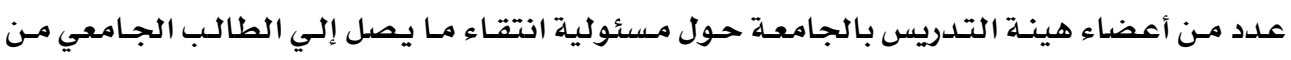

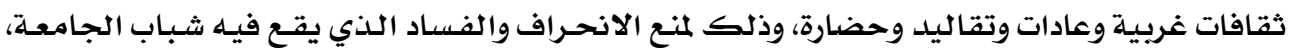
وتوصلت الدراسة إلي نتائج اهمها:

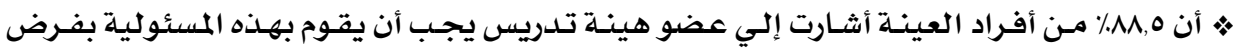

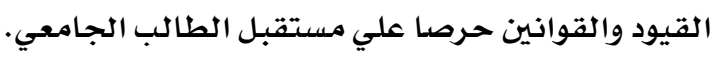

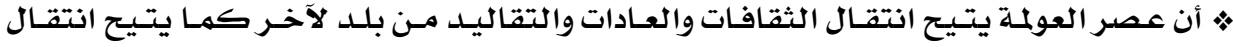

المساوئ والمحاسن يِّ كل مكان بالعالهم.

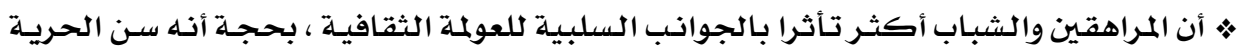

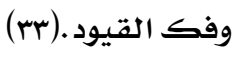

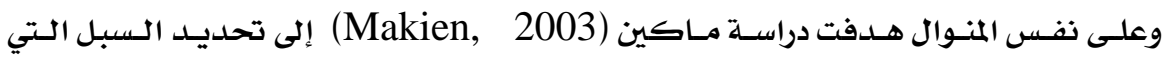

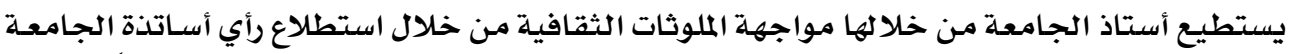

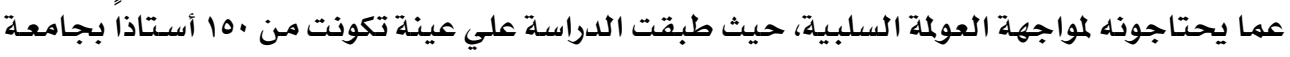

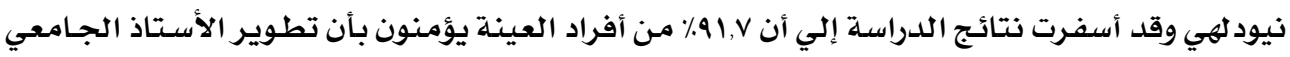

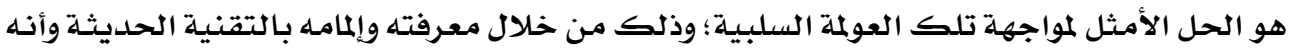

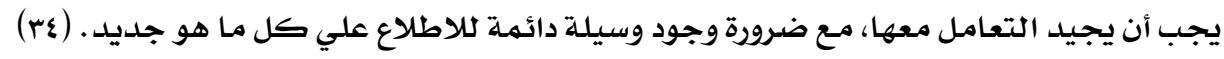


وبالتشابه مـع الدراسـة السابقة قام سميت (Semite, 2002) بدراسـة هدفت إلي المقارنة بين

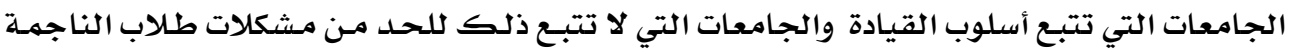

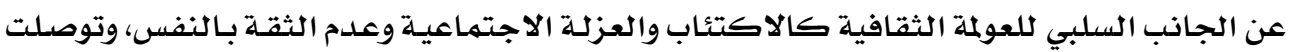

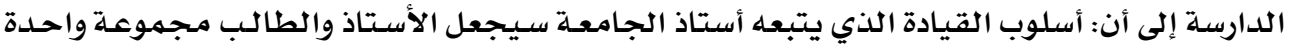

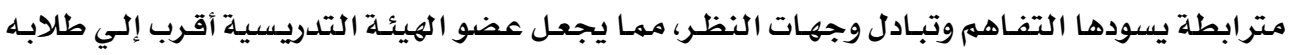

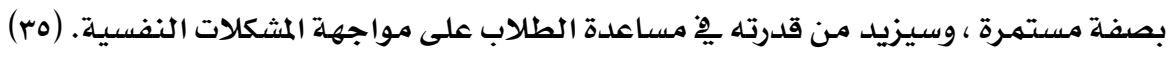

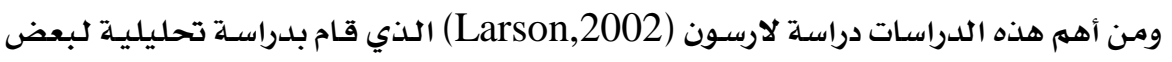

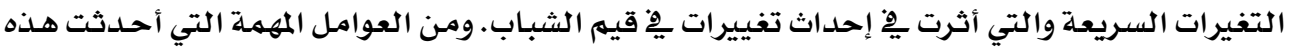

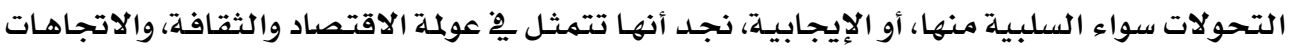

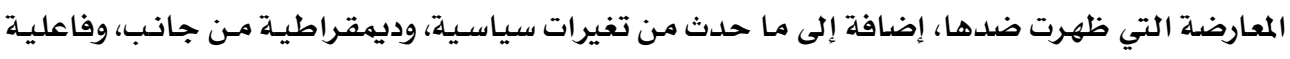

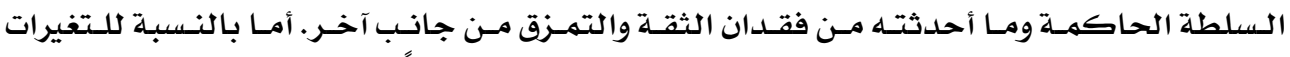

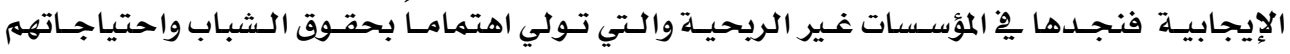

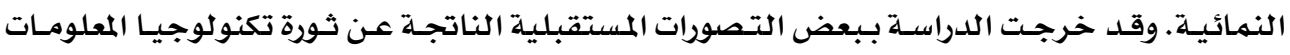

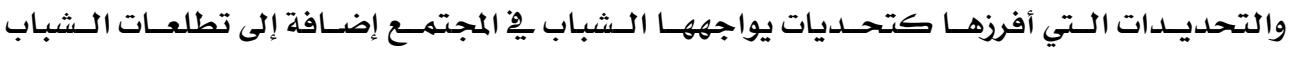

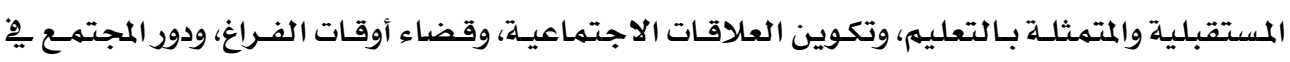

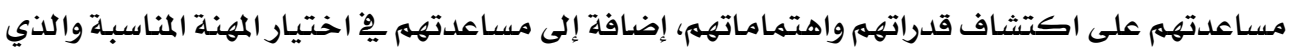

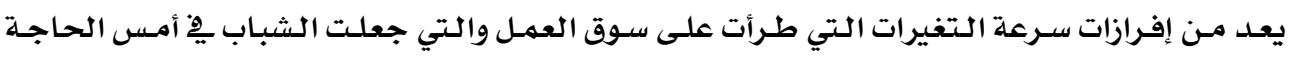

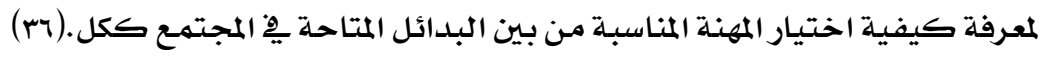

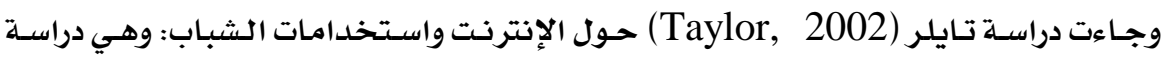

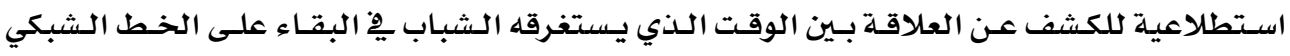
(Online)

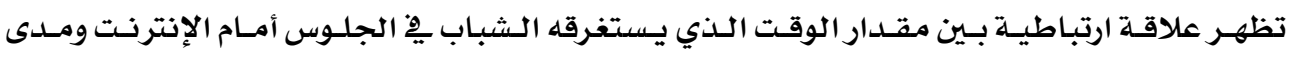

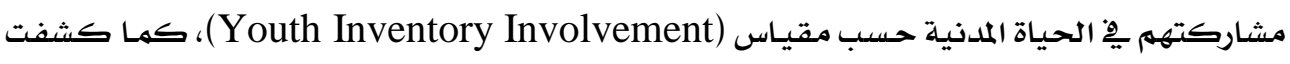

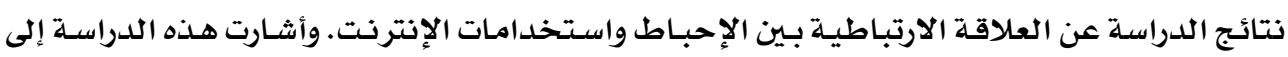

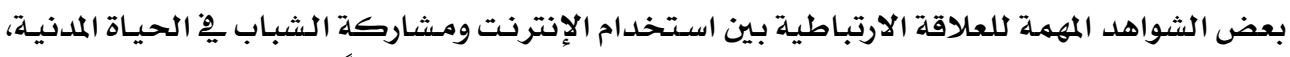

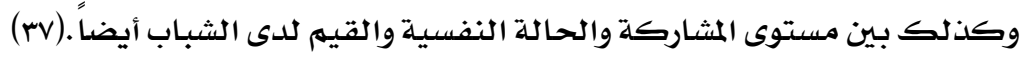

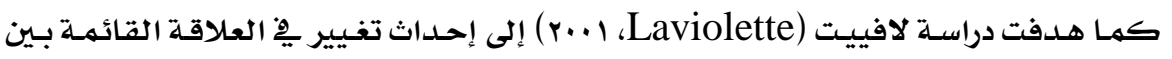

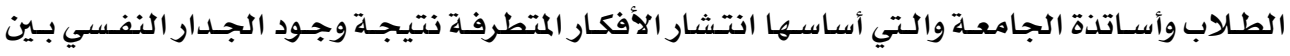

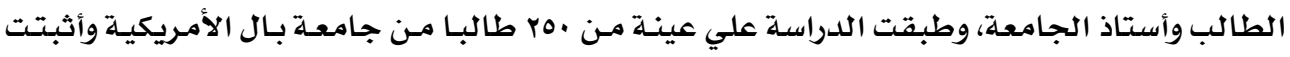

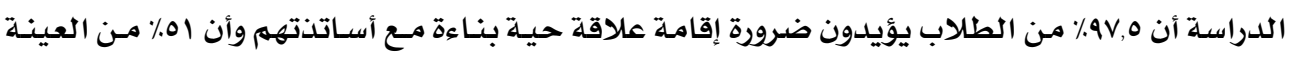

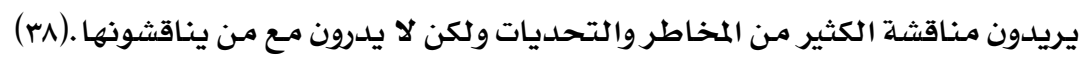


ومن الدراسات الأجنبية التي ركزت على التليفزيون كأحس وسـائل التلـوث الثقايِّوتأثيره

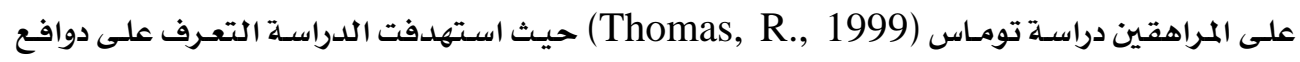

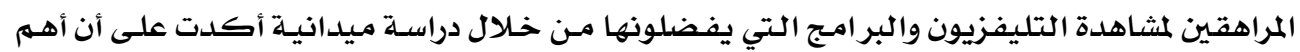

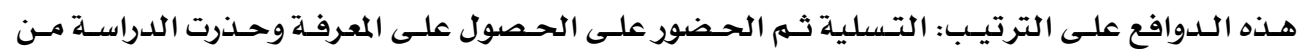

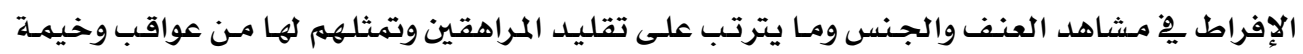

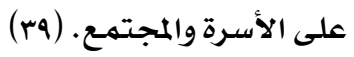

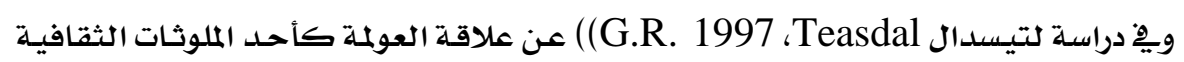

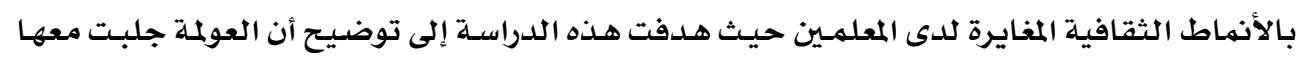

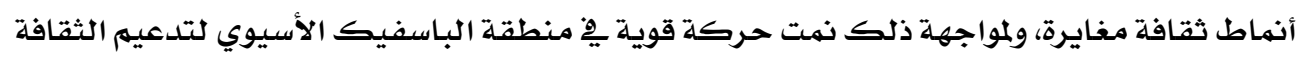

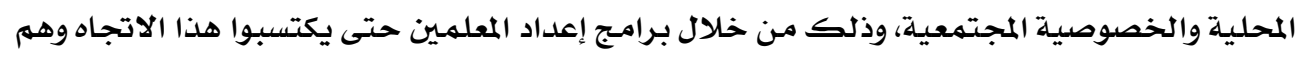

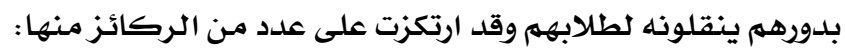

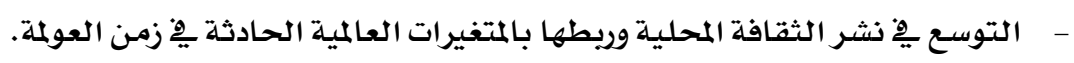

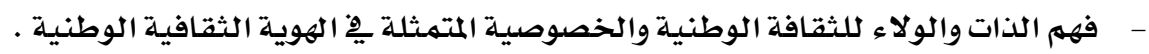

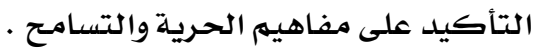

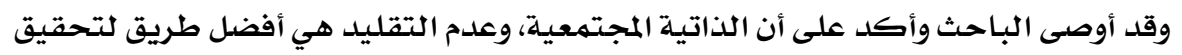

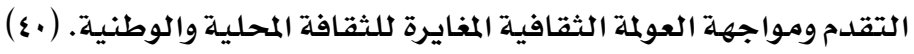
تعليق عام على الدراسات السابقة وملى استفادة اللدراسة الحالية منها:

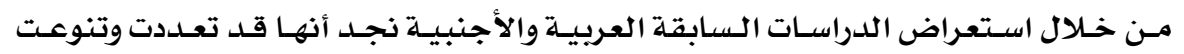

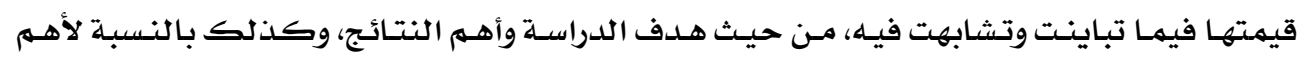

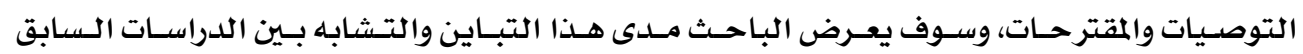
عرضها:

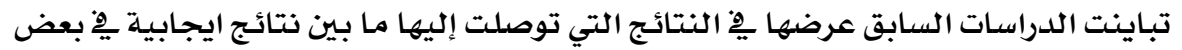

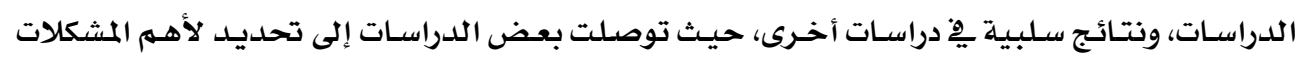

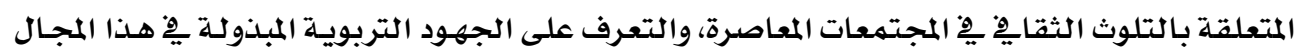

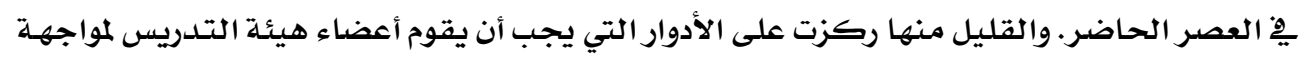
هذه الملوثات الثقافية.

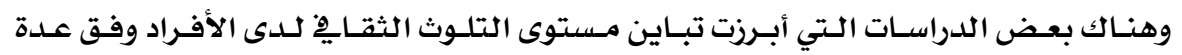

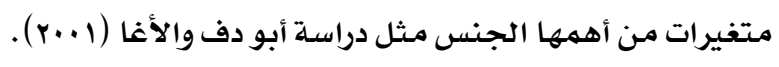

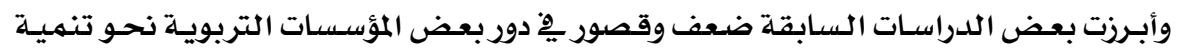

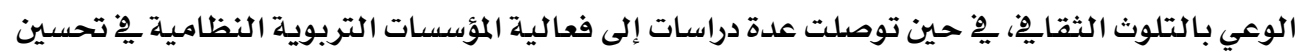

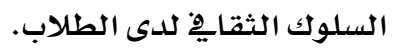




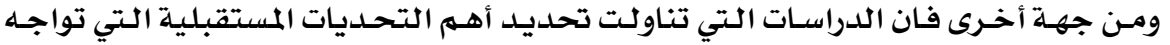

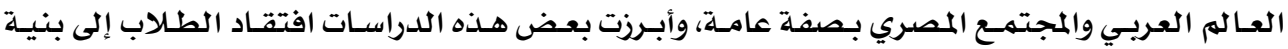

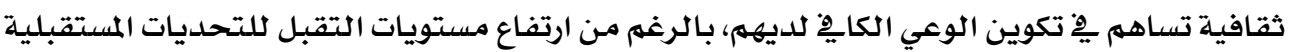
مثل دراسـة (عثمان الجزار، إكرام غلاب:

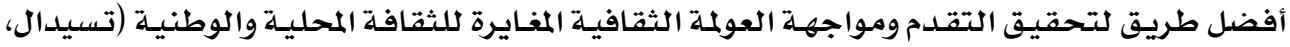

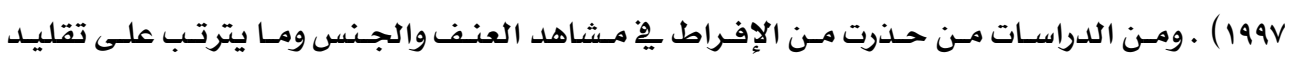

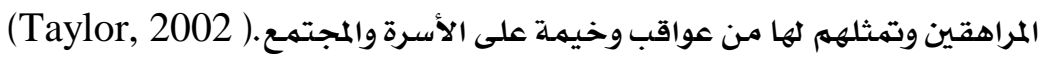

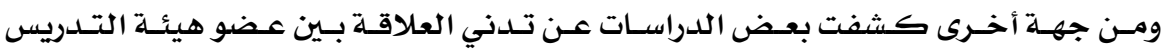

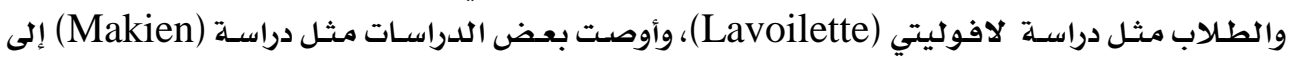

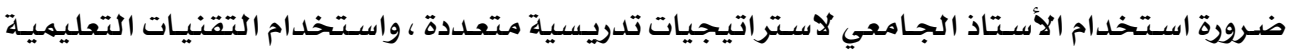
الحديثة والاستفادة من الحاسب الآلي يِّ التدريس.

\section{موقف اللدراسة الحالية من اللدراسات السابقة:}

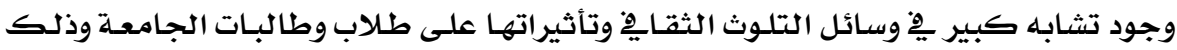

كما أظهرته نتائج معظم الدراسـات السـابقة.

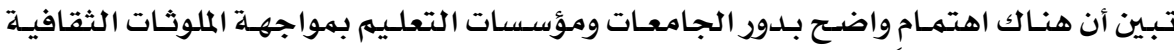

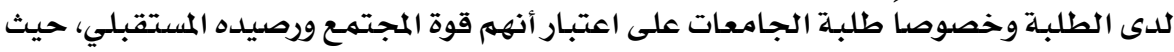

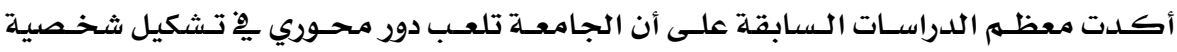

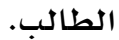

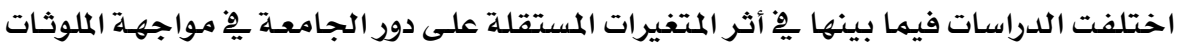

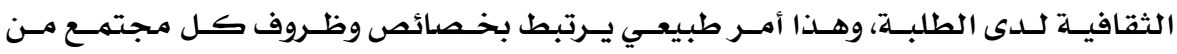

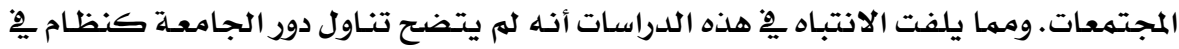

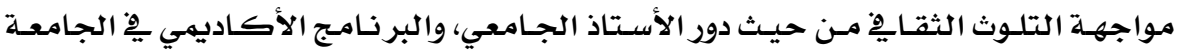

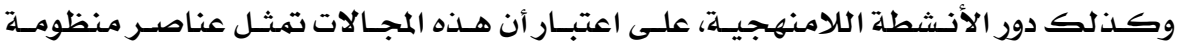

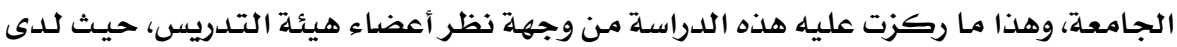

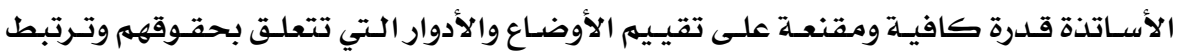
بهصالحهم وممارستهم، وهذا ما ميزها عن غيرها من الدراسات.

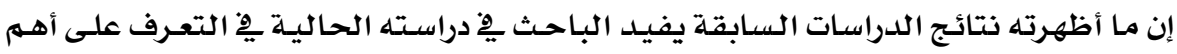

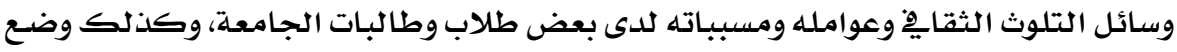

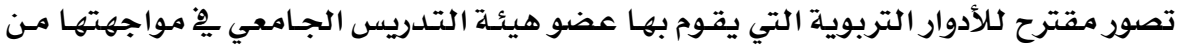

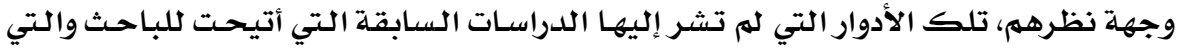

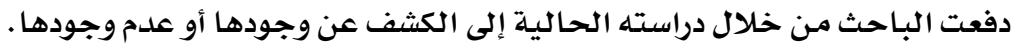


منهج الدراسة وأدواتها:

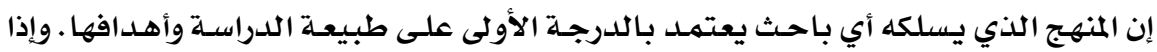

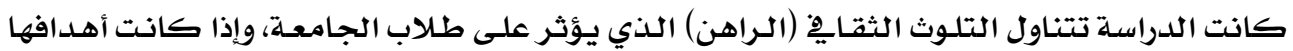

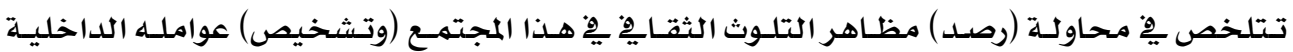

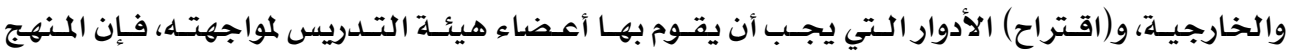

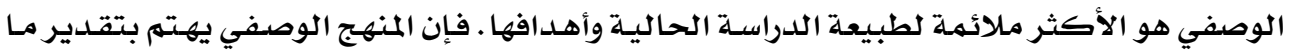

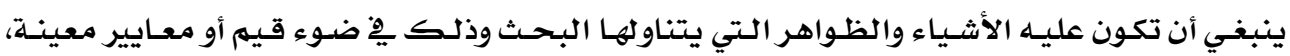

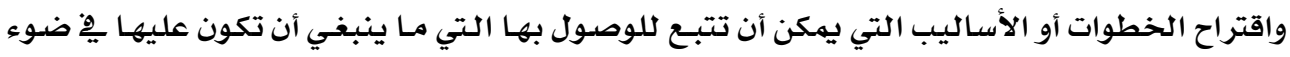

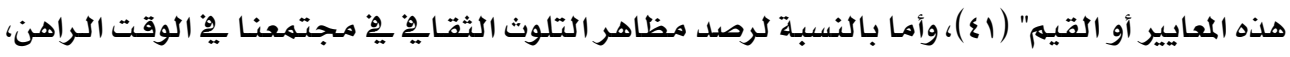

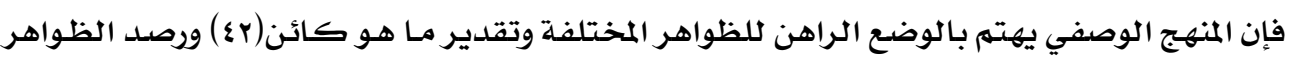

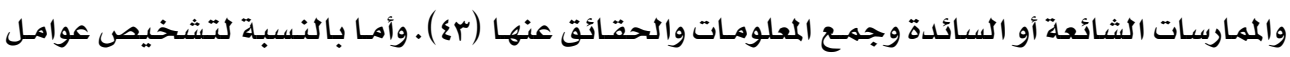

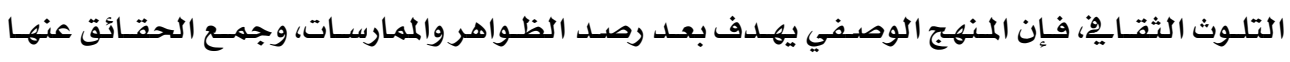

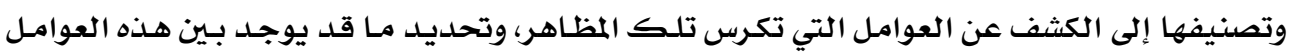

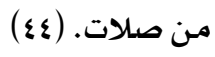

ولـذلك استخدمت الدراسـة المنهج الوصفي التحليلـي مـن خـلال عـرض الأدبيـات المختلفــة

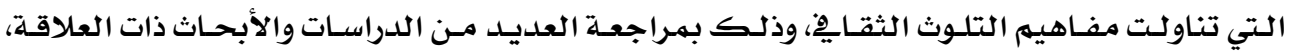

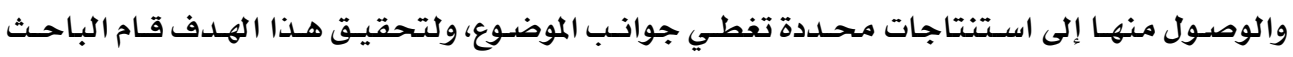

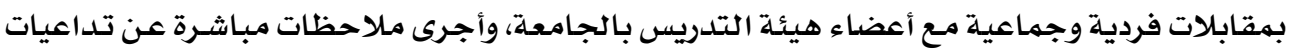

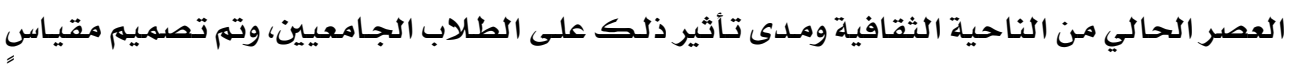

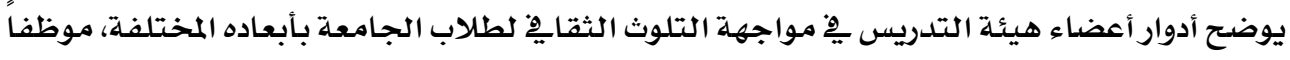

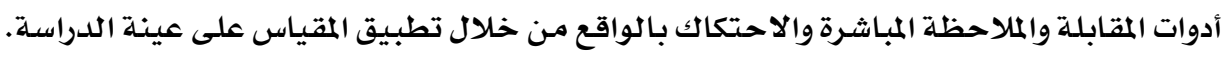

خطوات اللدراسة

تشتمل الدراسة على الخطوات التالية:-

أ) الإطار النظري: ويشتمل على النقاط التالية:

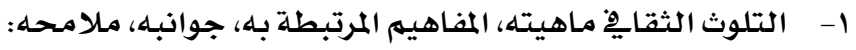

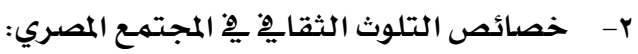

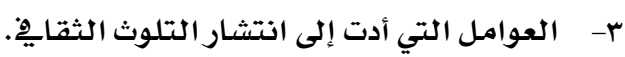

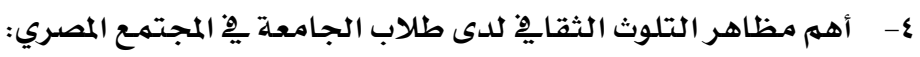

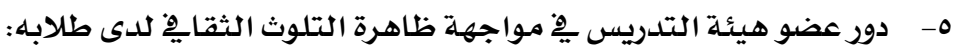

ب) الإطار الميداني: ويشتمل على النقاط التالية: 1- خطوات اختيار عينة الدراسلة. 


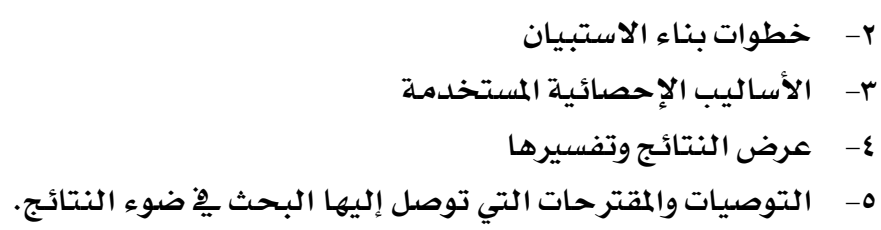

ثانيًا: الإطار النظري اللدراسية

أولا : التلوث الثقافي ماهيته، المفاهيه المرتبطة به، جوانبه، ملامحه:

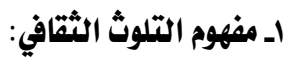

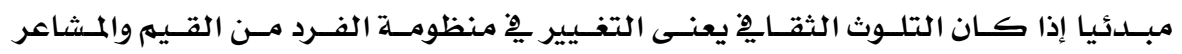

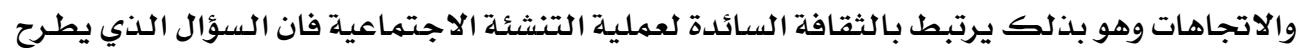

نفسسه هو ..

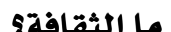

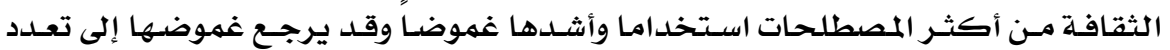

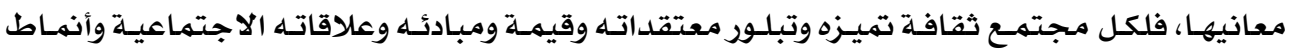

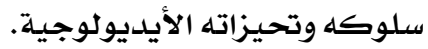

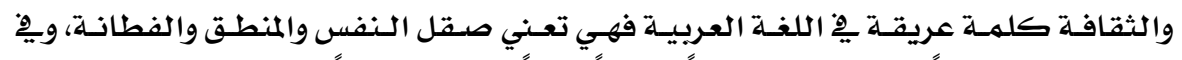

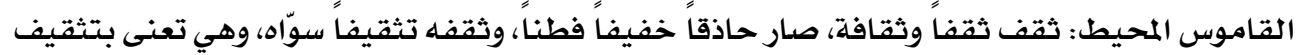

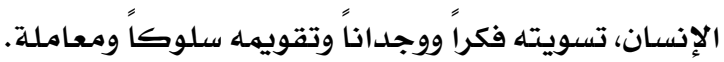

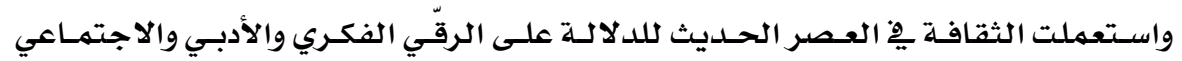

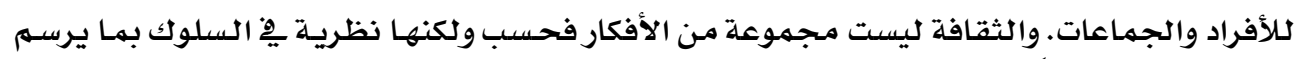

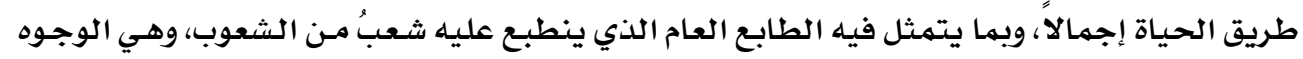

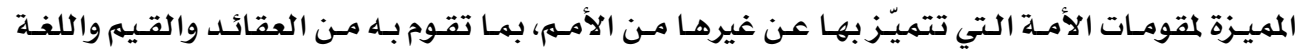

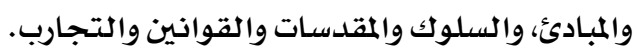

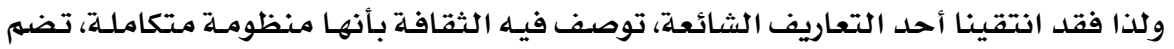

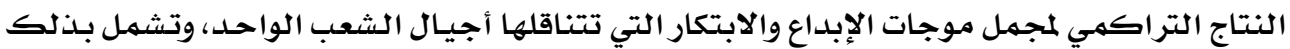

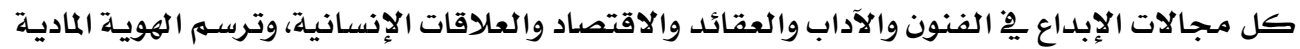

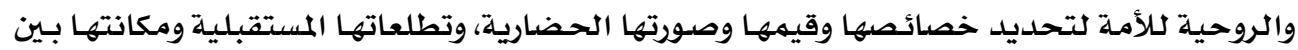

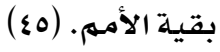

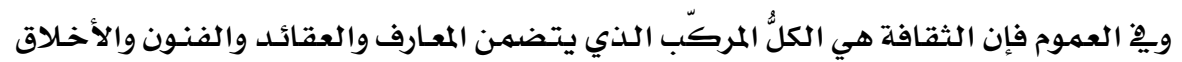

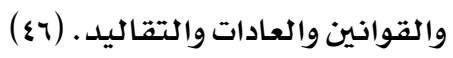

من هنا يتبـين لنـا أن الثقافة تتسم بمجموعـة مـن الخصائص تميزهـا وتختلف مـن مجتمـع لأخر واهم الخصائص تتمثل ِِّْ أنها:- 
ا- أنها ظـاهرة إنسانية، أي أنها الوسيلة المثلى بـين الإنسـان وسـائر المخلوقات لأنها تعبير عن

إنسانيته .

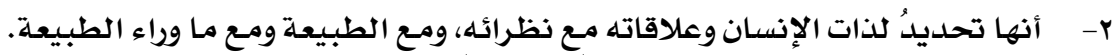

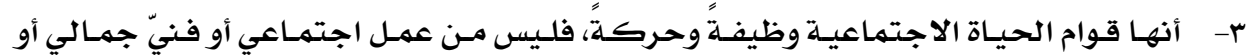
فكري يتهم إنسانيا خارج دائرتها.

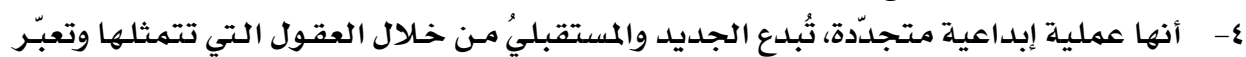
عنها.

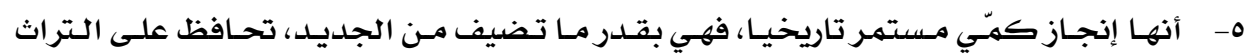

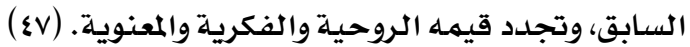

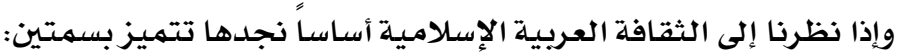
• أولهما / هي سمة الثبوت فيما يتعلق بالمصادر القطعية،، وما جاءت به من عقائد وتشريعات وقيم ومناهـج.

• وثانيهما : هي سمة التغيير فيما يتعلق باجتهادات المسلمـين وإبداعاتهم القابلة للصواب والخطأ

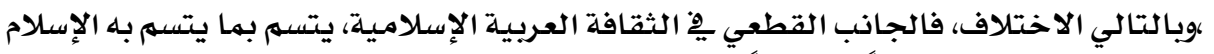

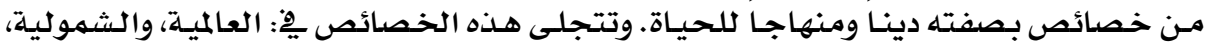

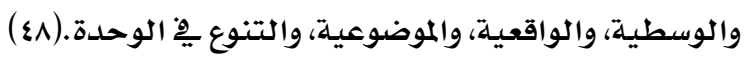

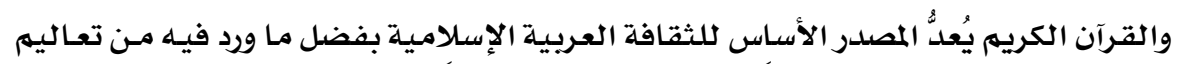

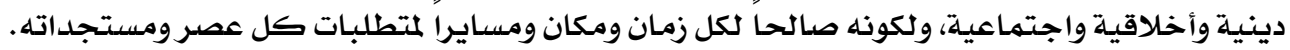

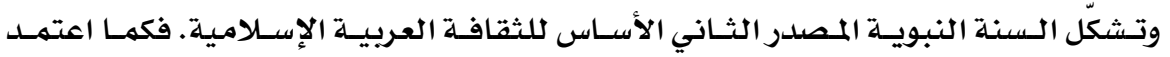

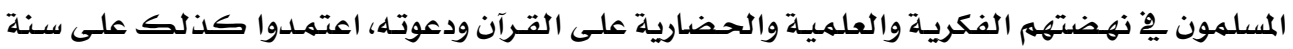

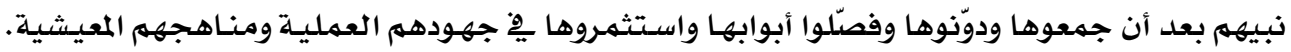

واللغلة العربية مقوّم أساس من مقومات الثقافة العربيـة الإسـلامية، ذلك أن العربيـة ليست

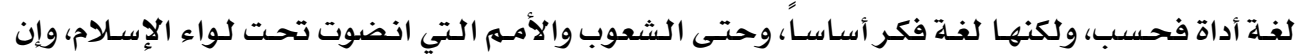

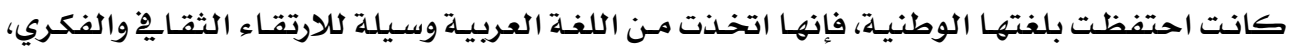

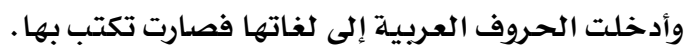

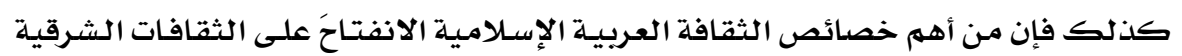

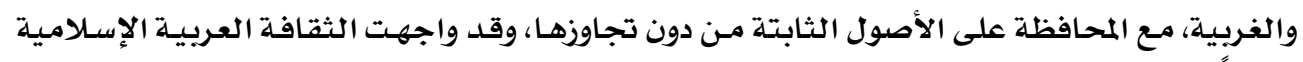

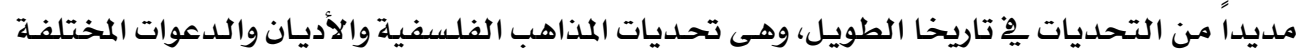

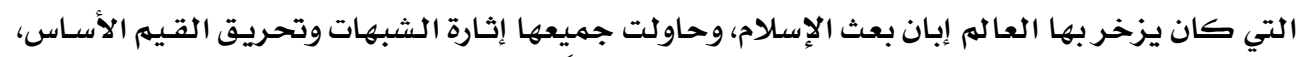

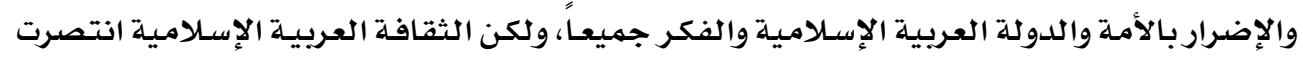

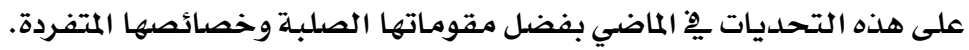


ولقد أكسبَ ذلك الثقافة العربية الإسلامية ثراءً وغنى، وقوة ومناعـة، وهى خاصية فريدة

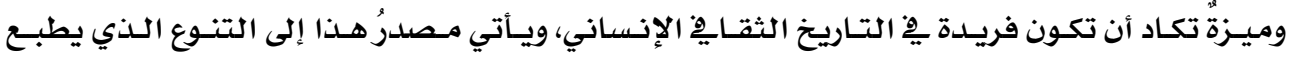

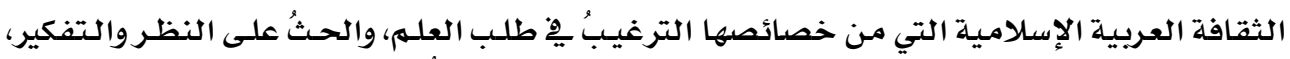

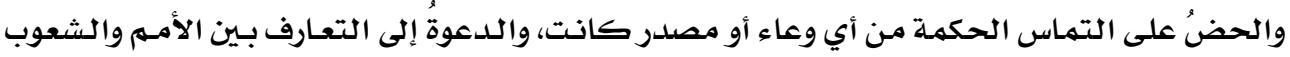

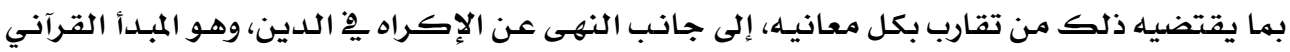

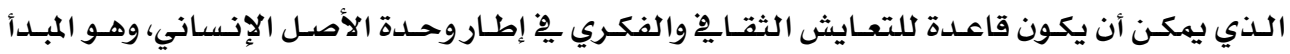

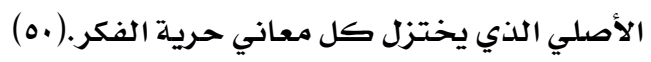

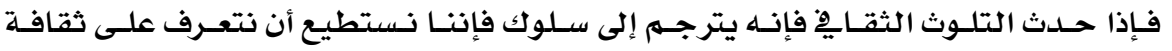

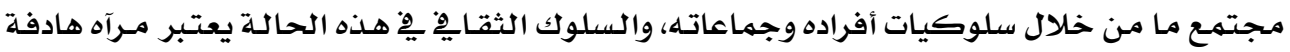

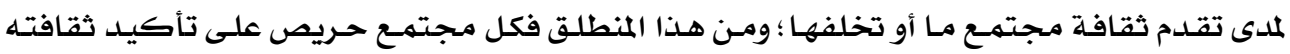
والسمو بها والاحتفاظ بعنصر الدينامية؛ لتنشيط فاعليات هذه الثقافة وتوريثها للأجيال الدلاحقة.

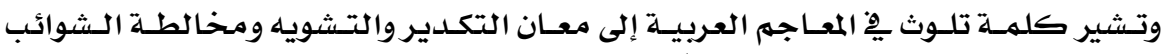

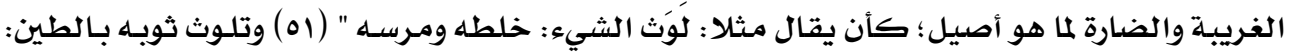

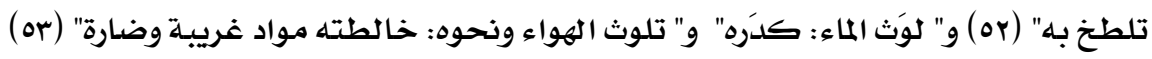
وفى ضوء ذلك يعرف التلوث الثقايِّ بأنه مفهوم اجتماعي نفسي يشير إلى التغيير الحسادث

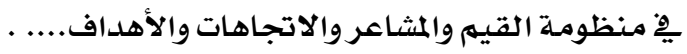

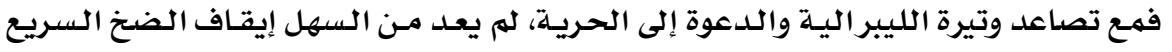

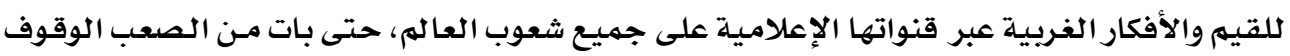

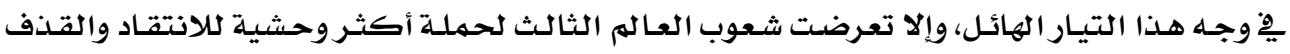
بكل صفات الانغلاق والتخلف والرجعية.

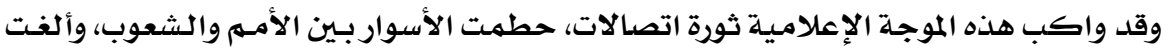

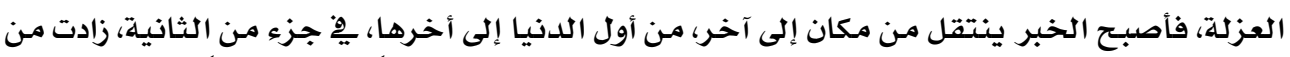

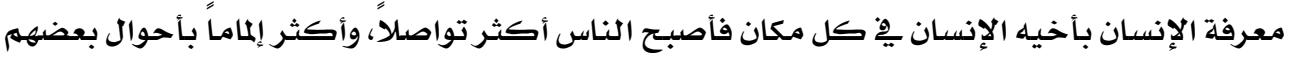

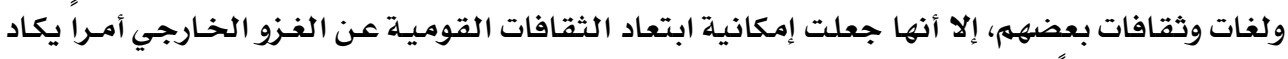

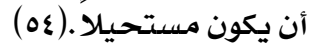

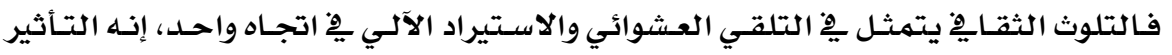

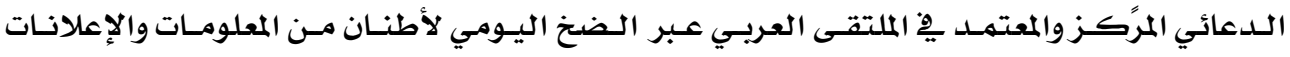

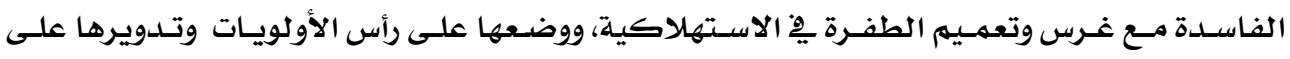

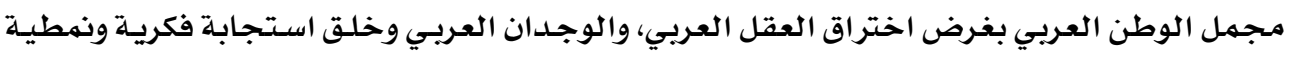

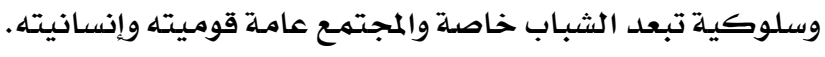
وقد امتد هذا التلوث الثقايِّ بشكل سريع ومفاجئ خلال السنوات القليلة الماضية، إلى ألعاب الماب

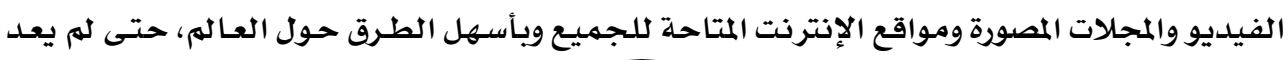




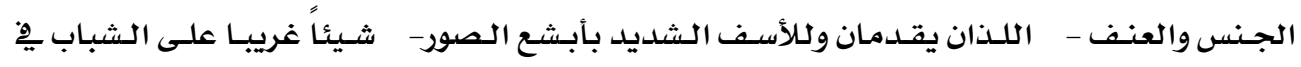

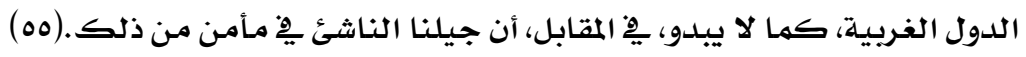

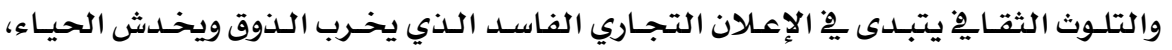

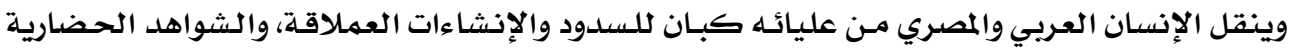

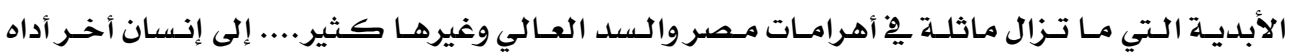
للاستهلاك وألة عرض لكالإعلان نفسـه.

والتلوث الثقايِّهو ذلك الذي يطرق عقل الإنسان العربي والمصري وعاطفته اليوم أكثر

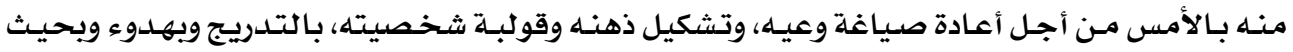

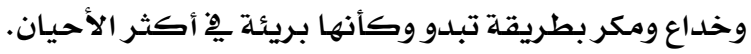

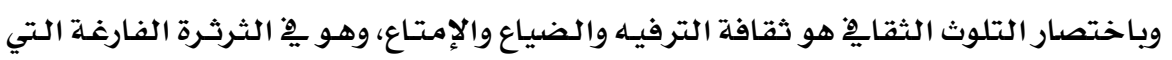
تقوم بتخدير الإنسان العربي وشل دورة الحضاري والانساني وسط خضهم الأحداث العالميلة.

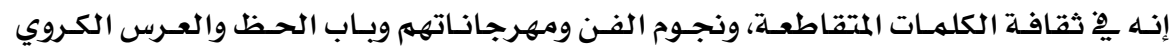

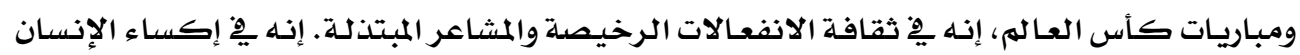
العربي هوية غير هويته وثوباً غير ثوبه.

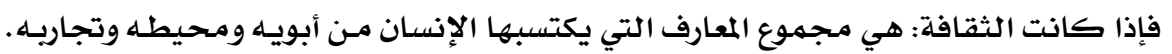

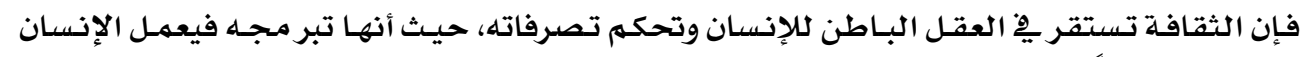

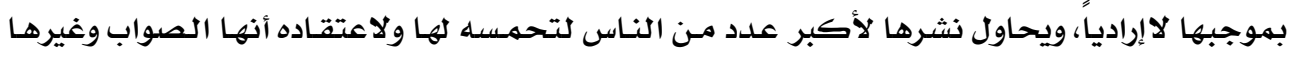

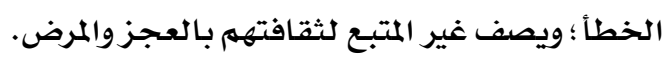

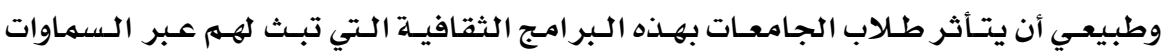

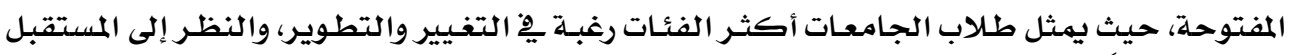

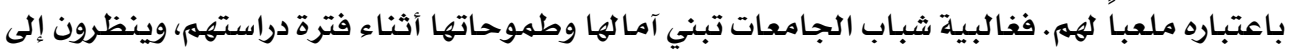

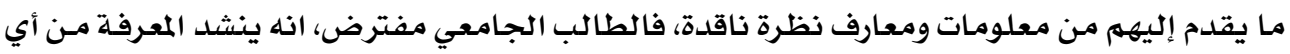

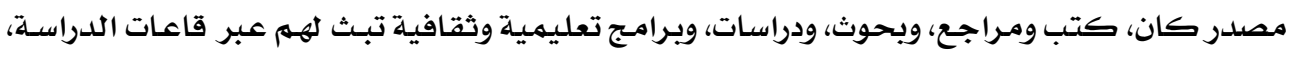

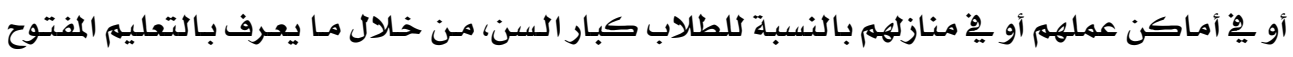

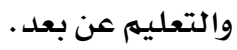

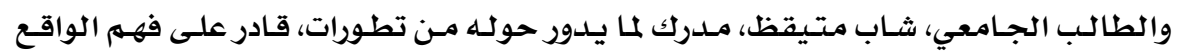

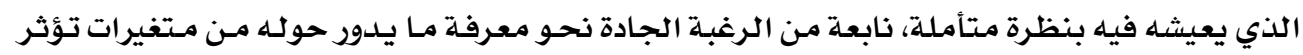

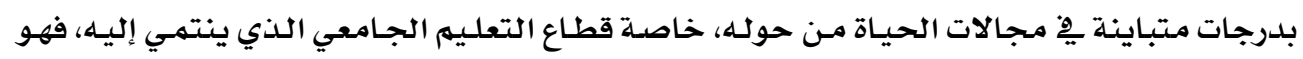

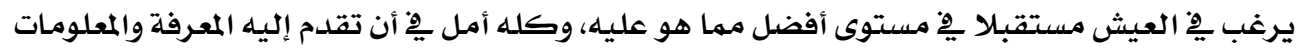

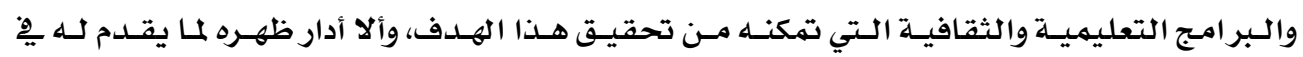

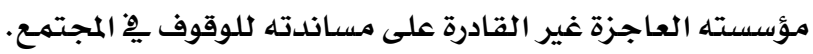


ביב

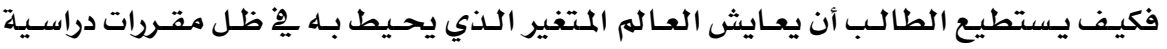

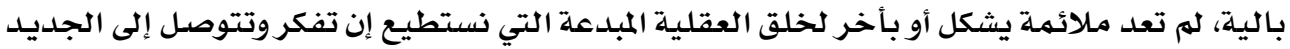

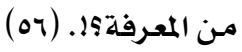

هنا، يقف الطالب يِّ مفترق الطرق ويتساءل، هل القصور يِّ عدم قدرته على تحصيل المعرفة

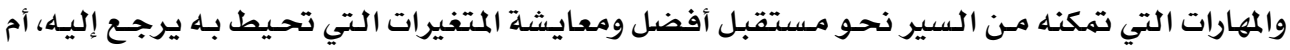

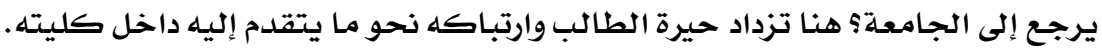

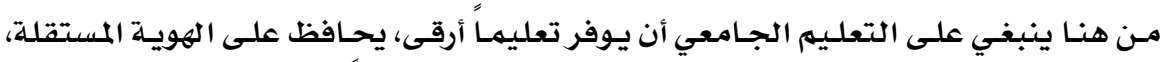

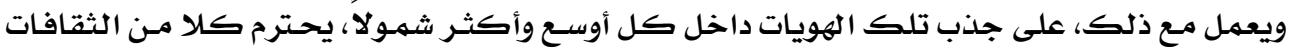

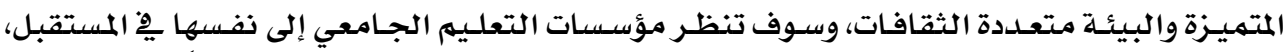

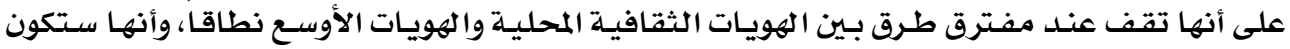

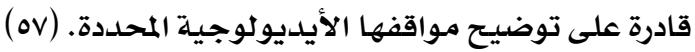

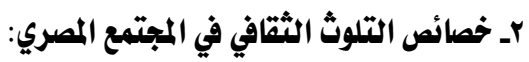

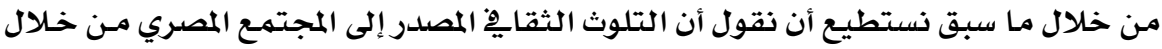

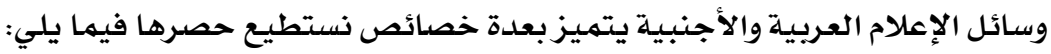
ا- التركيز على مـا يوصف بالثقافة الشعبية وتركيز صسناعة الإعلام والإعلان على تحويلها

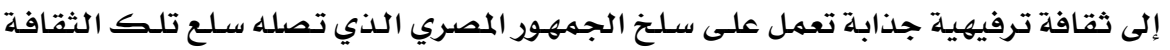

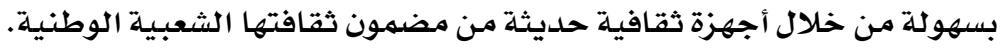

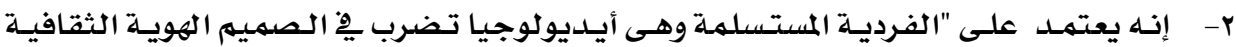

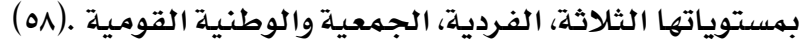

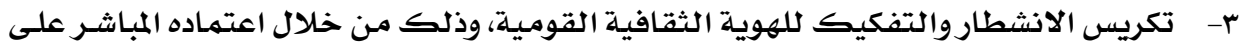

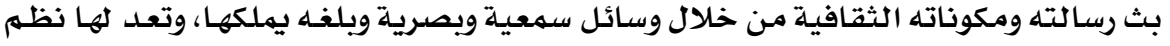

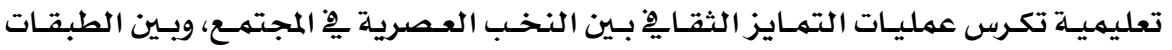

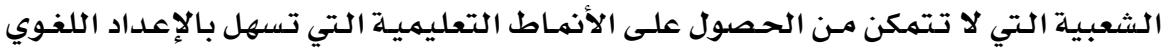

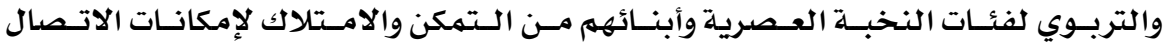

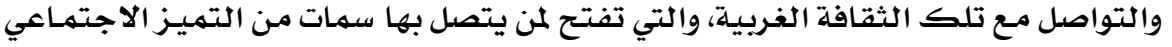

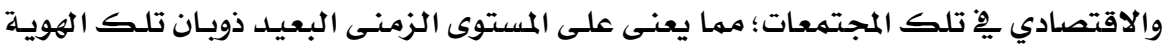

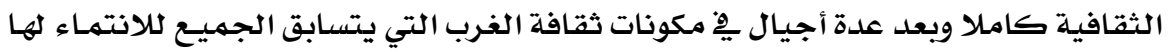

$$
\text { والاحتماء بهميزاتها. }
$$

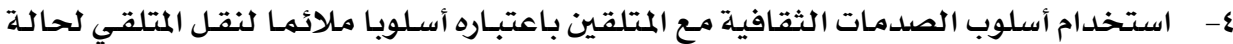

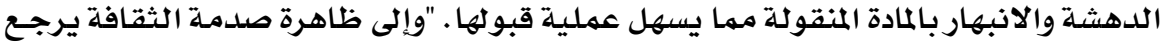

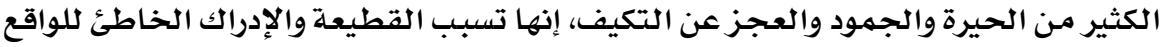

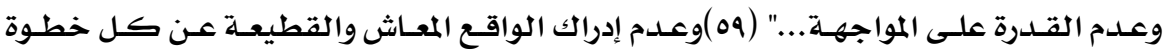




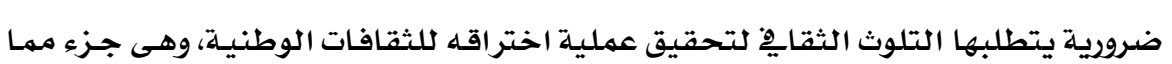

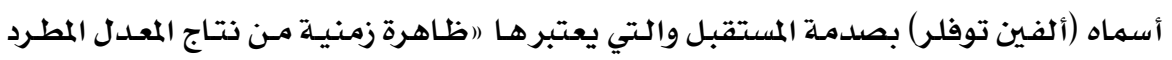

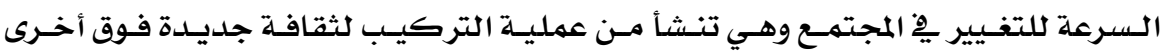

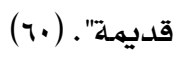

\section{rـ العوامل التي أدت إلى اتثشار وتكريس التلوث الثقافي.}

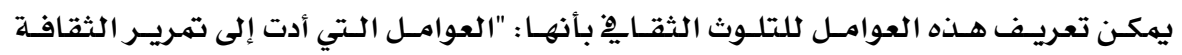

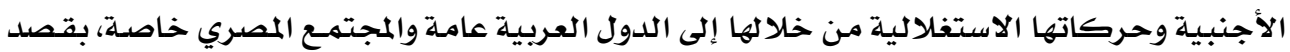

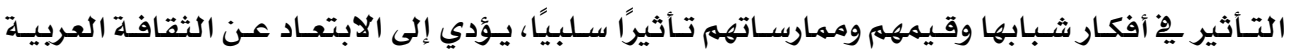

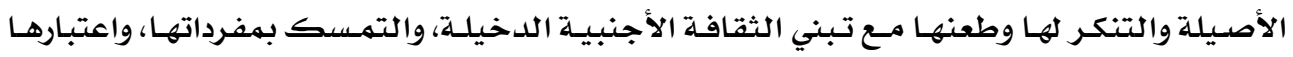

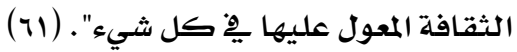

$$
\text { ويهكن تصنيف هذه العوامل إلى : }
$$

$$
\begin{aligned}
& \text { r- الاحتكالك الحضاري المباشر. } \\
& \text { ع- التبعية التربوية. }
\end{aligned}
$$

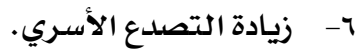

$$
\begin{aligned}
& \text { ^- - فقدان الهوية والانتماء. }
\end{aligned}
$$

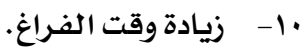

$$
\begin{aligned}
& \text { 1- وسائل الإعلام الجماهيرية. } \\
& \text { ب- المؤسسات الثقافية والتربوية. } \\
& \text { ه- - التبعية الاقتصادية. }
\end{aligned}
$$

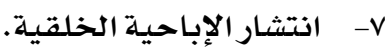

$$
\begin{aligned}
& \text { q- ت تناقض القيم والمعايير. }
\end{aligned}
$$

وسنشرح طبيعة هذه العوامل التي أدت إلى انتشار وتكريس ظاهرة التلوث الثقايِّ مـع توضيح

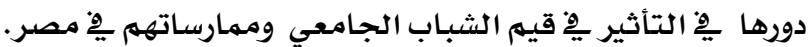

$$
\begin{aligned}
& \text { ا- وسائل الإعلام الجماهيرية : }
\end{aligned}
$$

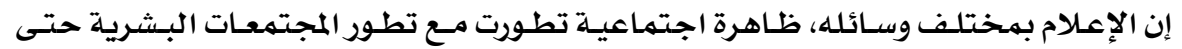

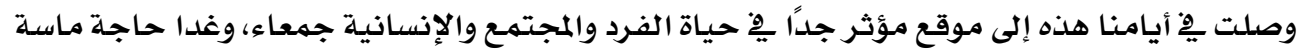

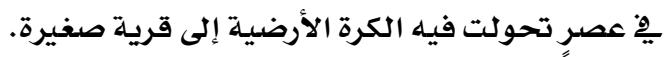

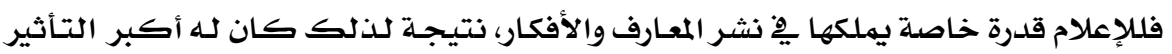

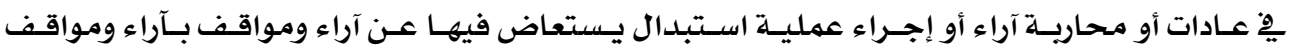

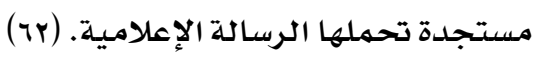

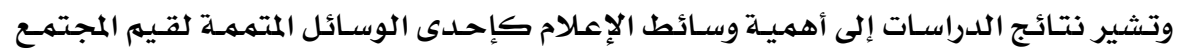

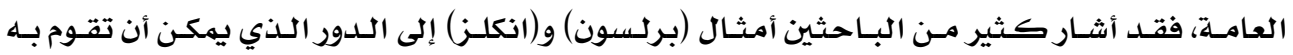

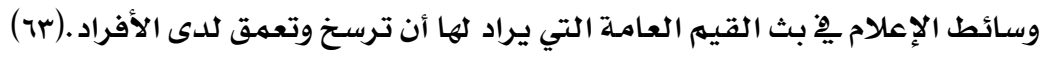

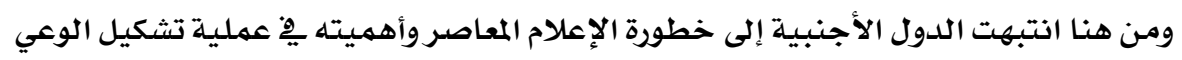

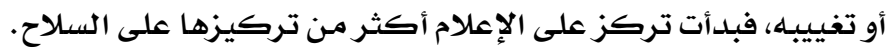


ولـذلك أكدت وسيائل الإعلام التي تمتلكها الأوسـاط المسؤولة عن تنظيهم حمـلات التلوث

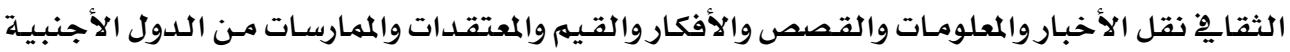

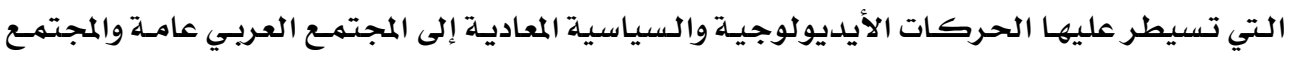

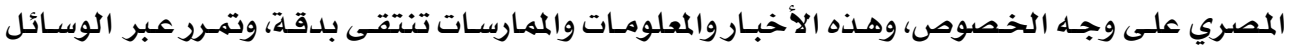

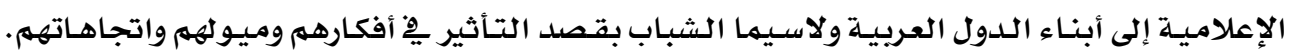

وإن الخطورة التي تمثلها وسائل الإعلام الأجنبية، ولاسيما التي تبـث باللغـة العربيـة كبيرة

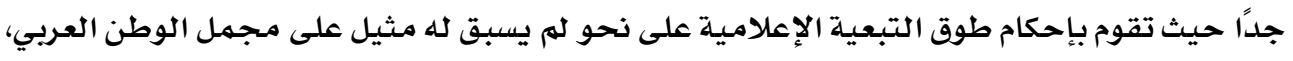

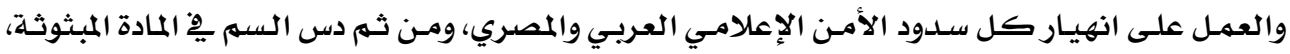

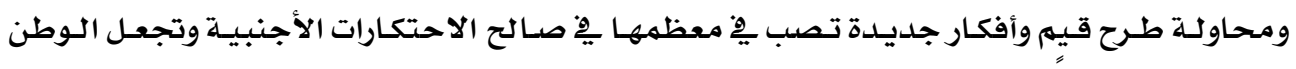

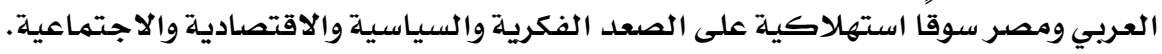

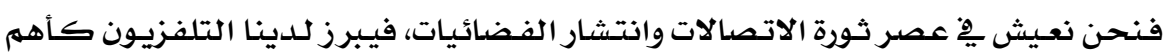

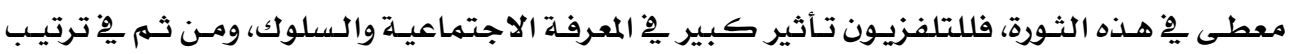

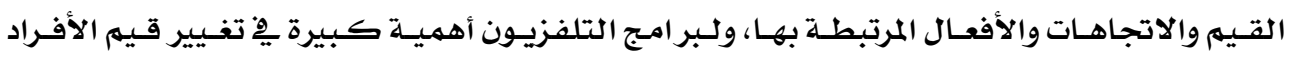

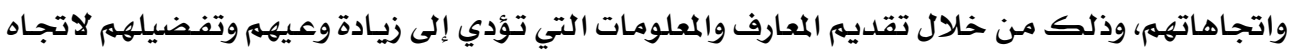
معين أو ابتعادهم عنه. (70)

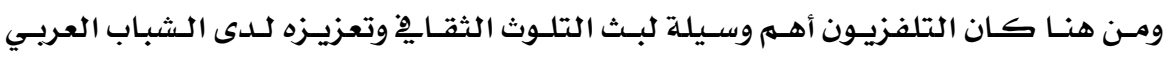

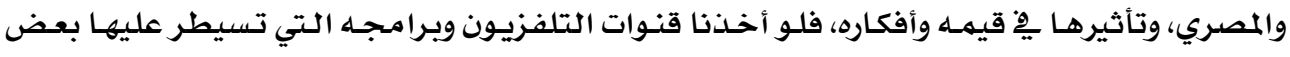

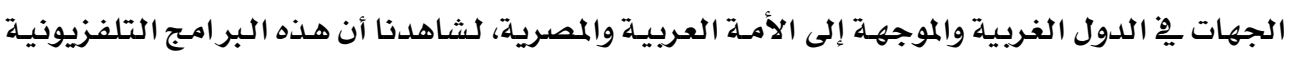

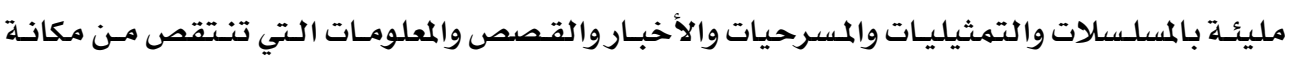

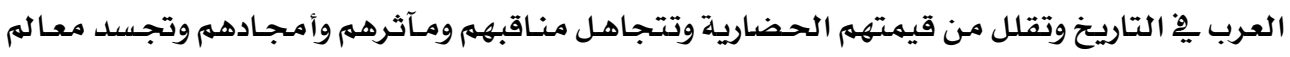

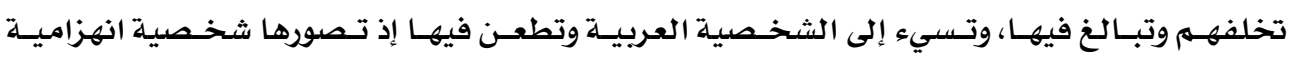

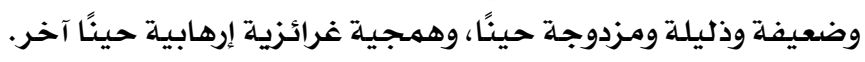

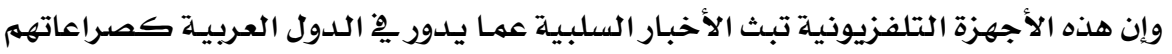

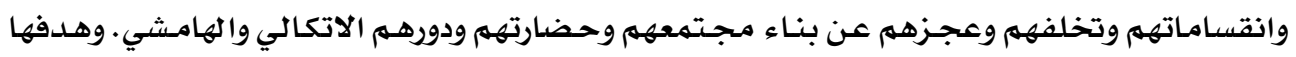

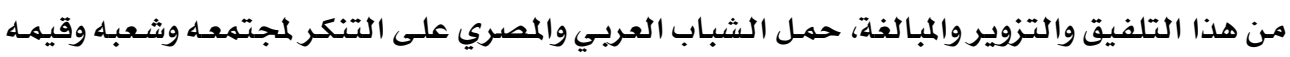

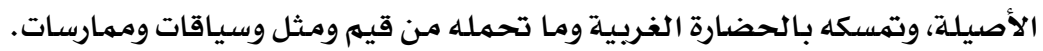

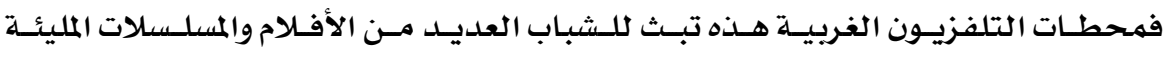

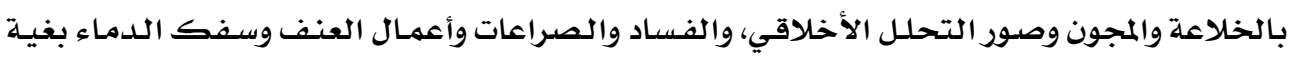

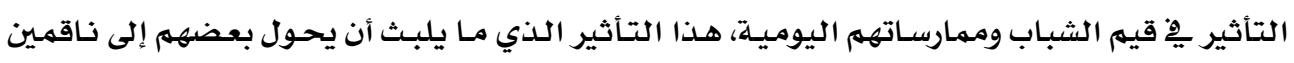

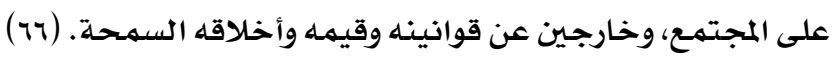




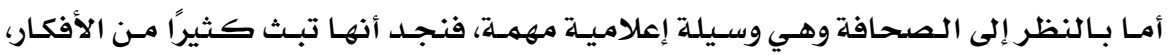

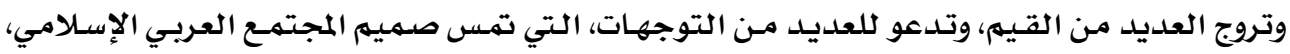

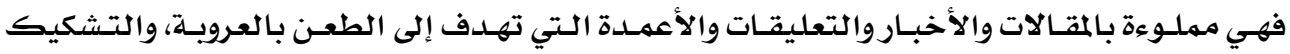

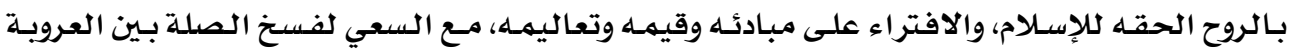

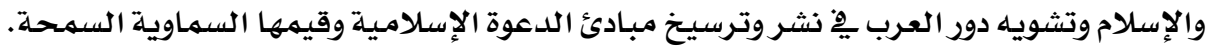

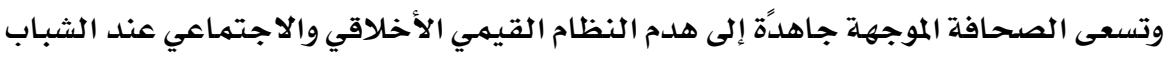

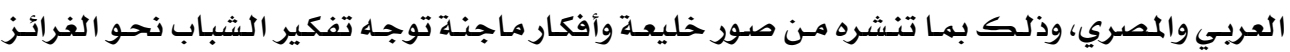

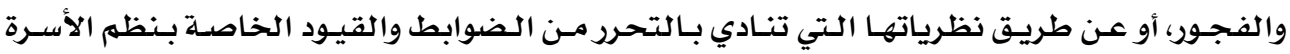

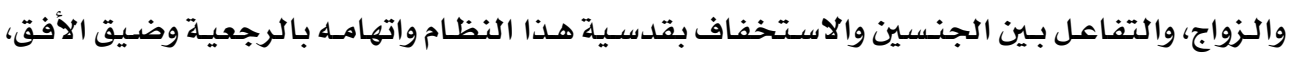

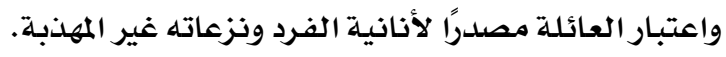

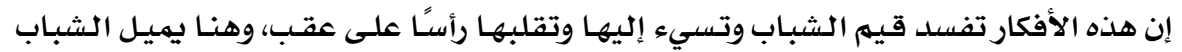

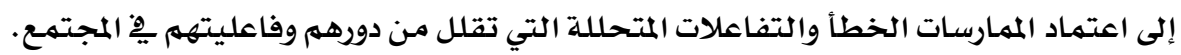

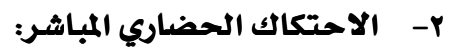

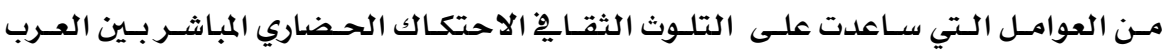

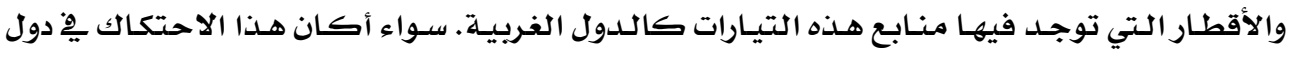

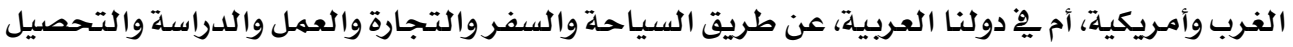

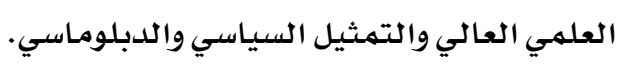

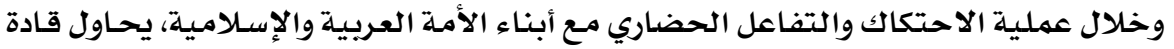

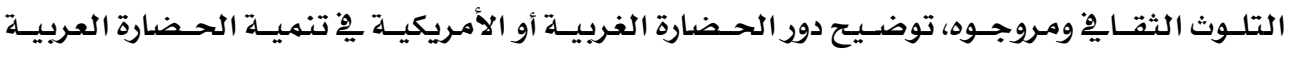

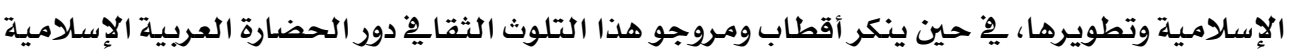

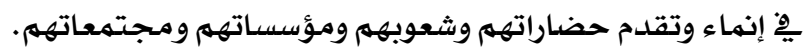

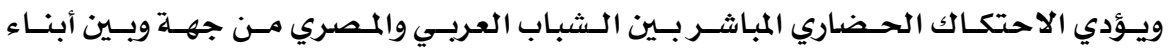

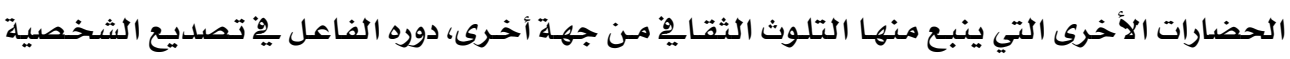

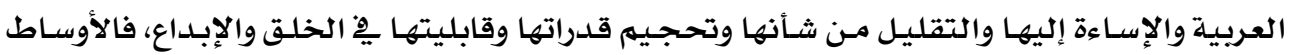

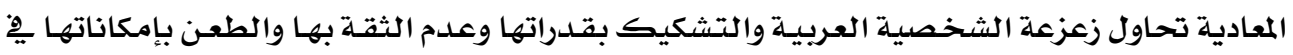

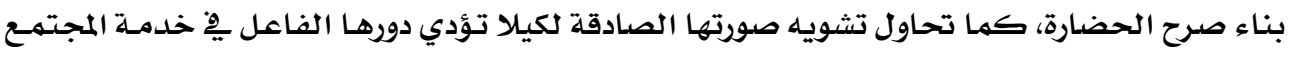

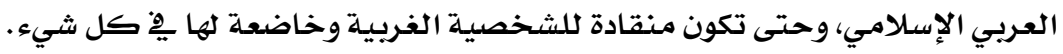

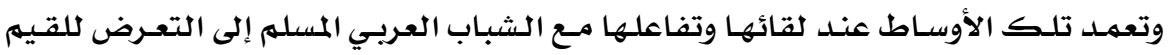

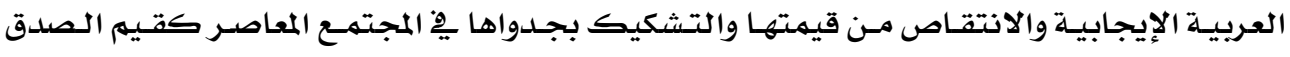

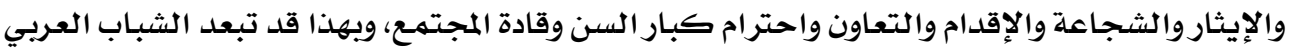

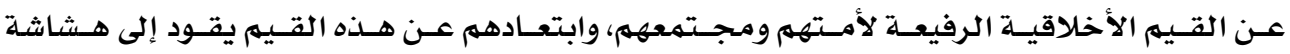

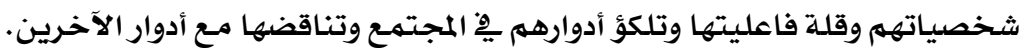


$\underline{\underline{ }}$

وقد تزرع هذه الأوساط عند الشباب العربي القيم الاجتماعية السلبية كقيم الأنانيـة وحب

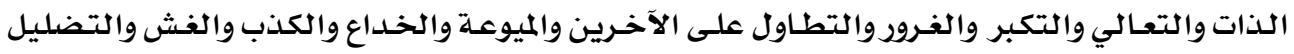

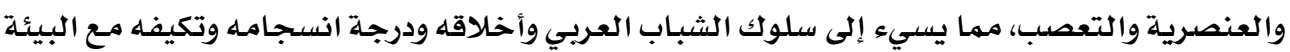

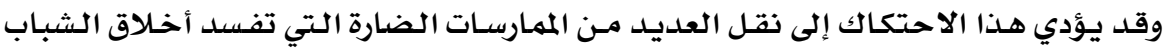

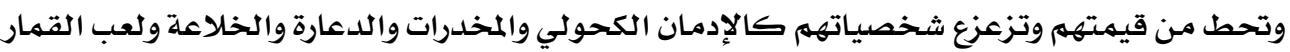

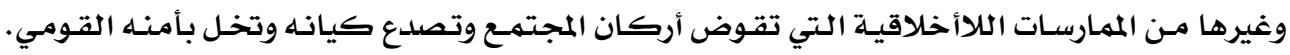

\section{r- r المؤسسات الثقافية والتربوية :}

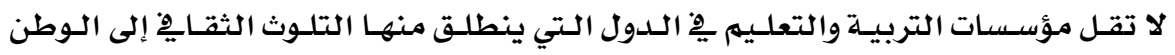

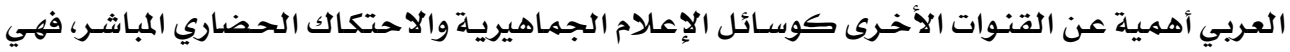

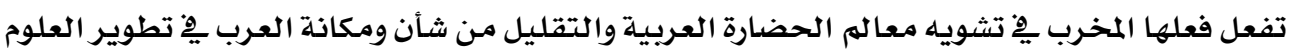
والفنون والآداب، والتصدي للهوية العربية وتمزيق خصوصيتها فئها القومية.

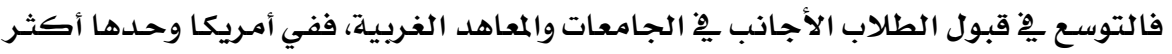

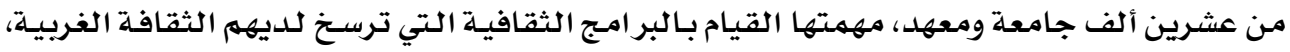

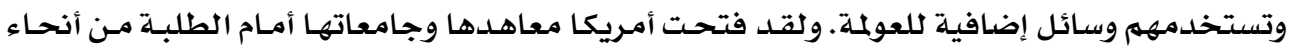

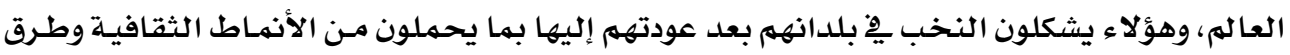

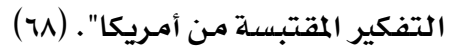

ولهذه المؤسسـات دور كبير ِِِ كسب الشباب المصري والعريسي المثقف وتحطيهم شخصيته

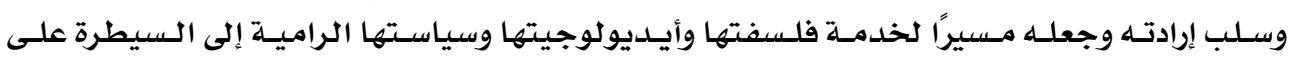

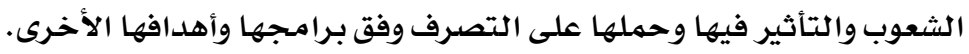

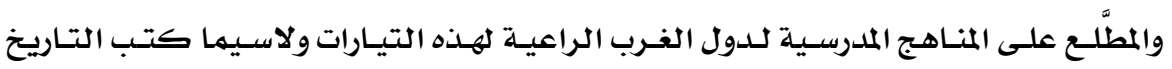

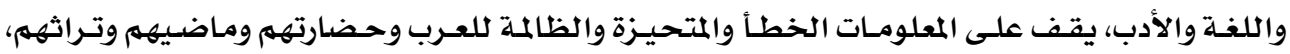

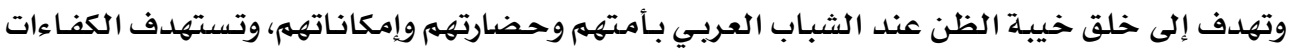

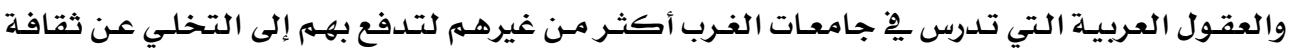

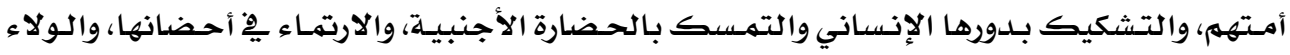

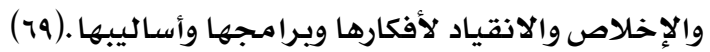

$$
\text { ع- عميق التبعية التربوية. }
$$

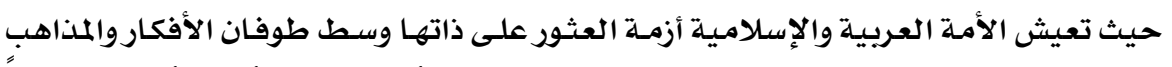

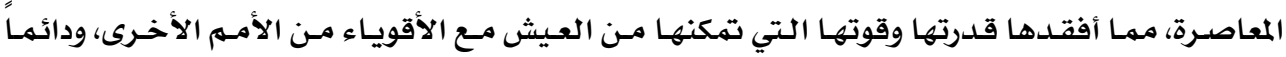

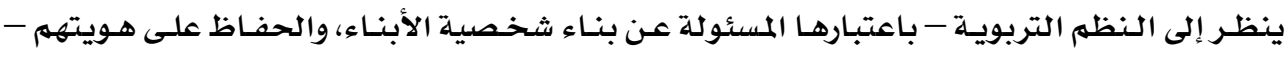


ويوجـه لهـا الاتهـام حيـث تخلـت عـن جـذورها وأصـولها وراحست تتقـصى أثر المنـاهج الغربيـة فأصسابها

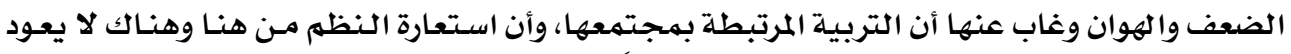

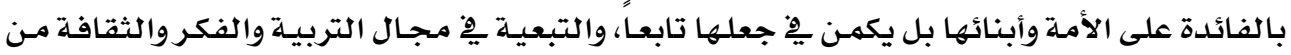

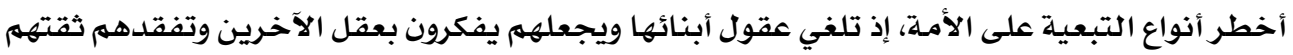

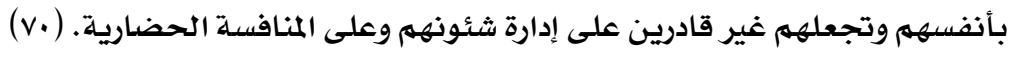

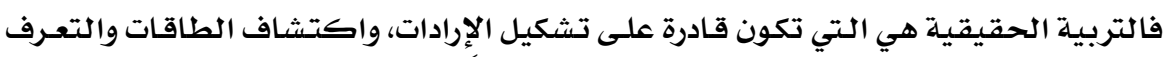

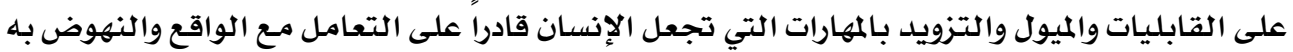
إلى مستويات المثل الأعلى والأهداف المئل المكنة.

ه- تعميق التبعية الاقتصادية.

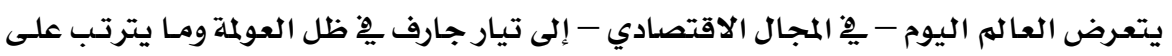

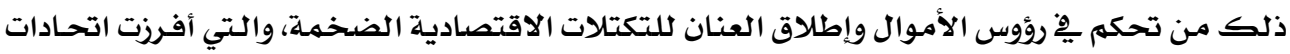

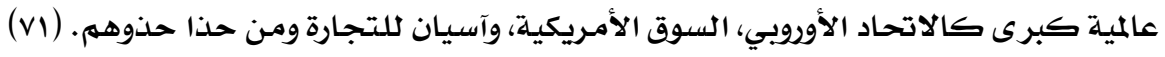

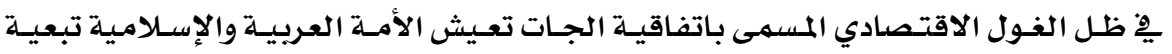

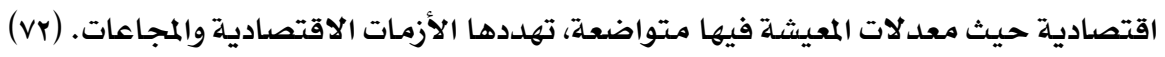
ولا سبيل إلى مغالبة الفقر والتبعية الاقتصادية وتحقيق تنمية سليمة بثقافة وتربية تحسن

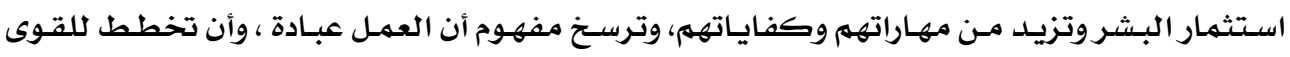

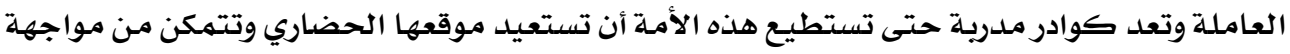
التحديات.

$$
\text { ج- زيادة التصلدع الأسري. }
$$

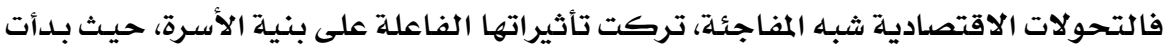

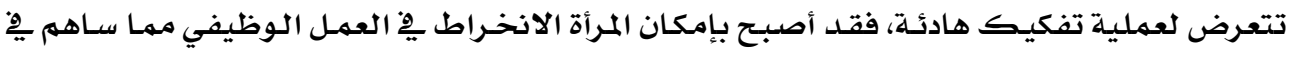

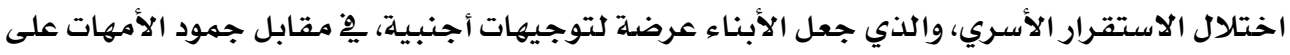

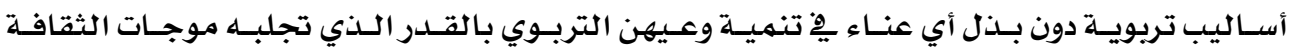

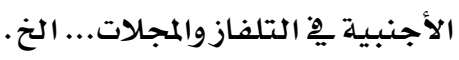

وكذلك دور الأب الذي بدأ بفقد سلطانه، بعد أن كان يستحوذ على المجال التربـوي داخل

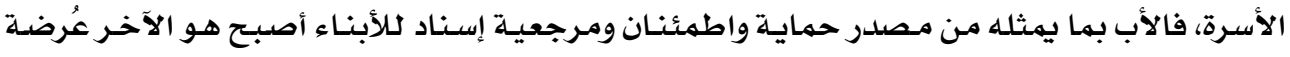

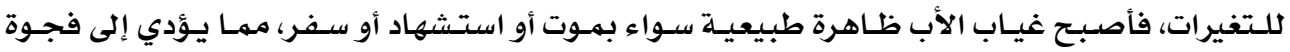

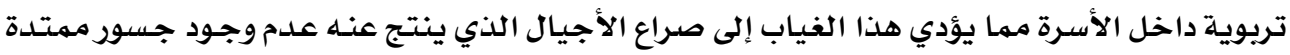

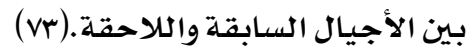

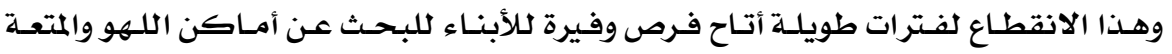

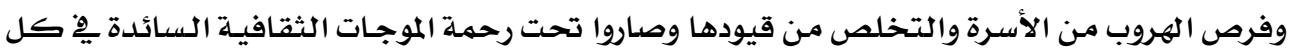


الاتجاهات، حتى إذا تشبـع الأبناء بهذه الموجات أصبـحت الأسـرة عاجزة عن إفراغ هذه الموجـات واسـتعادة دورها التربوي.

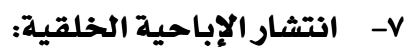

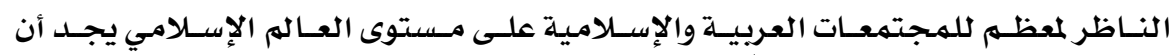

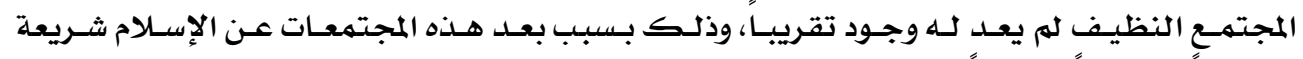

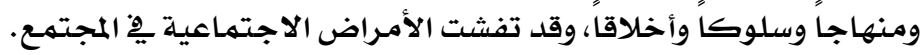

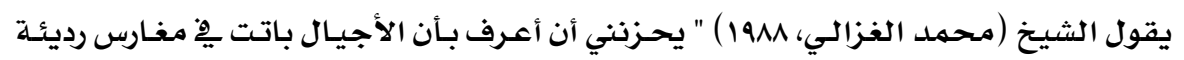

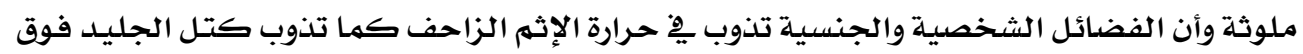

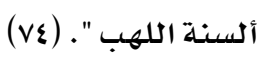

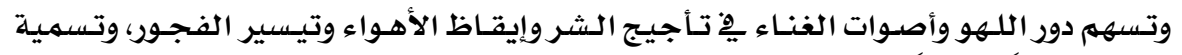

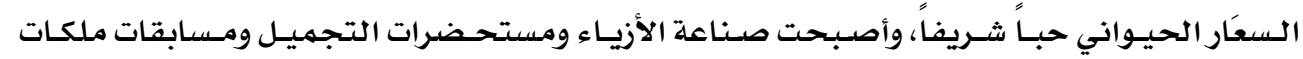

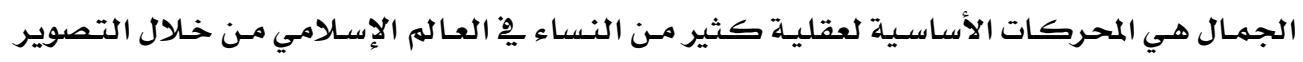

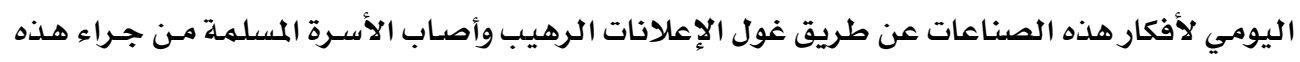

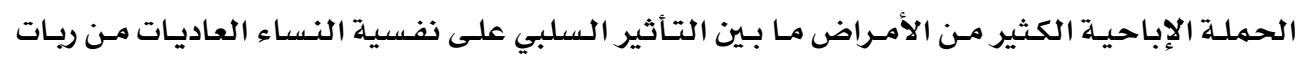

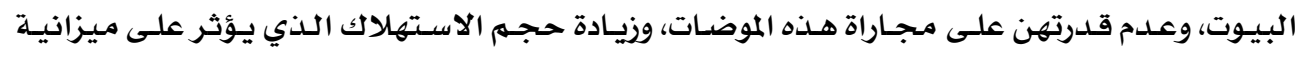

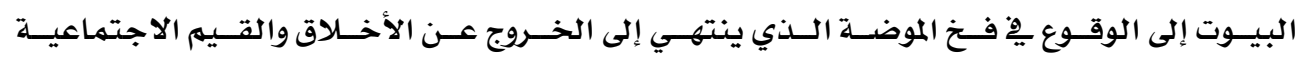

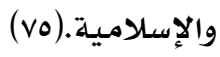

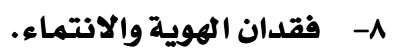

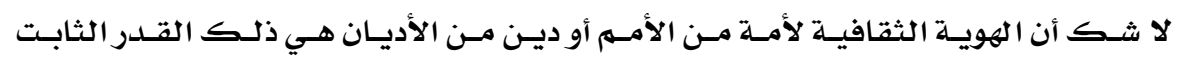

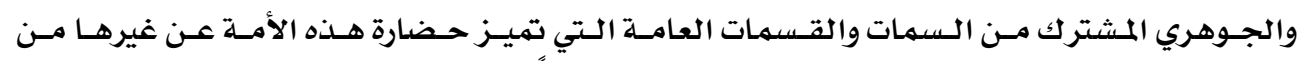

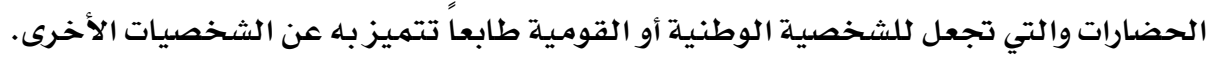

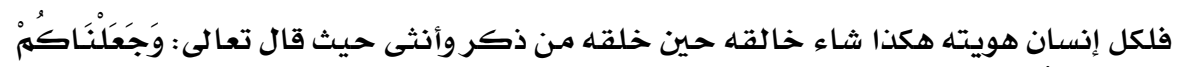

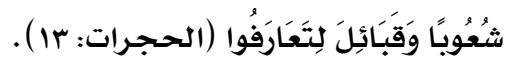

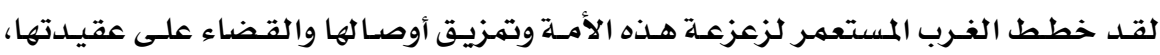

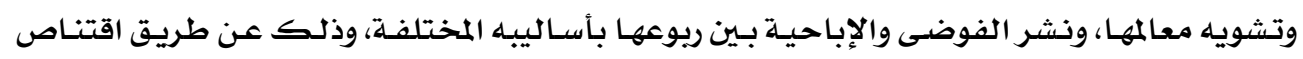

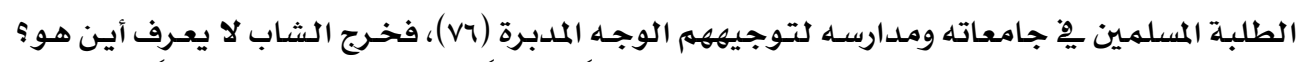

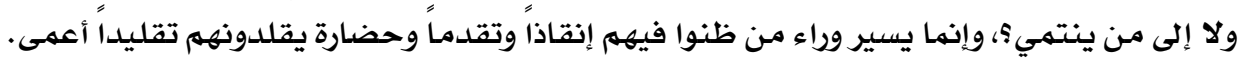

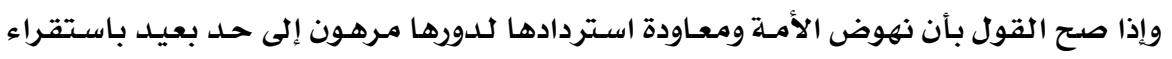

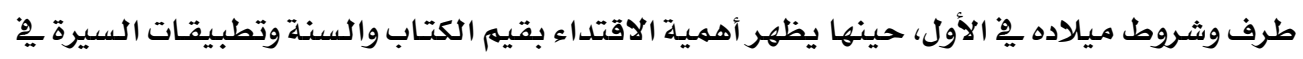

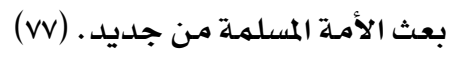




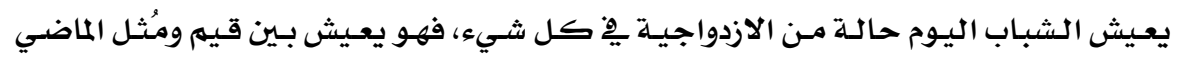

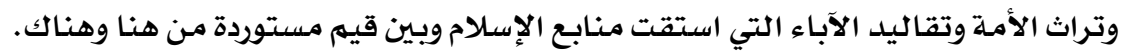

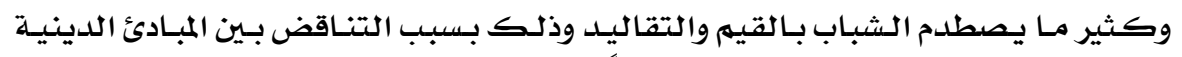

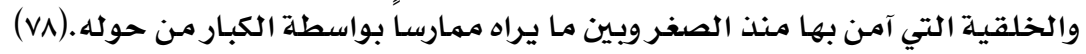

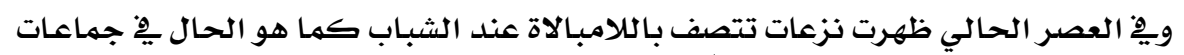

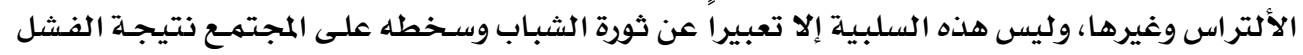
التربوي.

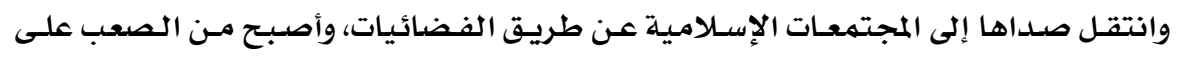

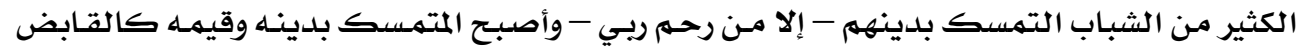

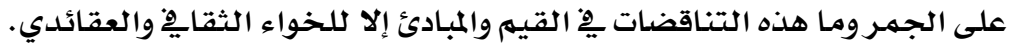

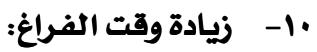
يعد الفراغ مفسدة للنفس، وأول مفاسـده التعود على العـادات الضـارة التي يقوم بها الأبناء

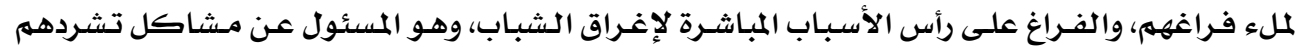

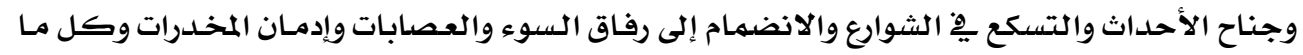

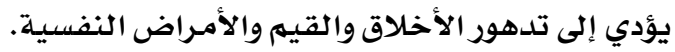

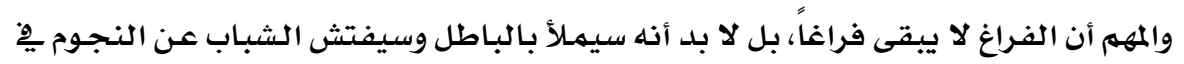

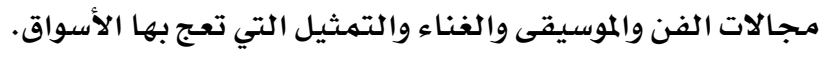

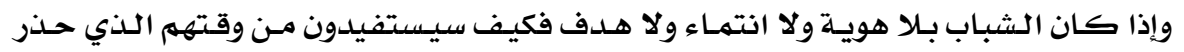

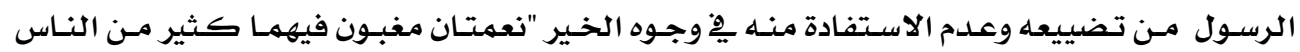

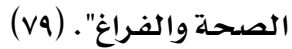

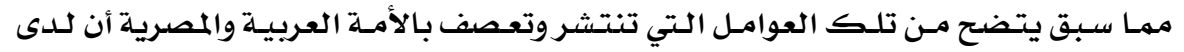

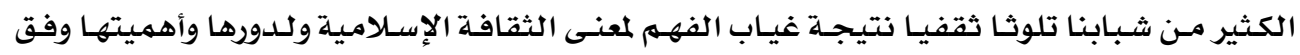

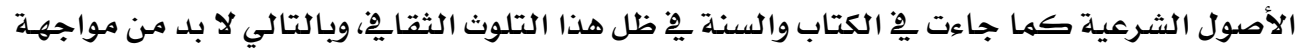
حقيقيـة.

\section{كـ أهم مظاهر التلوث الثقافي للدى طلاب الجامعة في المجتمع المصري:}

لا تحاول قنوات التلوث الثقايِ التي تستهدف الشباب المصري العربي تفتيت القيم وبعثرتها،

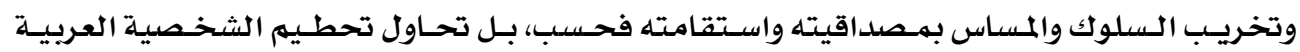

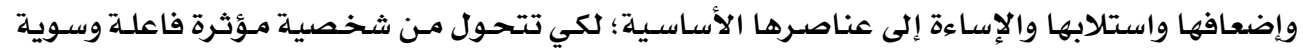
إلى شخصية ضعيفة وهشلة ومزدوجلة ومـريضلة. 
وإذا كانت الشخصية وهي حجر البناء الأساسي ِِّ بناء المجتهمع والحضارة تعاني مـا تعانيـه

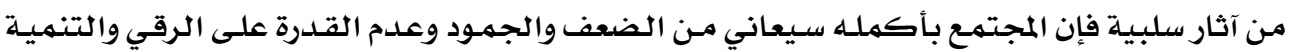
والتقدم.

إن أول مـا يقوم بـه مخططو هـذا التلـوث هـو تشويه الصورة الحقيقيـة الصـادقة للشخصية

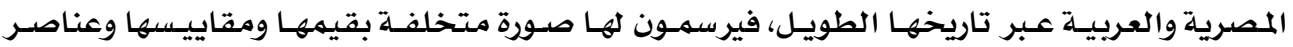

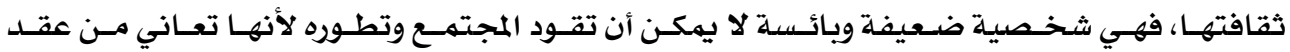

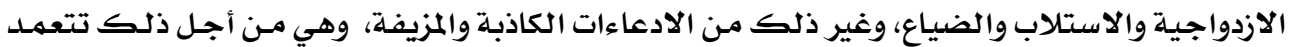

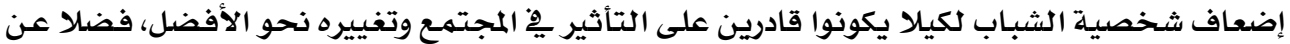

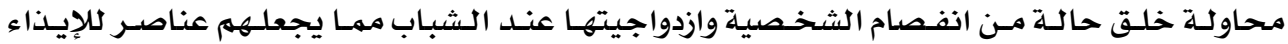

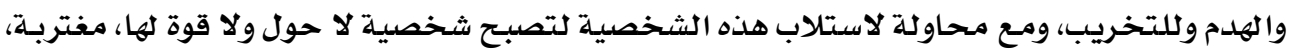

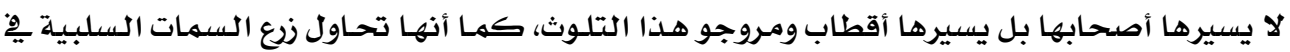

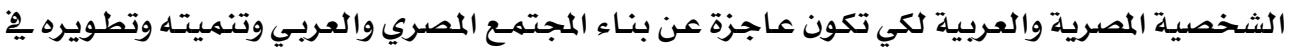

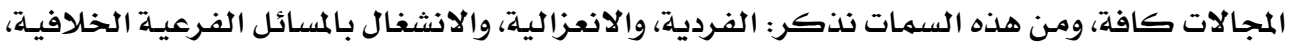

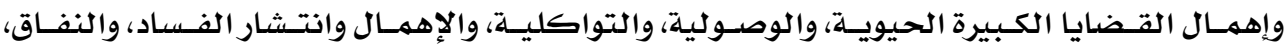

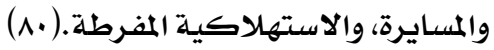
وفيما يلسي يعرض الباحـث للظـاهر التلوث الثقايِّ السابقة لدى طلاب الجامعة بشيء مـن

\section{1- الثقافة الجنسية:}

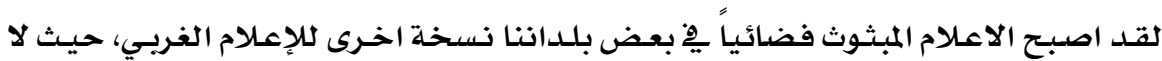

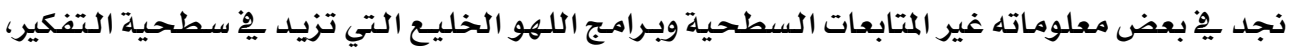

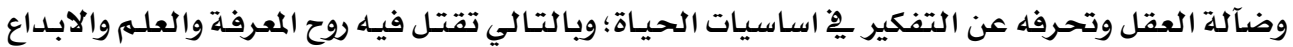

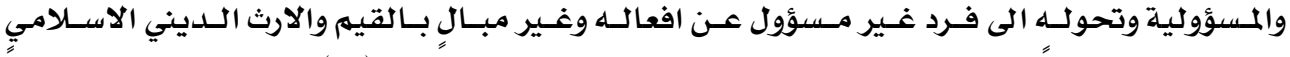

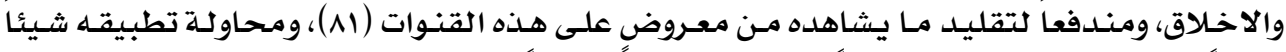

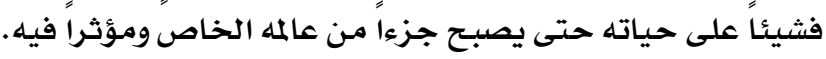

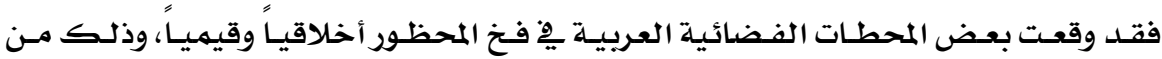

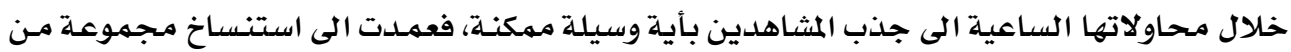

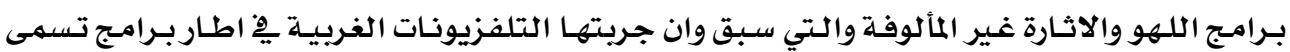

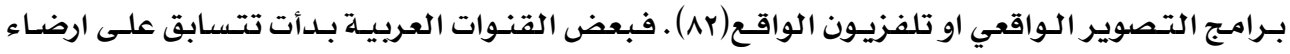

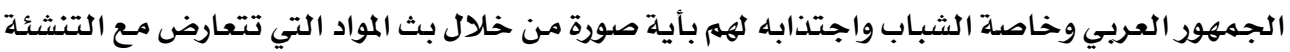

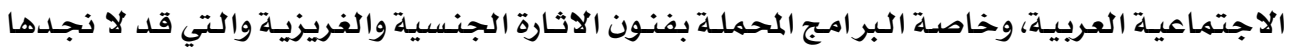
حتى يٍْ القنوات الأجنبية (rی). 
فاليوم نرى ان العديد مـن القنـوات الفضائية عامرة بكل مـا يثير الجنس وبهـواد له يألفها

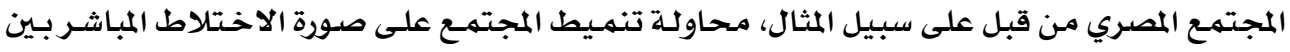

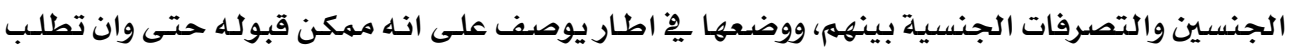
بعض الوقت.

ان بعض الفضائيات بقيامها ببث العديد من المواد الاباحيـة، مـا هي الا محاولـة منهـا لنشر

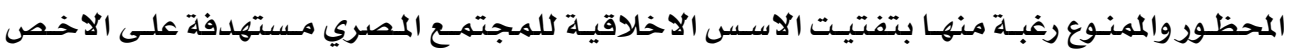

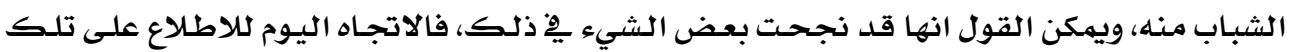

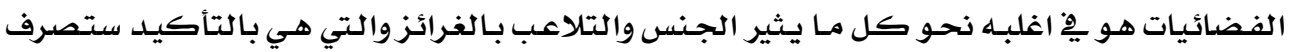

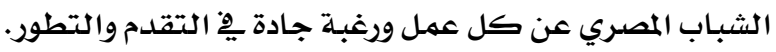

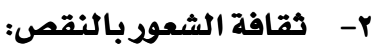

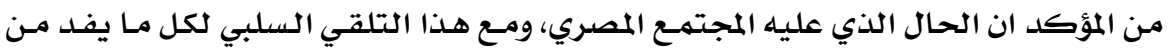

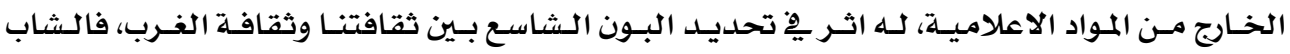

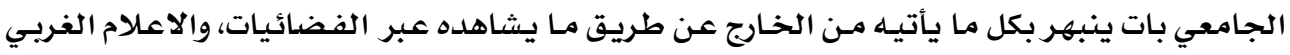
يستهدف يِّ ذلك اشعار المصري بالعجزوالنقص تجاه الغرب وآلياته المتطورة والهائلة.

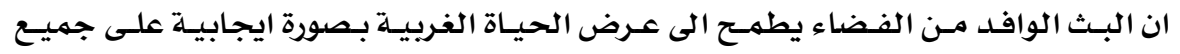

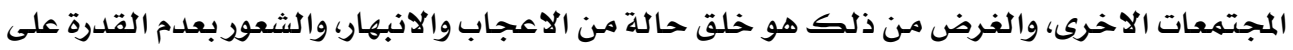

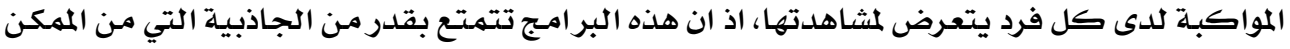

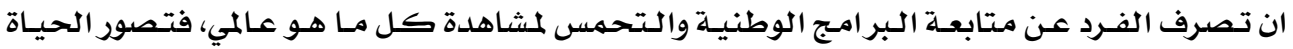

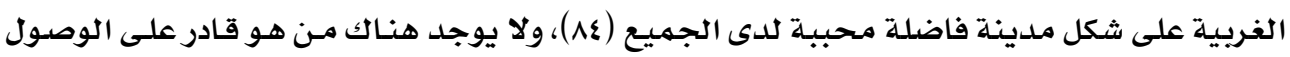

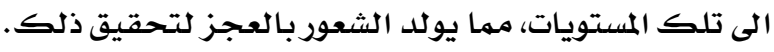

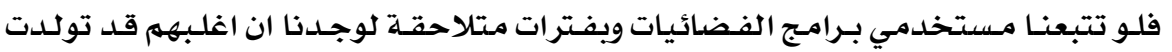

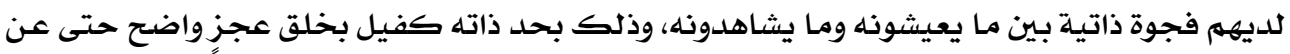

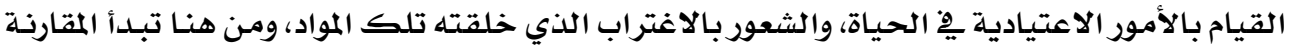

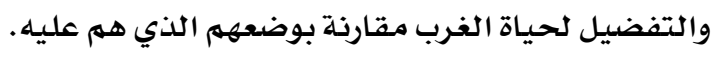
r- مقافة العنف:

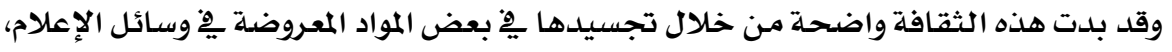

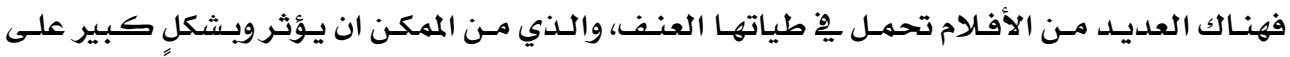

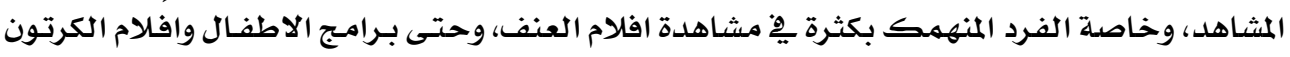

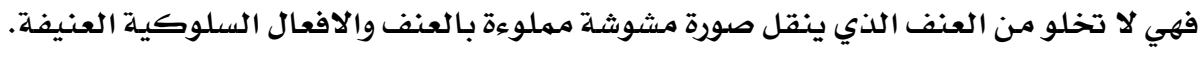

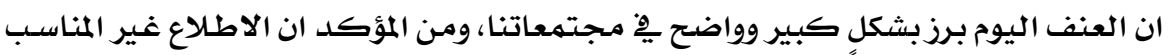

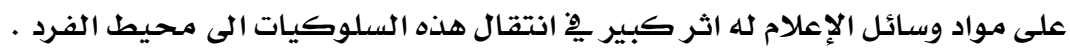


ع- مقافة الاستهلاك:

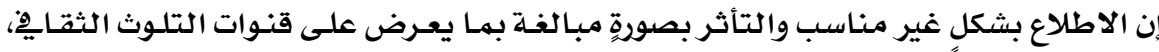

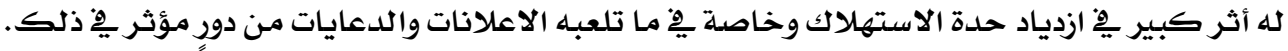

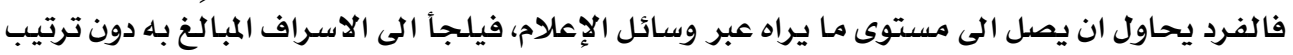
منطقي لاحتياجاته.

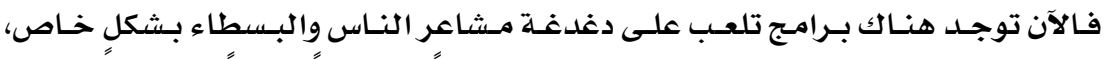

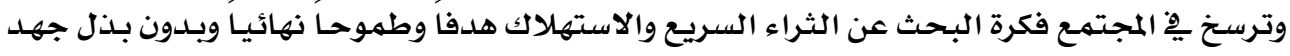

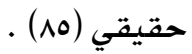

0- ثقافة مضادة للقيم الدينية: بـلا شــك ان وجـود المـواد الاباحيـلة والمـواد الـتي تحـرض علـى العنـف والاسـتهلاك والـشعور بالنقص، ستؤدي الى اضعاف المعتقدات الدينية وتشويهها . بادئ.

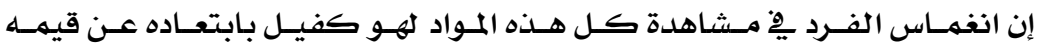

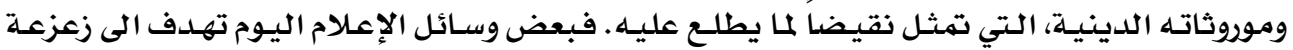

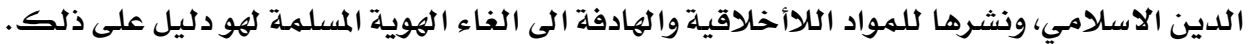
ولعل اخطر ما تقوم به الفضائيات الغربيـة هو محاولـة تشويه الدين الاسـلامي ونعتـه

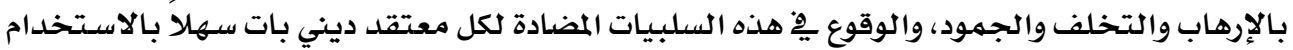
غير المناسب للفضائيات. 7- بقافة القوة: حيث تحاول العديد من القنوات الغربية وقلة من القنوات العربية المتآمـرة مـ ابراز ان القوة

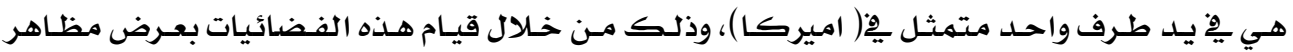

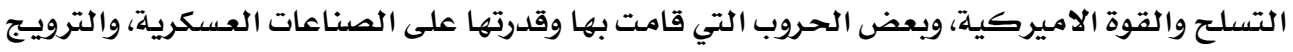

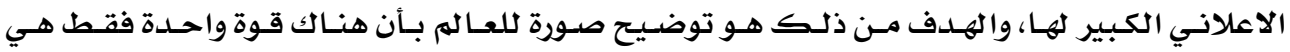
المسيطرة وتمتلك زمام الامور، متمثلة بأمريكا.

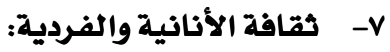

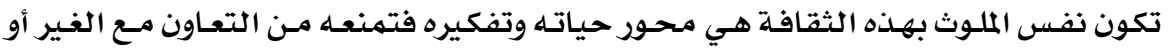

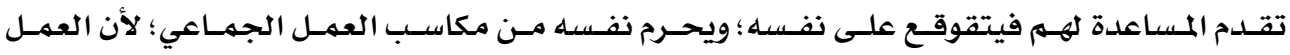
الجماعي له مكاسب كثيرة فالنحلة بمفردها لا تستطيع بناء الخلية وصنية وصنع العسل.

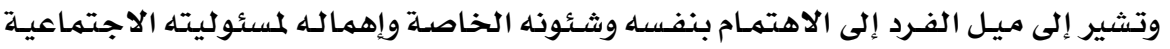

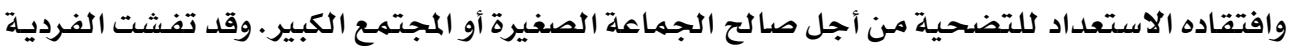

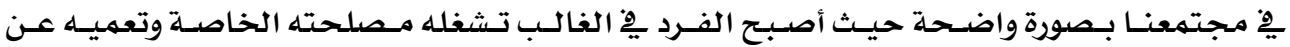

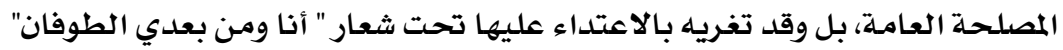




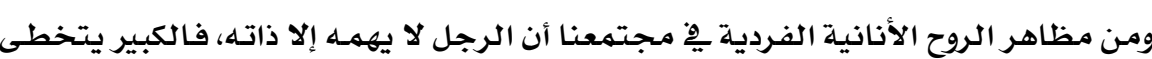

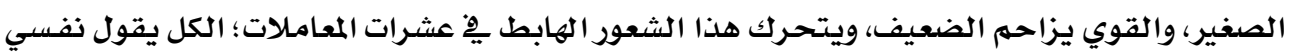

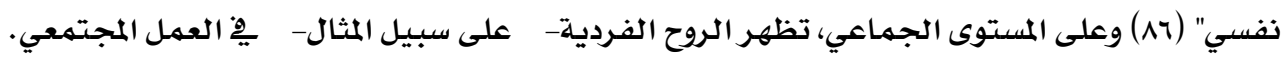

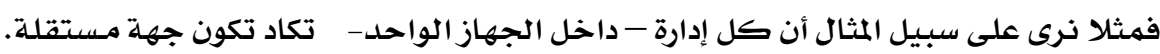

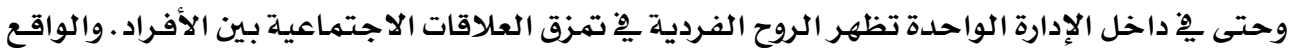

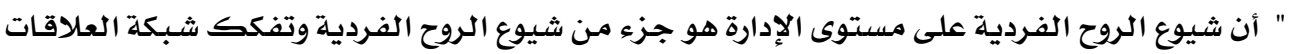

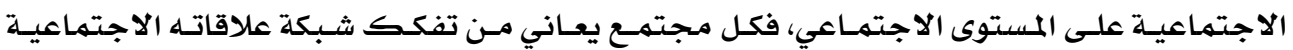

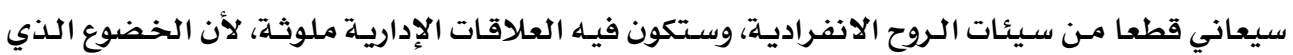

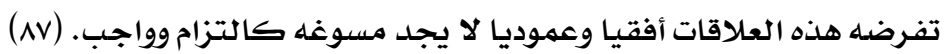

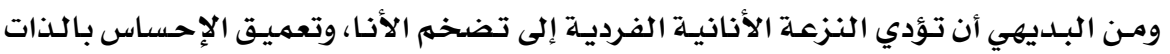

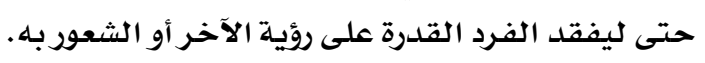

1- مقافة الكراهية والانعزال :

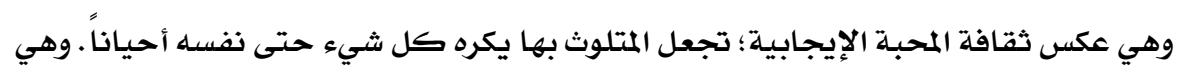

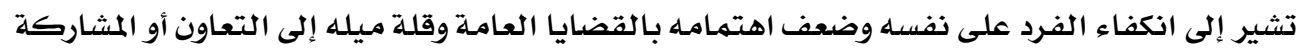

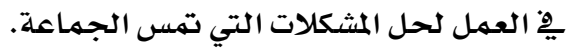
هكذا تباعد الروح الانعزالية الأفراد بعضهم عن بعض و" تشل الطاقات الاجتماعية وتشتتها

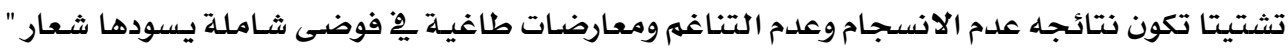

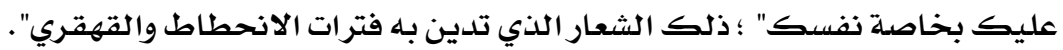

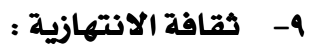

وتشير إلى محاولة الوصـول إلى المركز الأعلى بوسـائل غير مشروعة، ومسن ثم غير أخلاقيـة

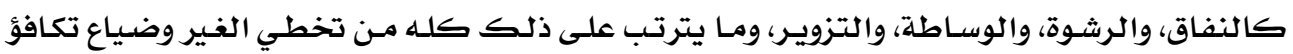

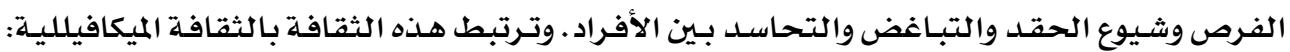

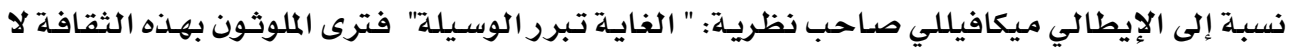

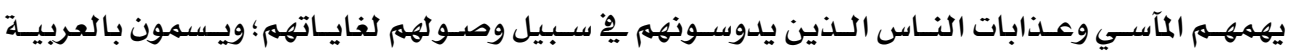
بالوصوليين.

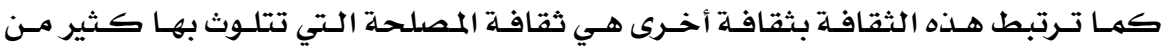

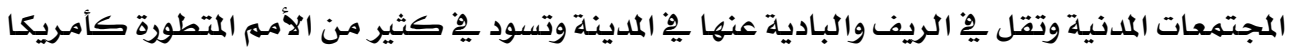

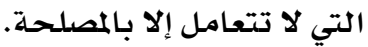
وترتبط الوصولية بعدم الاستقرار وتعلدد المفاجآت، وهذا يجعل الأفراد مهلددين ليس عندهمم

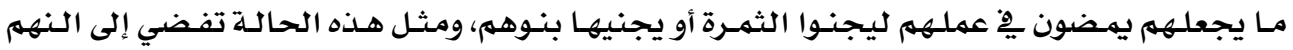

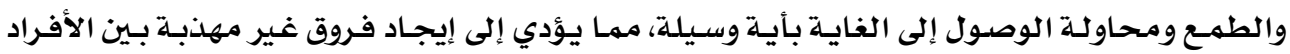




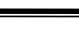

وإيجاد نظام الطبقات تحت أسهـاء مختلفـة وخلق طبقة غالبـة وطبقـة مغلوبـة. والأثر الطبيعي لهذا

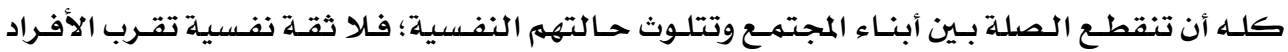

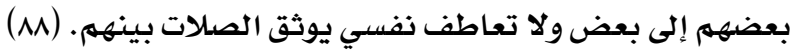

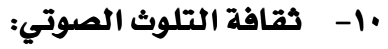

لقد أصبح الصخب والضجيج الصارخ من أخطر المثكلات التي يعاني منها الإنسان المصري

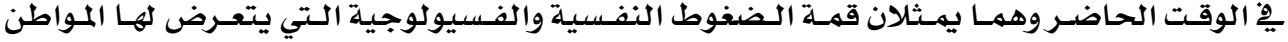

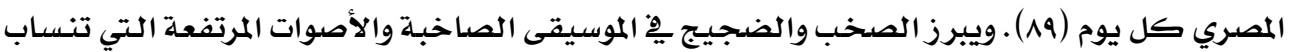

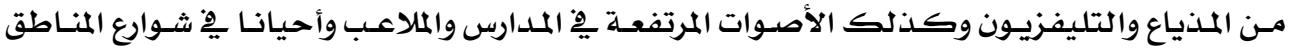

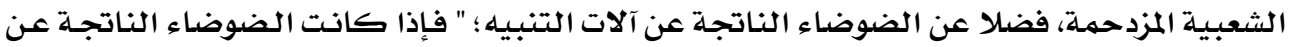

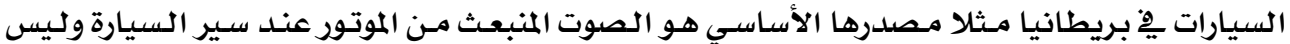

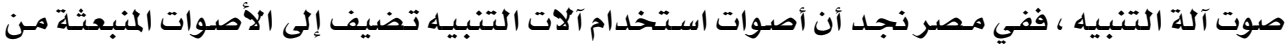

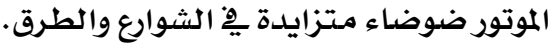

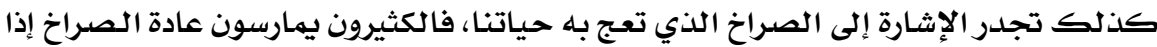

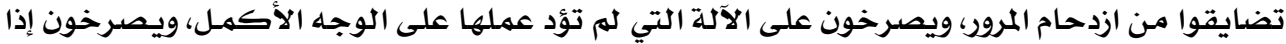

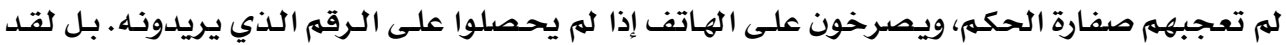

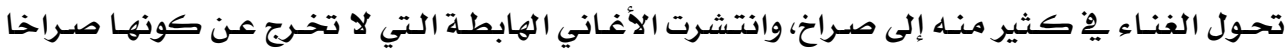

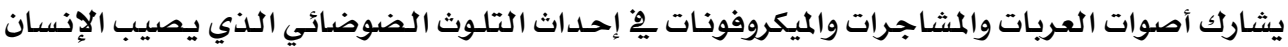
بالأمراض النفسية والعضوية. 11- قافة التلوث اللفظي:

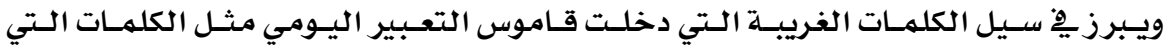

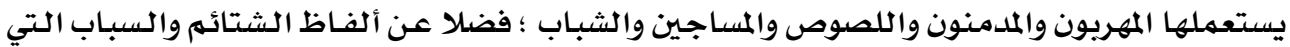

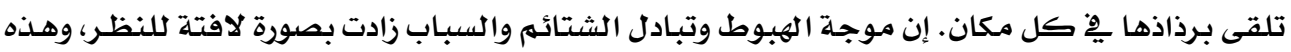

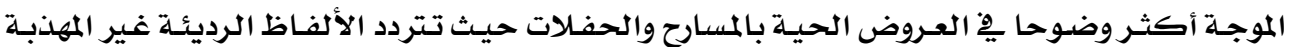

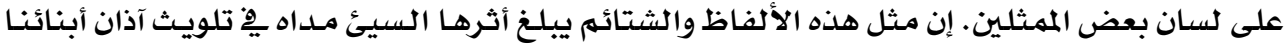
الصغار.

وفضلا عن ذلك، فقد غدا الشارع المصري أعجميا بفعل الانتشار الكاستح للأسماء الأجنبية

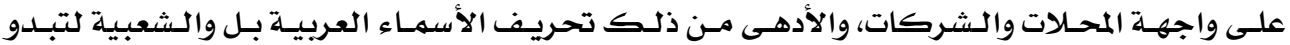

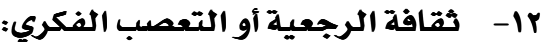

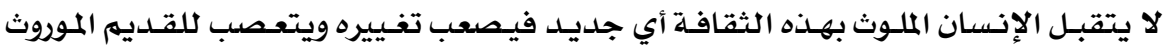

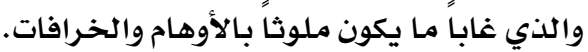




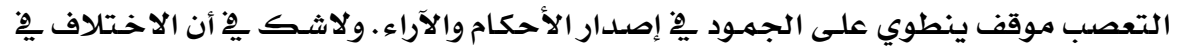

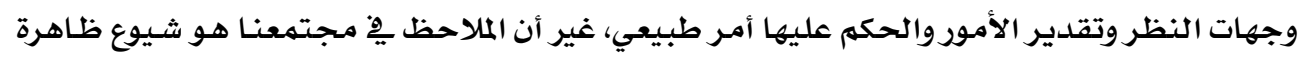

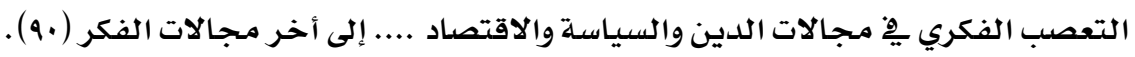

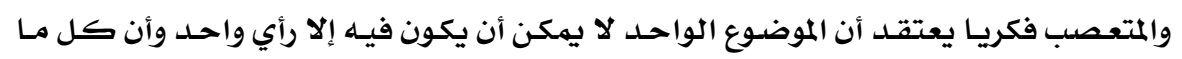

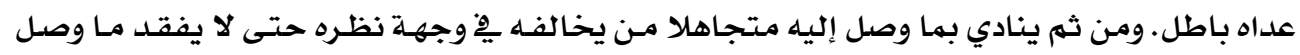

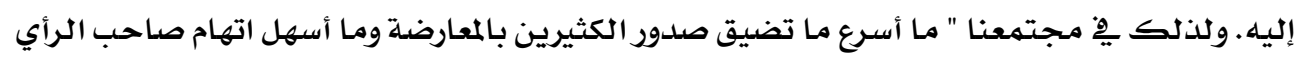

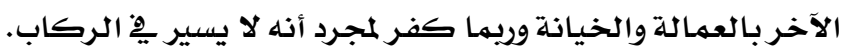

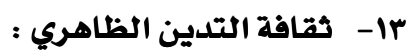

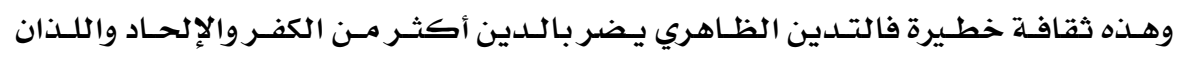

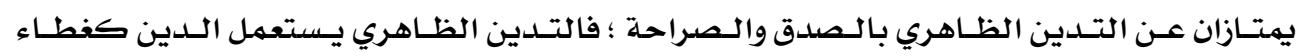

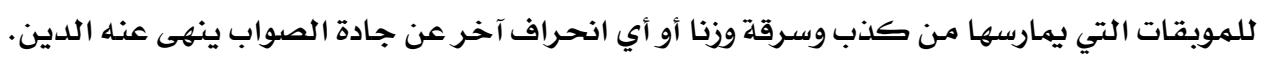

ـ دور عضو هيئة التدريس في مواجهة ظاهرة التلوث الثقافي لدى طلابه : أ- عضو هيئة التدريس وأهميته:

عندما يبدأ الباحث الحسديث عن عضو هيئسة التـدريس وأهميته، لابد وأن ندرك أند أن الحسديث

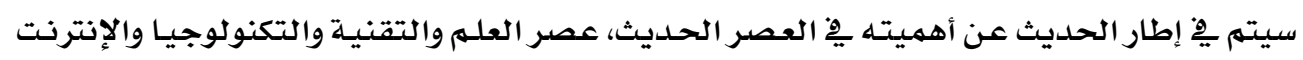
وثورة الاتصال والمعرفة .

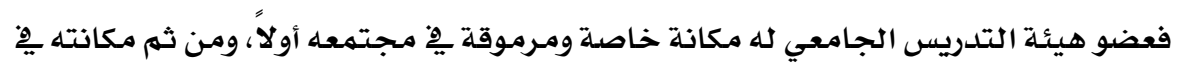

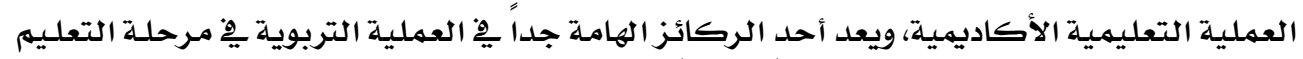

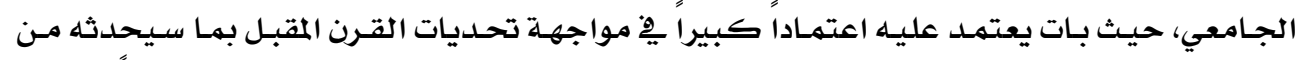

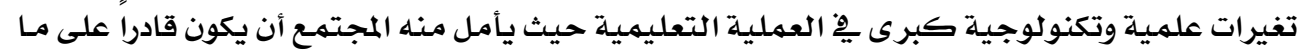

تحمـل أعبـاء التـدريس بكفـاءة عاليـة، وجـودة وإتقـان، حتى يستطيع مواجهـة تحسديات التلوث .

أن يكون إعـداده إعداداً جيـداً بشكل يجعلـه قـادراً على وضـع خطط لإصـلاح التعليهم الجـامعي وتطويره .

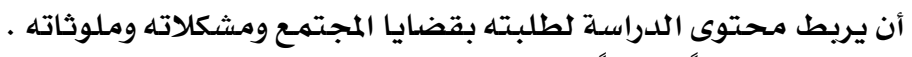

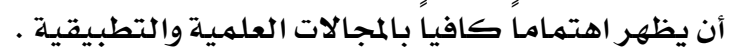

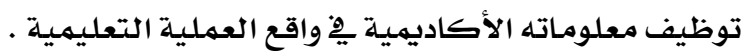

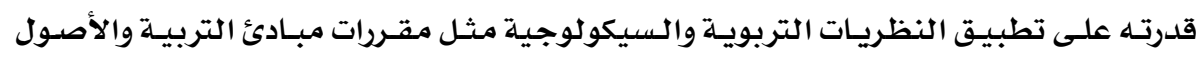

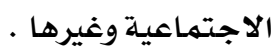




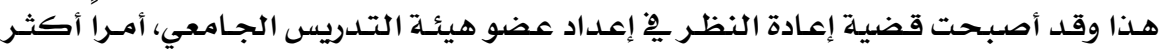

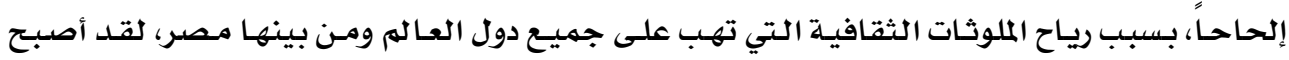

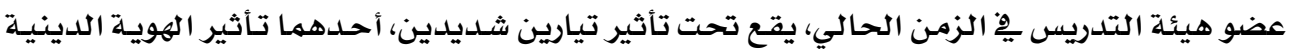

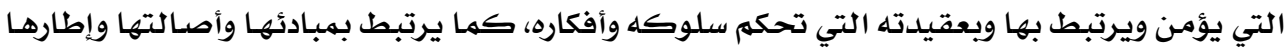
القيمي .

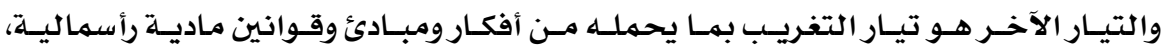

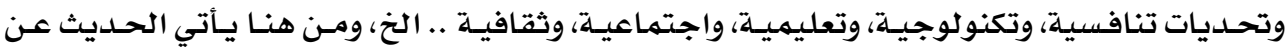

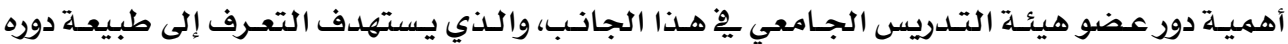

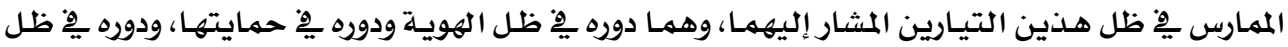

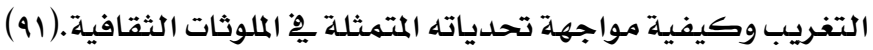

\section{ب- الأدوار التربوية لعضو هيئة التدريس الجامعي ـِ مواجهة آثار التلوث الثقامِّ:}

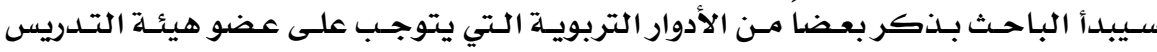

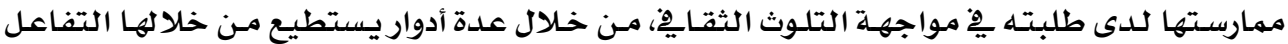

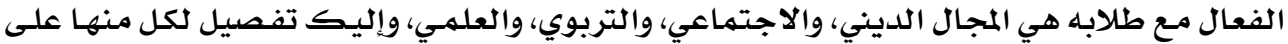

أ- الأدوار التربوية التي يجب أن يمارسها عضو هيئة التدريس لمواجهة آثار التلوث الثقايِ ِِِِ المجال الديني:

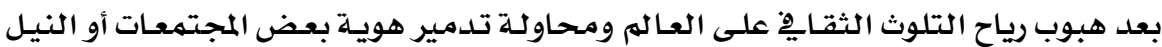

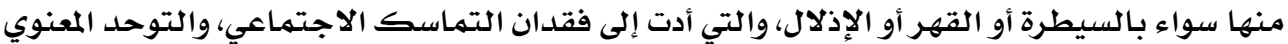
بين البشر، وانحراف بعض شباب المجتهمع عن التمسك بقيه دينه ومجتمعسه وسلوكياته، وأخلاقياتهـ

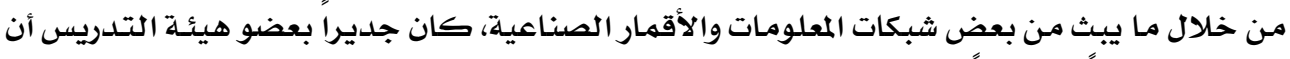

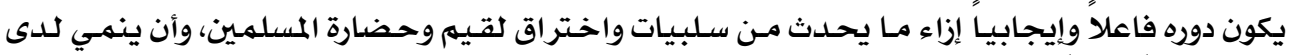

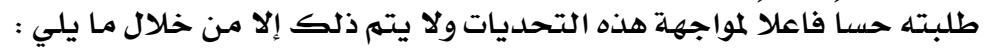

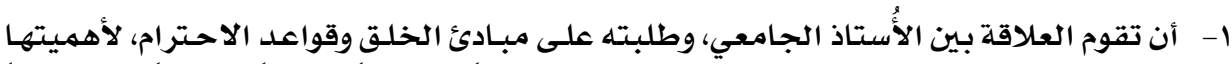

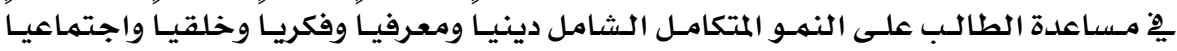
ونفسيا

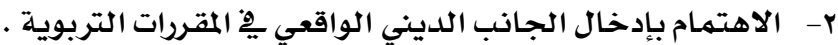

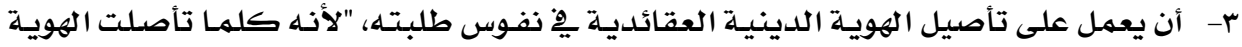

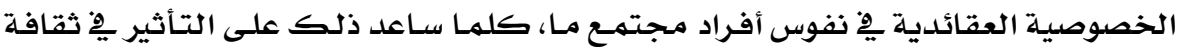

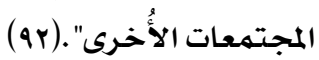

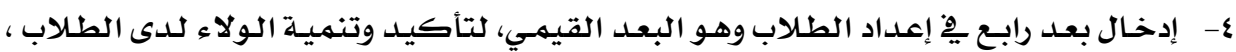

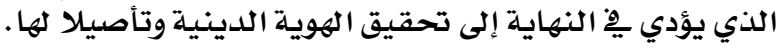


اللور التريوي لعضو هيئة التلريس

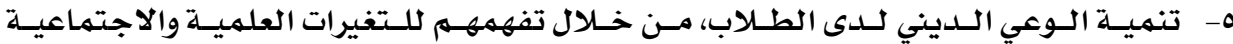

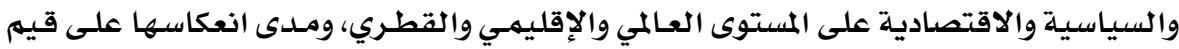
وهوية المجتمعات الدينية . ؟- مساعدة الطلبة وتزويدهم بثقافة علمية دينية، تساعدهم على الكتسـاب قيم مجتمعيـة على أساس علمي.

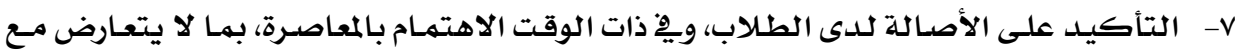

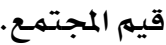

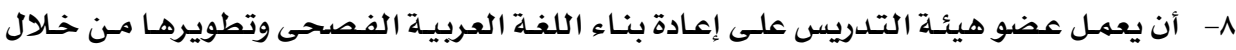

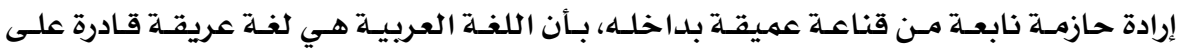

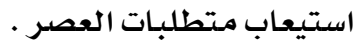

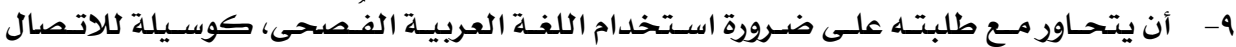

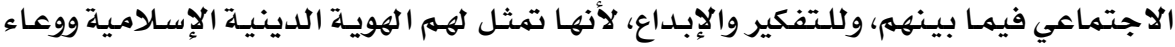

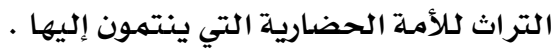

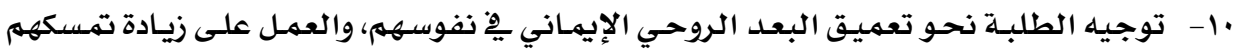

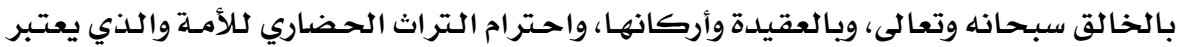

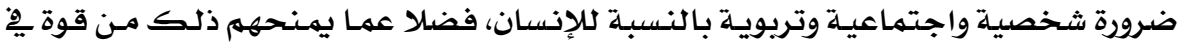

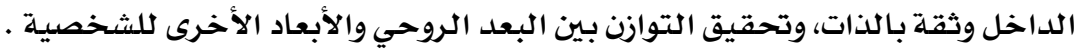

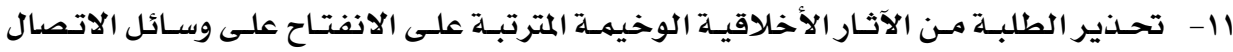
المغرضة والمسنمومـة.

ب- الأدوار التربوية التي يجب أن يمارسها عضو هيئة التدريس لمواجهة آثار التلوث الثقايِِ ِِِ المجال | الاجتماعي:

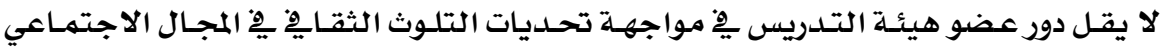

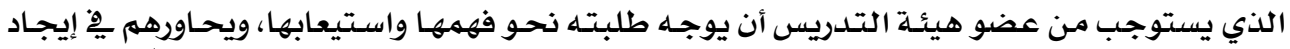

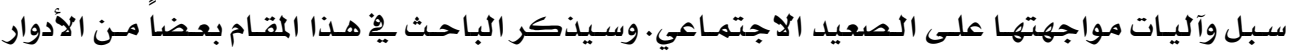

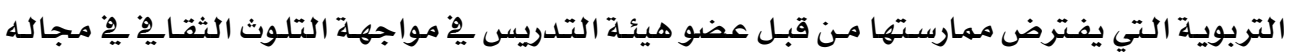

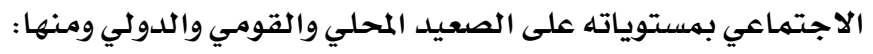

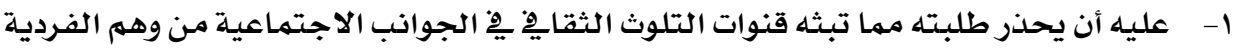

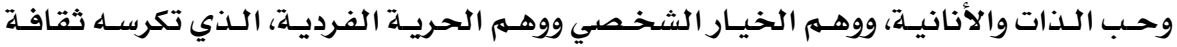

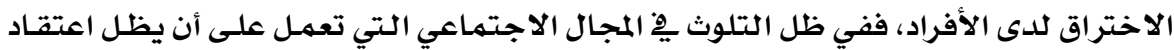

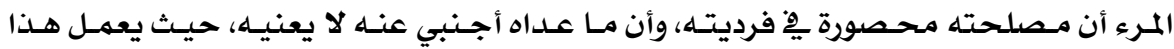

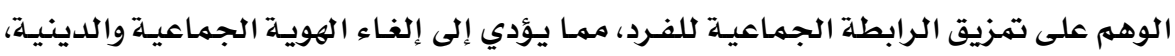

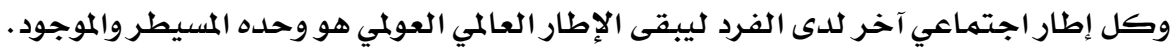




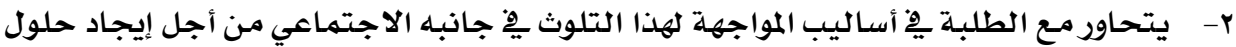

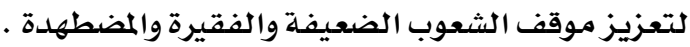

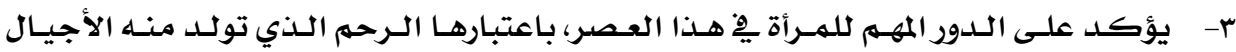

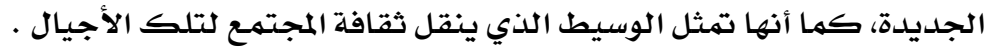

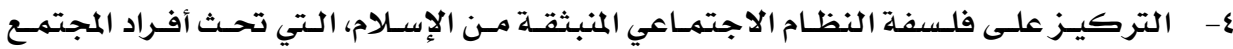

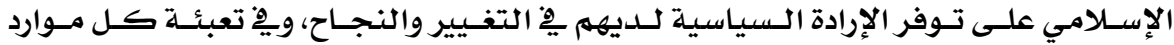

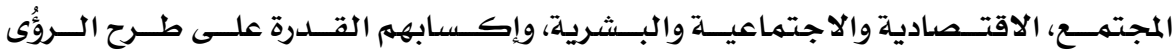

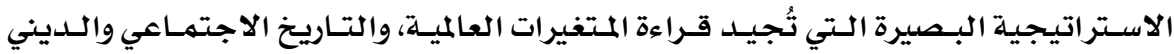
لـلأمة. ه- توجيه طلبته إلى أهم التحديات الاجتماعية التي تواجه المجتمـع المحلي، ونحسن على مشارف

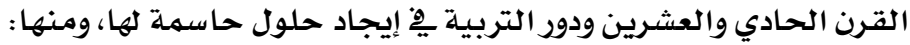

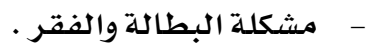

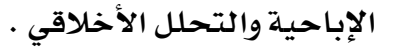
علاقة الرجل بالمرأة والعكس • مالاحسل

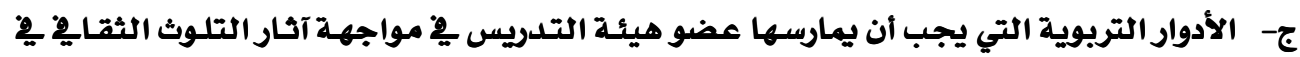
المجال التربوي:

يعتبر الدور التربوي لعضو هيئة التدريس ِِّ مواجهة التلوث الثقايِّ مـن أكثر الأدوار التي تفرض عليه توجيه عناية الطلبة نحوها وتتمثل فِّه :

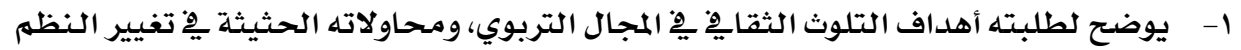

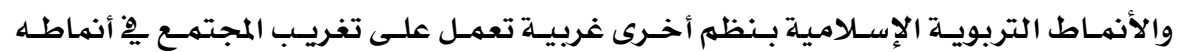

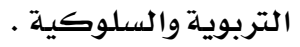

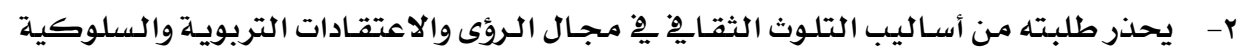

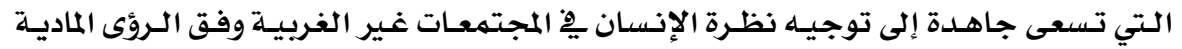

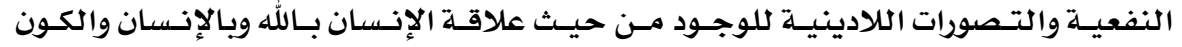

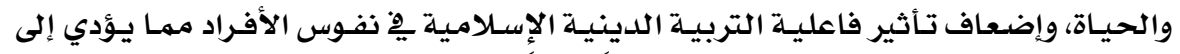

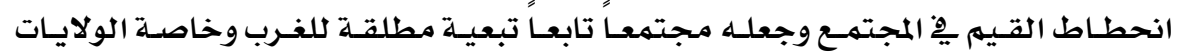

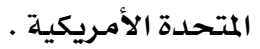

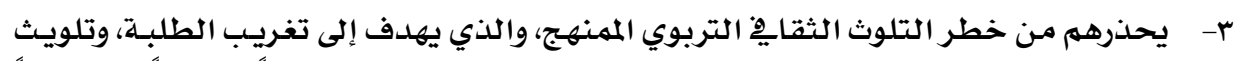

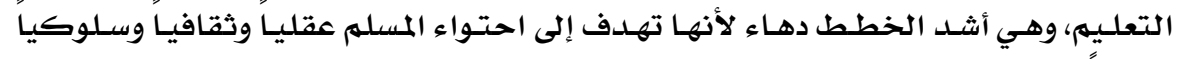

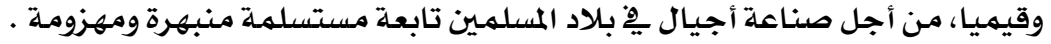

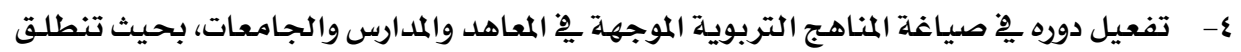

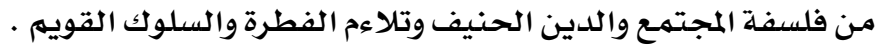




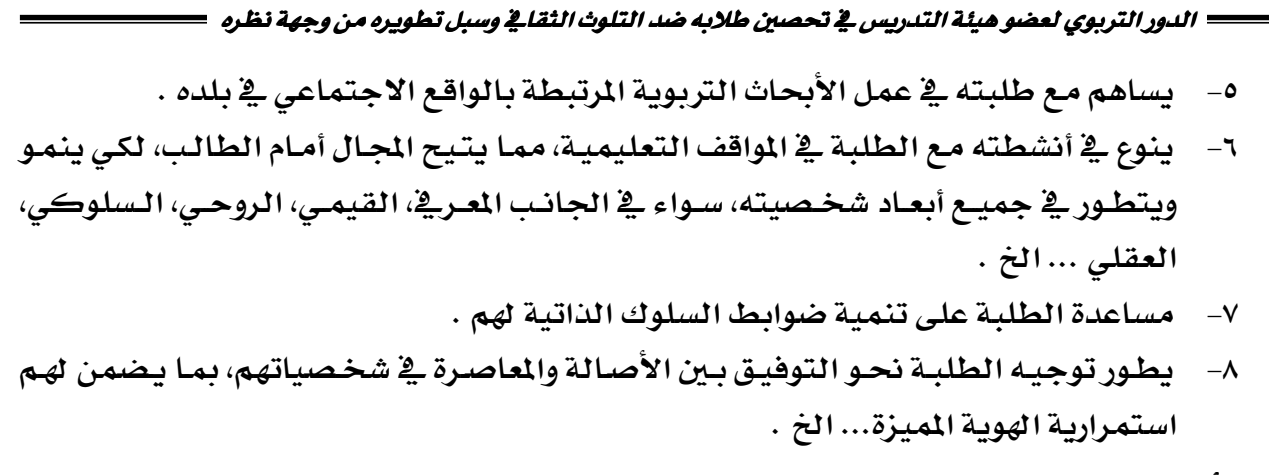

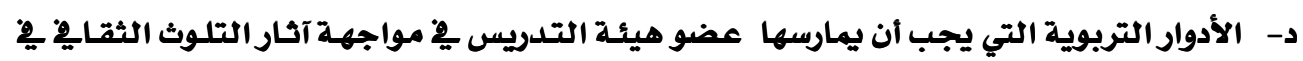

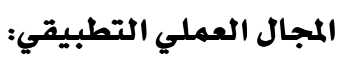

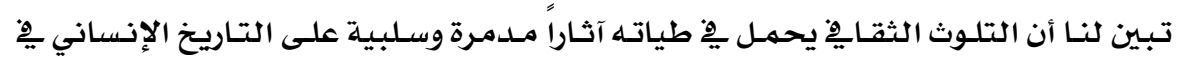

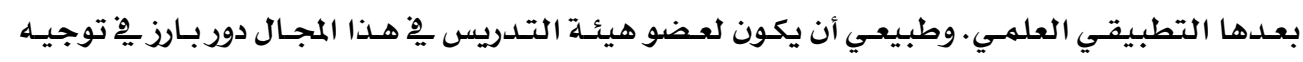

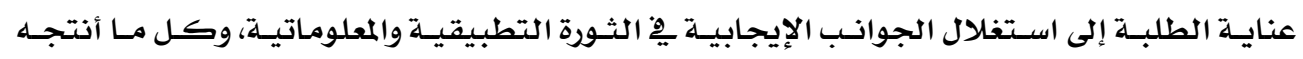

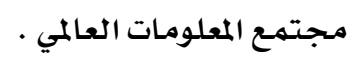

وسيذكر الباحث بعضاً من الأدوار التربوية العمليـة التي يتوجـب على عضو عضو هيئـة التدريس

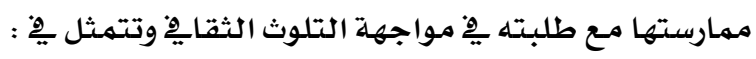

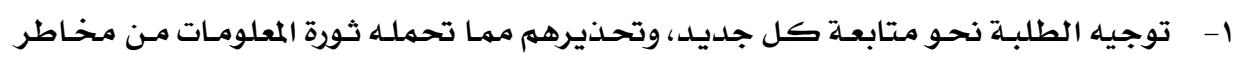

الهيمنة الثقافية.

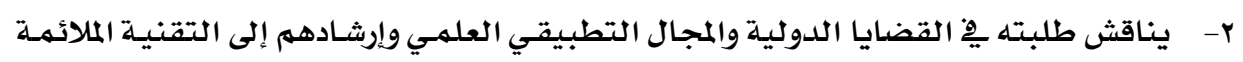
لمجتمعهمه

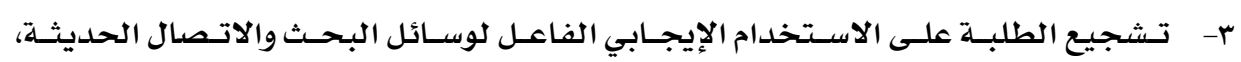

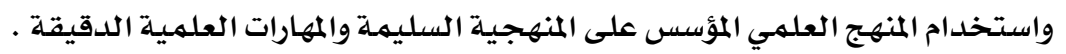

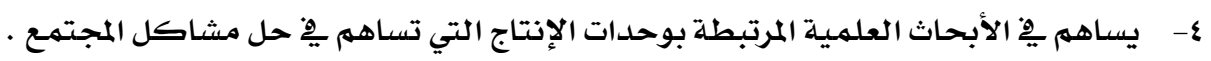

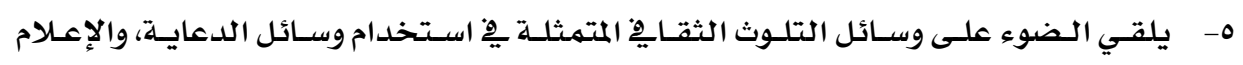

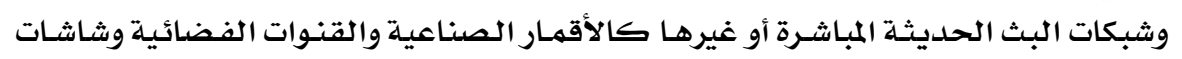
الحاسوب وشبكات الإنترنت.

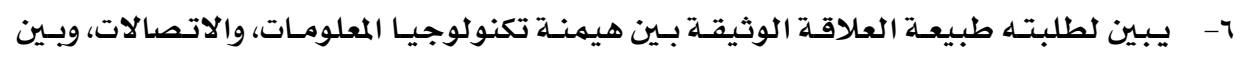
الهيمنة المعرفية والثقافية.

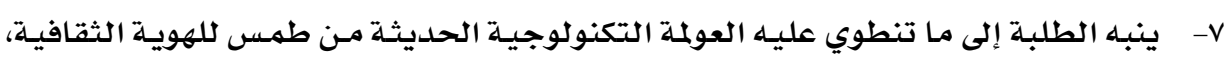

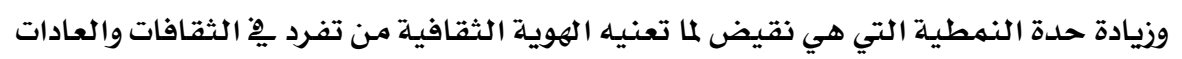
والقيم، والنظرة للكون والإنسان والحياة .

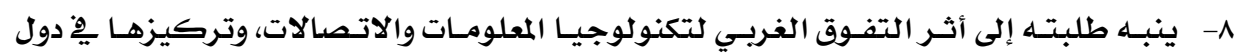
الشمال الغنية. 
$\underline{\underline{2}}$

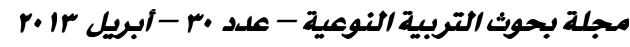

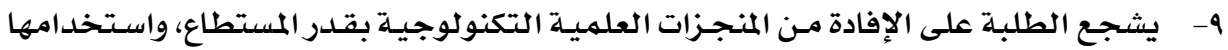

$$
\text { بفاعلية يخ حياتهم العملية. }
$$

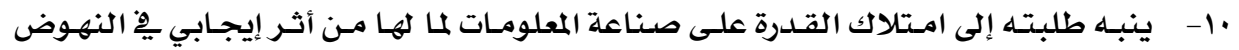

$$
\text { للمهجتمعات البشرية. }
$$

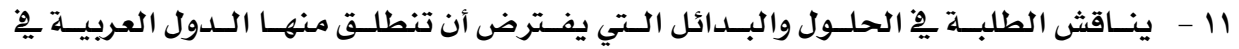

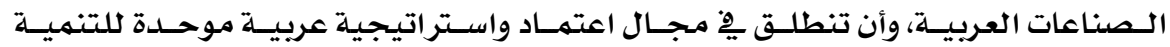

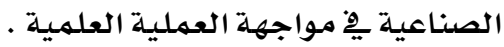

\section{ثالثً: الإطار الميداني اللدراسة:}

إجراءات الدراسة:

\section{تهميل:}

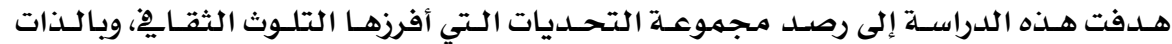

التحديات التي تواجه الدول العربية والمجتمهع المصري على وجه الخصوص .

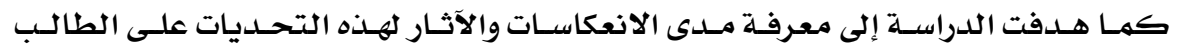

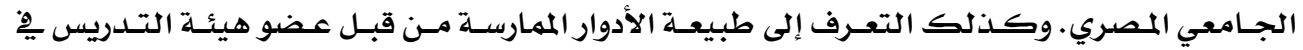
جـامعة قناة السـويس يْ مواجهة تحديات التلوث الثقايِّ سواء كانت هـذه الأدوار دينيـة، أو اجتماعيـة،

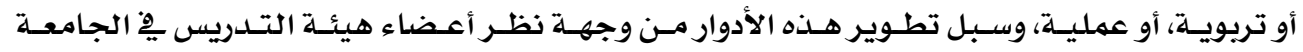

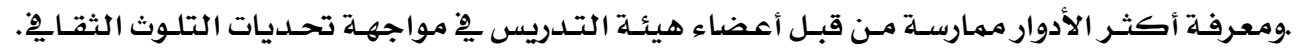
كما هدفت الدراسلة إلى الكثف عن دلالة الفروق يِ مواجهة تحديات التلوث الثقايْ من خلالال الأدوار الأربعـة السـابقة وفقاً للهتغيرات التالية (التخصص أو الكلية - المؤهل العلهي -سنوات الخبرة).

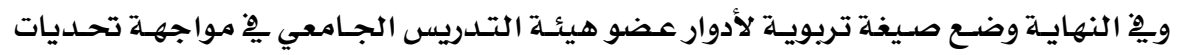

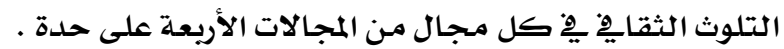

\section{منهج الدراسة:}

اعتمد البـاحث يِّ هذه الدراسـة المنهج الوصفي التحليلسي "وهـو المنهج الـذي يـدرس ظاهرة أو

حدثاً أو قضيـة موجودة حالية يهـكن الحصول منها على معلومـات تجيـب عن أسئلة البحث دون تدخل

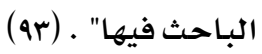

ويعتبر هــا المنهج مناسـباً لهذه الدراسـة لأنه يقـوم على جمـع البيانـات (ووصف واقـع الـدور

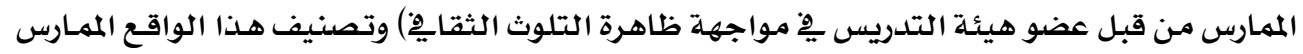

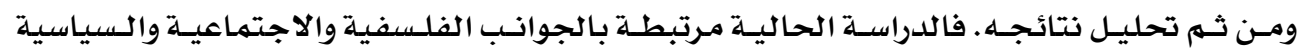

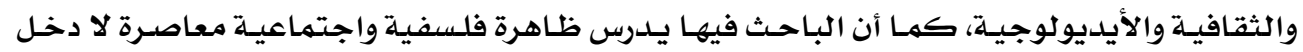

للبـاحث يْ تغيير مـجرياتها . 


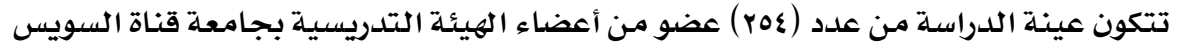

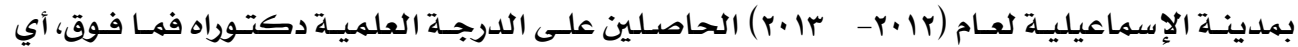
(مدرس - أستاذ مساعد - أستاذ) .

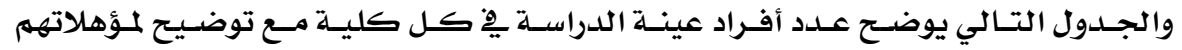

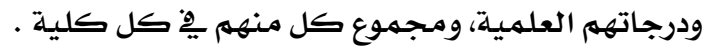

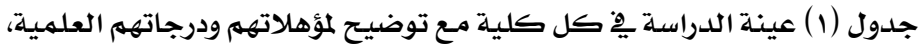

\begin{tabular}{|c|c|c|c|c|c|c|}
\hline المجموع & أستاذ & أستاذ مساعد & دكتوراه & القسم - القي & & 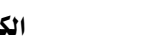 \\
\hline 1. & $\cdot$ & $\varepsilon$ & 9 & لفة عربية & \multirow{6}{*}{ كلية الآداب } & \multirow{18}{*}{ الإنسانية } \\
\hline v & $\cdot$ & 1 & 7 & لفة إنجليزية & & \\
\hline 7 & $\cdot$ & 1 & 0 & جغرافيا & & \\
\hline 7 & · & 1 & 0 & 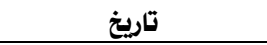 & & \\
\hline 0 & $\cdot$ & 1 & $\varepsilon$ & فرنسي & & \\
\hline$\wedge$ & 1 & $r$ & 0 & فلسفة & & \\
\hline v & . & $r$ & 0 & أصول تربية & \multirow{9}{*}{ كلية التربية } & \\
\hline ir & $\cdot$ & $r$ & 11 & مناهج وطرق تدريس & & \\
\hline$r$ & $\cdot$ & . & $r$ & تربية مقارنة وإدارة تعليمية & & \\
\hline 7 & - & 1 & $\varepsilon$ & علم النفس التربوي & & \\
\hline 0 & 1 & 1 & $r$ & صحة نفسية & & \\
\hline$r$ & 1 & • & $r$ & تربية خاصة & & \\
\hline 1 & 1 & • & - & تربية فنية & & \\
\hline$r$ & $\cdot$ & 1 & $r$ & تربية موسيقية & & \\
\hline$\varepsilon$ & $\cdot$ & 1 & $r$ & اقتصاد منزلي & & \\
\hline ir & $r$ & $\varepsilon$ & 1 & إدارة أعمال & \multirow{3}{*}{ كلية التجارة } & \\
\hline is & $\varepsilon$ & 0 & 0 & الاقتصاد & & \\
\hline ir & $r$ & $r$ & r & المحاسبة & & \\
\hline 19 & r & 1 & 11 & بيولوجي & \multirow{4}{*}{ كلية العلوم } & \multirow{6}{*}{ التليات العلمية } \\
\hline is & $\varepsilon$ & $r$ & $r$ & 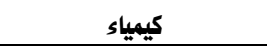 & & \\
\hline in & $\varepsilon$ & $r$ & 11 & 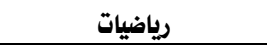 & & \\
\hline 19 & $\checkmark$ & r & 1. & فيزياء & & \\
\hline ro & v & 1 & ir & ميكنة زراعية & \multirow[t]{2}{*}{ كلية الزراعة } & \\
\hline 10 & 0 & 0 & 0 & صناعات غذائية & & \\
\hline 19 & $\cdot$ & $\wedge$ & 11 & 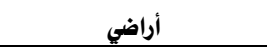 & & \\
\hline ros & $\llbracket$ & $\pi$ & $1 \leqslant \wedge$ & \multicolumn{3}{|c|}{ المجموع العام لكل الكليات من أعضاء هيئة التدريس } \\
\hline
\end{tabular}




$$
\begin{aligned}
& \text { تم تحديد متغيرات الدراسة على النحو التالي: } \\
& \text { 1- متغير الكلية أو التخصص (كليات إنسانية - كليات علمية تطبيقية). }
\end{aligned}
$$

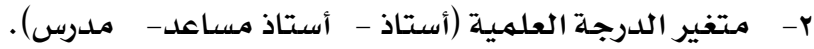

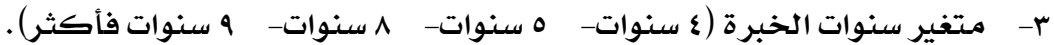

أداة الدراسة:

استخدم الباحث الاستبـانة كأداة رئيسـة للكشف عن واقـع الدـور التربـوي المهـارس مـن قبـل

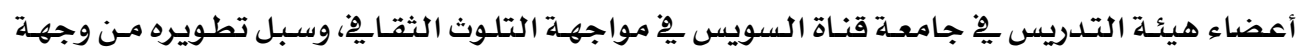
نظرهم، وهذه الاستبانة مقسمـة إلى قسمين:

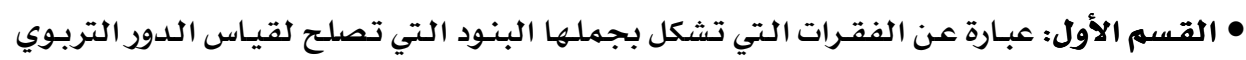

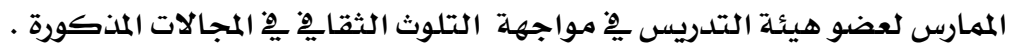

$$
\text { • القسم الثاني: عبارة عن سؤال مفتوح الطرف نصده كما يلي : }
$$

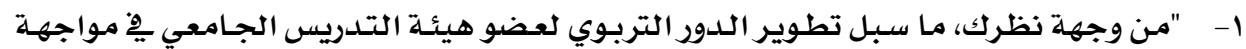

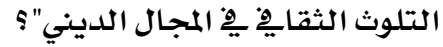

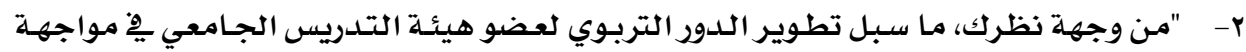

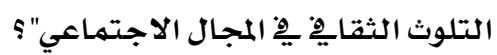

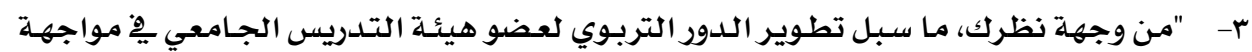

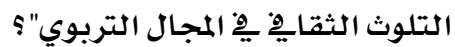

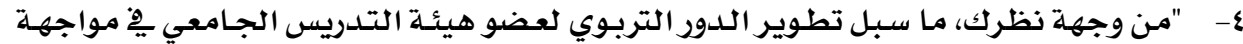

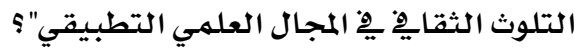

\section{وقد مر تصميم الاستبانة ويناؤها بالخطوات التالية :}

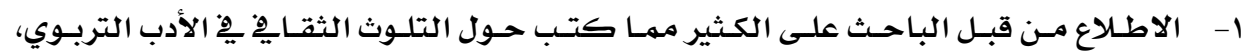

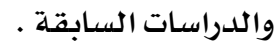

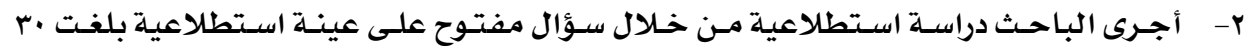

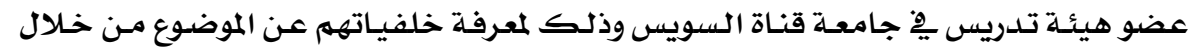

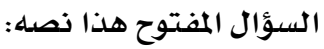

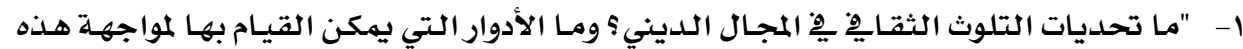

$$
\text { التحديات من وجهة نظرك" }
$$

• "ما تحديات التلوث الثقايِّ ِِِ المجال الاجتماعي؟ وما الأدوار التي يمكن القيام بها لمواجهة هذه التحديات من وجهة نظرك" 


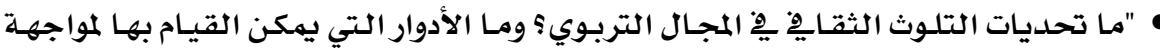
هذه التحديات من وجهة نظرك"

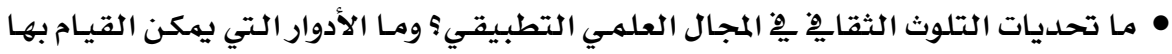

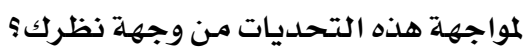

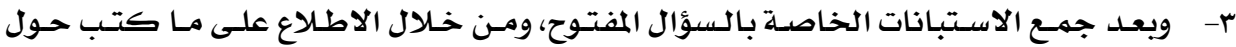

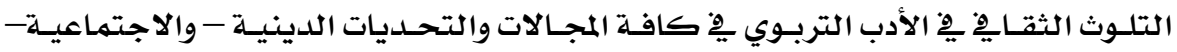

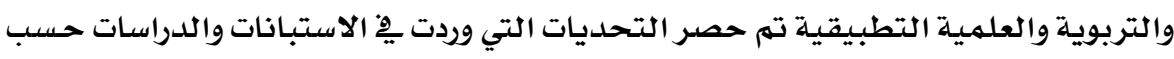

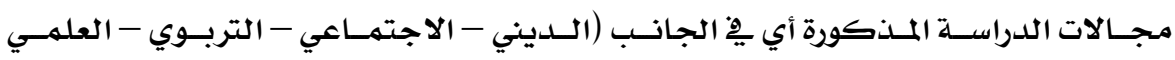
التطبيقي).

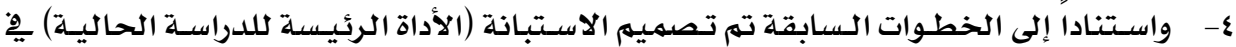

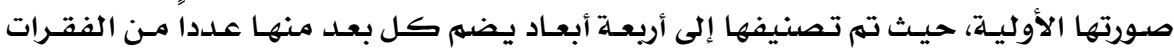
كالتالي:

المجال الأول: التحديات الدينية للتلوث الثقايِّو واشتمل المجال على (Yr) فقرة .

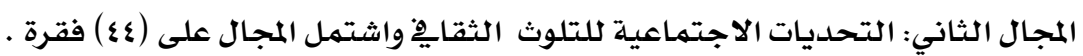

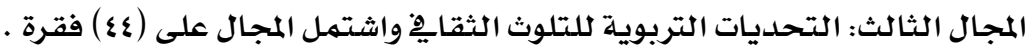

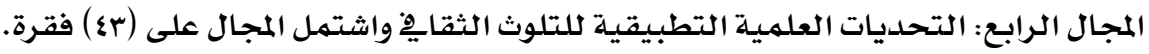
تم صياغة فقرات الاستبانة يِ صورتها الأولية وتكونت من (سד ) فقرة معبرة عن الأريعة.

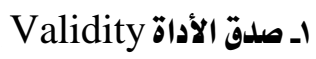

استخلدم الباحث الطرق التالية لحساب صدق الاستبانة :

أولا- صدق المحكمين (referees validity)

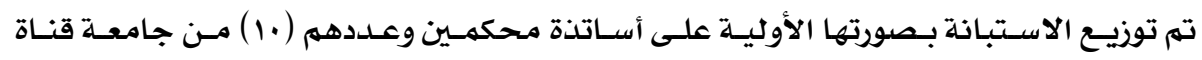

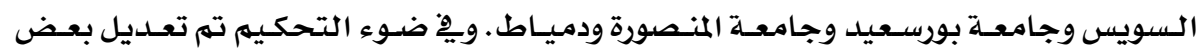

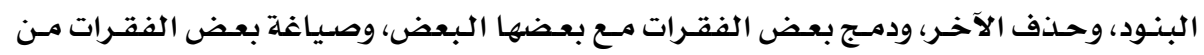

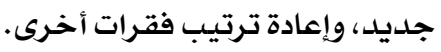

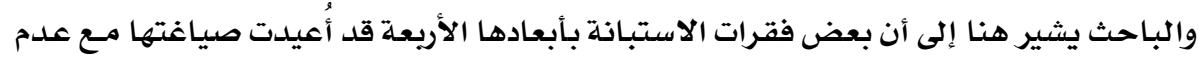
المساس بجوهر أداة الدراسـة.

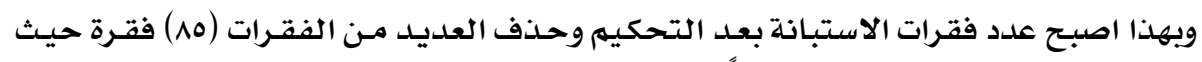

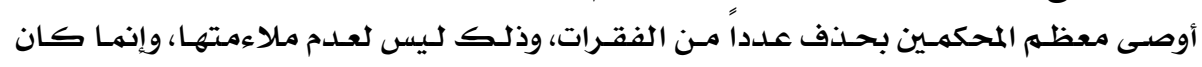

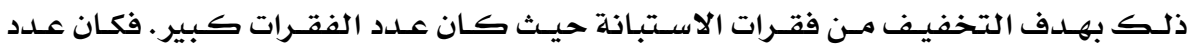

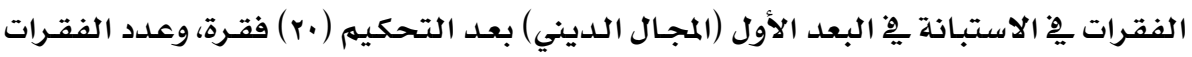

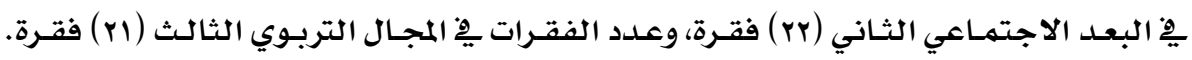




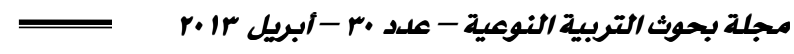

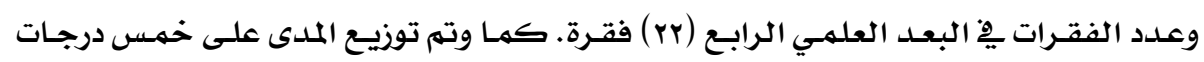

\begin{tabular}{|c|c|c|c|c|c|}
\hline أبـدا & نادرا & أحيانا & غالبـا & دائهما & المددى \\
\hline 1 & $r$ & $r$ & $\varepsilon$ & 0 & الرقم \\
\hline
\end{tabular}

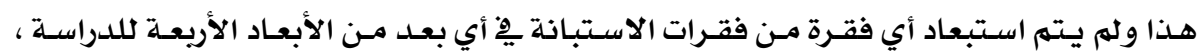

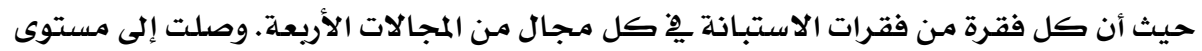

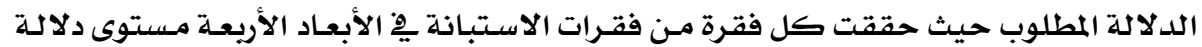

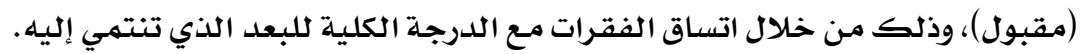
الاتساق الداخلي لفقرات المجال الثقافي (المجال الأول): قام الباحث كذلك بحسـاب معامل ارتباط درجة كل فقـرة مـع الدرجـة الكليـة للبعـد الذي تنتهي إليه كمما يلي: ا- المجال الديني (التحديات الدينية للتلوث الثقاية):

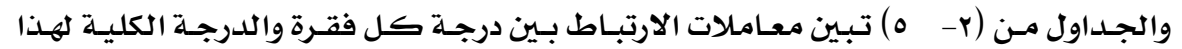
البعد: جدول (r) يبين معامل ارتباط درجة كل فقرة مع الدرجة الكلية للبعد الديني (التحديات الدينية للتلوث الثقاهِ)

\begin{tabular}{|c|c|c|c|c|c|}
\hline مستوى الدلالة & معامل الارتباط & رقم العبارة & مستوى الدلاية & معامل الارتباط & رقم العبارة \\
\hline$* *$ & •, ২৭. & ir & $* *$ & $\cdot, V \mid \varepsilon$ & 1 \\
\hline$* *$ & $\cdot, \wedge 17$ & ir & $* *$ & $\cdot, 0 \leqslant \wedge$ & $r$ \\
\hline$* *$ & •, IVI & $1 \varepsilon$ & $* *$ & •, TrA & $r$ \\
\hline$* *$ & •, OY\& & 10 & $* *$ & - , roy & $\varepsilon$ \\
\hline$* *$ & •, Orr & 17 & $* *$ & -, YoY & 0 \\
\hline$* *$ & -, V\o & iv & $* *$ & $\cdot, \wedge \vee Y$ & 7 \\
\hline$* *$ & $\cdot, \$ 0\rceil$ & 11 & $* *$ & -, rov & $v$ \\
\hline$* *$ & $\cdot, 079$ & 19 & $* *$ & - VrY & $\wedge$ \\
\hline \multirow[t]{3}{*}{$* *$} & -, OYr & r. & $* *$ & -, YAV & 9 \\
\hline & & & $* *$ & $\cdot, 07 r$ & 1. \\
\hline & & & $* *$ & •, IV. & 11 \\
\hline
\end{tabular}

* دالة عند مستوى 0 •,.

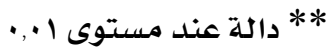


يتبين لنا من الجدول رقم (Y) أن جميع فقرات البعد الأول للاستبانة حققت مستوى الدلالة الدانة

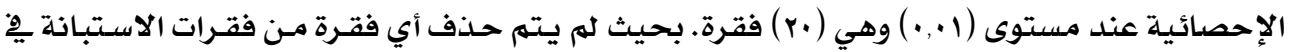

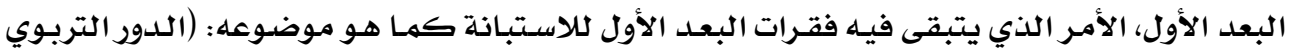

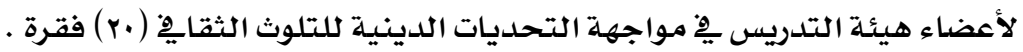

r ب المجال الاجتماعي (التحديات الاجتماعية للتلوث الثقايخ) :

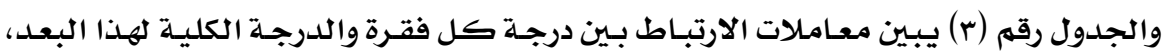

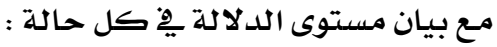
جدول (r) يبين معامل ارتباط درجة كل فقرة مـع الدرجة الكلية للبعد الاجتماعي (التحديات الاجتماعية للتلوث الثقايِّ) )

\begin{tabular}{|c|c|c|c|c|c|}
\hline مستوى الدلالة & معامل الارتباط & رقم العبارة & مستوى اللدلالة & معامل الارتباط & رقم العبارة \\
\hline$* *$ & $\bullet, \Lambda \mid \Lambda$ & ir & $* *$ & - $\vee \vee \wedge 9$ & 1 \\
\hline$* *$ & •,Arr & Ir & $* *$ & י דra & $r$ \\
\hline$* *$ & •, $\leqslant 7 r$ & $1 \varepsilon$ & $* *$ & $\cdot, 7 \cdot 0$ & $r$ \\
\hline$* *$ & $\bullet, 000$ & 10 & $* *$ & $\cdot, O \wedge \mathrm{V}$ & $\varepsilon$ \\
\hline$* *$ & $\bullet, \mathrm{VIr}$ & 17 & $* *$ & •, Arr & 0 \\
\hline$* *$ & $\cdot, \wedge 00$ & iv & $* *$ & $\cdot, 07 \mathrm{r}$ & 7 \\
\hline$* *$ & • & 11 & $* *$ & •, V५. & $v$ \\
\hline$* *$ & $\cdot, \wedge 11$ & 19 & $* *$ & -, OrV & $\Lambda$ \\
\hline$* *$ & -, $\vee v \vee$ & r. & $* *$ & , 70 . & 9 \\
\hline$* *$ & - , VTE & MI & $* *$ & •, YYI & 1. \\
\hline$* *$ & $\cdot, 71 V$ & rr & $* *$ & • & 11 \\
\hline
\end{tabular}

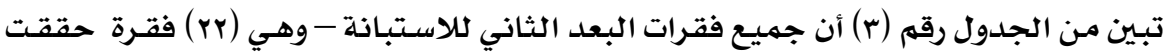

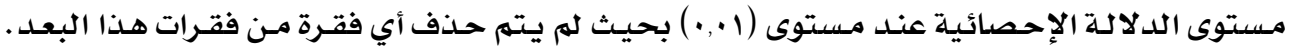

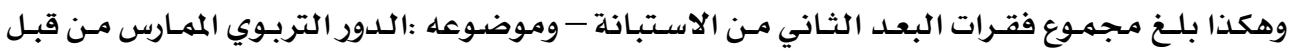

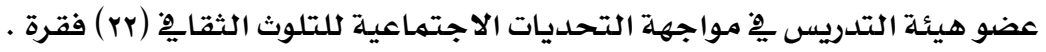
r- المجال التربوي (التحديات التربوية للتلوث الثقاية) : والجدول رقم (ع) يبـين معـاملات الارتبـاط بـين درجـة كل فقـرة والدرجـة الكليـة لهـذا البعدل،

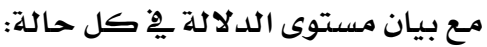




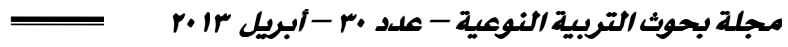

جدول ( ) يبين معامل ارتباط درجة كل فقرة مع الدرجة الكلية للبعد التربوي

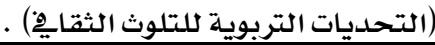

\begin{tabular}{|c|c|c|c|c|c|}
\hline مستوى الدلالة & معامل الارتباط & رقم العبارة & مستوى الدلالة & معامل الارتباط & رقم العبارة \\
\hline$* *$ & •, VYI & ir & $* *$ & •, VIY & 1 \\
\hline$* *$ & $\cdot, 0.1$ & ir & $* *$ & • TIV & $r$ \\
\hline$* *$ & •, Orr & 18 & $* *$ & $\cdot, 0 \leqslant r$ & $r$ \\
\hline$* *$ & •,vir & 10 & $* *$ & •, OrV & $\varepsilon$ \\
\hline$* *$ & -, Vrr & 17 & $* *$ & •,rir & 0 \\
\hline$* *$ & •,Ar. & iv & $* *$ & •, V7Y & 7 \\
\hline$* *$ & •, प $1 \leqslant \varepsilon$ & 11 & $* *$ & •, IrI & $v$ \\
\hline$* *$ & $\cdot, \vee \vee 1$ & 19 & $* *$ & $\cdot, \vee 70$ & $\Lambda$ \\
\hline$* *$ & - Y Yo7 & r. & $* *$ & •, १V. & 9 \\
\hline \multirow[t]{2}{*}{$* *$} & $\cdot, 791$ & rI & $* *$ & $\cdot, 70 \varepsilon$ & 1. \\
\hline & & & $* *$ & $\cdot, 700$ & 11 \\
\hline
\end{tabular}

** دالة عند مستوى ا.,.

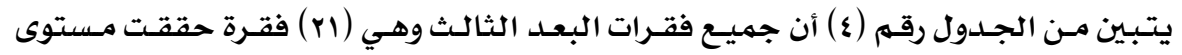

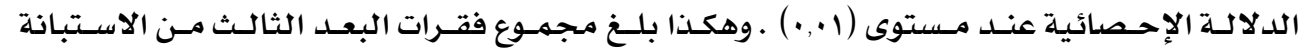

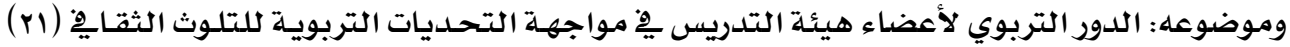
فقرة .

ع- مجال التحديات العلمية التطبيقية للتلوث الثقايو : والجدول رقم (ه) يبين معاملات الارتبـاط بـين درجـة كل فقـرة والدرجـة الكليـة لهذا المجـال،

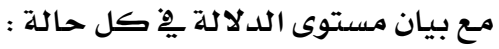


والجدول (0) يبين معاملات الارتباط بين درجة كل فقرة. والدرجة الكلية للبعد العلهي

(التحديات العلمية للتلوث الثقايِّ)

\begin{tabular}{|c|c|c|c|c|c|}
\hline مستوى الدلالة & معامل الارتباط & رقم العبارة & مستوى الدلالة & معامل الارتباط & رقم العبارة \\
\hline$* *$ & $\cdot, 0 \leqslant r$ & ir & $* *$ & $\cdot$, ¿Æ\& & 1 \\
\hline$* *$ & -, OV₹ & ir & $* *$ & - , $7 \leqslant 0$ & $r$ \\
\hline$* *$ & -, VYI & $1 \varepsilon$ & $* *$ & •, पाह & $r$ \\
\hline$* *$ & - IVq & 10 & $* *$ & •, VYI & $\varepsilon$ \\
\hline$* *$ & -, $0 \leqslant r$ & 17 & $* *$ & $\cdot, 701$ & 0 \\
\hline$* *$ & צז & iv & $* *$ & - Av. & 7 \\
\hline$* *$ & -, YII & in & $* *$ & $\cdot, 777$ & $\checkmark$ \\
\hline$* *$ & $\cdot, r \cdot \eta$ & 19 & $* *$ & • ר & $\Lambda$ \\
\hline$* *$ & $\cdot, \Lambda \cdot 7$ & r. & $* *$ & $\cdot, 091$ & 9 \\
\hline$* *$ & 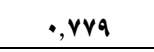 & rI & $* *$ & •, ২q. & 1. \\
\hline$* *$ & $\bullet, 70 \varepsilon$ & rr & $* *$ & •, Y^A & 11 \\
\hline
\end{tabular}

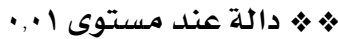

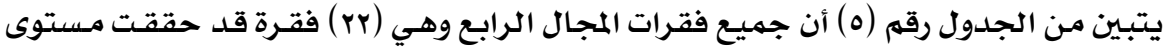

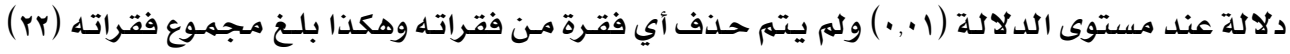

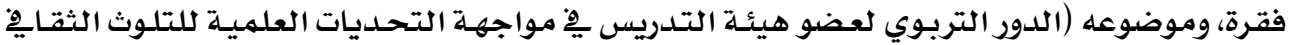
فقر (r)

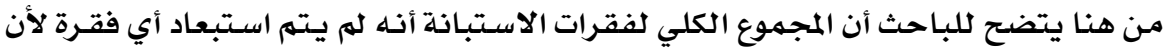

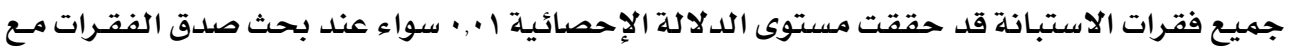

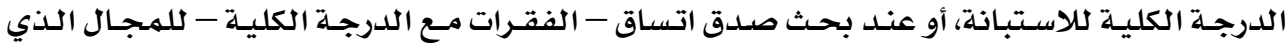
تنتهي إليه .

حساب اتساق المجالات الأربعة واللدرجة الكلية : الاتساق الداخلي للمـجالات . قام الباحث بحساب ارتباطات الأبعاد الأربعة المكونة للاستبانة مـع الدرجـة الكليـة للاستبانة،

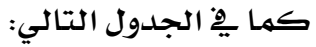




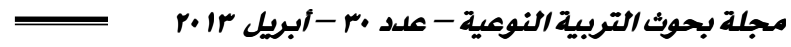

جدول (ج) يبين معامل ارتباط درجة كل بعد من الأبعاد الفرعية مع الدرجة الكلية للاستبانة

\begin{tabular}{|c|c|c|}
\hline مستوى الدلالة & قيمة (ر) & المجالات \\
\hline$+*$ & $\cdot, A v$ & الأول \\
\hline $\pm *$ & $\cdot, \wedge \varepsilon$ & الثاني \\
\hline$+*$ & $\cdot, \mathrm{VA}$ & الثاث \\
\hline $\pm *$ & •, vo & الرابع \\
\hline
\end{tabular}

من الجدول السابق يتضح للباحث ما يلي :

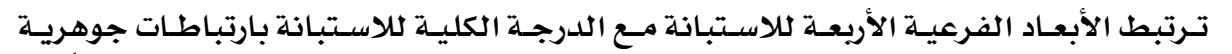

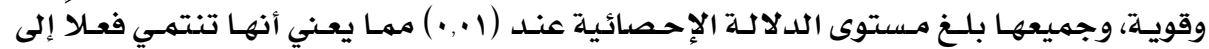

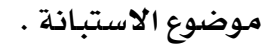

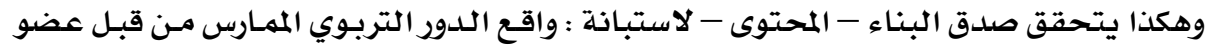

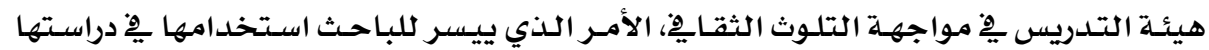

باطمئنان .

ثبات الأداة:

الثبـات بطريقـة التجزئـة النصفيـ Split Half Method: مـن أجـل التأكسد مـن ثبـات

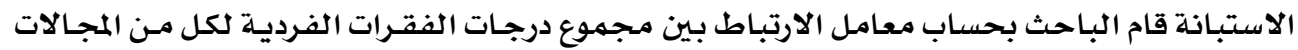

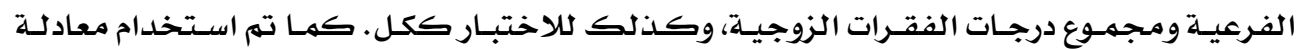

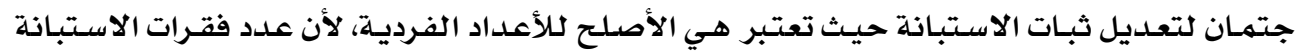

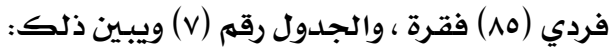

جدول (v) يبين قيم معاملات ثبات الاختبار بطريقة التجزئة النصفية قبل وبعد تعديل طول الاختبار

\begin{tabular}{|c|c|c|}
\hline بعد التعديل & معامل الارتباط قبل التعديل & أبعاد الاستبانة \\
\hline$\cdot, 19$ & $\cdot, \Lambda \mathrm{r}$ & الأول \\
\hline$\cdot, 9 r$ & $\cdot, \wedge 7$ & الثاني \\
\hline$\bullet, 9$. & $\cdot, \Lambda \mathrm{V}$ & الثالث \\
\hline$\cdot, \wedge \wedge$ & $\cdot, \wedge 9$ & الرابع - الع \\
\hline$\cdot, \wedge 7$ & $\cdot, \wedge 1$ & الدرجة الكلية \\
\hline
\end{tabular}

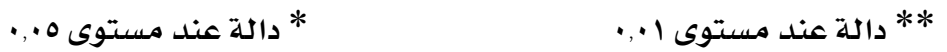

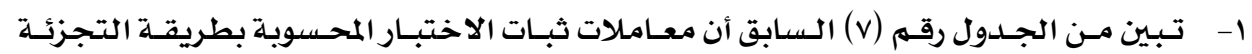

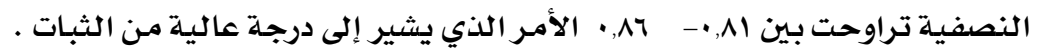


CronbchAlpha : ب - الثبات بطريقة ألفا كرونباخ

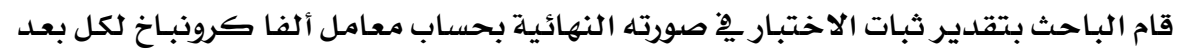

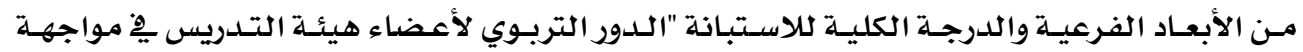

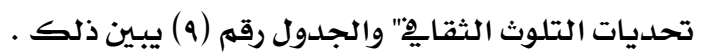

حيث أن معامل ألفا كرونباخ= $\}$ re $1+\dot{0}$

$$
\begin{aligned}
& \text { حيث ن = عدد فقرات الاستبانة . } \\
& \text { عr = تباين الاستبانة ككل . }
\end{aligned}
$$

م-جع = المجموع الكلي لتباين أو كل بعد من أبعاد الاستبانة كل فقرة من فقرات الاستبانة جدول رقم (^) يبين قيمة ألفا كرونباخ لاستبانة الدور التربوي الممارس من عضو هيئة التدريس الجامعي

\begin{tabular}{|c|c|c|}
\hline قيمة ألثا كرونباخ & 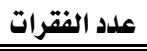 & 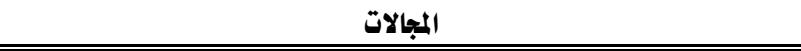 \\
\hline$\cdot, \wedge 9$ & r. & المجال الأول الدور التربوي الممارس في مواجهة التحديات الدينية للتلوث الثقافي \\
\hline$\cdot, \wedge 0$ & rr & المجال الثاني الدور التربوي الممارس في مواجهة التحديات الاجتماعية للتلوث الثقافي \\
\hline$\cdot, \wedge \xi$ & ri & المجال الثالث الدور التربوي الممارس في مواجهة التحديات التربوية للتلوث الثقافي \\
\hline$\cdot, \wedge \mathrm{V}$ & rr & المجال الرابع الدور التزبوي الممارس في مواجهة التحديات العلمية للتلوث الثقافي \\
\hline$\cdot, \wedge 7$ & 10 & 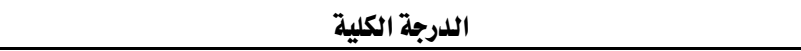 \\
\hline
\end{tabular}
مِّْ مواجهة تحديات التلوث الثقايِّ بجامعة قناة السويس.

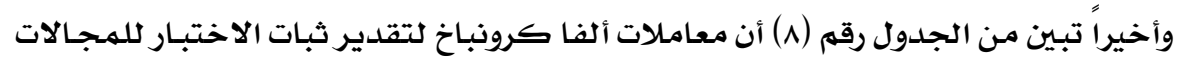

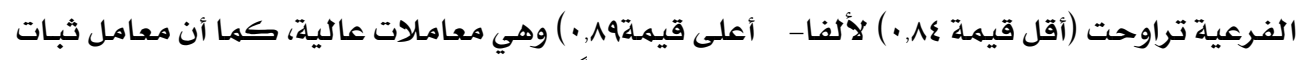

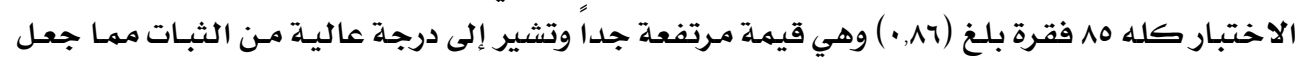

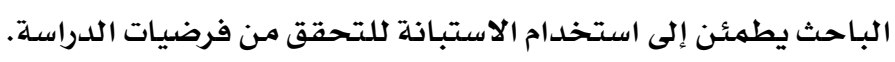

\section{سادسا- المعالجات الإحصائية}

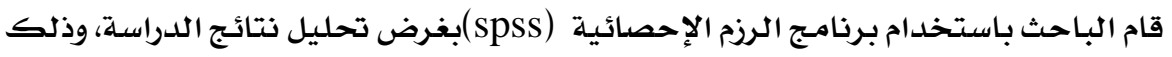

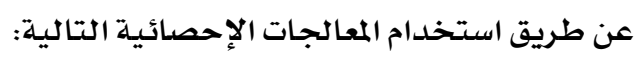

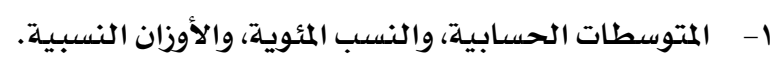

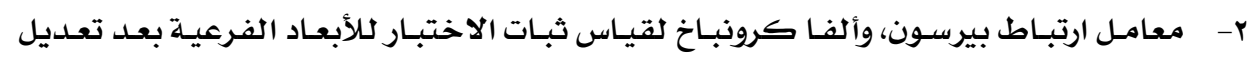

$$
\begin{aligned}
& \text { الثبات عن طريق معادلة جتمان. }
\end{aligned}
$$

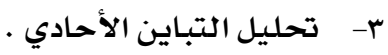

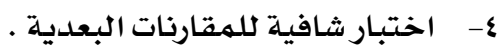




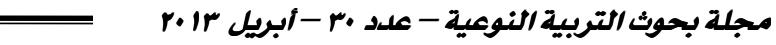

ه- طريقة التجزئسة النصفية - ومعادلة جتهـان لتعـديل ثبـات الاستبانة لأن عدد فقراتها فردي وليس زوجي فهي (10) فقرة .

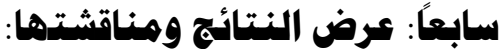

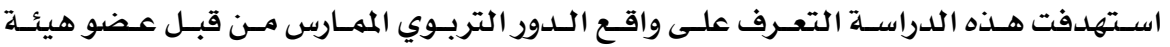

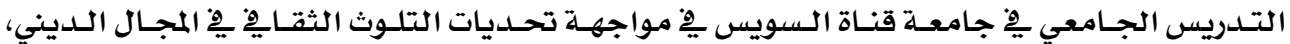

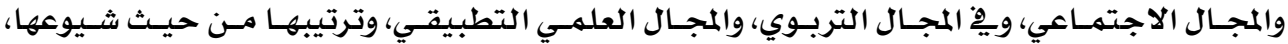

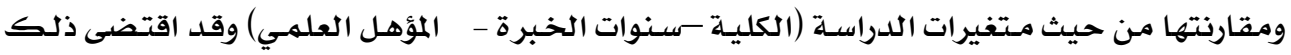

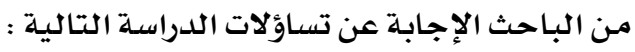

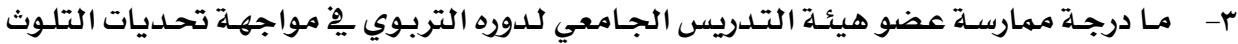

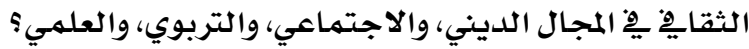

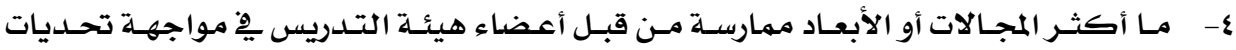
التلوث الثقايِّ؟

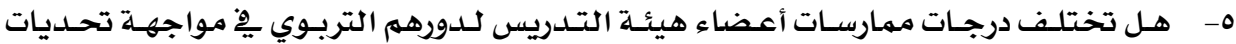

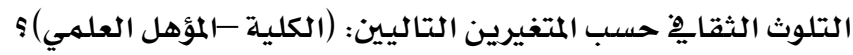

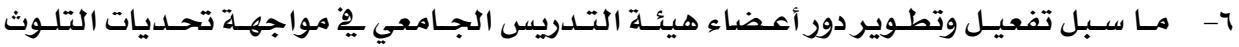

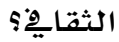

V- ما التصور المقترح لتطوير دور عضو هيئة التدريس الجامعي لمواجهة تحديات التلوث الثقايِ

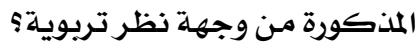

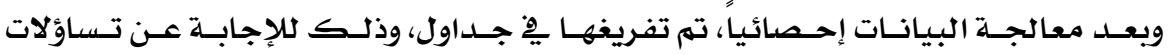
الدراسة، والتي جاءت على النحو التالي : تقائج الدراسة: أولاً: عرض نتائج السؤال الثالث ومناقشتها: للإجابة عن السؤال الثالث والذي ينص على ما يلي: "ما درجـة ممارسـة عضو هيئسة التـدريس

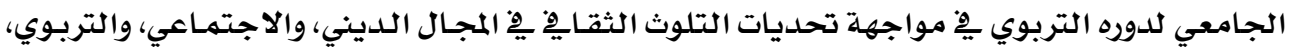
والعلهي التطبيقي" الدوهيري

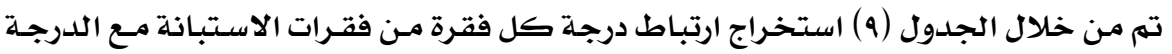
الكلية لها ِِِ المجالات الأريعة للدراسـة، وكذلك معامل ارتباط درجة كل فقـرة مـن فقرات الاستبانة

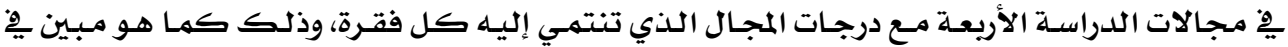

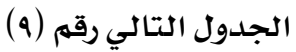


جدول (ه) يبين قيم معامل ارتباط درجة كل فقرة من فقرات الاستبانة يِّ المجالات الأربعة مـع درجتها الكلية

\begin{tabular}{|c|c|c|c|}
\hline مستوى الدلالة & $\begin{array}{c}\text { Pearson correlation } \\
\text { قيهة رمعامل الارتباط } \\
\end{array}$ & رقم العبارة المجال & الرقم المتسلسل \\
\hline$* *$ & •, or & 1 & 1 \\
\hline$* *$ & •, $1 \xi$ & $r$ & $r$ \\
\hline$* *$ & $\cdot, r r$ & $r$ & $r$ \\
\hline$* *$ & $\cdot, \S 0$ & $\varepsilon$ & $\xi$ \\
\hline$* *$ & $\cdot, A 1$ & 0 & 0 \\
\hline$* *$ & •, vq & 9 & 9 \\
\hline$* *$ & •, vr & v & v \\
\hline$* *$ & $\cdot, v$. & $\wedge$ & $\wedge$ \\
\hline$* *$ & $\cdot, \mathrm{VY}$ & 9 & 9 \\
\hline$* *$ & $\cdot, \infty 0$ & 1. & 1. \\
\hline$* *$ & • ra & 11 & 11 \\
\hline$* *$ & $\cdot, \mathrm{vq}$ & ir & ir \\
\hline$* *$ & $\cdot$ • Ar & ir & ir \\
\hline$* *$ & $\cdot, n$ & $1 \varepsilon$ & Is \\
\hline$* *$ &., 00 & 10 & 10 \\
\hline$* *$ & •, & 17 & 17 \\
\hline$* *$ & $\cdot, \mathrm{Vq}$ & iv & iv \\
\hline$* *$ &., 74 & in & in \\
\hline$* *$ & $\cdot, 79$ & 19 & 19 \\
\hline$* *$ & $\cdot, \mathrm{VI}$ & r. & r. \\
\hline$* *$ & • & 1 & r \\
\hline$* *$ &., 70 & $r$ & rr \\
\hline$* *$ & •, rr & $r$ & rr \\
\hline$* *$ & $\cdot, A r$ & $\varepsilon$ & $r \xi$ \\
\hline$* *$ & •,r. & 0 & ro \\
\hline$* *$ & .01 & 1 & rq \\
\hline$* *$ & $\cdot, \mathrm{VA}$ & v & $r r$ \\
\hline$* *$ & $\cdot, 77$ & $\wedge$ & ra \\
\hline
\end{tabular}




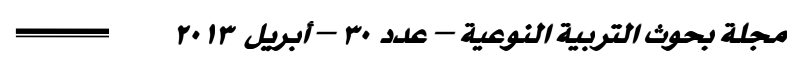

\begin{tabular}{|c|c|c|c|}
\hline مستوى الدلالة & $\begin{array}{c}\text { Pearson correlation } \\
\text { قيمة رمامل الارتباط } \\
\end{array}$ & رقم العبارة المجال & الرقم المتسلسل \\
\hline$* *$ & •, ro & 9 & ra \\
\hline$* *$ & $\cdot, \wedge 1$ & 1. & $r$. \\
\hline$* *$ & $\cdot, \mathrm{Vr}$ & 11 & r \\
\hline$* *$ & $\cdot, \lambda \cdot$ & ir & $r r$ \\
\hline$* *$ & •, & ir & $r r$ \\
\hline$* *$ & $\cdot, 7 v$ & $1 \xi$ & rs \\
\hline$* *$ & $\cdot, 01$ & 10 & ro \\
\hline$* *$ & $\cdot, 79$ & 17 & rq \\
\hline$* *$ & •, or & iv & rr \\
\hline$* *$ & $\cdot, \mathrm{vr}$ & 11 & ra \\
\hline$* *$ & •,Ar & 19 & ra \\
\hline$* *$ & $\cdot, \& 9$ & r. & $\xi$ \\
\hline$* *$ & $\cdot, \mathrm{Vq}$ & ri & $\$ 1$ \\
\hline$* *$ & $\cdot, \mathrm{rA}$ & $r r$ & $\varepsilon r$ \\
\hline$* *$ &., 00 & 1 & $\xi \pi$ \\
\hline$* *$ & rit, & r & $\xi \xi$ \\
\hline$* *$ & •, rr & $r$ & \$o \\
\hline$* *$ & $\cdot, 70$ & $\varepsilon$ & $\Sigma \eta$ \\
\hline$* *$ & $\cdot, 71$ & 0 & sv \\
\hline$* *$ & $\cdot, 79$ & 7 & $\{\Lambda$ \\
\hline$* *$ & $\cdot, \mathrm{rV}$ & $\checkmark$ & $\leqslant 9$ \\
\hline$* *$ & •, $\mathrm{va}$ & $\wedge$ & 0. \\
\hline$* *$ &., 00 & 9 & 01 \\
\hline$* *$ & $\cdot, 1 \varepsilon$ & 1. & or \\
\hline$* *$ & $\cdot, 09$ & 11 & or \\
\hline$* *$ & $\cdot, \mathrm{VA}$ & ir & $\Delta \varepsilon$ \\
\hline$* *$ & •, $0 \xi$ & ir & $\infty 0$ \\
\hline$* *$ & •, vo & $\varepsilon$ & 07 \\
\hline$* *$ & $\cdot, v 9$ & 10 & or \\
\hline
\end{tabular}


الدور التريوي لعضو هيئة التسريس فِ تحصين طلابه ضل التلوث الثقاِِ وسبل تطويره من وجهة نطره =

\begin{tabular}{|c|c|c|c|}
\hline مستوى الدلالة & $\begin{array}{l}\text { Pearson correlation } \\
\text { قيمة ر معامل الارتباط }\end{array}$ & رقم العبارة المجال & الرقم المتسلسل \\
\hline$* *$ & $\cdot, A 1$ & 17 & $\Delta \Lambda$ \\
\hline$* *$ & $\cdot, r$ & iv & $\Delta 9$ \\
\hline$* *$ & $\cdot, \Lambda \cdot$ & M & 7. \\
\hline$* *$ & •, v9 & 19 & 71 \\
\hline$* *$ & $\cdot, 77$ & r. & ar \\
\hline$* *$ & $\cdot, 70$ & rI & $7 r$ \\
\hline$* *$ & •, Yo & 1 & $7 \varepsilon$ \\
\hline$* *$ & $\cdot,\{r$ & $r$ & 70 \\
\hline$* *$ & •, Yo & $r$ & 79 \\
\hline$* *$ & $\cdot, \$ 9$ & $\varepsilon$ & IV \\
\hline$* *$ & $\cdot, 7 r$ & 0 & $7 \Lambda$ \\
\hline$* *$ & $\cdot, \mathrm{YY}$ & 7 & 79 \\
\hline$* *$ & $\cdot, 70$ & v & v. \\
\hline$* *$ & $\cdot, \wedge 1$ & $\Lambda$ & n \\
\hline$* *$ & $\cdot, \mathrm{Vr}$ & 9 & VY \\
\hline$* *$ & $\cdot$, Ir & 1. & vr \\
\hline$* *$ & $\cdot,\{V$ & 11 & $v \varepsilon$ \\
\hline$* *$ & $\cdot, \vee \varepsilon$ & ir & vo \\
\hline$* *$ & $\cdot, 70$ & ir & vy \\
\hline$* *$ & $\cdot, \wedge \cdot$ & $1 \varepsilon$ & vr \\
\hline$* *$ & $\cdot, 09$ & 10 & $\checkmark \wedge$ \\
\hline$* *$ & $\cdot, \mathrm{v}$ & 17 & va \\
\hline$* *$ & $\cdot, \mathrm{Vq}$ & iv & $\wedge$. \\
\hline$* *$ & •,Ar & 11 & 11 \\
\hline$* *$ & $\cdot, 7 \varepsilon$ & 19 & Ar \\
\hline$* *$ & •, 74 & r. & Ar \\
\hline$* *$ & $\cdot, r v$ & rI & $\wedge \varepsilon$ \\
\hline$* *$ & $\cdot, 79$ & rr & 10 \\
\hline
\end{tabular}

* * دالة عند مستوى 1 •., 
* دالة عند مستوى 0 .,

تكون مستوى الدلالة عند (0., •) عندما تساوي قيمة (ر) الر. • فما فوق.

يتبين من الجدول السابق رقم (ه) أن فقرات الاستبانة دالة عند مستوى دلالة أكثر من ا. .,

$$
\text { وهي (10) فقرة، }
$$

مناقشة نتائج السؤال الثالث:

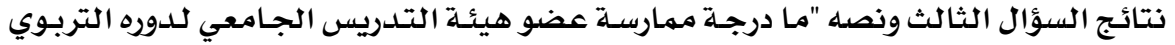

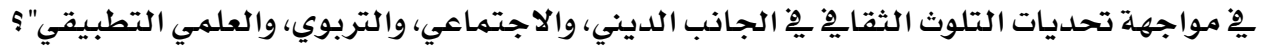

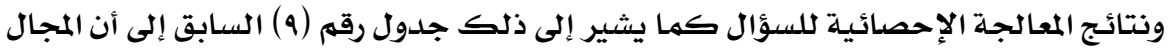

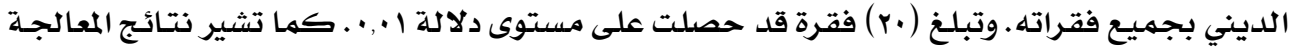

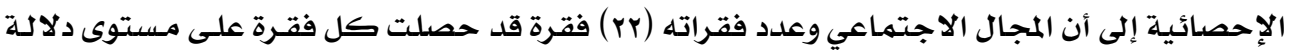

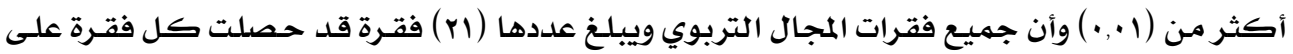

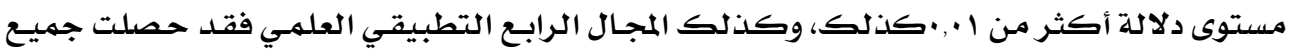

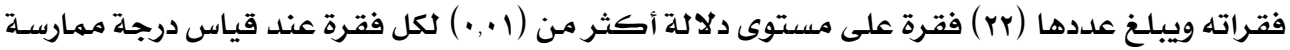

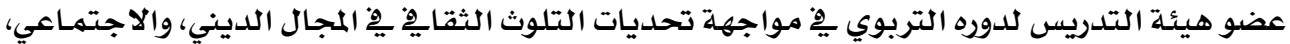

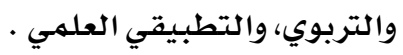

$$
\text { ويعزو الباحث ذلك إلى ما يلي : }
$$

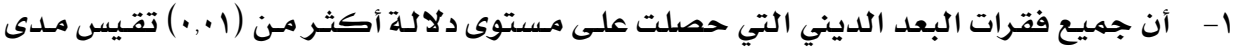

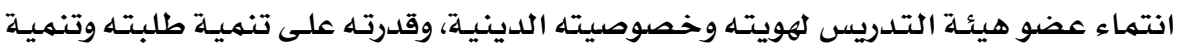

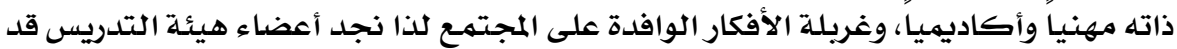

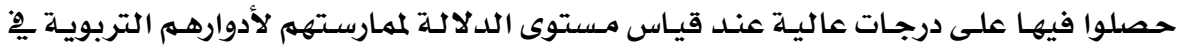

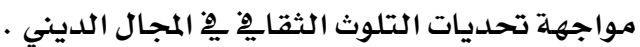

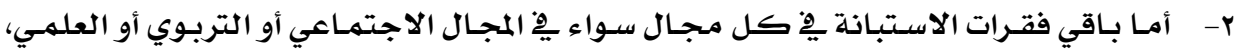

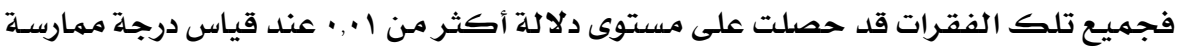

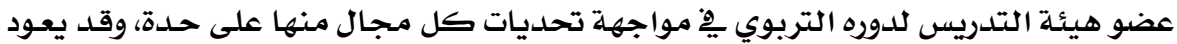

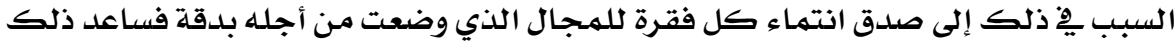

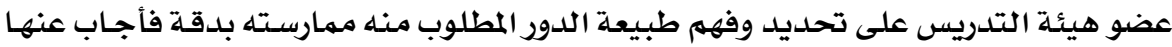

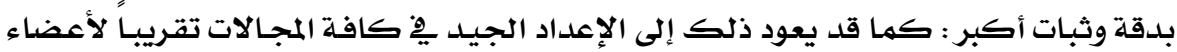

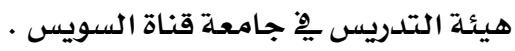
ثانياً: عرض نتائج السؤال الرابع ومناقشتها:

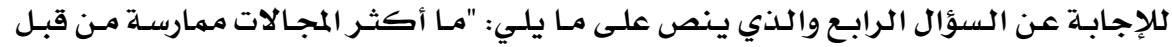

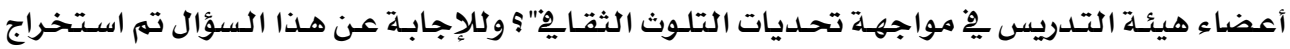


المتوسطات الحسابية والأوزان النسبية لكل مجال مـن مجـالات أداة الدراسـة. وذلك كمها هو مبيـين في جدول رقم (1.) (1) (1) جدول ( ـ ا) يبين المتوسطات الحسابية والأوزان النسبية لمجالات أداة الدراسة

\begin{tabular}{|c|c|c|c|c|}
\hline الترتيب & الوزن النسبي ٪ & الانحراف المعياري & المتوسط الحسابي & 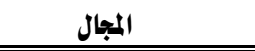 \\
\hline الثاني & $\%$ \% & Ir,or & Vo, $\bullet 19$ & اـ المجال الديني \\
\hline الثاث & $\% \vee \cdot, v$ & $17, v 9$ & vY,07 & لــ المجال الاجتماعي \\
\hline الأور ال & $\% \mathrm{vr}, \mathrm{r} \cdot$ & $1 \varepsilon, \vee q$ & $V q, A v$ & بـ المجال التربوي \\
\hline 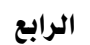 & $\% \vee v, \cdot 1$ & $17, \cdot \cdot$ & $r Y, q r$ & كـ المجال العلمي التطبيقي \\
\hline
\end{tabular}

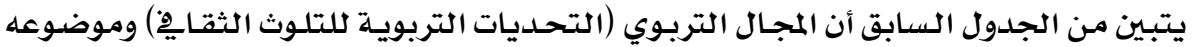

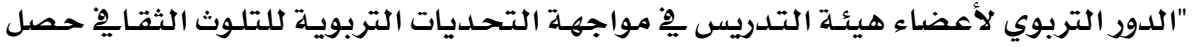

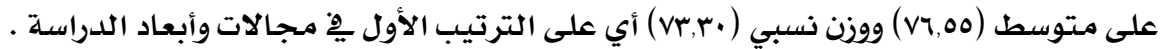

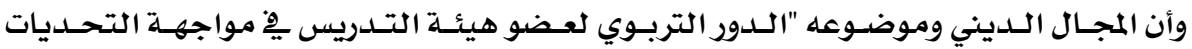

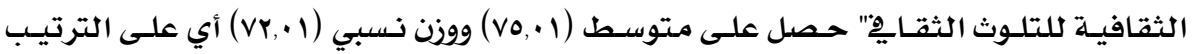

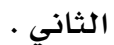

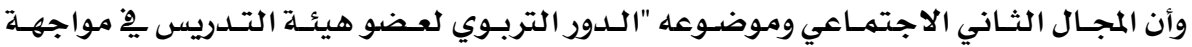

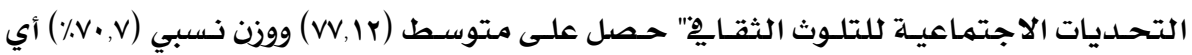
على الترتيب الثالث.

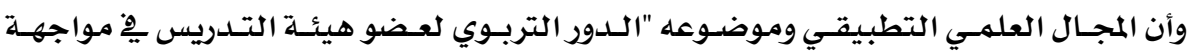

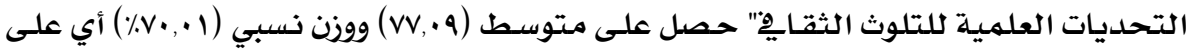

$$
\text { الترتيب الرابع. }
$$
مناقشة نتائج السؤال الرابع:

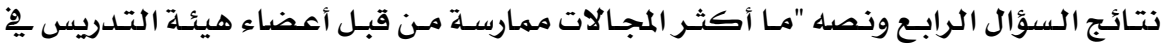

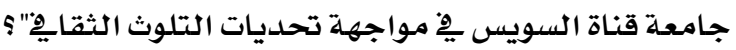

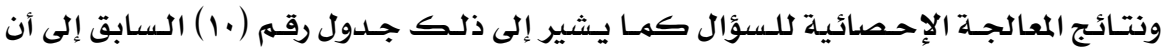

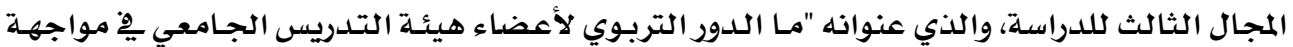

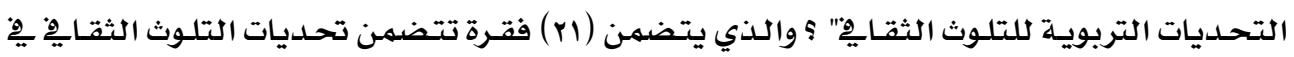

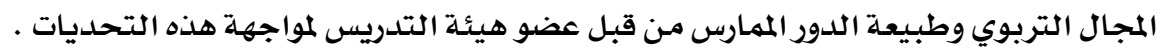

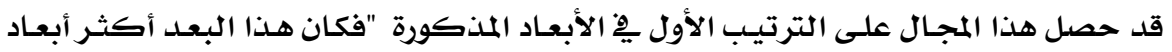

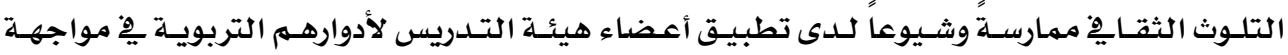

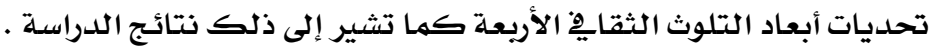
ويعزو الباحث ذلك إلى ما يلي : 
1- تخضع جامعة قناة السويس فِ الأسـاس إلى عدة منطلقات منها :

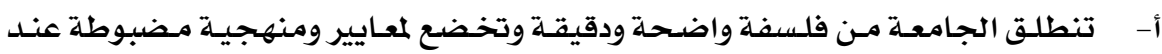

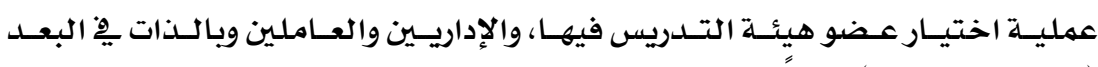

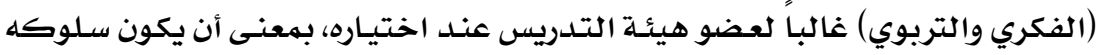

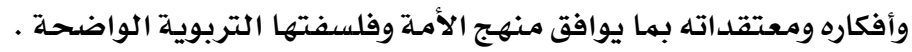

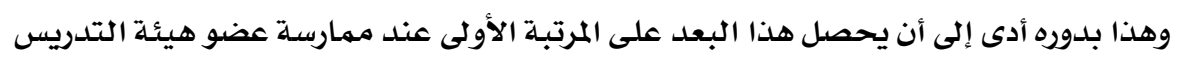

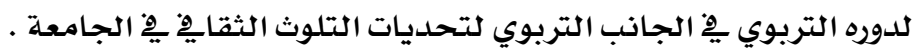

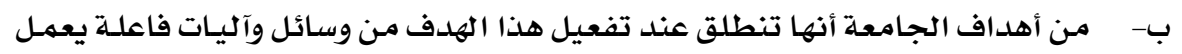

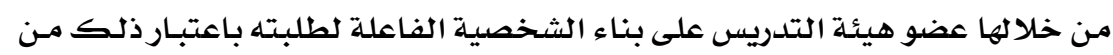

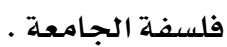

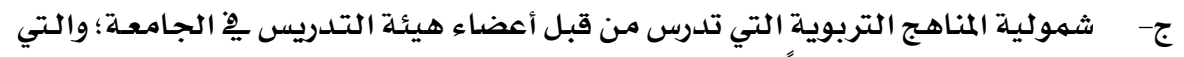

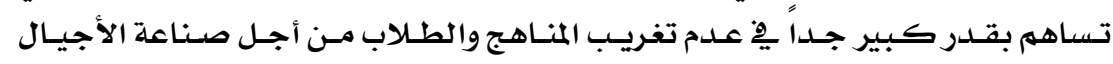

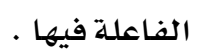

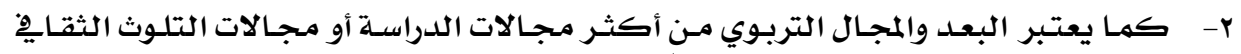

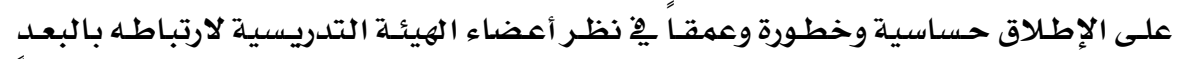

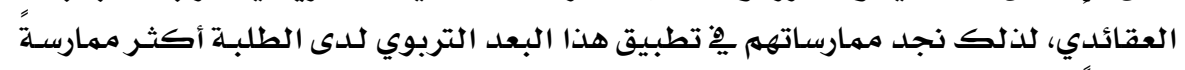

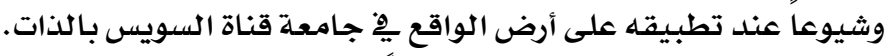

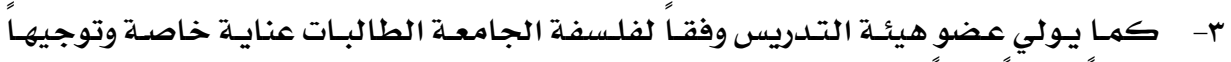

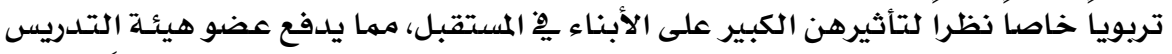

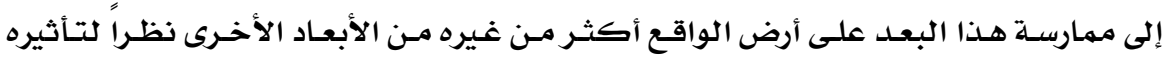

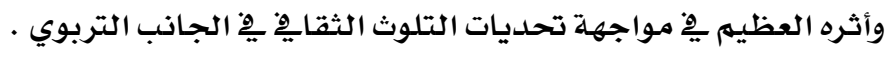

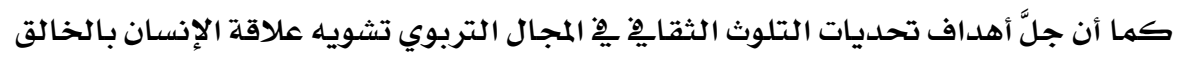

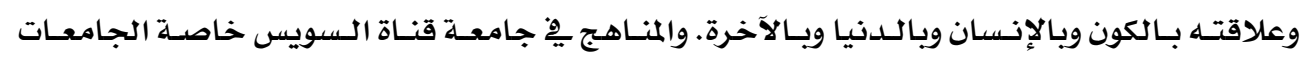

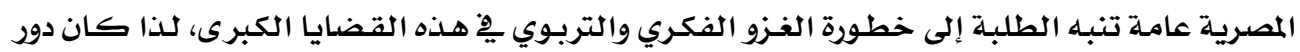

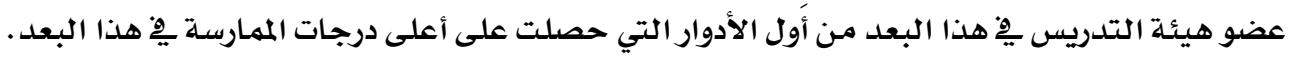

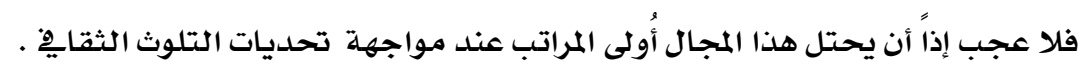

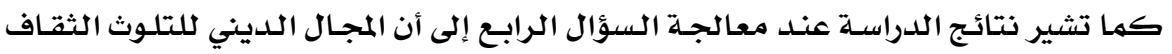

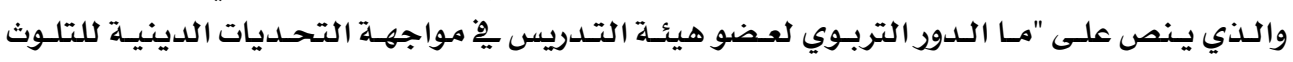

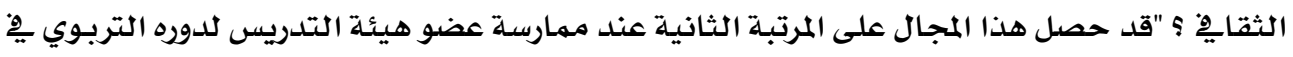

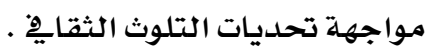
ويعزو الباحث ذلك إلى ما يلي : 


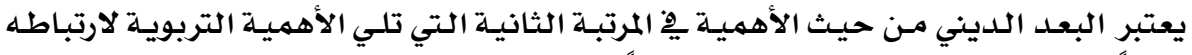

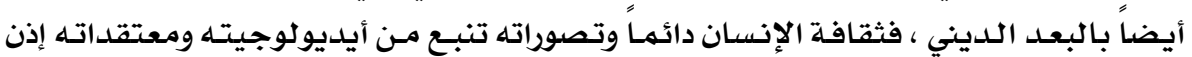

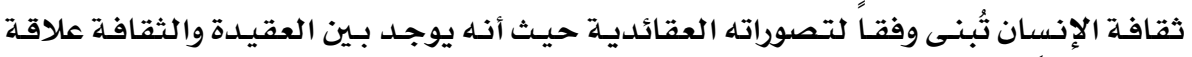

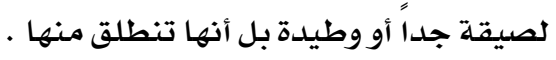

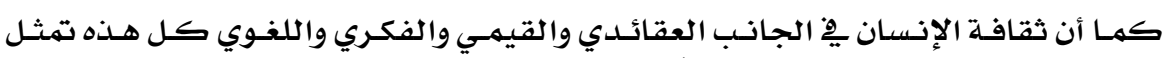

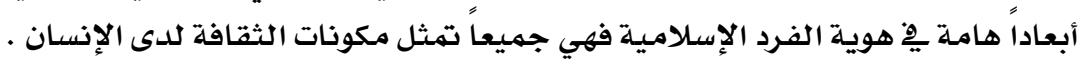

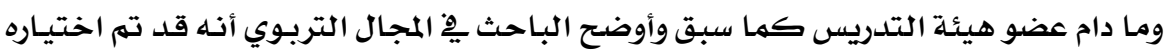

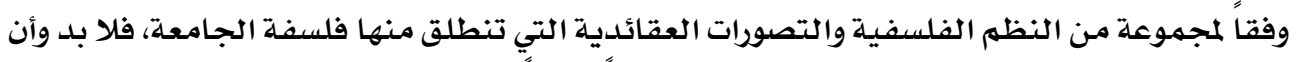

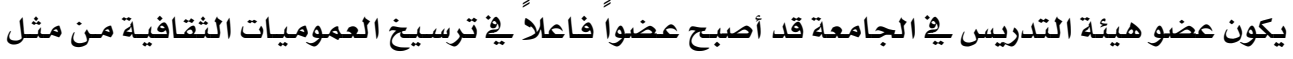

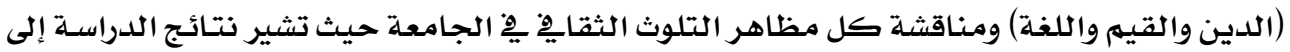

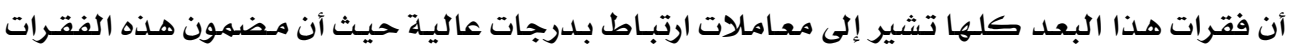

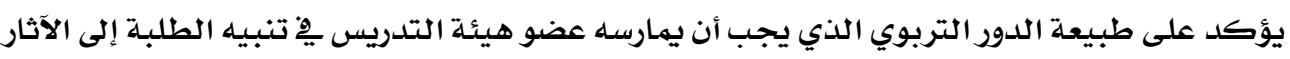

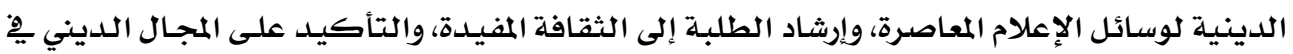

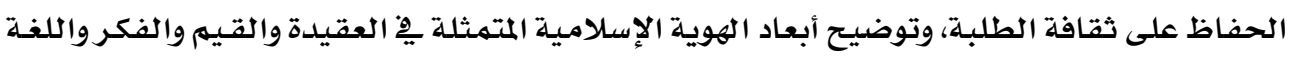

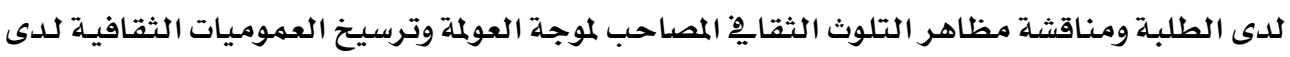

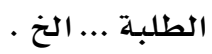

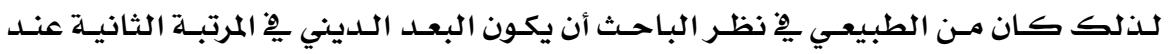

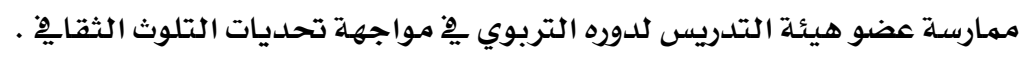

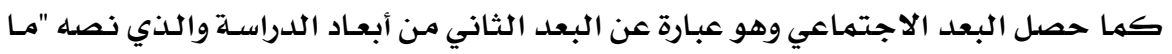

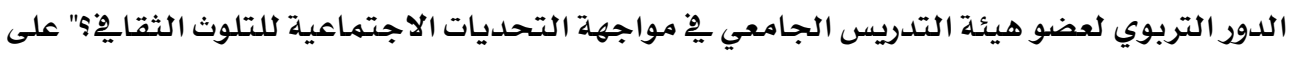

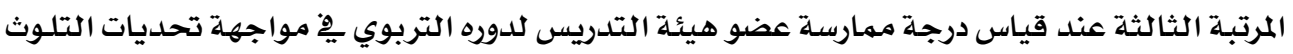

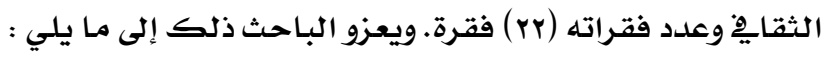

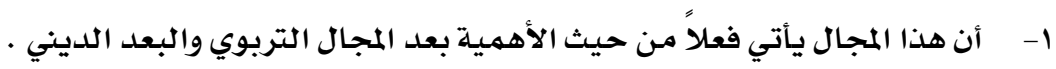

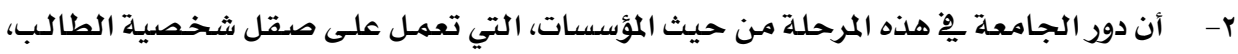

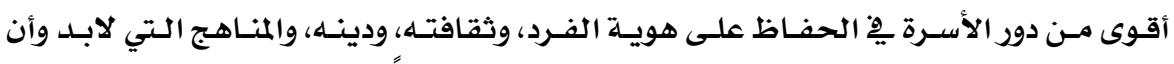

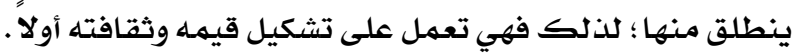

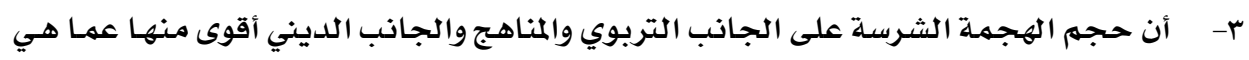

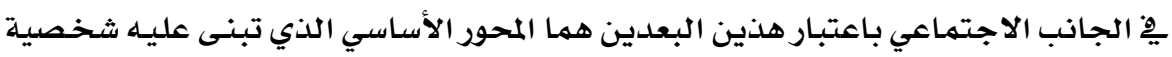

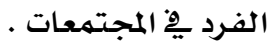

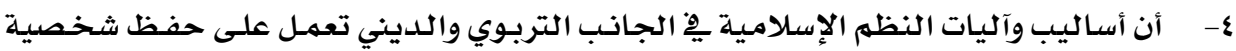

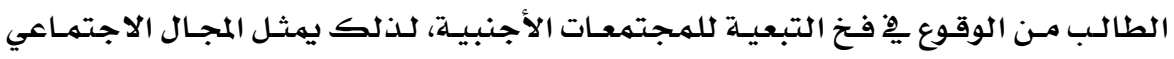




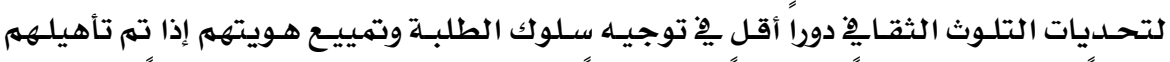

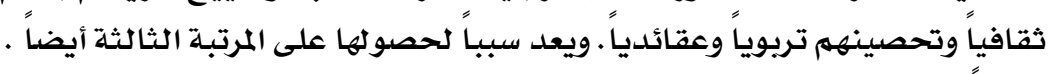

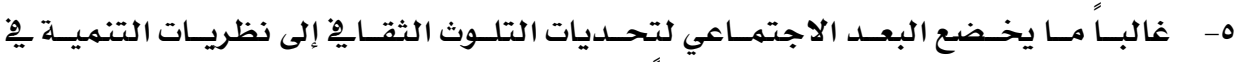

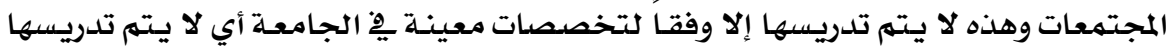

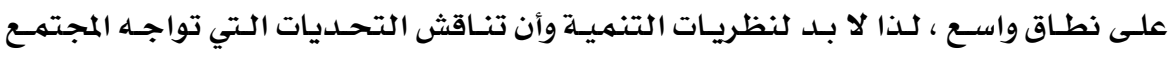

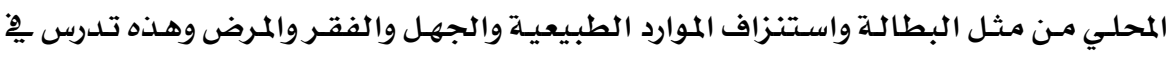

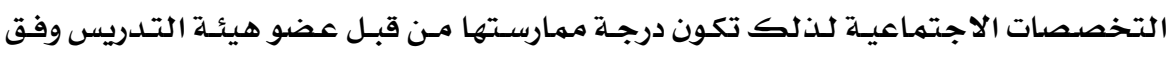

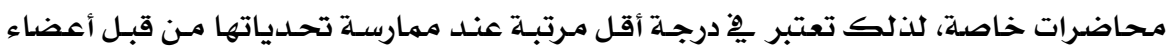

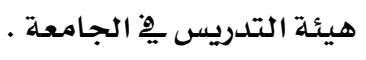

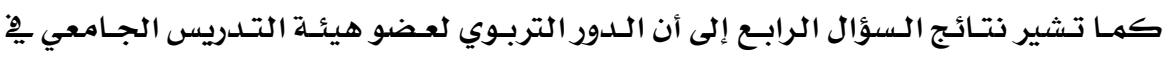

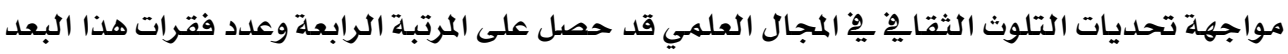

$$
\text { ويعزو الباحث ذلك إلى ما يلي : }
$$

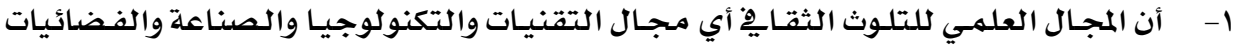

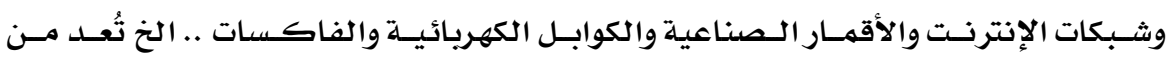

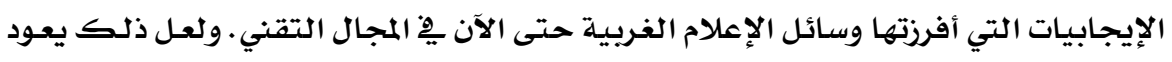

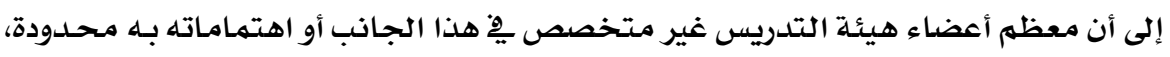

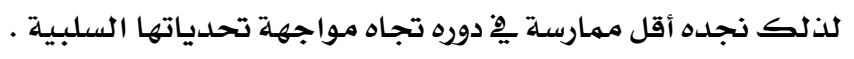

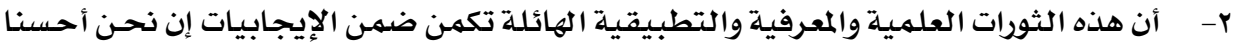

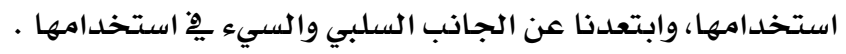

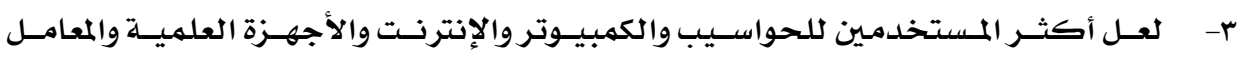

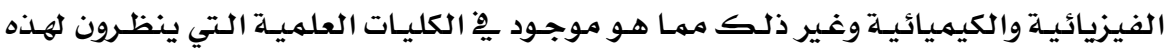

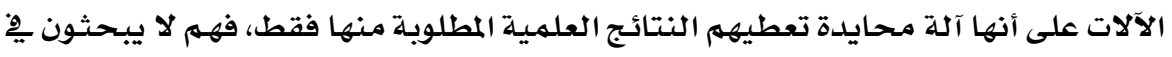

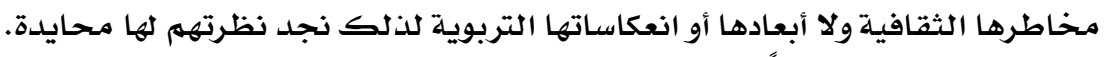

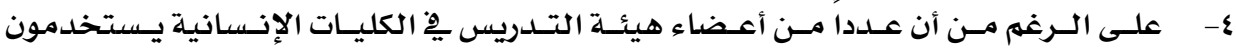

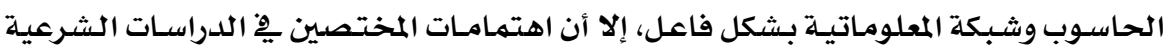

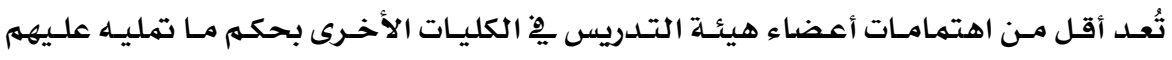

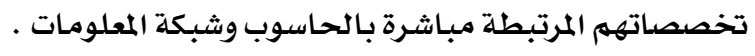
ثالثاً: عرض نتائج السؤال الخامس (فروض الدراسة) ومناقشتها:

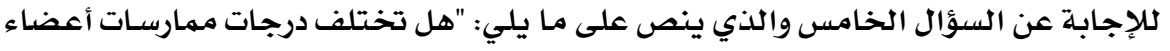

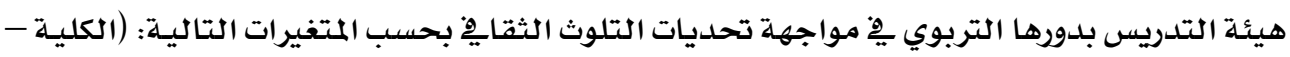

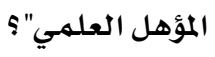




$$
\text { كلإجابة عن السؤال السابق تم فحص نتائج الفرضية الأولى · }
$$

$$
\text { تنص الفرضية الأولى على ما يلي: }
$$

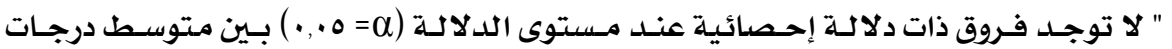

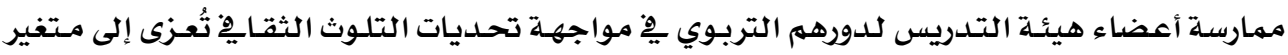
الكلية (إنسانية، تطبيقية).

ا - نتائج الفرض الأول ومناقشتها : "وللتحقق من صدق هذه الفرضية تم استخدام اختبار تحليل التبـاين الأحسادي لمعرفة دلادلة

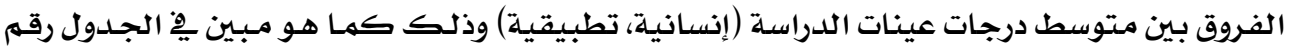

$$
\text { الفرض الأول: (إنسانية- تطبيقية) }
$$

\begin{tabular}{|c|c|c|c|c|c|c|}
\hline مستوى الدلالة & قيمة ف & متوسط المربعات & درجات الحرية & مجموع المربعات & مصدر التباين & المجال \\
\hline \multirow{3}{*}{$* *$} & \multirow{3}{*}{$r \leqslant,\{v 0$} & rava, I7r & $r$ & 090,rrY & بين المجموعات & \multirow{3}{*}{ الأول المجال } \\
\hline & & $|r|, v \leqslant 0$ & 109 & 19rov, 578 & داخل المجمهوعات & \\
\hline & & & 171 & roriz, va. & المجموع & \\
\hline \multirow{3}{*}{$* *$} & \multirow{3}{*}{ YE, raq } & Orrr,IAY & r & 1,777,rrr & بين المجموعات & \multirow{3}{*}{ الاثاني المجال } \\
\hline & & rIA, TIr & 109 & rะv०q,011 & |داخل المجموعات | & \\
\hline & & & 171 & 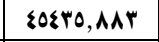 & المجموع & \\
\hline \multirow{3}{*}{$* *$} & \multirow{3}{*}{ rr,IT. } & ravr, $\{\leqslant 9$ & $r$ & V9รบ, А97 & بين المجموعات & \multirow{3}{*}{ الثالث المجال } \\
\hline & & |vi,va. & 109 & FrYIE, ITE & داخل المجموعات & \\
\hline & & & 171 & roral,orl & المجموع & \\
\hline \multirow{3}{*}{$* *$} & \multirow{3}{*}{$v, \cdot \bullet$} & $1779,1 \mathrm{rr}$ & $r$ & rrrA, rミo & بين المجموعات & \multirow{3}{*}{ الرابع المجال } \\
\hline & & rrA, $\{\$ 0$ & 109 & rvalr,vq7 & |داخل المجموعات | & \\
\hline & & & 171 & s1rol,III & المجهوع & \\
\hline \multirow{3}{*}{$* *$} & \multirow{3}{*}{ rr, IEO } & or.sV, IVY & r & $1 \cdot \xi \cdot 90, r \leqslant 0$ & بين المجموعات & \multirow[t]{3}{*}{ اللدرجة الكلية } \\
\hline & & $r r o \cdot, r \cdot r$ & 109 & rrrqaA, vq. & داخل المجموعات & \\
\hline & & & 171 & Errvar,1.0 & المجموع & \\
\hline
\end{tabular}

جدول رقم (11) يبين نتائج تحليل التباين الأُحادي لمعرفة دلالة الفروق بين متوسط درجات عينات الدراسة 
يتضـح من الجدول السـابق أن قيم (ف) على الأبعاد الأريعـة والدرجـة الكليـة كانت دالـة عنـــ

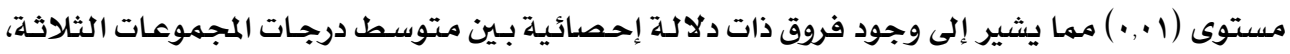

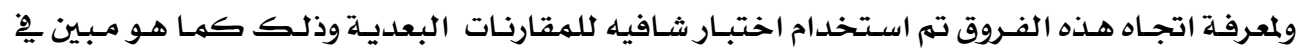

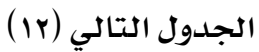

\begin{tabular}{|c|c|c|c|c|}
\hline المتوسط & العدد & الكلية & & \\
\hline $71, \wedge 9 \&$ & or & $r$ & التطبيقية العملية & \multirow[t]{2}{*}{ المجال الديني } \\
\hline$* * *_{Y},+\varepsilon 1$ & $r r$ & $r$ & الإنسانية & \\
\hline $90, r \times 1$ & or & $r$ & التطبيقية العملية & \multirow[t]{2}{*}{ rا المجال الاجتماعي } \\
\hline$* *_{\Lambda 1, \bullet \wedge r}$ & Vr & $r$ & الإنسانية & \\
\hline 70,807 & or & $r$ & التطبيقية العملية & \multirow[t]{2}{*}{ ب المجال التربوي } \\
\hline$* * v q, r 19$ & $r r$ & $r$ & الأدبية & \\
\hline$V \cdot, \cdot 1 v$ & or & $r$ & التطبيقية العملية & \multirow{2}{*}{ ع المجال العلمي } \\
\hline$* *_{\text {VY }}, \mathrm{YIA}$ & vr & $r$ & الإنسانية & \\
\hline Mar,IE. & or & $r$ & \multirow[t]{2}{*}{ الدرجة الكلية } & \\
\hline **r| & vr & r & & \\
\hline
\end{tabular}

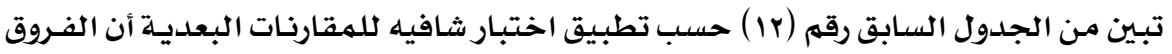

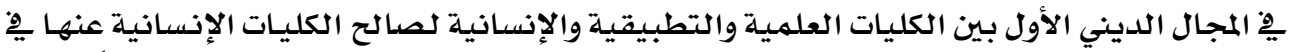

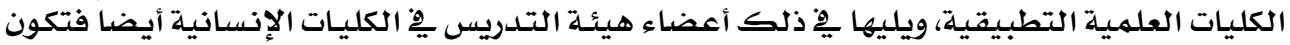

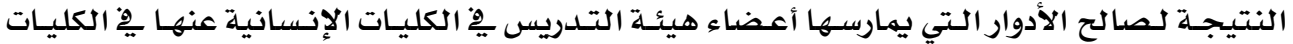

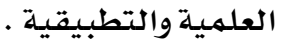

وكذلك الحال ِِ المجال الاجتماعي والمجال التربوي .

$$
\text { مناقشة نتائج الفرض الأول: }
$$

ويعزو الباحث نتائج الفرض الأول إلى ما يلي :

عند دراسة نتائج المعالجة الإحصائية للبعد الأول حسب متفير الكليـة (إنسانية - تطبيقيـة)

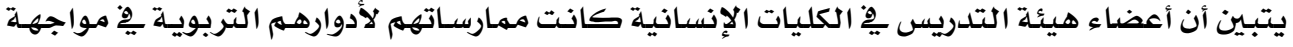

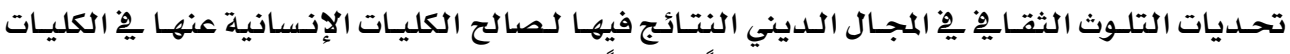

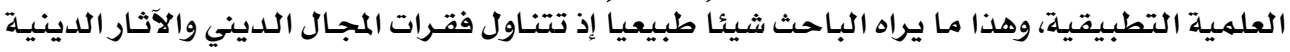

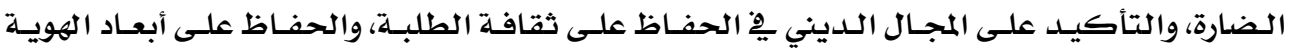

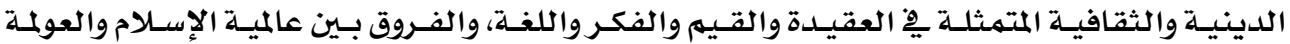


الغربية، ومظاهر التلوث الثقايِ المرافق لموجة العولمة، وترسيخ العموميـات الثقافيـة مثل الدين واللغـة

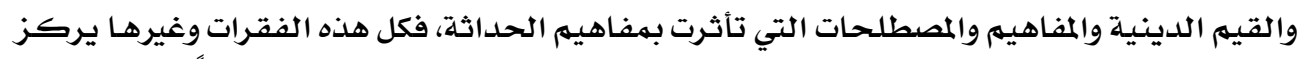

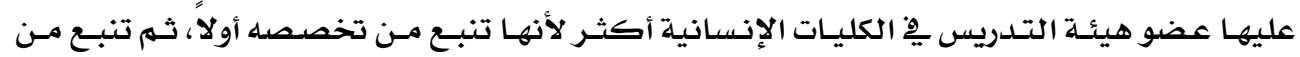

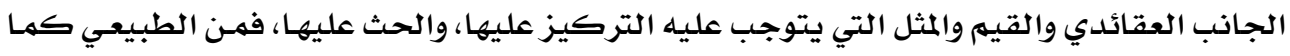

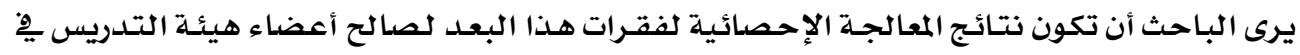

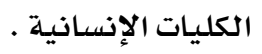

يتضح من خلال الجدولين السابقين أن المجال الثاني (التحديات الاجتماعية للتلوث الثقايِّ)

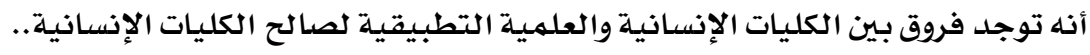

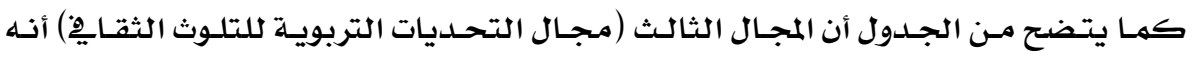

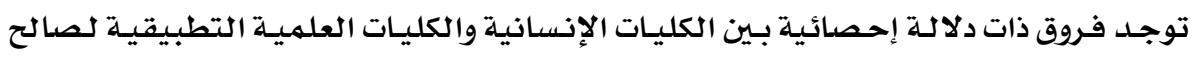
الكليات الإنسانية.

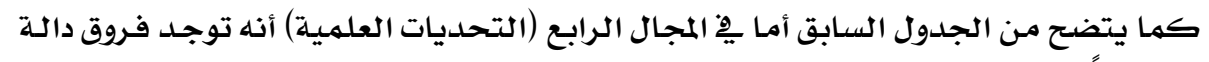

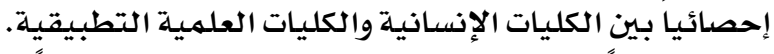

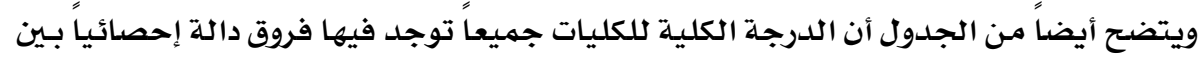

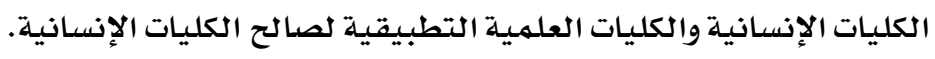

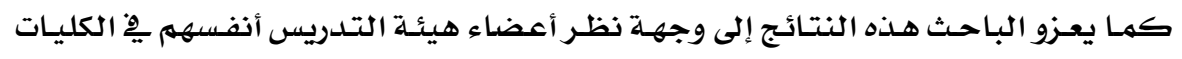

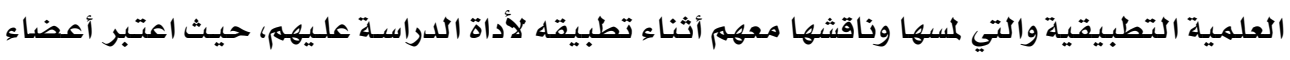

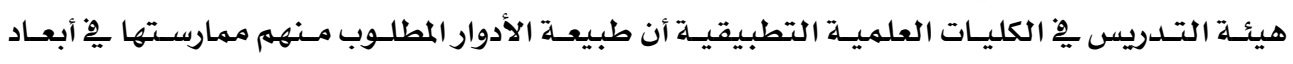

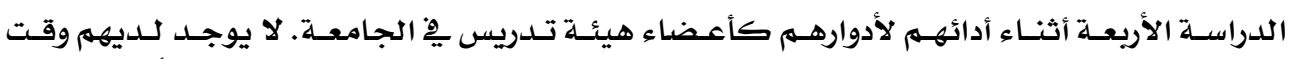

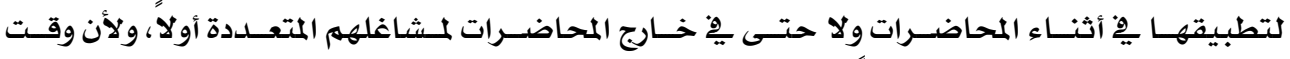

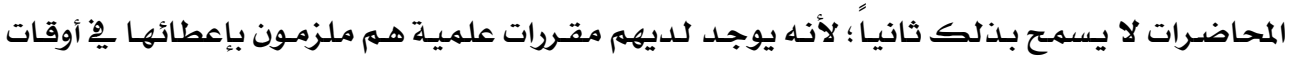

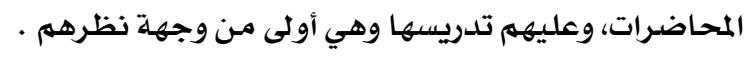

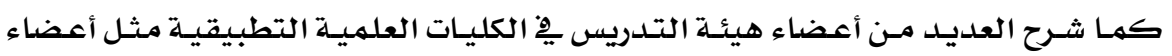

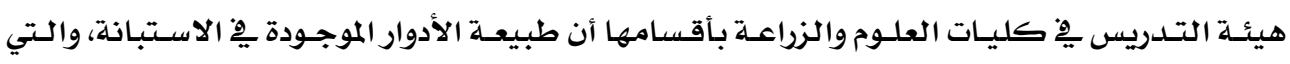

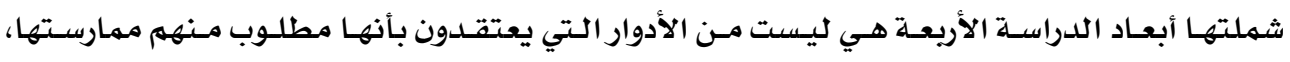

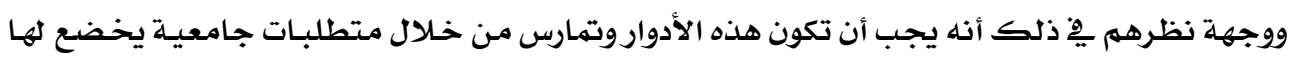

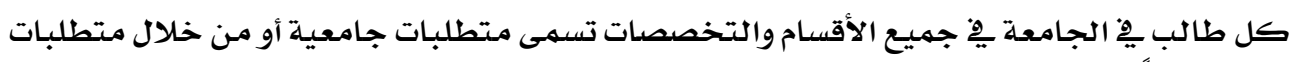
الكلية أيضاً.

وهذه وجهة نظر ريما لاقت القبول لدي ولكن ليس لدرجـة الاقتنـاع الكامـل بوجهـة نظرهم؟؛

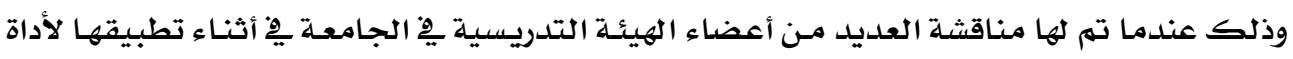

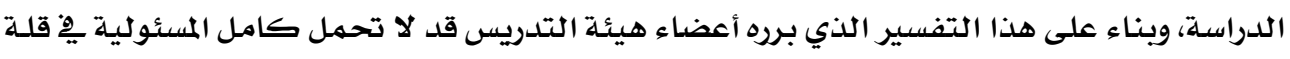

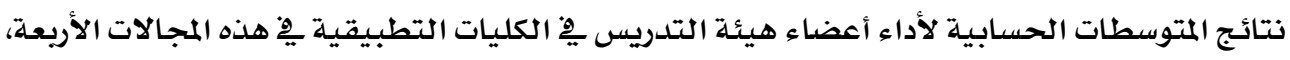




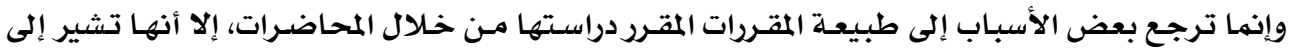

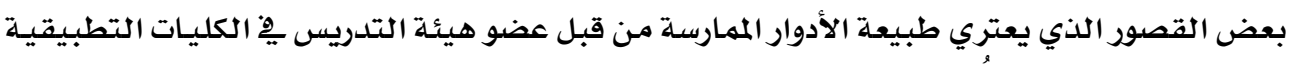

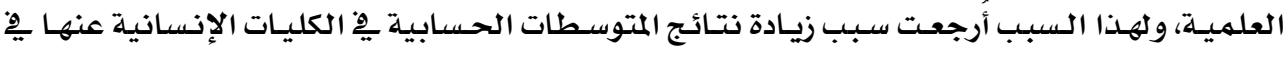

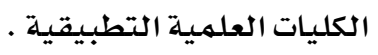

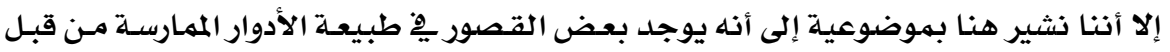

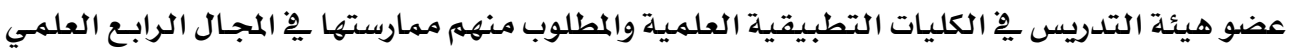

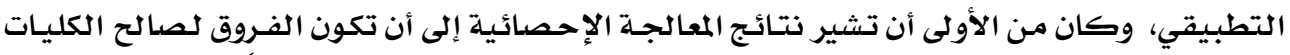

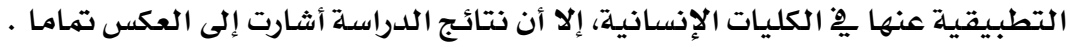

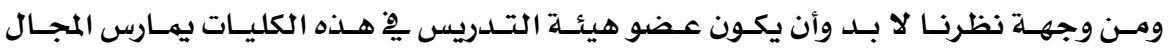

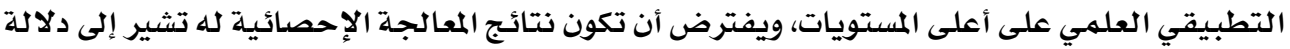

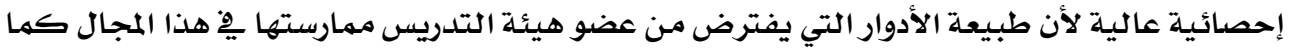

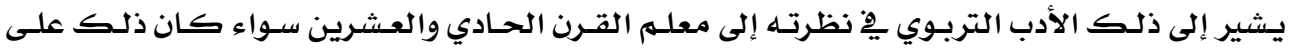

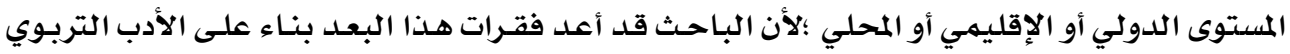

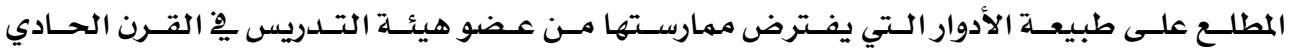

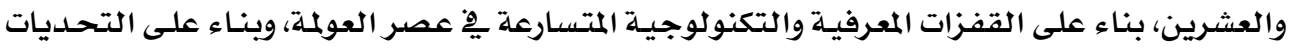

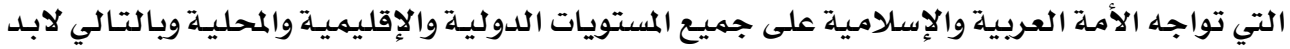

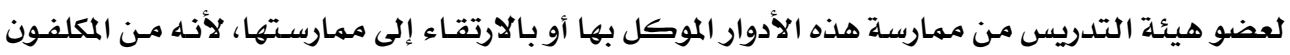

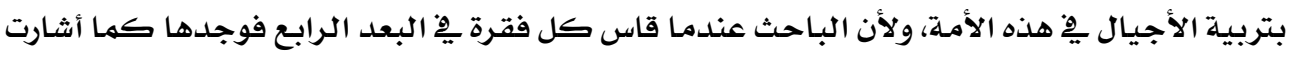

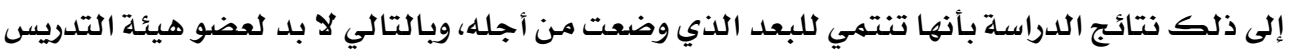

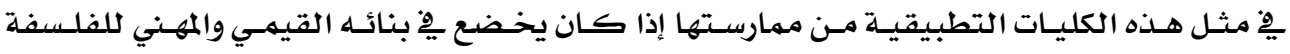

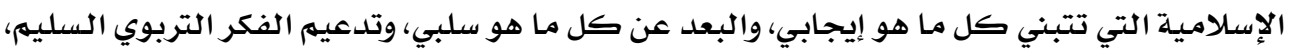

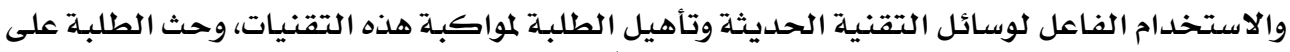

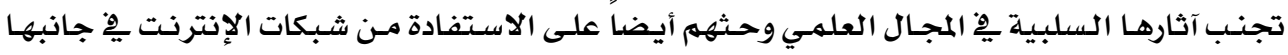

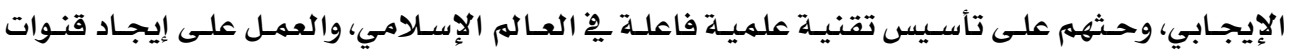

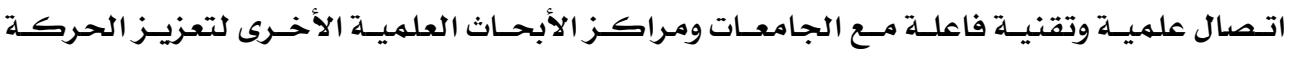

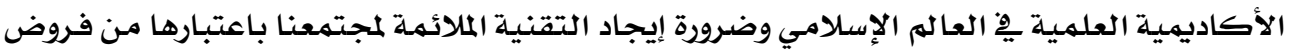

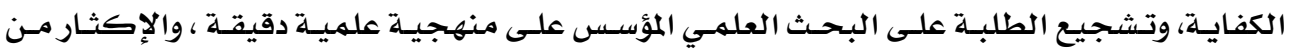

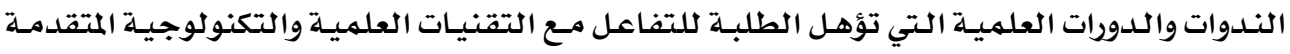

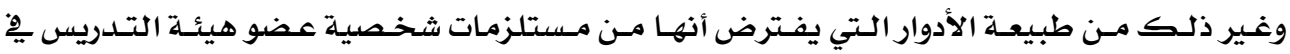

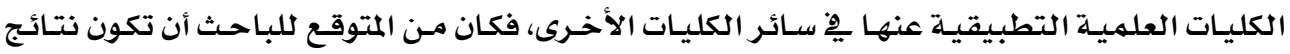

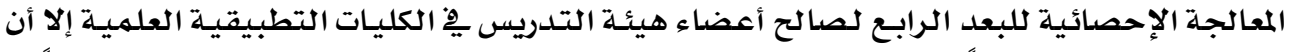

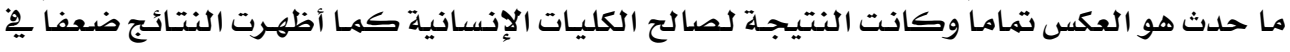

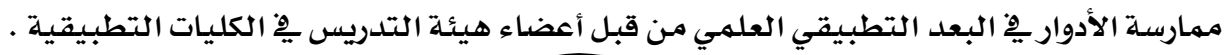




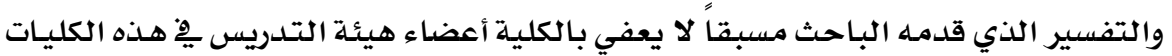

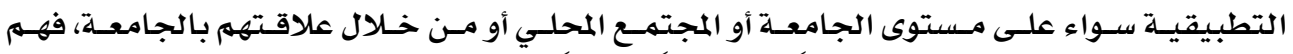

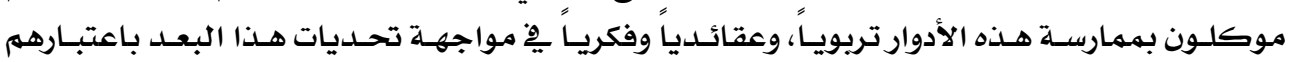

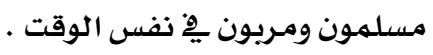

$$
\text { ويرجع الباحث تفسير ذلك إلى ما يلي : ألى }
$$

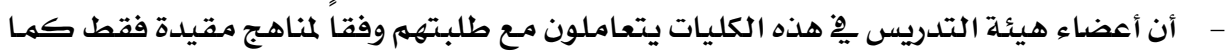

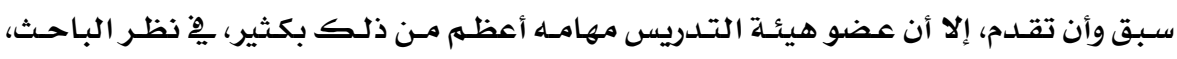

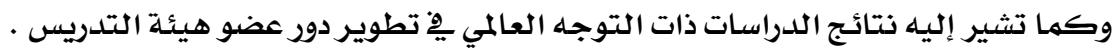

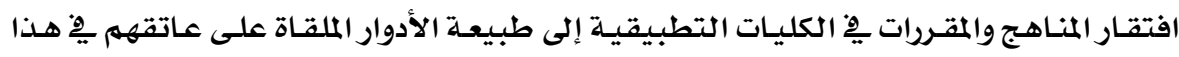

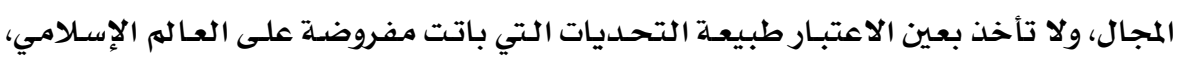

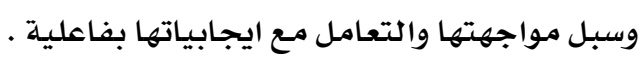

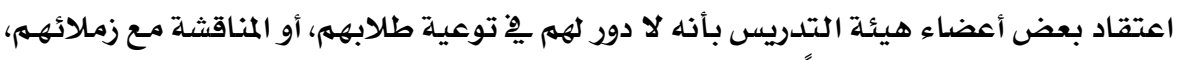

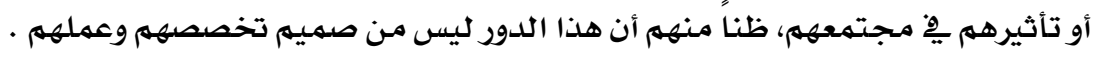

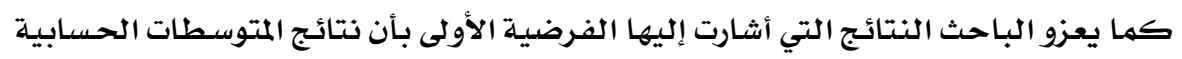

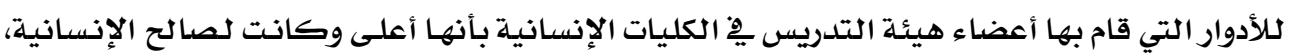

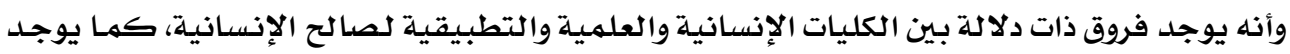

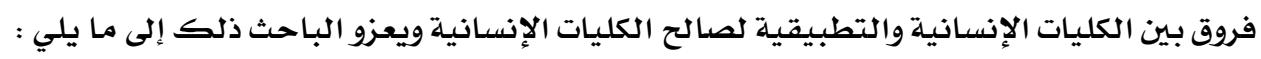

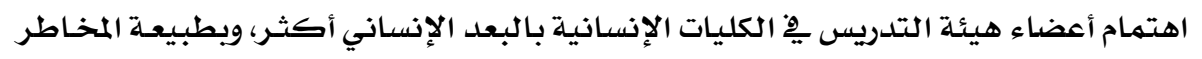

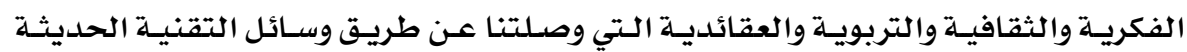

$$
\text { أكثر أنفر }
$$

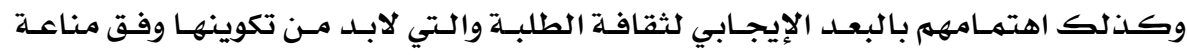

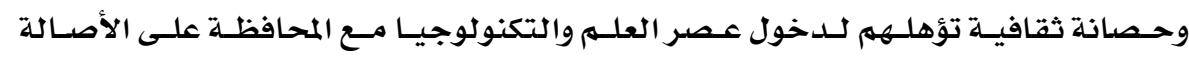

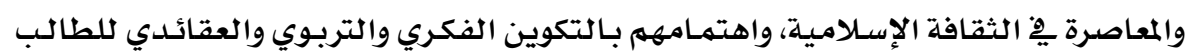

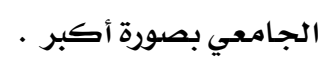

حرص أعضاء هيئة التدريس يِّ هذه الكليات على غريلة الوافد من المناهج والأفكاروالمفاهيه،

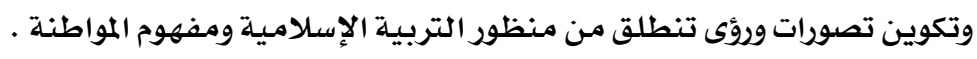

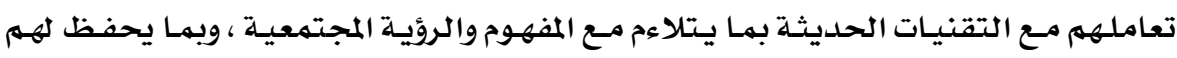

$$
\text { ولطلبتهم هويتهم الدينية. }
$$

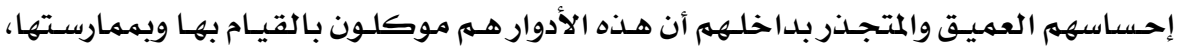

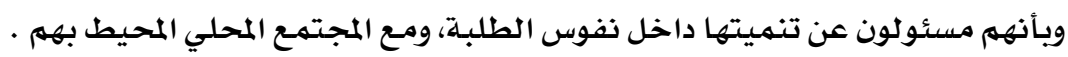




$$
\text { وينص الفرض الثاني على ما يلي: }
$$

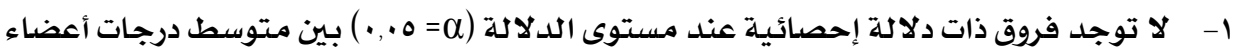

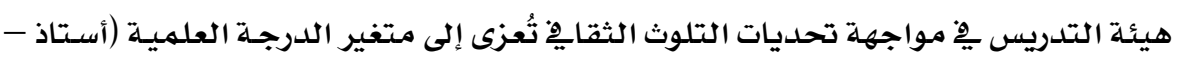

$$
\text { أستاذ مساعد - مدرس). }
$$

وللتحقق من صحة هذه الفرضية تم استخدام تحليل التباين الأحسادي ANOVA ONE

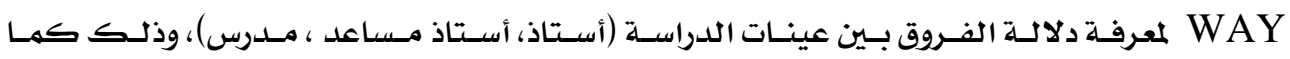

يوضحها جدول رقم (Ir)

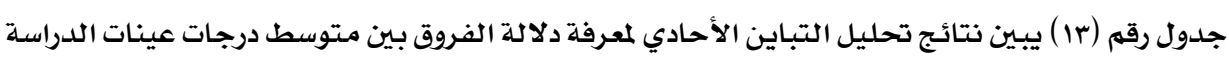

\begin{tabular}{|c|c|c|c|c|c|c|}
\hline مستوى الدلالة & قيمة ف & متوسط المربعات & درجات الحرية & مجموع المربعات & مصلدر التباين & المجال \\
\hline \multirow{3}{*}{ غير دالة } & \multirow{3}{*}{ 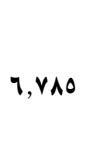 } & $990, r \leqslant 0$ & $r$ & $199 \cdot, 791$ & بين المجهوعات & \multirow[t]{3}{*}{ الأول } \\
\hline & & $1 \leqslant 7, v \cdot 0$ & 109 & rrrry,1.. & داخل المجموعات & \\
\hline & & & 171 & rorly, va. & المجموع & \\
\hline \multirow{3}{*}{ غير دالة } & \multirow{3}{*}{$0, \cdot 7 r$} & 1 Iroq, $9 \leqslant 4$ & $r$ & rVIa, A10 & بيز المجموعات & \multirow[t]{3}{*}{ الثاني } \\
\hline & & ryA,091 & 109 & $8 Y r \cdot 0,991$ & داخل المجموعات & \\
\hline & & & 171 & SOSYO, AAY & المجموع & \\
\hline \multirow{3}{*}{ غير دالة } & \multirow{3}{*}{$7, \cdot$ vo } & $\mid$ rol, r|. & $r$ & ro.r,sr. & بين المجموعات & \multirow[t]{3}{*}{ الثاث } \\
\hline & & $r \cdot q, \cdot r q$ & 109 & rrron,III & داخل المجموعات & \\
\hline & & & 171 & rormi,orl & المجموع & \\
\hline \multirow{3}{*}{ غير دالة } & \multirow{3}{*}{$r, 0 \leqslant 9$} & $7 \varepsilon \cdot$, Als & $r$ & IrAI, Irr & بيز المجموعات & \multirow[t]{3}{*}{ الرابع } \\
\hline & & rol, rA. & 109 & P9979,\$A\& & داخل المجموعات & \\
\hline & & & 171 & \&1YOI,II & المجموع & \\
\hline \multirow{3}{*}{ غير دالة } & \multirow{3}{*}{$\cdot, \cdot$ Vo } & YrY, 910 & $r$ & $700, \wedge r q$ & بيز المجموعات & \multirow{3}{*}{ اللدرجة } \\
\hline & & 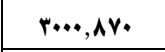 & 109 & SYrIrA, rry & داخل المجموعات & \\
\hline & & & 171 & కVVVA\&, 1.0 & المجهوع & \\
\hline
\end{tabular}

وفق متغير الدرجة العلميلة (أستاذ، أستاذ مسـاعد ، مدرس) يِّ كل بعد من أبعاد الدراسة

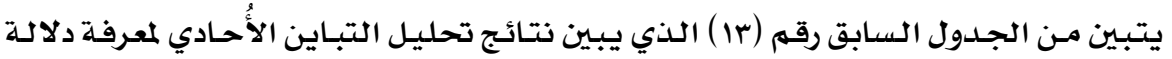

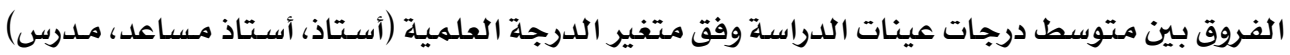

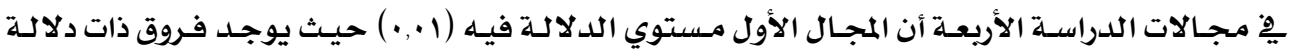

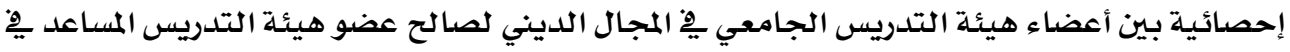

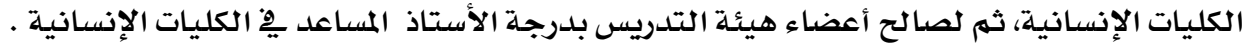




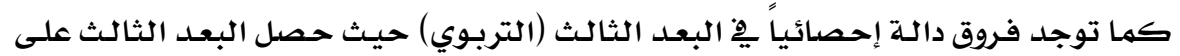

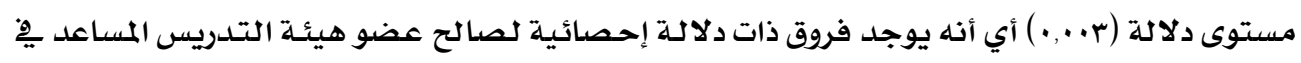

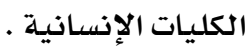

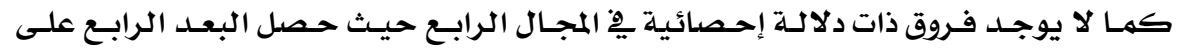

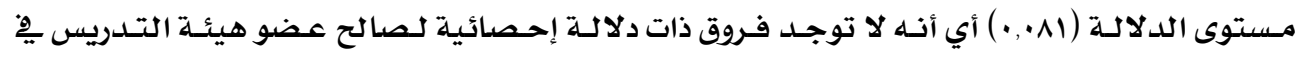

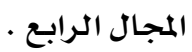

جدول (\{ ا ) يبين اختيار شافيه لمعرفة اتجاه الفروق

\begin{tabular}{|c|c|c|}
\hline المتوسط & العدد & المتفير \\
\hline rar, rAo & r & أستاذ \\
\hline rIr,rrr & V₹ & أستاذ مساعد \\
\hline rAY,rIr & IV & مدرس \\
\hline
\end{tabular}

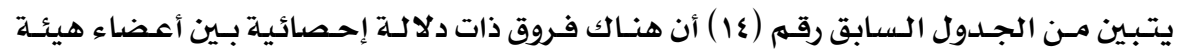

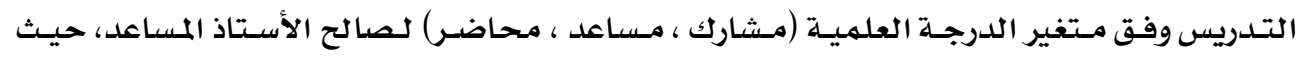

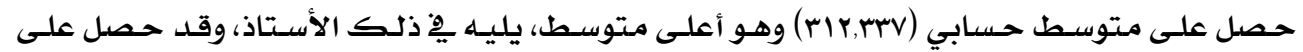

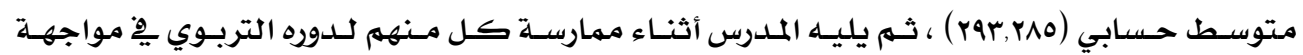

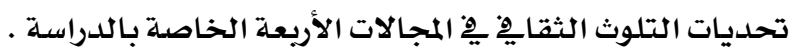

$$
\text { ويعزو الباحث ذلك إلى ما يلي : }
$$

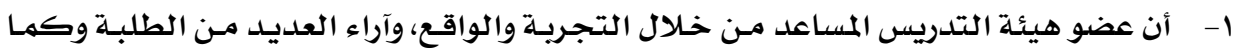

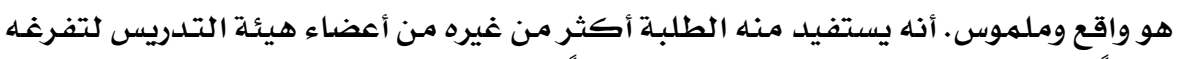

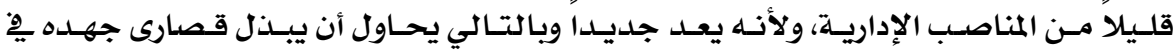

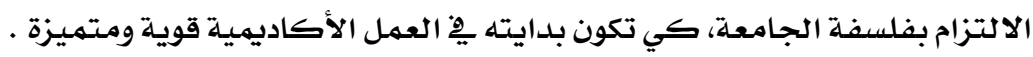

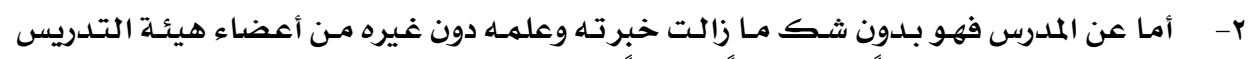

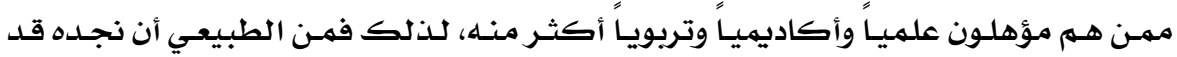

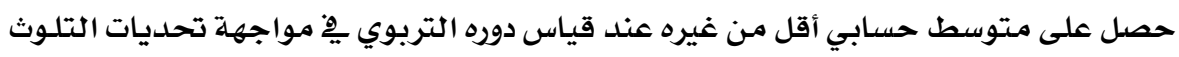

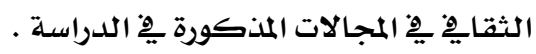

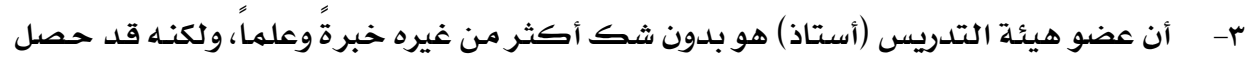

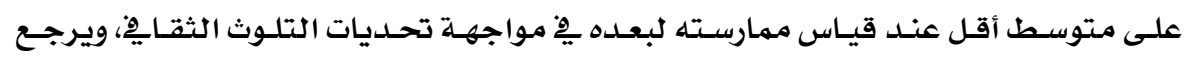

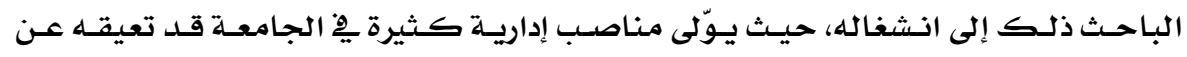

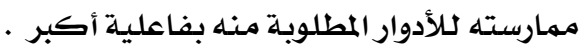




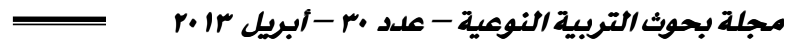

رابعاً:- عرض نتائج السؤال السادس (سبل تطوير الدور التربوي لعضو هيئة التـدريس مـن وجهة نظرهم).

للإجـابـة عـن السؤال السـادس ونـصده "مـا سـبل تفعيـل وتطـوير الـدور التربـوي لعـضو هيئسة

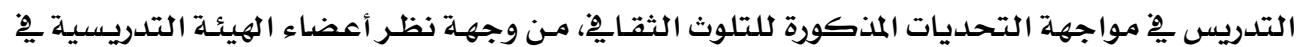

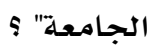

اعتمد الباحث على ما يلي :

ا- التصور المقترح لتطوير هذا الدور من وجهة نظر أعضاء الهيئة التدريسية من خلال إجابتهم

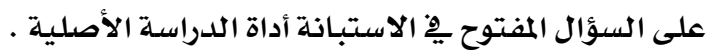

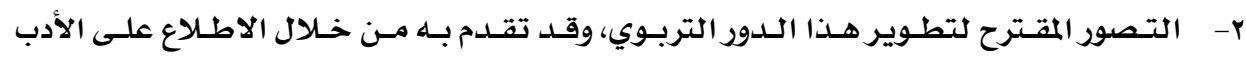

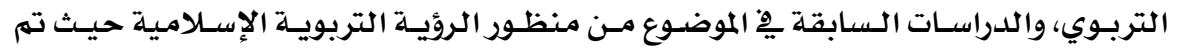

التوصل إلى عدد من النتائج وبيانها فيما يلي:

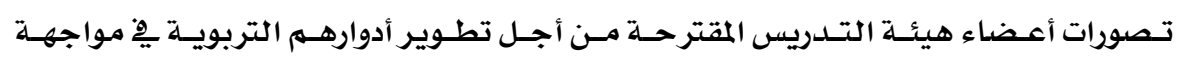

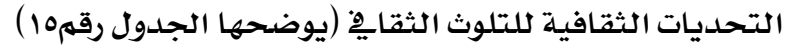




\begin{tabular}{|c|c|c|}
\hline المئوية النسبة & التصورات المقترحة لتطوير الدور التربوي لعضو هيئة التدريس الجامعي في مواجهة التحديات الدينية للتلوث الثقافي من وجهة نظرهم & P \\
\hline $17, \cdot \varepsilon$ & | تعميق الوعي للدى أعضاء هيئة التدريس بتحديات التلوث الثقافي في المجال الديني من خلال عقد المؤتمرات والأيام الدراسية وورش العمل الخاصة & 1 \\
\hline $1 \&, 19$ & 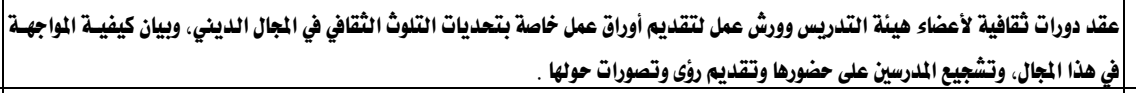 & r \\
\hline$r \xi, \bullet r$ & 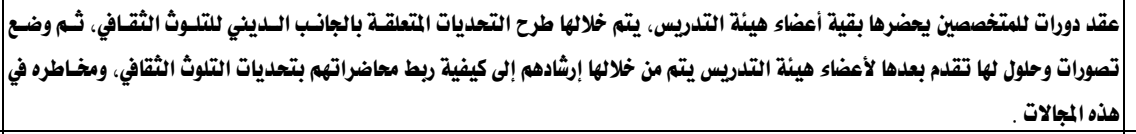 & $r$ \\
\hline $1 \xi, \cdot 9$ & | متابعة آثار وانعكاسات التلوث الثقافي على العالمين العربي والإسلامي، وإلقاء الضوء على أهم وسائل التلوث الثقافي في فـرض هيمنتها على العـاثم، & $\varepsilon$ \\
\hline $1 \&, 19$ & | إصدار نشرات دورية ونصف سنوية خاصة بالموضوع تكثف عن خطورة التلوث الثقافي في هذا المجال، على أن يتم تفعيلها وتوزيعها داخل الجامعـة & 0 \\
\hline $7,1 v$ & 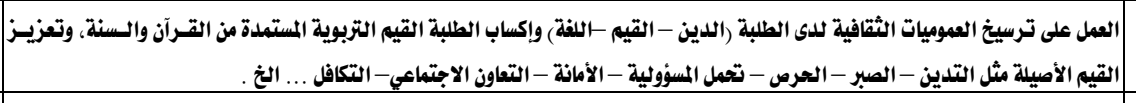 & 1 \\
\hline $9, \wedge \vee$ & | تفعيل المؤسسات التعليمية والتربوية في بث الوعي عن قضية التلوث الثقافي ومخاطره على الخصوصيات الدينية للمجتمعات الإسلامية . & $\checkmark$ \\
\hline $10, \xi \%$ & 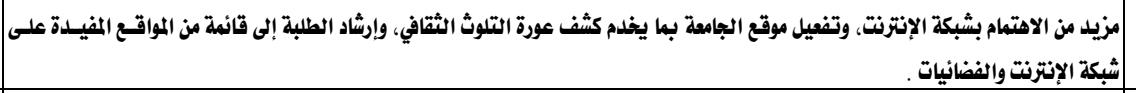 & $\wedge$ \\
\hline$\checkmark, \xi \cdot$ & | تشجيع عضو هيئة التدريس على دراسة مجموعة المهارات العلمية والتقنية والتكنولوجية التي تساعده على فهم المكونات الثقافية لدى الآخرين. & 9 \\
\hline $11, r r$ & 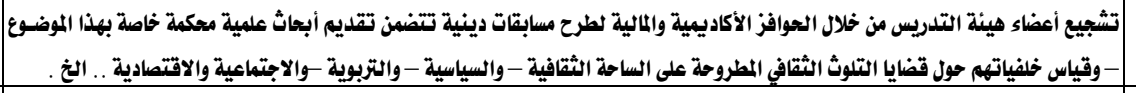 & 1. \\
\hline$\wedge, 1 \varepsilon$ & | استخدام منابر المساجد للدعوة إلى الإسلام عبادةً وسلوكاً لإكساب الأجيال حصانة ومناعة ثقافية تقيهم من تحديات التلوث الثقافي في المجال الديني & 11 \\
\hline$\Lambda, \cdot r$ & | مثقفين عدة من الجامعات يشار منتديات ثقافية وفكرية طلابية ورعايتها من قبل النخب (أعضاء هيئة التدريس في الجامعات) تهتم بالمجالات الدينية، تستضيف & ir \\
\hline $7,1 v$ & 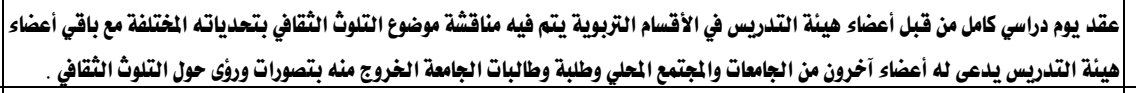 & ir \\
\hline$r, \mathrm{r}$. & | إقامة أندية وجمعيات مناهضة للتلوث الثقافي يتبنى فكرة وهدف الدفاع والنقد والتمحيص لكل ما يتصل بالموضوع . & $1 \varepsilon$ \\
\hline$r, \bullet \wedge$ & | تنظيه مؤتتر في الجامعة لبحث أثر التلوث الثقافي وانعكاساته على المجتمع. & 10 \\
\hline$\varepsilon, \pi$ & 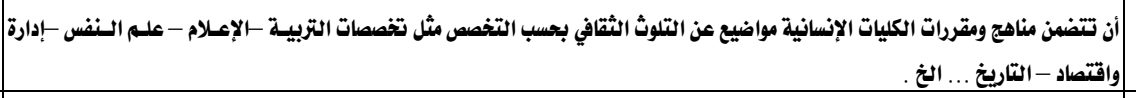 & 17 \\
\hline$\varepsilon, r r$ & |حث الطلبة على كتابة وعمل أبحاث تخرج تتعلق بموضوع التلوث الثقافي وانعكاساته أو سلبياتها في مجال تخصص الطالب & iv \\
\hline $\mathrm{v}, \xi \cdot$ & 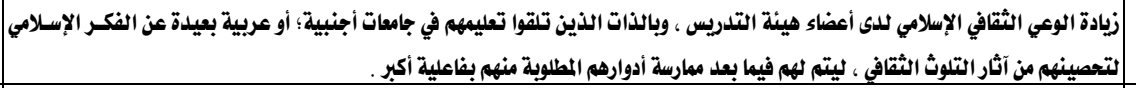 & in \\
\hline$r, \$ 7$ & لتشجيع المدرسين والطلاب على نقد التلوث الثقافي من خلال الكتابة في الصحف المجتمعية المختلفة. & 19 \\
\hline 1,10 & 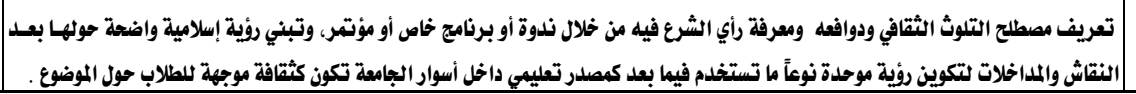 & r. \\
\hline
\end{tabular}


يتبـين لنا من خلال الجدول رقم (10) أن أكثر الفقـرات التي تتضمن تصورات أعضاء هئسئة

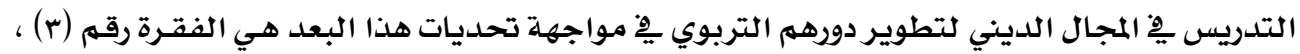

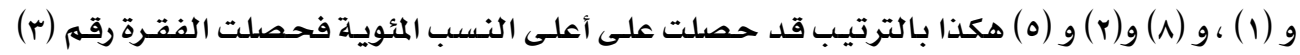

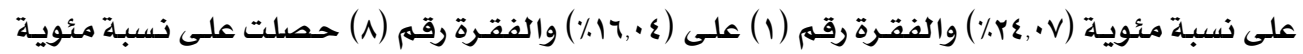

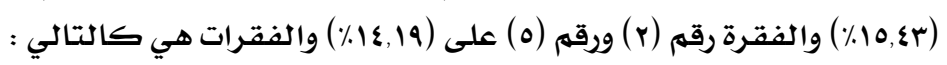

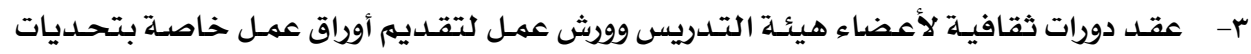

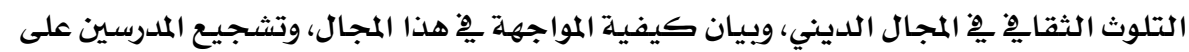

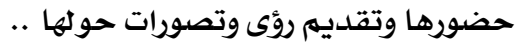

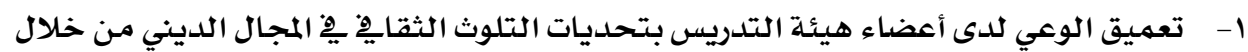

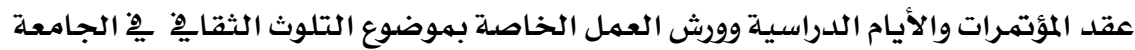

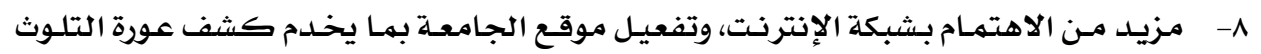

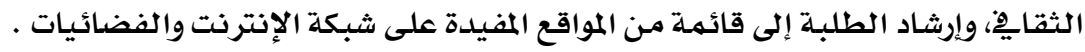

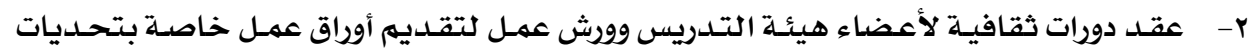

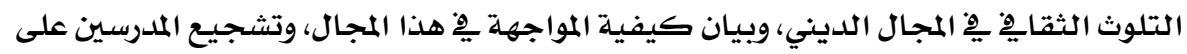

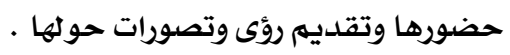

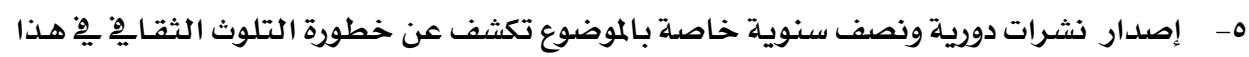

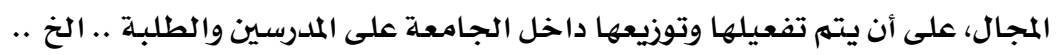

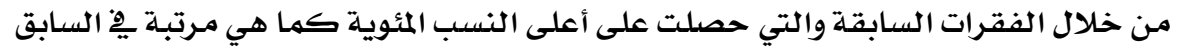

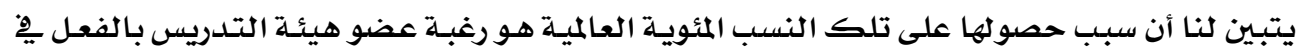

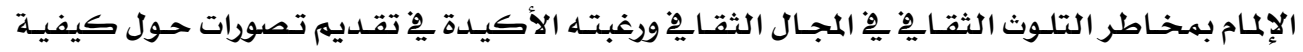
مواجهتها تساعده على ممارسة دوره ِِّ هذا المجال بفاعلية أكبر . 
ب- تصورات أعضاء هيئة التدريس المقترحة من أجل تطوير أدوارهم التربوية ِِّ مواجهة التحديات

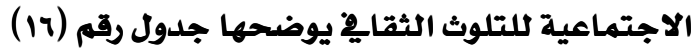

جدول (17) يوضـح تصورات أعضاء هيئة التدريس ِِّ مجال التحديات الاجتماعية للتلوث الثقايِّ من وجهة نظرهم

\begin{tabular}{|c|c|c|}
\hline 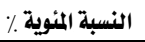 & التصورات المقترحة لتطوير الدور التربوي لعضو هيئة التدريس الجامعي في مواجهة التحديات الاجتماعية للتلوث الثقافي من وجهة نظرهم & A \\
\hline rI, १. & 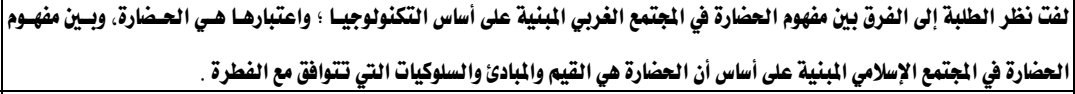 & \\
\hline rr,Ar & |الاجتماعي والتنمية الاجتماعية . النظام الاجتماعي الإسلامي من خلال مقررات دراسية معينة ودوره في حفظ الشخصية من الوقوع في فخ التبعية، وإشـاعة العـل & $r$ \\
\hline $10,8 \%$ & |تنبيه الطلبة إلى مخاطر التلوث الثقافي من خلال الندوات والمحاضرات التي تحاول فرض نهط ثقافي اجتماعي واحد. & $r$ \\
\hline$\Lambda, \cdot r$ & |تفعيل دور الجامعة مع المجتمع المحلي خارج الجامعة بإنشاء أعضاء هيئات التدريس في الجامعات لجمعيات خيرية توضح أساليب التلوث الثقافي & $\xi$ \\
\hline $1 \cdot, \S 9$ & |لفت نظر الطلبة إلى محاولات التلوث الثقافي في المجال الاجتماعي القضاء على جميع الخصوصيات المجتمعية والدينية والقومية . & 0 \\
\hline 9, ro & | والأبحاث والتقارير والنشرات التاليب التلوث الثقافي في الوصول إلى أهدافها في المجتمعات الإسلامية، والكشف عز هذه الوسائل والأساليب؛ من خـلال المؤتمرات & 1 \\
\hline$\xi, r r$ & |اندماج عضو هيئة التدريس مع الواقع الاجتماعي، والاختلاط بالناس للتعرف على مشكلاتهم المعاصرة . & $\mathrm{v}$ \\
\hline $7,1 v$ & 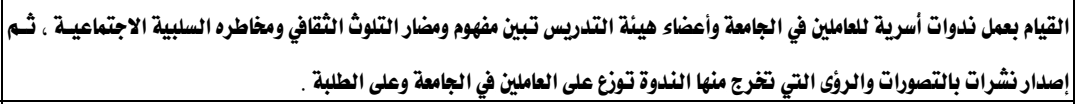 & $\wedge$ \\
\hline$\varepsilon, q$ & التنسيق بين الجامعة والمؤسسة الإعلامية في طرح الآثار السلبية المترتبة على التلوث الثقافي الاجتماعية . & 4 \\
\hline$\xi, r r$ & | التحذير من خطر المؤسسات المدعومة غربياً والتي تعمل وفقاً للأجندة الفربية . & 1. \\
\hline $7,1 \mathrm{r}$ & التعاون بين الجامعة والجامعات الأخرى على توجيه منظمات ومؤسسات حقوق الإنسان والمؤسسات النسوية بما يتلاءم مع الرؤية الإسلامية . & 111 \\
\hline 11,11 & | ضرورة زيادة الوعي الديني للعلاقات الاجتماعية في الإسلام وبمفهوم العولة الاجتماعية لدى أعضاء هيئة التدريس من أجل تببني أدوارهـم & ir \\
\hline $1 r, \Delta \lambda$ & |حث الطلبة وأعضاء هيئة التدريس على عمل أبحاث ودراسات لتحديد ملى التأثيرات الاجتماعية للتلوث الثقافي على الطلبـة ، والتقويم & ir \\
\hline 0,00 & |التبشير عبر أجهزة الاتصال الحديثة بالنمط الاجتماعي الإسلامي، وبث القيه الإسلامية الصحيحة من خلالها . & $1 \varepsilon$ \\
\hline $\mathrm{v}, \xi \cdot$ & 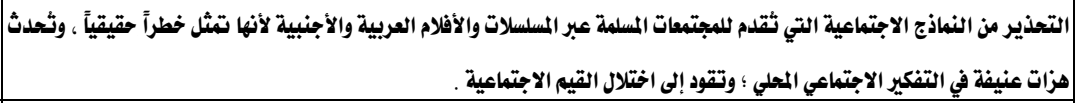 & 10 \\
\hline $\mathrm{v}, \xi \cdot$ & الطلبة . التكيد على التمسك بالشريعة الإسلامية والتراث الروحي للأمة المسلمة وذلك بغرس القيه والمفاهيه والعادات الإسلامية السليمة في نفوس & 17 \\
\hline $7, \times 9$ & تنمية شخصية الطالب الاجتماعية بأبعادها المختلفة ؛ باعتبارها هدقاً تعليمياً هاماً ، وتزكية نفوس الطلبة وتربيتهم على روح الإيثار لغيرهم & iv \\
\hline
\end{tabular}


يتبـين لنـا مـن خـلال الجـدول رقـم (17) السذي يوضـح لنـا التصورات المقترحسة لأعضاء هيئسة

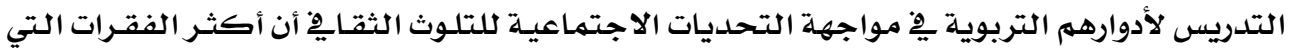

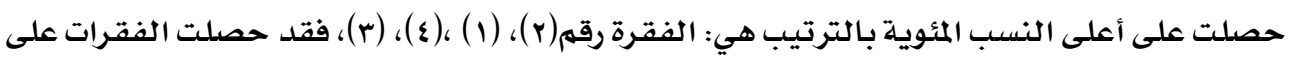

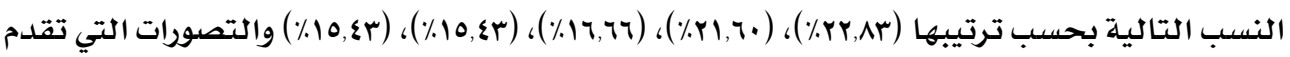

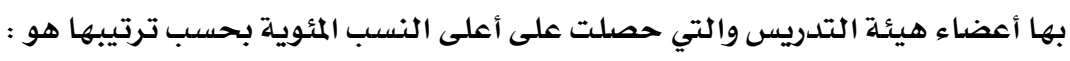

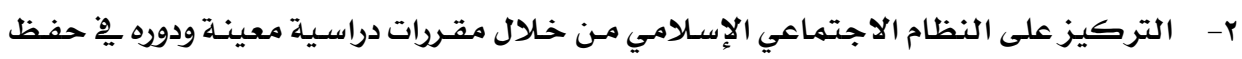

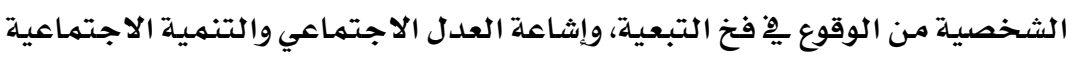

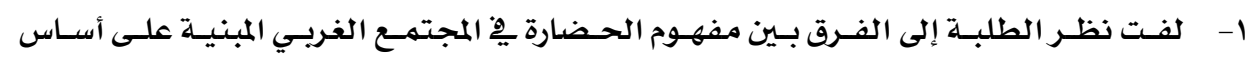

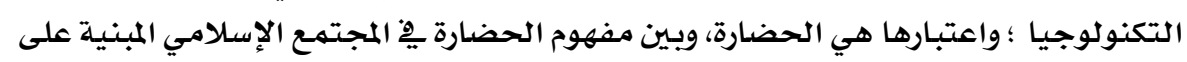

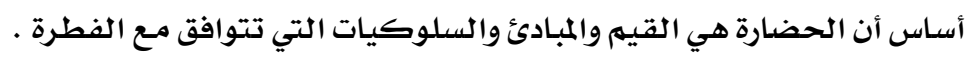

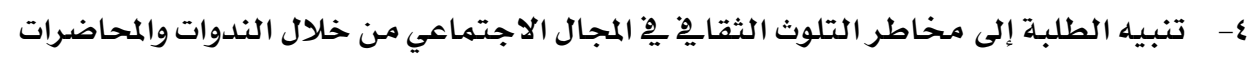
التي تحاول فرض نمط ثقايِّ اجتماعي واحدل .

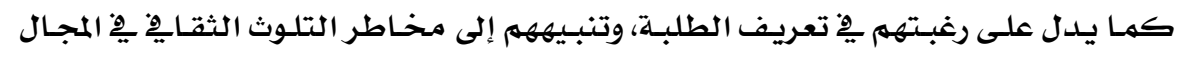

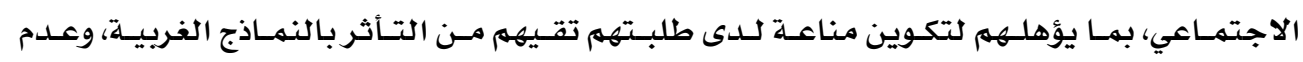

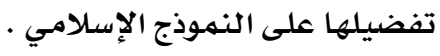


ج- تصورات أعضاء هيئة التدريس المقترحة من وجهة نظرهم من أجل تطوير أدوارهم التربويـة ـِ

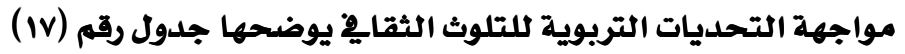

جدول رقم (VV) يوضح تصورات أعضاء هيئة التدريس يِّ مجال التحديات التربوية للتلوث الثقايِ من وجهة نظرهم

\begin{tabular}{|c|c|c|}
\hline 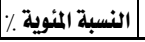 & التصورات المقترحة لتطوير الدور التربوي لعضو هيئة التدريس الجامعي في مواجهة التحديات التربوية للتوث الثقافي من وجهة نظرهم & P \\
\hline rq,o६ & إلتابعة الطلبة والمدرسين للندوات والمؤتترات التربوية لمواكبة كل جديد في الميلان التربوي . & 1 \\
\hline $1 \%, 01$ & |حث الطلبة على قراءة الإتتاج العلمي للمفكرين المهتمين بالتأصيل الإسلامي للعلوم التربوية . & $r$ \\
\hline$r \xi, \bullet r$ & |رصلد أعضاء هيئة التدريس للآثار التربوية السلبية المحلية الناتجة عن موجة التلوث الثقافي & $r$ \\
\hline $1 \cdot, \S 9$ & | مناقشة الطلبة في مظاهر اغتراب المنهاج التعليمي الجامعي على الأسس التربوية الأصلية . & $\xi$ \\
\hline ri, rr & |متابعة الطلبة والمدرسين لنتائج الأبحاث التربوية المعاصرة الأصيلة والمحكمة . & 0 \\
\hline$r \cdot, r v$ & | تقديم اقتراحات من قبل أعضاء هيئة التدريس تساهم في تبادل الخبرات التربوية بين الجامعات المحلية والإقليمية والعالية . & 7 \\
\hline $1 \cdot, \S 9$ & |الباليحث عن عوامل ضعف المؤسسات التربوية والتعليمية المحلية من خلال أبحاث هادفة، وإيجاد سبل لتطويرها، بحيث تواكب المؤسسات التربوية & v \\
\hline 17,01 & ضرورة استفادة التربية الإسلامية من أحلث الوسائل التعليمية، والأساليب التدريسية ومناقشة الشككلات التي تواجه النظام التربوي للدينا . & $\wedge$ \\
\hline$|\xi, \wedge|$ & | التركيز على الجانب التطبيقي في المناهج التربوية. & 9 \\
\hline$\|, r r$ & | الإنبانيه الطلبة إلى خطورة التفريب التربوي، والفزو الفكري التتمثل في تشويه علاقة الإنسان بالقضايا الكبرى التالية: الخالق - الكون - & 1. \\
\hline$\Lambda$, १६ & |إبراز أهمية المناهج التربوية التي رسخها الإسلام، والتي أثبتت صحتها عندما أخذ الفرب عن الإسلام ، والتأكيد على التراث القيمي & 11 \\
\hline 11,11 & 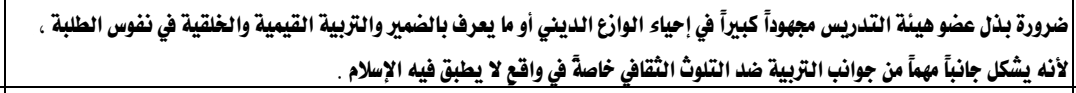 & ir \\
\hline 9, ro & |حث الجامعة لأعضاء التدريس على إجراء دراسات وبحوث أصيلة تبرز المنظور الإسلامي للتربية . & ir \\
\hline Ir, r\& & | عقد دورات متخصصة عن آثار العولمة على المجال التربوي؛ على أن يعطي هذه الدورات أساتذة متخصصون من كلية التربية . & $1 \varepsilon$ \\
\hline$\wedge, 7 \xi$ & | منهج اللّه تعالى ـ خلال المحاضرات والندوات الجامعية على دور الأسرة في التربية ، وتوعية هذه المصانع التي تخرج الجيل التربوي المطلوب وفق & 10 \\
\hline v,\&. & المحلية . التقويم الدوري المستمر لآثار الأفكار التربوية الوافدة الناتجة عن موجة التلوث الثقافي الفربي والتي باتت تحل محل المبادئ التربوية & in \\
\hline 0,00 & |الثساهمة من قبل الجامعة وأعضاء هيئة التدريس فيها في تنظيم وتفعيل الرقابة المجتمعية على التعليه ، حرصاً على تسرب مفاهيه التلوث & 19 \\
\hline $7, \mathrm{Ya}$ & |ضرورة العمل من أجل امتلاك الطلبة لآخر ما توصلت إليه التقنيات الحديثة ، وكسب مهارة استخدامها وتوجيهها لصالح البحث العلمي. & r. \\
\hline $7,1 \mathrm{~V}$ & | اطلاع أعضاء الهيئة التدريسية على أحدث وسائل التربية لدى الآخرين أو اكتساب أساليب التربية الفاعلة وطرائقها. & ri \\
\hline r,Al & |قبول الوافد إلينا من خلال التقنيات في عصر التلتئة التدريس بالفلسفة التربوية الإسلامية وأساليبها الفعالة ؛ حتى تقكنه من فهم المعايير التي على أساسها يمكن رفض أو & $r r$ \\
\hline$\Lambda, 7 \varepsilon$ & | التركيز على تعلم اللفة العربية لفة القرآن الكريم، والتحدث بها. & $r$ \\
\hline 9, ro & |تفعيل المدرسين في الكليات، بإعطائهم المعايير التربوية الصحيحة، لمواجهة التحديات المذكورة للتلوث الثقافي . & $r \varepsilon$ \\
\hline$\Lambda, \cdot r$ & | تكوين لجنة خاصة من أساتذة الجامعات تشرف على المنهاج التربوي العلمي الجامعي ، ويتم تدريس مساق حول العولمة لجميع تخصصات & ro \\
\hline
\end{tabular}




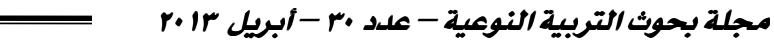

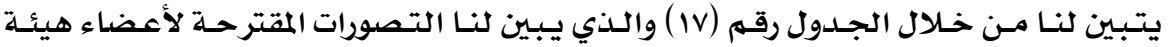

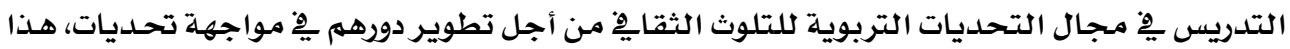

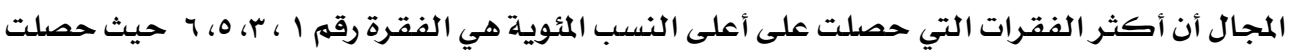

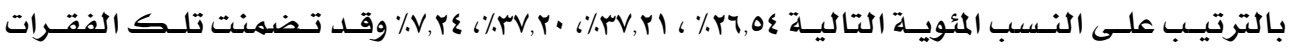

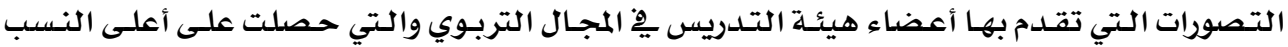

$$
\text { المئوية وهي: النهورات التئي }
$$

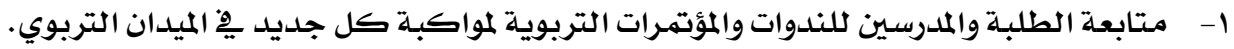

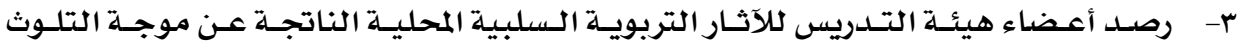
الثقايِ.

ه- متابعلة الطلبة والمدرسين لنتائج الأبحاث التربوية المحاصرة الأصيلة والمحكمة

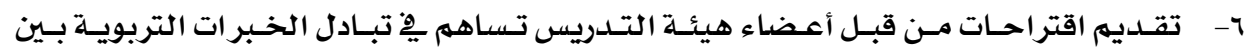

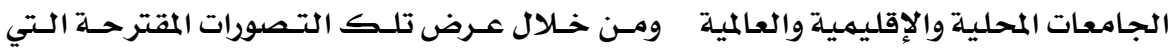

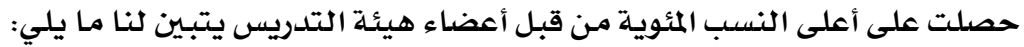

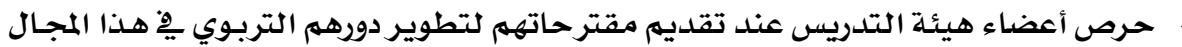

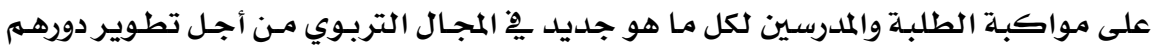

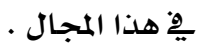
حرصهم على متابعة أيضاً نتائج الأبحاث المعاصرة لتطوير دورهم وتطوير طلبتهمه، ومتابعة المجال

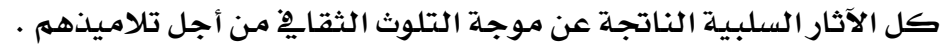

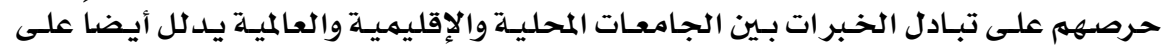

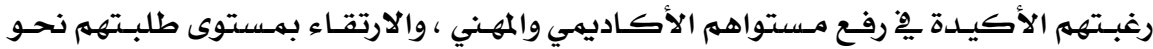
الأفضل . 


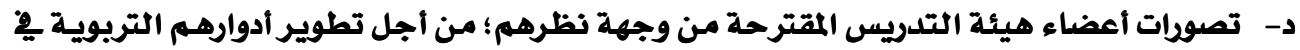

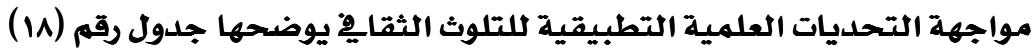

جدول رقم (1) يوضتح تصورات أعضاء هيئة التدريس ِِّ مجال التحديات العلمية للتلوث الثقايِّ من وجهة

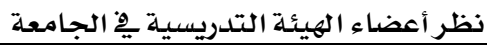

\begin{tabular}{|c|c|c|}
\hline 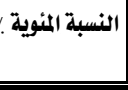 & | التصورات المقترحة لتطوير الدور التزبوي لعضو هيئة التدريس الجامعي في مواجهة التحديات التطبيقية العليمية للتوث الثقافي من وجهة & a \\
\hline r.,91 & أن يحرص أعضاء الهيئة التدريسية على الشاركة في الدورات المؤهلة للتفاعل الواعي مع وسائل الاتصال الحديثة . & \\
\hline $17,8 \varepsilon$ & |الاستفادة من الكمبيوتر وشبكة الإنتزنت وغيرها من وسائل الاتصال في اليدان العلمي والتزبوي ما أمكن & \\
\hline $1 \mathrm{r}, 97$ & | حثل الجامعة لأعضاء التدريس فيها على المطالعة العلمية الستمرة، ومتابعة الندوات والمؤتقرات والاكتشافات والاختراعات العلمية ، والبحوث| & \\
\hline 17,8 & محاولة الجامعة لايجاد قنوات اتصال فاعلة بينها وبين الجامعات الأخرى من أجل تعزيز الحركة الأكاديية العليية ذات الآفاق العالية & \\
\hline$|\xi, \Lambda|$ & |حث إدارة الجامعة على تحديث برامج تدريب معلميها بحيث تتضمن استخدام وسائل التكنولوجيا الحديثة في الحقل التربوي التأصيلي. & \\
\hline $1 \%, 97$ & |الاهتمام بالدراسات التي تبين الهارات الأساسية اللازمةل لأعضاء هيئة التدريس في العصر الحالي. & | \\
\hline $\mid r, \mathrm{rq}$ & 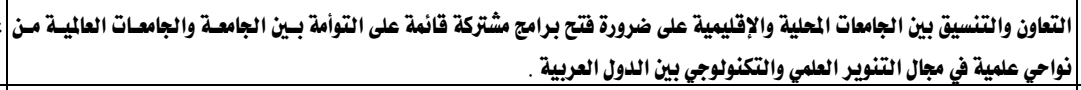 & $v$ \\
\hline $1 \%, \Delta 1$ & 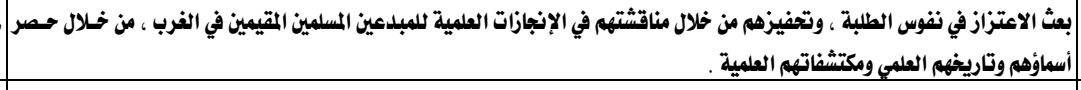 & $\wedge$ \\
\hline $\mid \xi, 19$ & 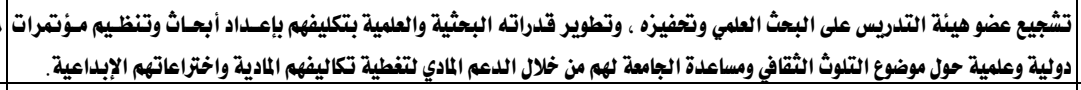 & \\
\hline$\Lambda, 7 \varepsilon$ & |لاستقادة القصوى منها ما أمكن . & 1. \\
\hline$r \cdot r v$ & 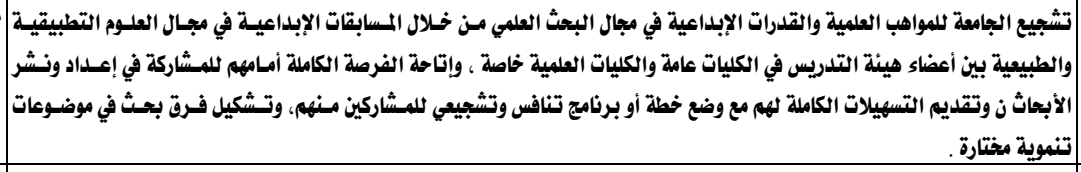 & $川 \|$ \\
\hline 7, va & تشجييع الطلبة على الالتحاق بالكليات العلمية التطبيقية التي بدأت تشكو من قلة أعداد الطلبة المتحقين بها مثل الفيزياك وغيره . & $\pi$ \\
\hline$\varepsilon, Q r$ & | إلجامة . . لجامعة لعارض علمية للمخترعات الطابية ولأعضاء هيئة التدريس التميزة ، وإصدار نشرات علمية فيها ، وتشجيع النشر في هذا | & 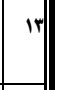 \\
\hline A,7६ & 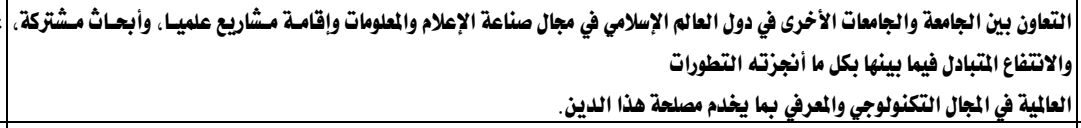 & $12 \|$ \\
\hline 11,11 & 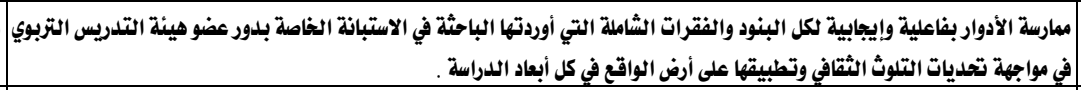 & $10 \|$ \\
\hline $1 \%, \Delta 1$ & أن يوضح المدرس للطالب أثر القدرة على امتلاك صناعة المعلومات في النهوض الاقتصادي للمجتمعات البشرية . & 17 \\
\hline$\varepsilon, q r$ & كفت نظر الطلبة إلى أزمة التخلف العلمي والتكنولوجي ، وتأثيراتها السلبية على دول العالهم الإسلامي . & iv \\
\hline$\Lambda, \bullet r$ & |تزويل عضو هيئة التدريس بشكل منظم بنشرات وإرشادات ترشده إلى عناوين الدراسات والأبعاث التي تهتم بالجوانب العليية والبحثية & 从 \\
\hline 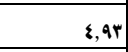 & تنمية مهارات التفكير ، والبحث العلمي للدى طلبة الجامعة . & 19 \\
\hline $7, \mathrm{va}$ & صقل عقلية وشخصية عضو هيئة التدريس الجامعي بالمفاهيم الإسلامية بشكل أعمق ، لكي يكون روية خاصة ناقدة وموجهة. & $r$. \\
\hline 0,00 & |حث إدارة الجامعة على توفير الكستلزمات العلمية للتخصصات العلمية في الكليات التطبيقية فيها ، وتشجيع الإبداعات العلمية فيها. & rn \\
\hline
\end{tabular}




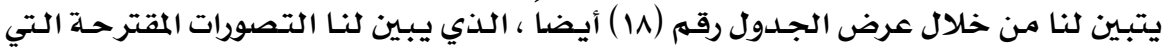

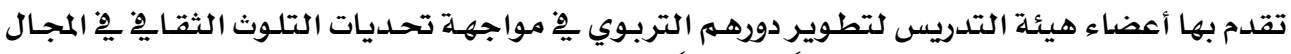

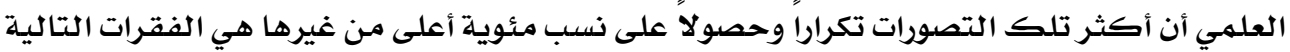

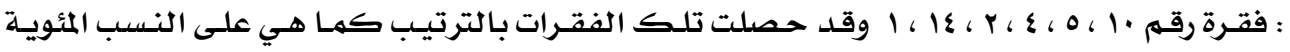

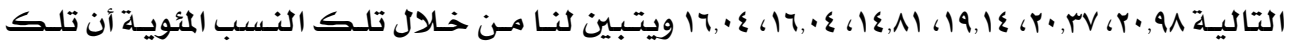

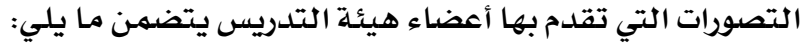

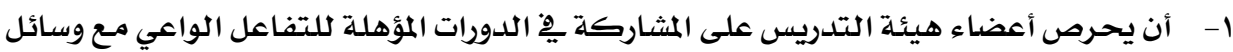

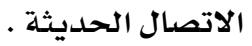

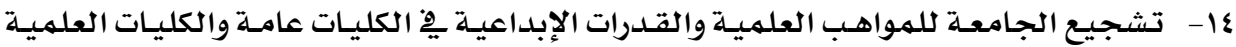

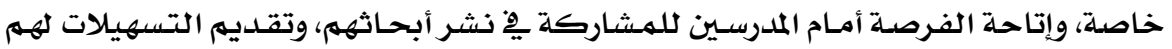

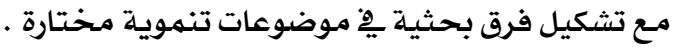

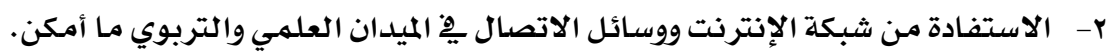

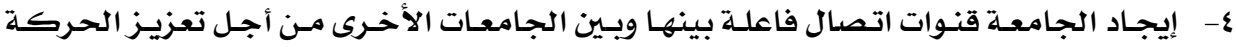
الأكاديمية العلمية .

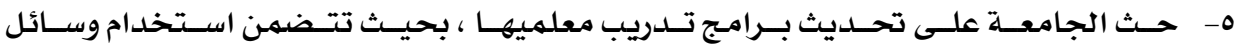

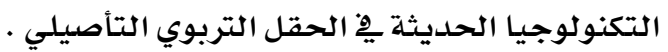

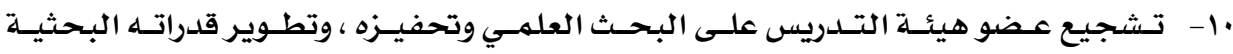

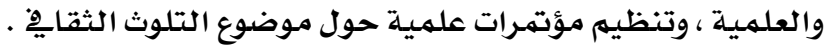

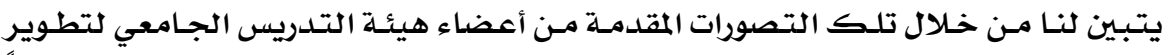

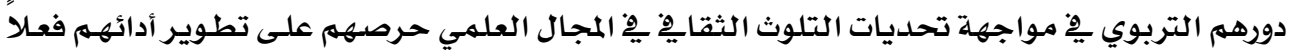

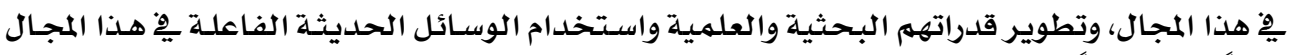

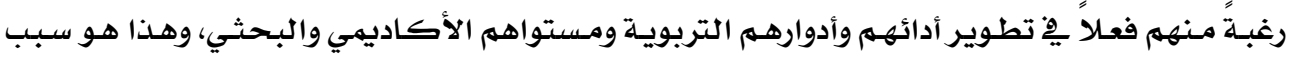

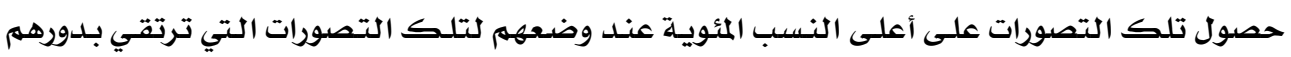

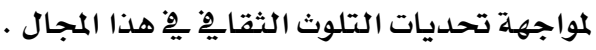

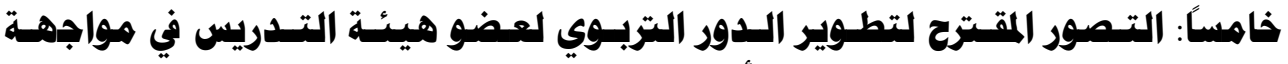 تصديات التلوث الثقافي في هجالاتها الأربعة:}

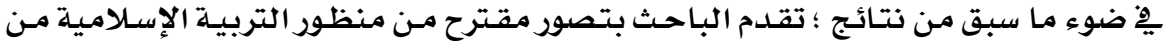

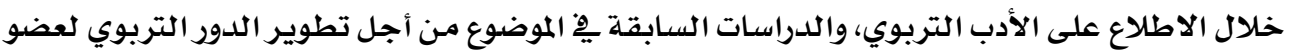

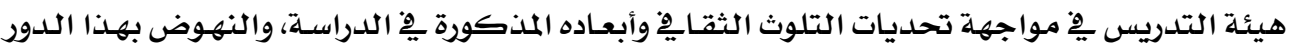

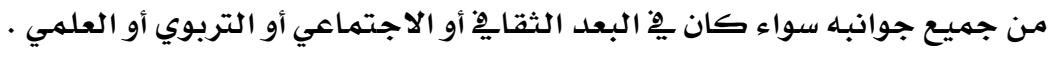
وقد تم التوصل إلى عدد من النتائج وفيما يلي بيانها : 


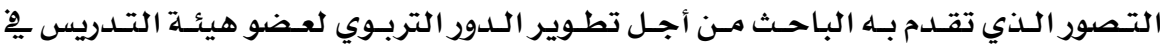

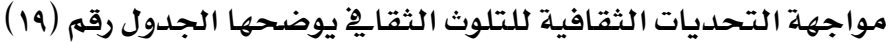

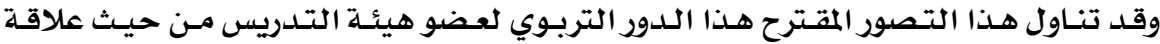

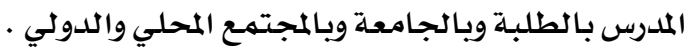

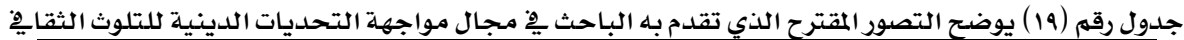

\begin{tabular}{|c|c|}
\hline التصور المقترح لمواجهة التحديات الدينية للتلوث الثقافي & A \\
\hline أن يلفت نظر الطلبة إلى مظاهر الثقافة الانهزامية الشائعة في المجتمع؛ والمنبهرة بالمجتمعات الفربية & 1 \\
\hline إقناع الطلبة بضرورة ابتكار البدائل الأصيلة الأدبية والفنية والثقافية على مستوى المجتمع. & $r$ \\
\hline إتاحة الفرصة أمام الطلبة للحوار حول مفهوم العولمة، وآثارها الثقافية والاجتماعية . & $r$ \\
\hline التأكيد على التماء الطلبة إلى الثقافة العربية الإسلامية & $\varepsilon$ \\
\hline محاولة توجيه مواقف الطلبة إزاء أبعاد التلوث الثقافي بعا يتلاءم مع الرؤية الإسلامية. & $\circ$ \\
\hline تشجيع الطلبة على الممارسات السلوكية العملية التي تثثل الهوية والخصوصية الثقافية . & 1 \\
\hline مناقشة الطلبة في الوسائل والآليات الفاعلة التي تدعم المناعة الثقافية لديهي. & $\checkmark$ \\
\hline لفت نظر الطلبة إلى ما يتضمنه مفهوم التلوث الثقافي من خطورة الاستلاب والاجتياح الثقافي، ومحاولات فرض نهط ثقافي واحد . & $\wedge$ \\
\hline
\end{tabular}

ب- ِّْ مجال التحديات الاجتماعية للتلوث الثقايِّ:

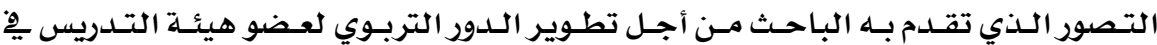

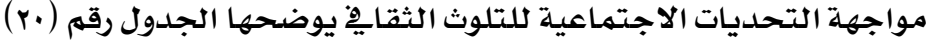

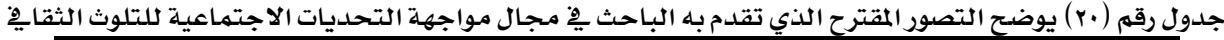

\begin{tabular}{|c|c|}
\hline التصور المقترح لمواجهة التحديات الاجتماعية للتوث الثقافي & \\
\hline | العمل على إيجاد المؤسسات الاجتماعية التي تعني بالتفاعل الاجتماعي للدى الشباب & 1 \\
\hline |مناقشة الطلبة في الإجراءات المقترحة لمواجهة تحديات التلوث الثقافي الاجتماعية . & r \\
\hline |تنبيه الطلبة إلى الآثار الاقتصادية السيئة للتلوث الثقافي. & $r$ \\
\hline | أن يبيز للطلبة دور الشركات العالية العابرة للحدود في التحكم في موارد الدول النامية . & 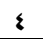 \\
\hline مناقشة الطلبة في آثار التلوث الثقافي على استثمار الموارد البشرية في عملية التنمية التكاملة . & 0 \\
\hline | أن يعذر طلبته من مضامين المؤتترات الدولية والمحلية التي تتدرج ضمن مطالب العولة الاجتهاعية & 1 \\
\hline | أذ يعق عند الطلبة بعض المصطلحات الأصيلة البلديلة للمصطلحات الوافدة مثل (الشورى في مقابل الديمقراطية) & r \\
\hline |مناقشة الطلبة حول أهم التحديات التي تواجه الأسرة كالتفكيك الأسري ، وضعف الرقابة على الأبناي & $\wedge$ \\
\hline أن يؤكل لطلبته على مفهوم التنفية الاجتماعية الأصيل، في مقابل التنبية المرتبطة بحركة المجتمع الفربي . & 9 \\
\hline أن يناقش طلبته فيما تقلدهه البرامج الإعلامية المحلية والعالية من نماذج اجتماعية وسلوكية مناقضة للعايير الاجتماعية الإسلامية . & 1. \\
\hline | أن يظهر لطلبته ضرورة توحل المجتمعات العربية والإسلامية وتكتلها لتجنب تأثيرات التلوث الثقافي. & 11 \\
\hline | أن يحذر طلبته إلى أساليب التلوث الثقافي في فرض نطط المجتمع المهيمز الواحلد. & ir \\
\hline |أن يعذر طلبته من أخطار التلوث الثقافي التي يستهدف فئة الشباب . & ir \\
\hline | مناقشة الطلبة حول الظواهر الاجتماعية الوافدة في عصر العولة . & $1 \varepsilon$ \\
\hline | أن يتحاور مع طلبته في ملامح الأنشطة الاجتماعية التي تلائم مجتمعاتنا العربية الإسلامية . & 10 \\
\hline |أن يعقق اتتماء الطلبة للأمة الإسلامية، والإيمان بوحدة الصف على مستوى المجتمع العربي الإسلامي & 17 \\
\hline |أذ يتيح للطلبة فرصة اقتراح خطط لمواجهة تحديات التلوث الثقافي في المجال الاجتماعي. & iv \\
\hline |الاهتمام بتنمية روح الجماعة لدى الطلبة من خلال أساليب تدريس تقوم على الحواروالشاركة & $1 \mathrm{~A}$ \\
\hline
\end{tabular}

$\Lambda$. 


\begin{tabular}{|c|c|}
\hline 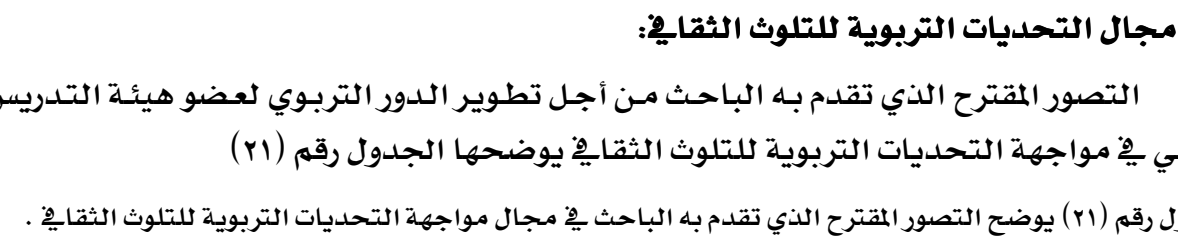 & \\
\hline التصور المقترح لمواجهة التحديات التربوية للتوث الثقافي & 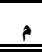 \\
\hline أن يشارك عضو هيئة التدريس الجامعي في الأنشطة الداعمة لبرامج التعليم التي تقكن النشء من مواجهة أسباب التلوث الثقافي والتعليمي & 1 \\
\hline بالأحداث - التربية بالاكتشاف). & r \\
\hline أن يلفت نظر الطلبة إلى أهمية دور التربية الإسلامية في نقل الثقافة وتأصيلها ـ. & r \\
\hline ت تنبيه الطلبة إلى خطورة انفصال التعليم في بعض المجالات عن مطالب التنمية ، وأثر ذلك على جمود التعليم والتنمية . & $\varepsilon$ \\
\hline أن يبين للطلبة خطورة العولة في سعيها لتذويب النظم التربوية المحلية ؛ في نظام تربوي عالمي واحد. . & 0 \\
\hline أن يحاول مع زملائه من أعضاء هيئة التدريس في التخصصات الششتركة صياغة المقرر الدراسي للطلبة بما يتلاءم مع الإسلام من حيث الأهداف والمحتوى. & 1 \\
\hline توجيه الطلبة إلى العناية بالتربية الذاتية لمواجهة التحديات التربوية المعاصرة . & r \\
\hline أن يلدعم في نفوس طلبته اتجاه تبنى عالية الخطاب الإسلامي ، النابع من عالية الرسالة الإسلامية . & $\Lambda$ \\
\hline أن يبين للطلبة ضرورة الجمع بين الأصالة المعاصرة في بناء النظام التعليمي . & 9 \\
\hline توجيه عناية الطلبة إلى المرحلة الدراسية الجامعية ؛ بوصفها المرحلة الأهم في بناء الشخصية المستقلة الأصيلة بجوانبها المختلفة & 1. \\
\hline لفت نظر الطلبة إلى ما تتضمنه المقررات اللدراسية من أمور لا تتوافق مع المبادئ الإسلامية . & 11 \\
\hline أن يوجه طلبته ندو الاهتمام بالجوانب التطبيقية للتعليم ، والدورات التدريبية التي تؤهل الطلبة للتفاعل المستمر مع الفكر التزبوي المعاصر & ir \\
\hline أن يرغب الطلبة في التوجه نحو التخصصات النادرة ذات العلاقة بالتقدم والتنمية الشاملة للمجتمع الفلسطيني . & ir \\
\hline ي يبين للطلبة دور النظام التربوي في تسليح الأفراد بأنماط التفكير والمعرفة التي تكنهم من مواكبة التحولات العالية المتسارعة. & $1 \varepsilon$ \\
\hline ينبه طلبته إلى العلاقة بين التبعية في الأخذ بالنظم التعليمية للفرب والهلدر البشري المسبب للبطالة الظاهرة والمقنعة . & 10 \\
\hline أن يلفت نظر الطلبة إلى ضرورة الربط بين نوع التعليم وسوق العمل . . & 17 \\
\hline أن يوجه الطلبة نحو دراسات وبحوث ؛ تساهم في تطوير البرامج التعليمية ؛ دون الوقوف في فخ التبعية للفرب . & iv \\
\hline ينبه الطلبة إلى المشكلات التربوية المحلية بنظرة إسلامية من حيث التشخيص والعلاج . & 11 \\
\hline أن يحث الطلبة على تعلم اللفة الإنجليزية ؛ بوصفها وسيلة معاصرة لمواجهة التلوث الثقافي & 19 \\
\hline أن يوجه طلبته إلى القراءة المستمرة والفاعلة & r. \\
\hline توجيه الطلبة إلى الاستخدام الفاعل لتكنولوجيا التعليم في العملية التزبوية . & ri \\
\hline حث الطلبة إلى الاستفادة من شبكة الإنترنت ، وغيرها من وسائل الاتصال في الميدان التزبوي . & rr \\
\hline يبين لطلبته الأهية الثصوى لبناء فلسفة تربوية إسلامية توجه مجالات العملية التربوية برمتها . & rr \\
\hline يقدم اقتراحات للجامعة تساهم في تفعيل تبادل الخبرات التربوية بين الجامعات المحلية والعالية. & rq \\
\hline تفعيل الدور التربوي للطلبة على مستوى أسرهم والمؤسسات التزبوية الأخرى . & ro \\
\hline يعرف الطلبة بالدور الذي ينبفي أن تقوم به كليات التربية في مواجهة التلوث الثقافي . & rq \\
\hline أن يحث زملائه من أعضاء هيئة التدريس في الجامعة على تبادل الخبرات في المجال التربوي ؛ عن طريق الدراسات العلمية الششتركة ، والمناقشات & rv \\
\hline
\end{tabular}

أ- بْ مجال التحديات العلمية التطبيقية للتلوث الثقايِ؛ التصور المقترح الذي تقدم به الباحث لتطوير الدور التربوي لعضو هيئسة التـدريس الجـامعي

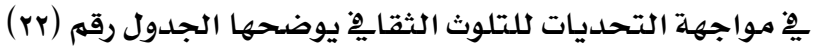




\begin{tabular}{|c|c|}
\hline التصور المقترح لمواجهة التحديات العلمية للتوث الثقافي & 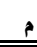 \\
\hline أن يوجه الطلبة نحو متابعة كل جديل نافع ؛ تحمله ثورة المعلومات المعاصرة . & 1 \\
\hline أن ينبه طلبته مما تحمله ثورة المعلومات من مخاطر الهيمنة الثقافية على المجتمعات الضعيفة. & r \\
\hline يوجه الطلبة إلى الاستخدام الفاعل لتكنولوجيا التعليم في العملية التربوية . & $r$ \\
\hline يوضح للطلبة دور التكنولوجيا الحديثة في تكريس الهوة بين الدول المتقدمة وبقية دول العالم. & $\varepsilon$ \\
\hline يبين للطلبة أن القوة في اعتماد المعادلة الاقتصادية الحديثة ترتكز على قوة العقل والتعليم أكبر من اعتمادها على الموارد الطبيعية والأيدي العاملة. & $\circ$ \\
\hline أن يلفت نظر طلبته إلى أن بناء الإنسان المتكامل في جميع جوانب شخصيته هو الأساس في دخول العالم التكنولوجي . & 1 \\
\hline أن يلفت نظر طلبته إلى إيجابيات وسائل الاتصال الحديثة المتثثلة في اخترال المساقة والزمن والجهل . & $r$ \\
\hline يوضح الفرق للطلبة بين استيراد مظاهر التكنولوجيا وإتتاجها داخل حدود العالم الإسلامي . & $\wedge$ \\
\hline يبين لطلبته ما يمليه التطور التقني التتسارع على التربية من حيث التأكيد على تعلم المهارات أكثر من جمع المعلومات . & 9 \\
\hline يحث طلبته على الاستفادة من تقنية الاتصال الحديثة ؛ بوصفها من أهم الوسائل الداعمة للفكر الإسلامي. & $1 \cdot$ \\
\hline ينبه الطلبة إلى تحديات تكنولوجيا المعلومات الجديدة التمثلة في الاعتداء على البيانات الشخصية والأموال والحقوق . & 11 \\
\hline يحذر الطلبة مما تمارسه بعض وسائل الاتصال الحديثة (الفضائيات والإنترنت) مز ترويج للجنس والجريمة . & ir \\
\hline يوضح للطلبة الآثار النفسية والاجتماعية المترتبة على انشفال الإنسان المعاصر بوسائل الاتصال الحديثة لمدة طويلة . & ir \\
\hline تشجيع الطلبة على الإفادة من المنجزات العلمية بقدر المستطاع ، واستخدامها بفاعلية في حياتهم العملية. & is \\
\hline لفت نظر الطلبة إلى أثر التكنولوجيا العلمية الحديثة على تبعية المجتمعات المستهلكة للنمط الثقافي الفربي . & 10 \\
\hline ينبه الطلبة إلى أثر التفوق الفربي في مجال استثمارات البحوث ، والتطوير العلمي التقني وبراءات الاختراع على تعميـق الفجـوة بـين الــدول المتقدمة & 17 \\
\hline والنامية. & \\
\hline تشجيع الطلبة على الإفادة من المنجزات العلمية التكنولوجية بقدر المستطاع ، واستخدامها بفاعلية في حياتهم العملية . & iv \\
\hline يوضح لطلبته طبيعة العلاقة بين التنمية الاقتصادية، ومشاريع البحث العلمي الفاعل . & 11 \\
\hline توجيه الطلبة إلى ضرورة الاستفادة من وسائل التقنية الحديثة على اختلاف تخصصاتهم . & 19 \\
\hline يلقى ندوات حول أهمية التعامل مع التدريس الجامعي من خلال التقنيات الموجودة، وأهمية التدريب الميداني . & r. \\
\hline
\end{tabular}

\section{التوصيات:}

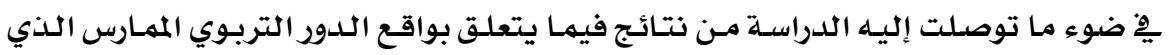
يتعرض له عضو هيئة التدريس يْ مواجهة تحديات التلوث الثقايِّ يقدم الباحث التوصيات التالية: 1- استمرارية اطلاع عضو هيئة التدريس على آخر ما توصلت إليه الأبحاث والدراسات فِّ مجال

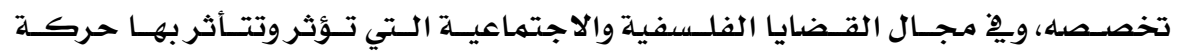

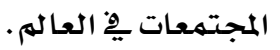

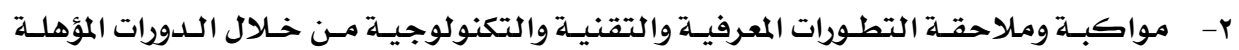

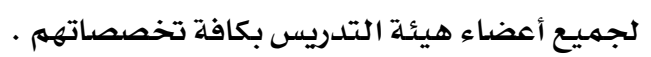

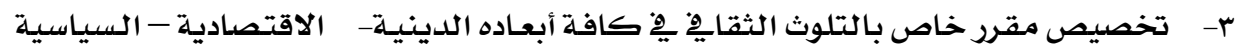

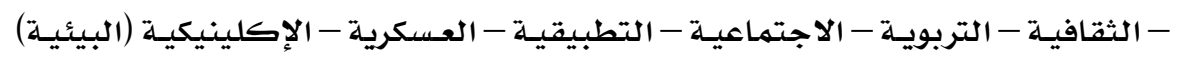

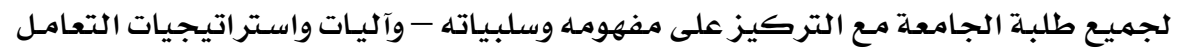

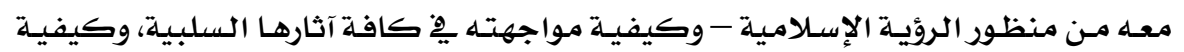

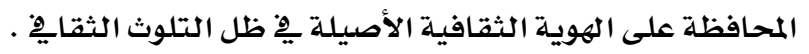




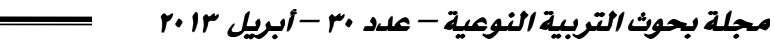

ع- تركيز عضو هيئة التدريس على بناء شخصية الطالب الجـامعي بتكامليـة أكبر ِِِ جميـع

$$
\text { جوانب شخصيته . }
$$

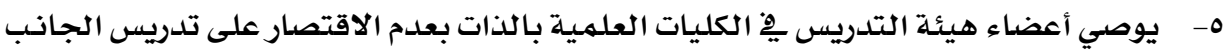

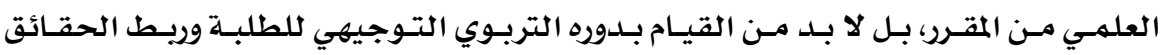

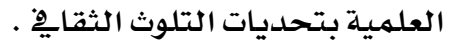

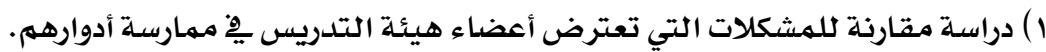

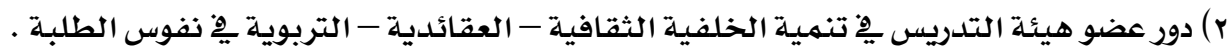

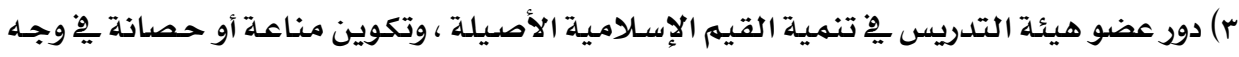

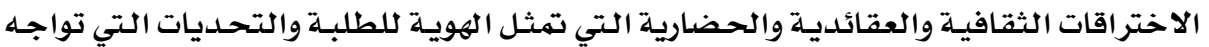

$$
\text { أعضاء هيئة التدريس فِ ذاتك }
$$




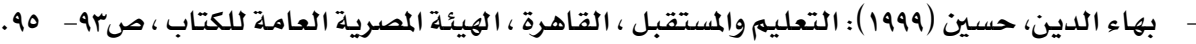

-Etchevery ،F.E: A resource for the Human Capital Development of University Students ،Dissertation Abstracts International ، Vol. 58,No.11A. P. 4228.

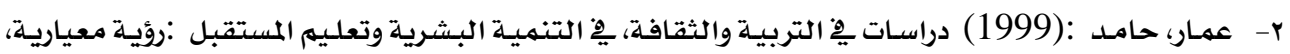

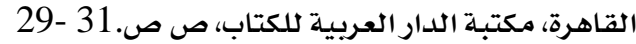

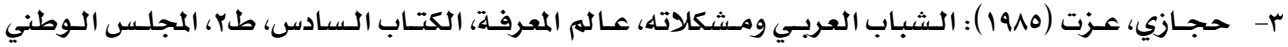
كلثقافة والفنون والآداب، الكويت، ص.rV.

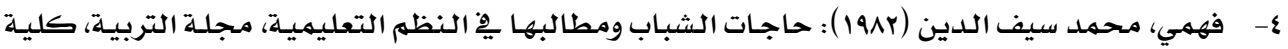

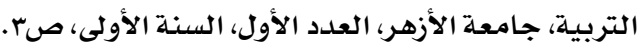

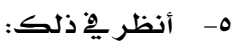

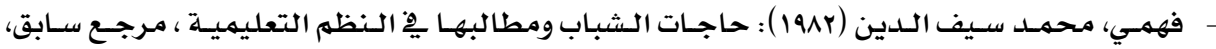

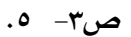

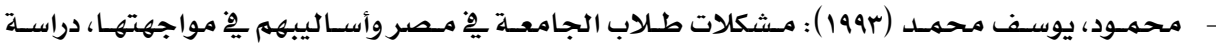

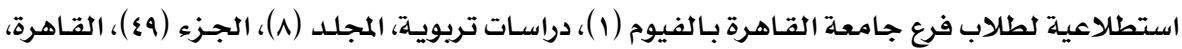

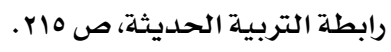

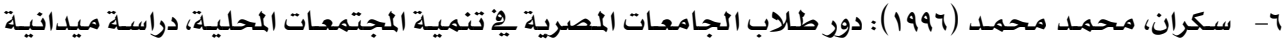

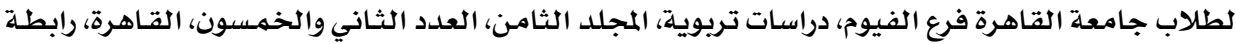

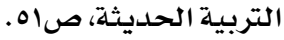

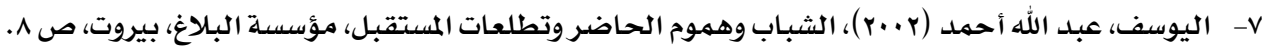

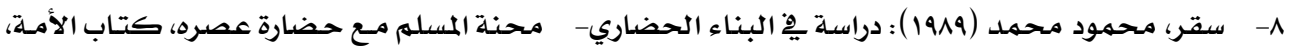

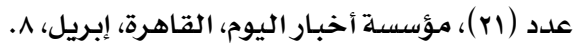

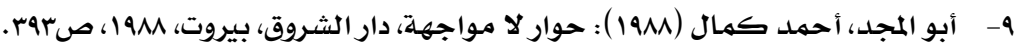

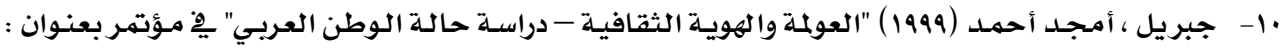

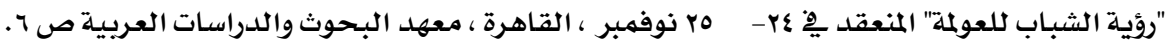

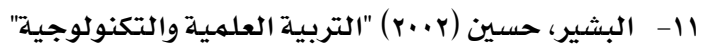

http://www.najah.edu.arabic.text/internet.com/internet4.htm. 6/11/2002.p.1-3.

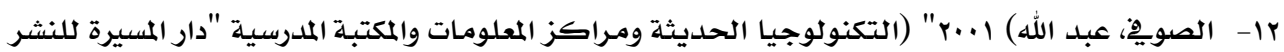
والتوزيع : عمان، صبدان 19.

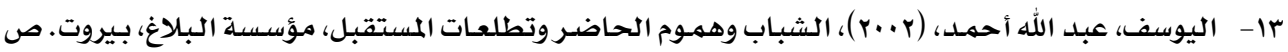
$.17 \varepsilon \quad-175$ 


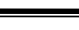

عا- عبد الباري، إسماعيل حسن (1994) : اتساق الهوية الثقافية عند الطفل ِِّ مجتمع متغير، المؤتمر السنوي

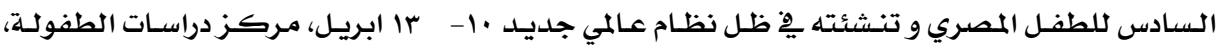

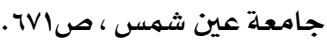

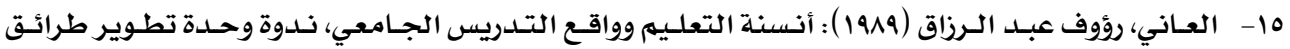

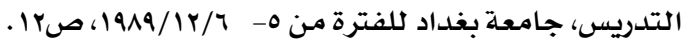

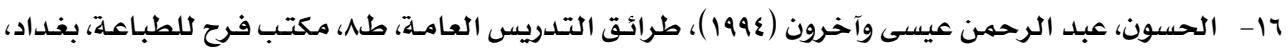
ص94.

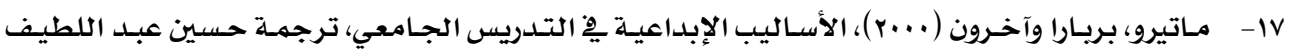

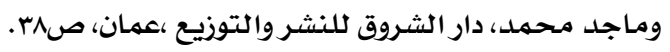

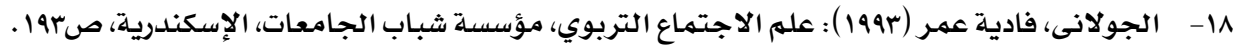

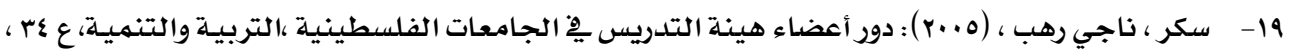

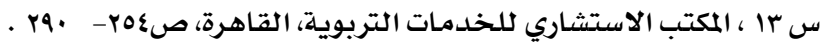

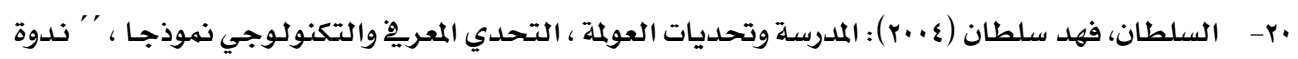

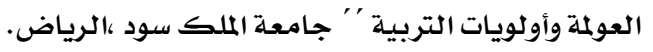

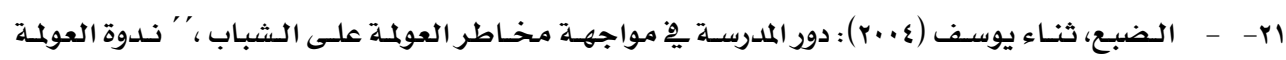

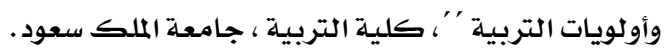

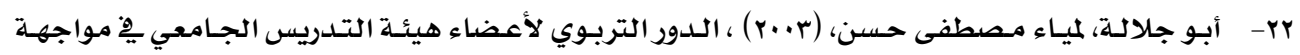

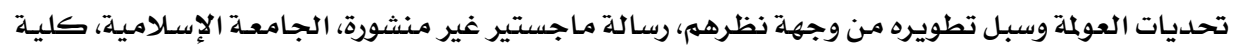

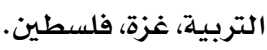

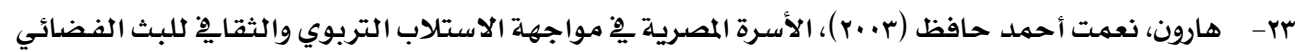

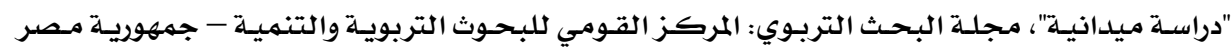

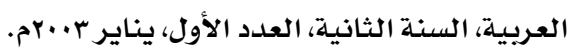

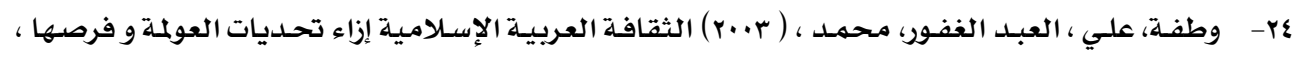

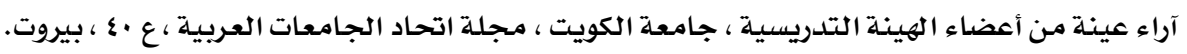

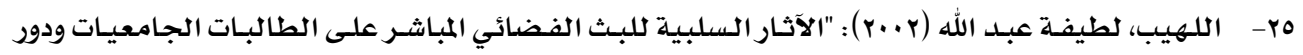

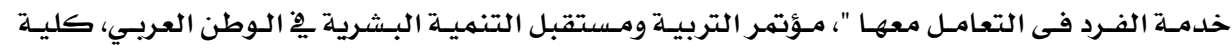

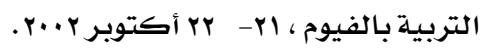

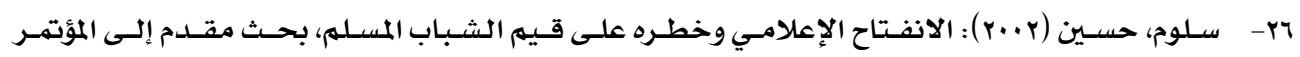

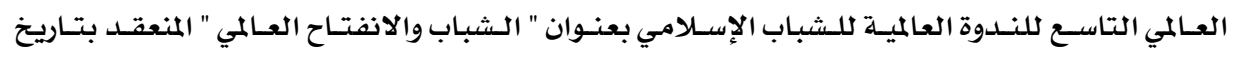

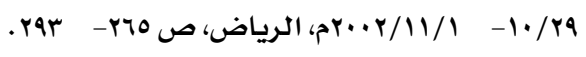

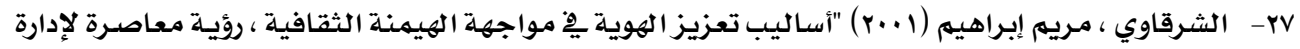

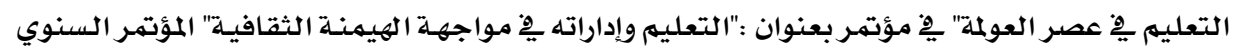

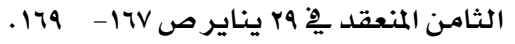




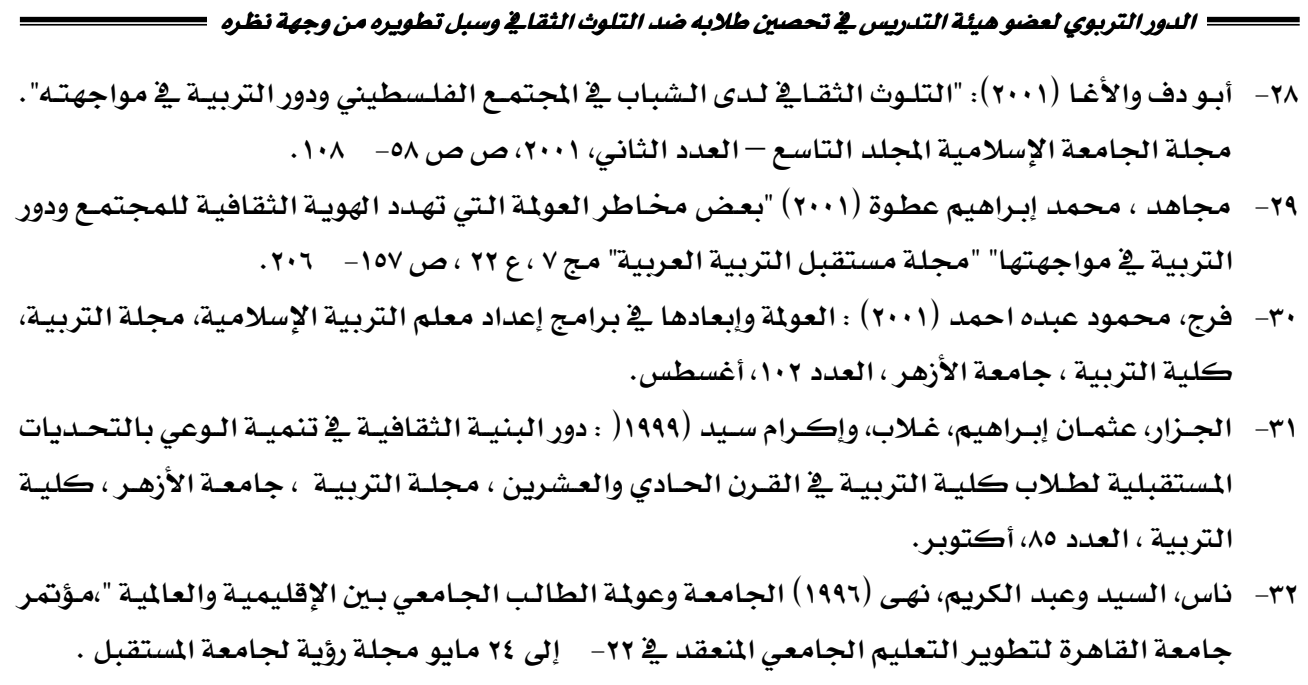

33- Legrain،Philippe (2004), The property of selectivity in the Academic professor at the time of cultural ,The Globalization American, Journal for Humanities and Psychology, Vol.424, No.1 ،pp rr - r.

34- Makien , Sakkara (2003) : Developing the Academic Professor for Opposing the Negative Cultural Globalization, The International Journal for Education development, Vol.211, No.1,pp. 33-59.

35- Semite , D.H (2002) :Leader Spumoni Academic professors, a key to face Globalization, Journal of the American Association of the School and University Education, Vol. 104, No.1, pp.114-133.

36- Larson, R.W (2002) Globalization, Societal Changes, and New Technologies: What They Mean for The Future of Adolescence, Journal of Research on Adolescence, Vol.12 no.1, pp 1-30. (ERIC: A95682587)

37- Taylor, Trevor P.D (2002) The Internet and Youth Engagement: An Exploration of How Youth Spend Their Time Online and Its Relation to Civic Involvement, Unpublished Master Thesis. (ERIC: MQ75889) http://wwwlib.umi.com/dissertations/citations/print

38- Lavallette, Jensen (2001): Adopting New Values, How can the Academic Professor Faces the Cultural Globalization in the University, The International Journal of the Cultural Glamorization and knowledge systems, Vol. 95, No.1 .P.20-42.

39- Thomas, R. (1999) Television in the lives of Adolescents, The University of Chicago Press. 
40- Teasdal, G.R. (1997); “Globalization, Localization: Impacts" and Implication for Teacher Education in the Asia Pacific Region, ERIC, No: Ed 416038 http://www.askeric.org/cgi-bin/eric abqueryz.P1search Eric Abstract 10/11/2002.

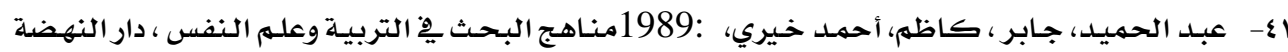

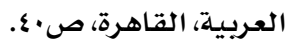

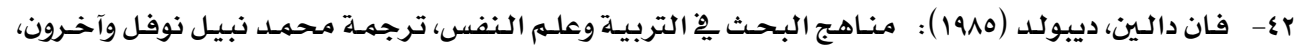

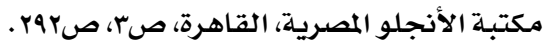

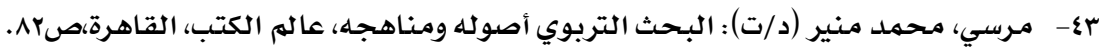

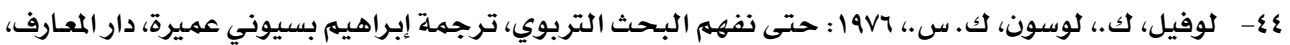

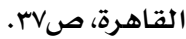

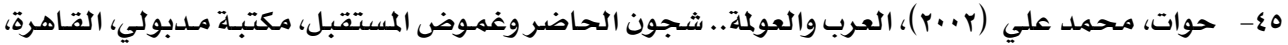
ص ص

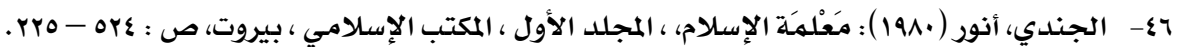

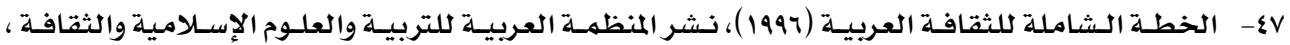

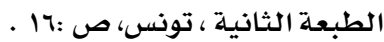

1ـ- الاستراتيجية الثقافية للعالم الإسلامي (199V)، نشر المنظمة للتربية والعلوموالثقافة - إيسيسكو الرياط.

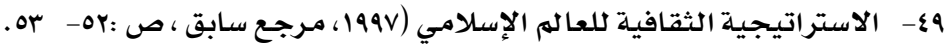

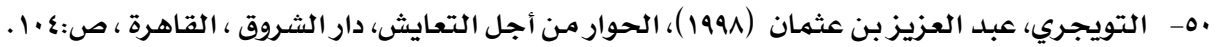

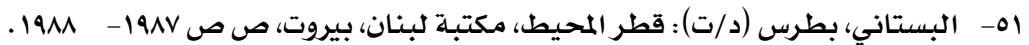

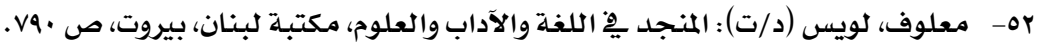

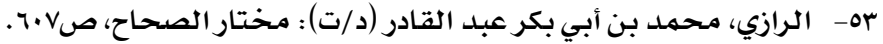

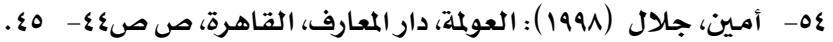

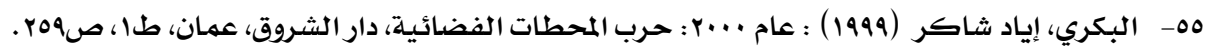

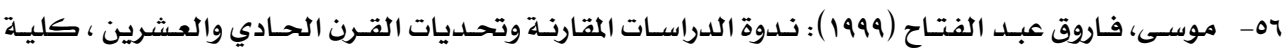

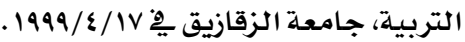

57- Herman, G . (2000 :(Institutional Challenges, responses AND Strategies، Working Paper Presented at the Regional Conference and Higher Education : National Strategies and Regional Co-operation for the 21st Century, Tokyo , 820July , UNESCO, Japanese National Commission for UNESCO/UNU/AUAP, P.27.

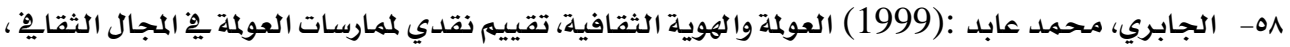

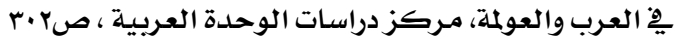




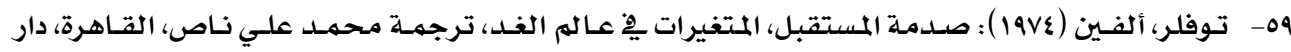

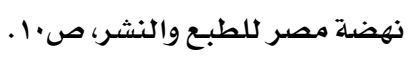

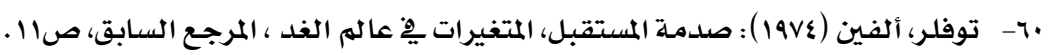

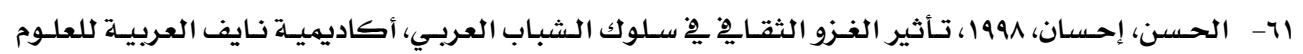

$$
\text { الأمنية، الرياض، ص و الحسن، }
$$

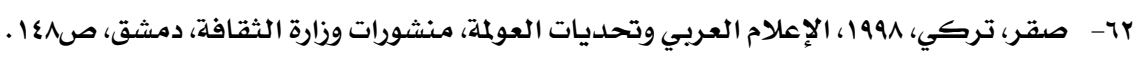

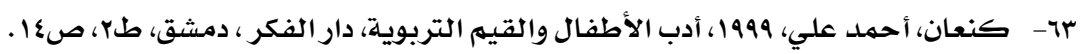

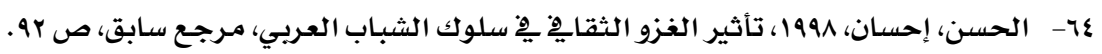

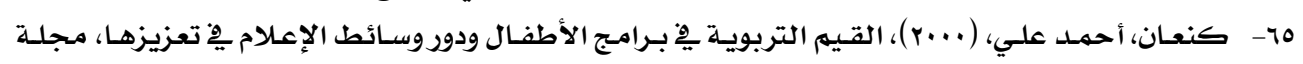

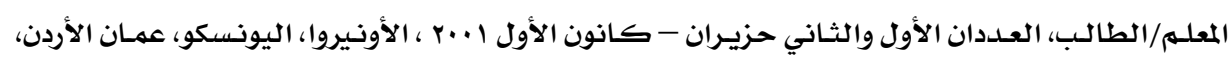

$$
\text { ص } 18
$$

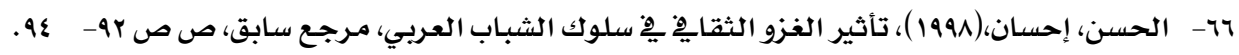

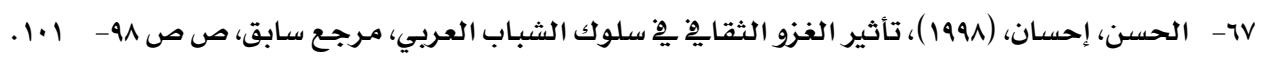

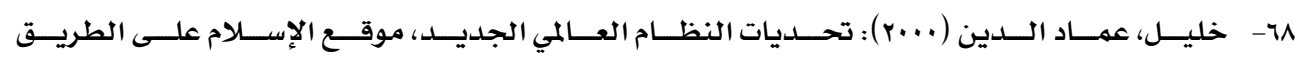

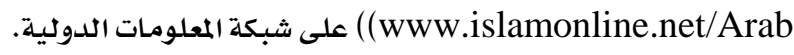

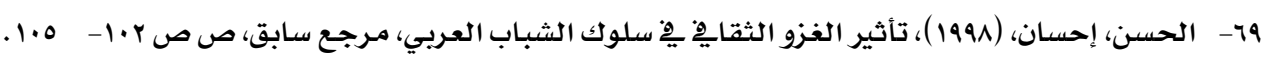

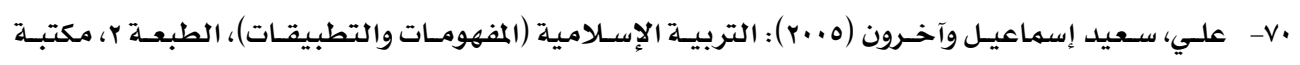

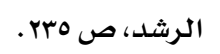

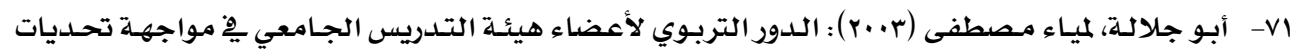

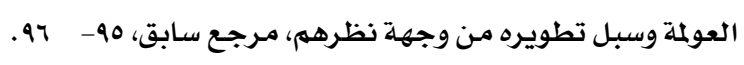

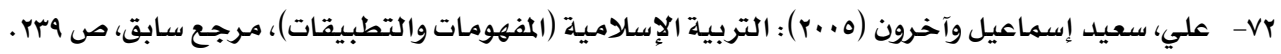

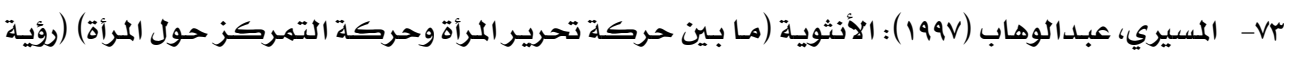

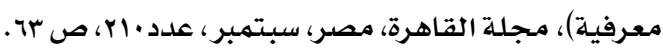

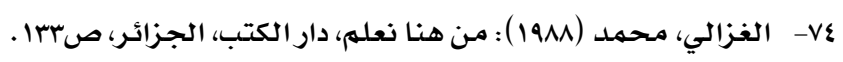

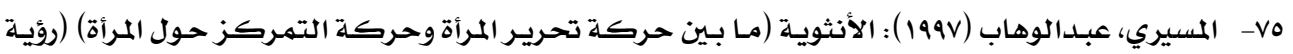

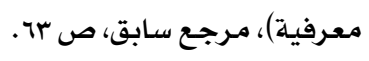

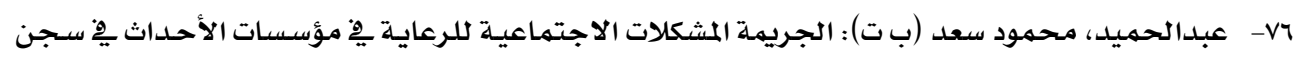

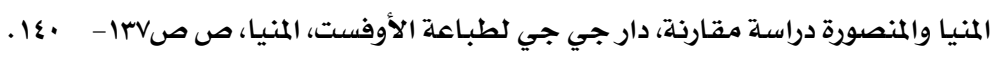

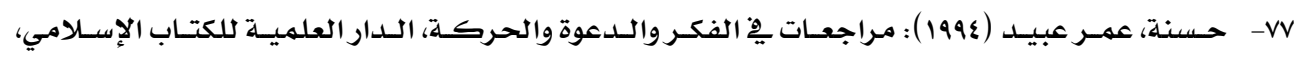

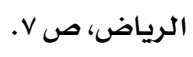

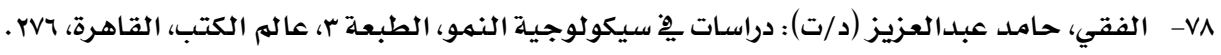

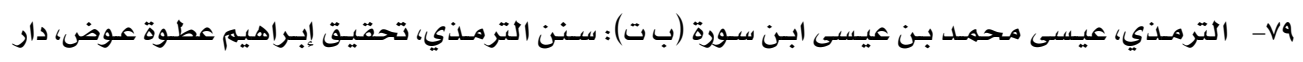

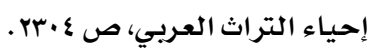




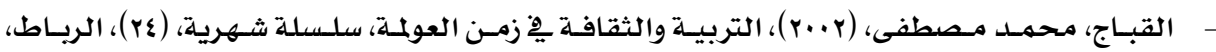

$$
\text { منشورات رمسيس. }
$$

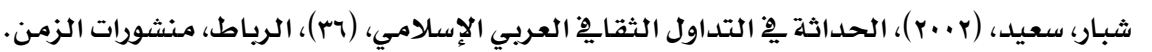

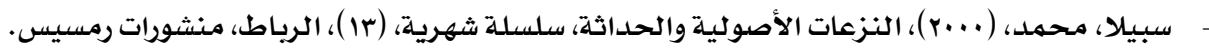

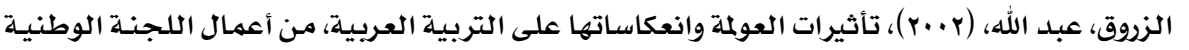
الليبية للتربية والثقافة والعلوم، طرابلس، (ورقة غير منشورة).

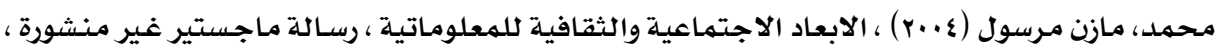

كلية الآداب ، جامعة بغداد، صوه1.

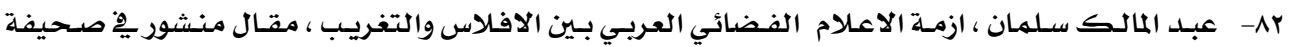
الوطن على الانترنيت :

www.alwatan.com/graphics/2004/03mar/9.3/daigyhtml/opinion.html-150k.

rی- خطر الغزو الثقايِّ والاعلامي على المجتمـع العربي، مقال منشور على الانترنت: www.balagh.com/thaqafa/7t100wbp.htm-21k.

عـ- محمد، مـازن مـرسول(2004) ، الابعاد الاجتماعية والثقافية للمعلوماتية ،مرجـع سابق، ص.98

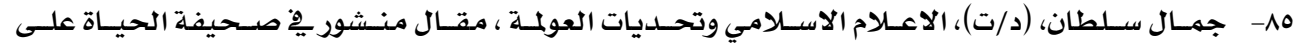
www.albayan-magazine.com/files/global/05.htm-50k. الانترنيت:

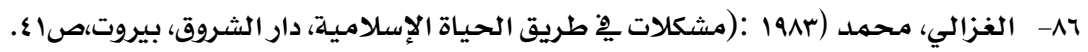

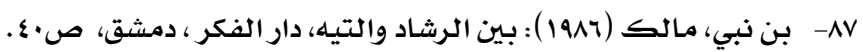

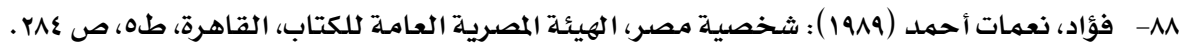

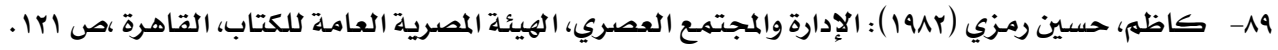

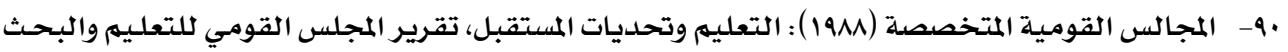

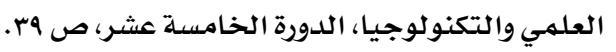

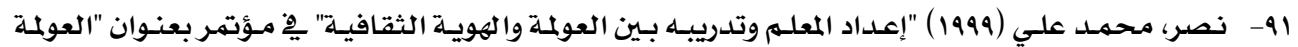
ومناهـج التعليه" المؤتمر السنوي الحادي عشر ، الجمعية المصرية للمـناهج وطرق التدريس ص بآ- با.

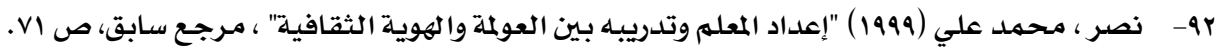

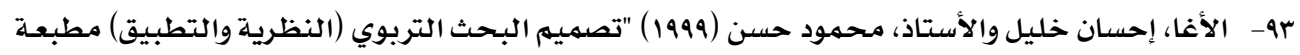
الرنتيسي: غزة . ص سم. 